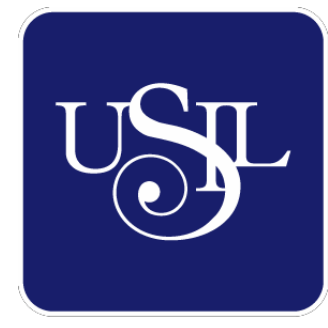

UNIVERSIDAD

SAN IGNACIO

DE LOYOLA

ESCUELA DE POSTGRADO

\title{
PLAN DE NEGOCIOS ANIMAL LOVERS
}

Trabajo de Investigación para optar el grado de:

\author{
LUIS ALBERTO IBARRA RAMIREZ \\ Maestro en Ciencias Empresariales con Mención en \\ Gestión de Marketing
}

RONALD CRISTHIAM MARTINEZ ARMACANQUI

Maestro en Ciencias Empresariales con Mención en Gestión de Operaciones

MIGUEL ANGEL SERNA HUARANCA

Maestro en Ciencias Empresariales con Mención en

Gestión del Capital Humano

\author{
Asesor: \\ Dr. Edmundo Rafael Casavilca Maldonado \\ Lima - Perú
}

2019 



\section{TABLA DE CONTENIDO}

CAPÍTULO I

GENERALIDADES

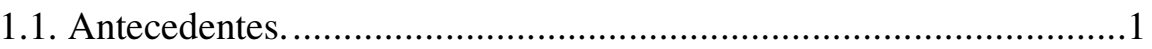

1.2. Determinación del Problema u Oportunidad. ...................................2

1.3. Justificación del Proyecto................................................................

1.4. Objetivos Generales y Específicos ........................................6

1.5. Alcances y Limitaciones de la Investigación.....................................

CAPITULO II.

ESTRUCTURA ECONÓMICA DEL SECTOR.........................................9

2.1. Descripción del Estado Actual de la Industria..................................9

2.1.1. Segmentación de la industria................................................. 12

2.1.2. Empresas que la conforman (ubicación, volumen de ventas,

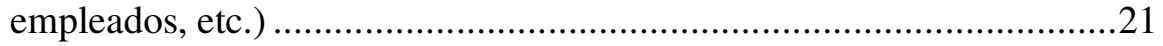

2.2. Tendencias de la Industria (crecimiento, inversiones) ..................23

2.3. Análisis Estructural del Sector Industrial ....................................24

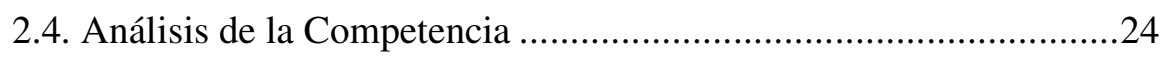

2.4.1. Empresas que ofrecen el mismo producto o servicio, indicando las semejanzas y diferencias que tienen con el proyecto de la empresa ......25

2.4.2. Participación de mercado de cada uno de ellos ...........................27

2.4.3. Matriz de perfil competitivo ....................................................27

2.5. Análisis del Contexto Actual y Esperado......................................28

2.5.1. Análisis Político-Gubernamental .............................................28

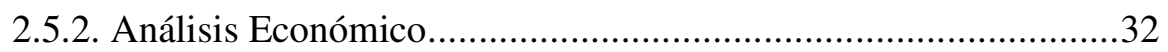

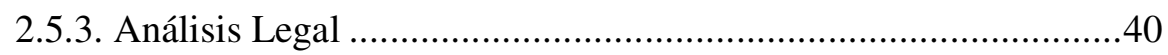

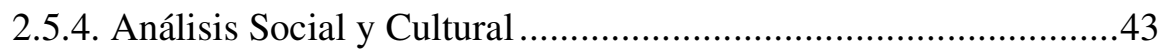

2.5.5. Análisis Tecnológico .............................................................46

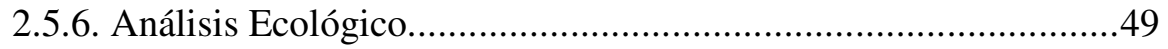

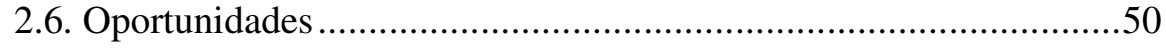

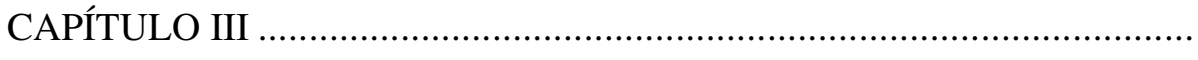

ESTUDIO DE MERCADO ..................................................................

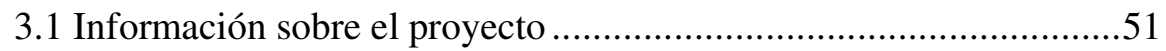

3.2 Descripción del servicio o producto ............................................53

3.3. Selección del segmento del mercado ............................................54

3.4. Investigación Cualitativa ...........................................................58

3.4.1. Muestreo, diseño del instrumento y aplicación de entrevistas a profundidad 
3.4.2. Muestreo, diseño del instrumento y aplicación de grupos de enfoque .62

3.4.3. Análisis y procesamiento de datos ...........................................62

3.5. Investigación Cuantitativa .........................................................65

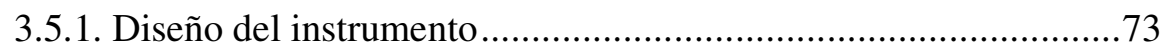

3.5.2. Análisis y procesamiento de datos ..........................................73

3.6. Conclusiones y recomendaciones del Estudio Cuantitativo............79

3.7. Perfil del consumidor tipo y sus variantes.....................................80 CAPÍTULO IV

PROYECCIÓN DEL MERCADO OBJETIVO.......................................82

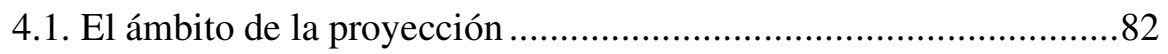

4.2. Selección de método de proyección..................................................84

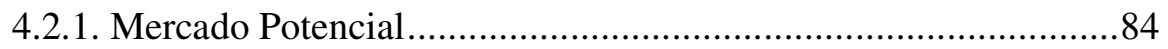

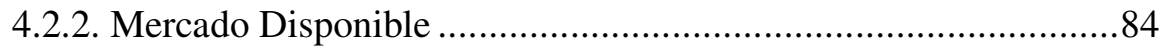

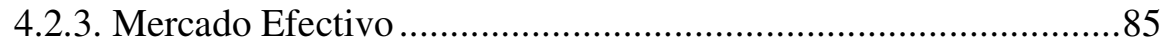

4.2.4. Mercado Objetivo................................................................ 86

CAPÍTULO V

PLAN DE MARKETING

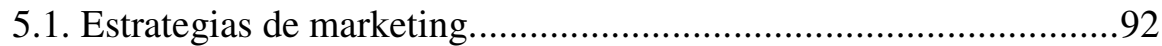

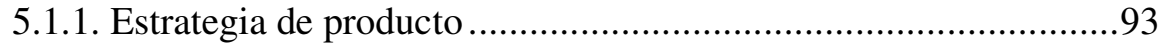

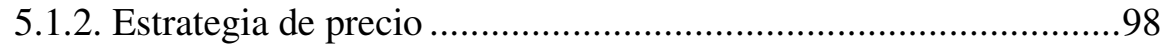

5.1.3. Estrategia de plaza y distribución ............................................. 103

5.1.4. Estrategia de promoción y publicidad ......................................... 105

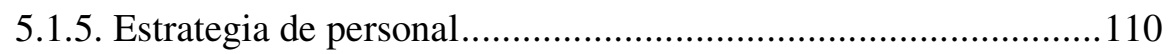

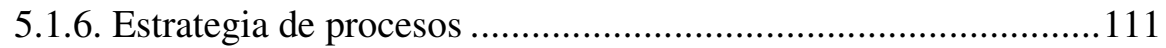

5.1.7. Estrategia de Productividad y Calidad ......................................... 114

5.1.8. Estrategia de Presencia Física .................................................115

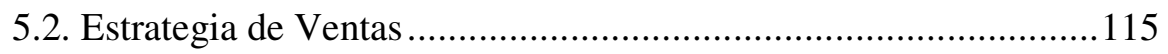

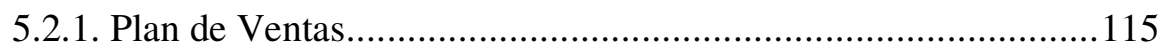

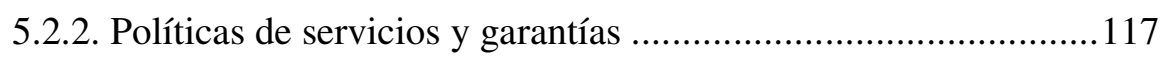

CAPÍTULO VI.

PRONÓSTICO DE VENTAS

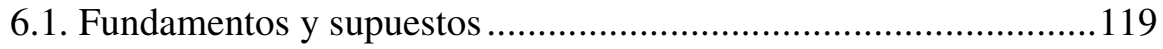

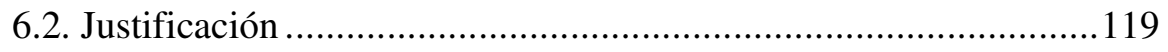

6.3. Aspectos críticos que impactan el pronóstico de ventas ................121

CAPÍTULO VII

INGENIERÍA DEL PROYECTO 


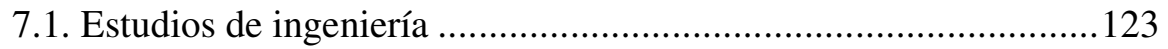

7.1.1. Modelamiento y selección de procesos productivos ...................123

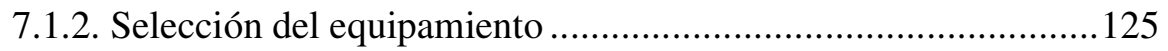

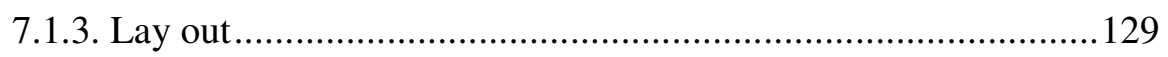

7.1.4. Distribución de equipos y maquinaria.......................................130

7.2. Determinación del Tamaño...................................................130

7.2.1. Proyección de crecimiento..................................................... 132

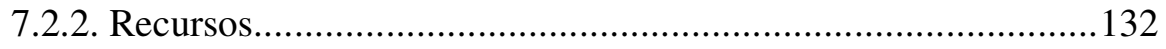

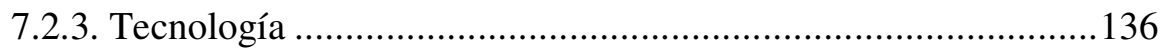

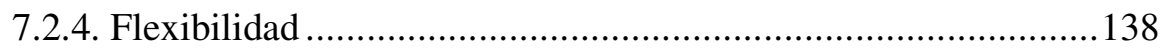

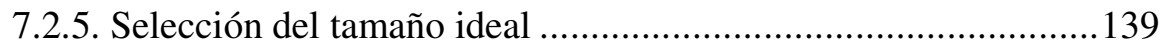

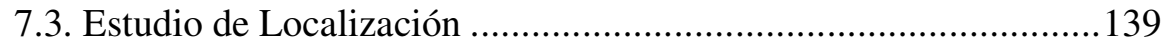

7.3.1. Definición de factores locacionales........................................ 139

7.3.2. Consideraciones legales....................................................... 142

7.3.2.1 Identificación del marco legal. ........................................... 142

7.3.2.2. Ordenamiento jurídico de la empresa ................................ 144

7.4. Determinación de la localización óptima ...................................... 148

CAPÍTULO VIII.

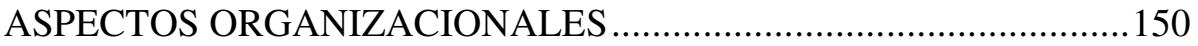

8.1. Características de la cultura organizacional. ................................150

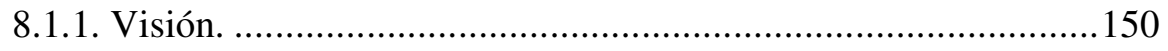

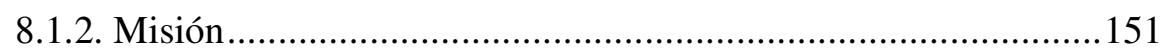

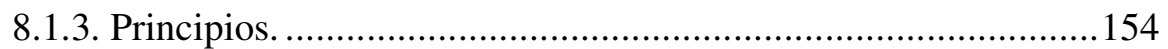

8.2. Formulación de las Estrategias del Negocio.................................156

8.3. Determinación de las Ventajas Competitivas Críticas..................163

8.4. Diseño de la estructura organizacional deseada.............................166

8.5. Diseño de los Perfiles de Puestos Clave.......................................167

8.6. Remuneraciones, compensaciones e incentivos ...........................169

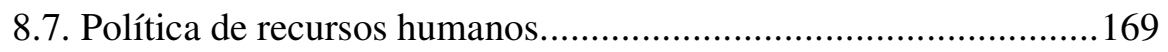

CAPÍTULO IX.

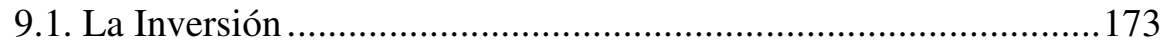

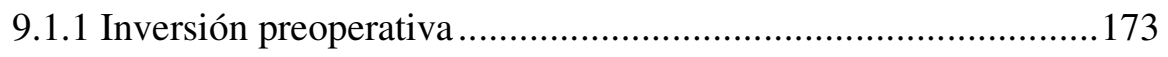

9.1.2. Inversión en capital de trabajo ................................................ 176

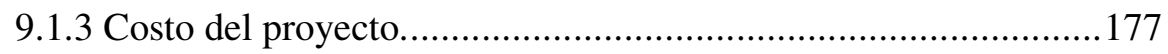

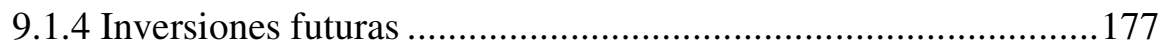

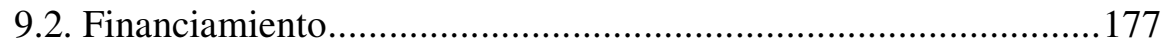

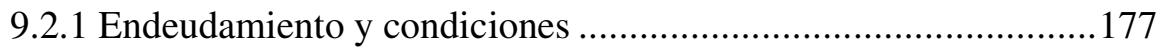




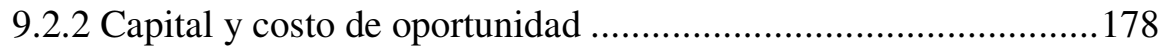

9.2.3 Costo de capital promedio ponderado ....................................... 181

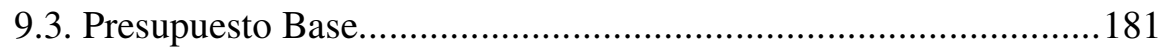

9.3.1 Presupuesto de venta .......................................................... 181

9.3.2 Presupuesto de costo de producción............................................182

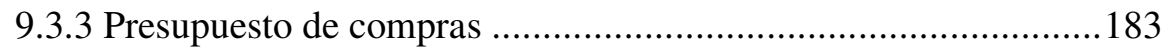

9.3.4 Presupuesto de costo de venta ...............................................186

9.3.5 Presupuesto de gastos administrativos ..................................... 187

9.3.6 Presupuesto de marketing y ventas .......................................... 188

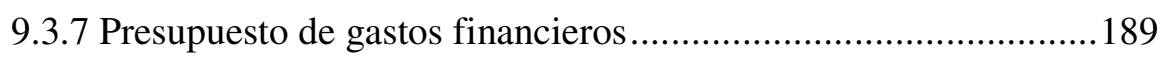

9.4. Presupuestos de Resultados .......................................................189

9.4.1 Estado de ganancias y pérdidas proyectado...............................189

9.4.2 Balance proyectado .............................................................. 190

9.4.3 Flujo de caja proyectado......................................................... 190

CAPÍTULO X

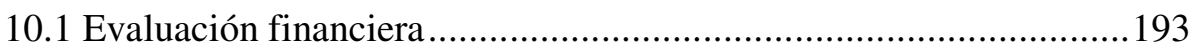

10.1.1 La Tasa Interna de Retorno - TIR ...........................................193

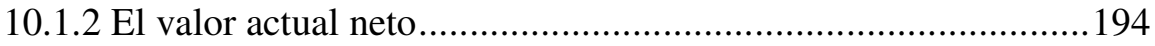

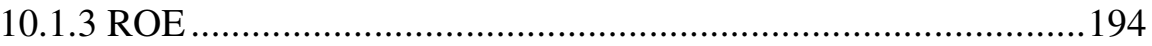

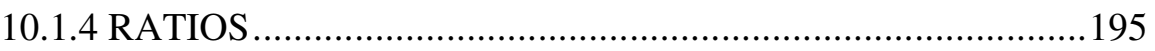

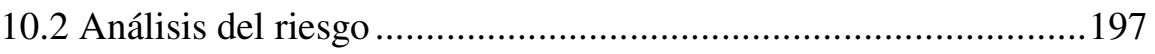

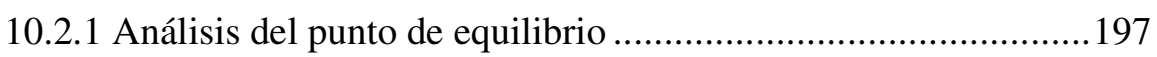

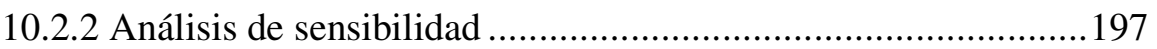

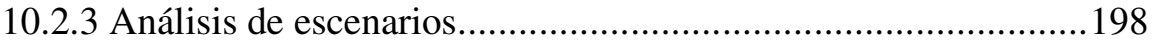

CONCLUSIONES Y RECOMENDACIONES .............................200

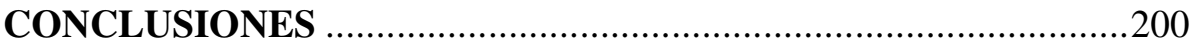

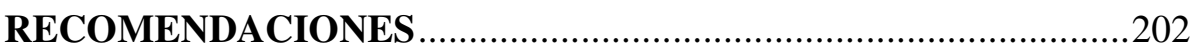

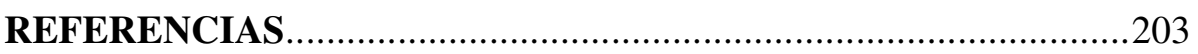

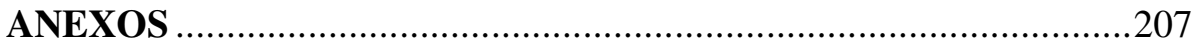

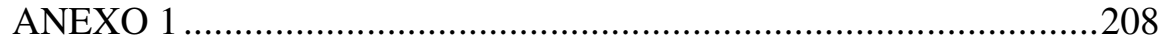

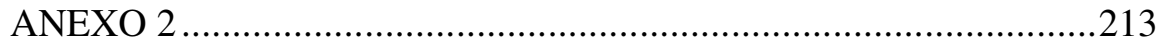

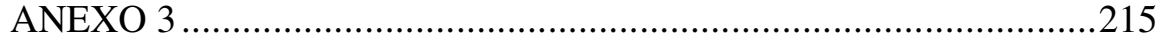

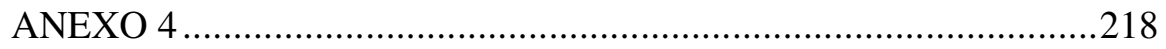

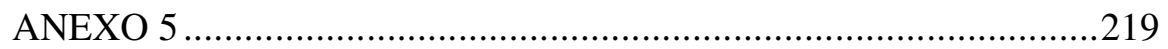

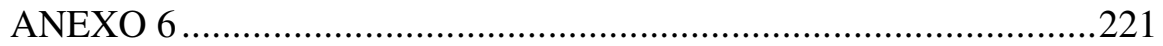

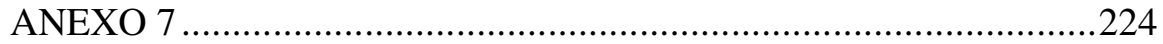

ANEXO 8 


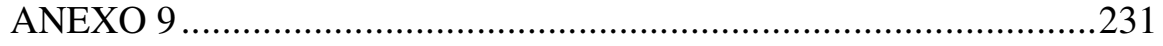

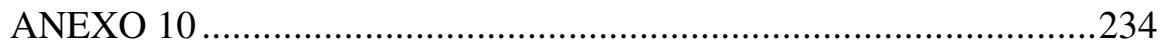

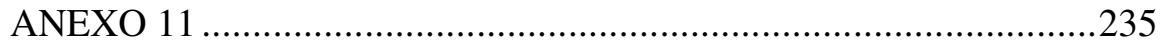




\section{ÍNDICE DE TABLAS}

TABLA 1.- BENEFICIOS DE ANIMAL LOVERS

TABLA 2.- LIMA METROPOLITANA: POBLACIÓN Y HOGARES SEGÚN DISTRITOS - 2018 (EN MILES)...

TABLA 3.-DISTRIBUCIÓN DE NSE POR ZONA APEIM 2018 - LIMA METROPOLITANA ......................8

TABLA 4.-SEGMENTACIÓN DE LA INDUSTRIA: CLIENTES, COMPETIDORES DIRECTOS, PROVEEDORES, PRODUCTOS SUSTITUTOS Y POTENCIALES COMPETIDORES ...................... 14

TABLA 5.-PODER DE NEGOCIACIÓN DE LOS COMPETIDORES DIRECTOS ....................................... 15

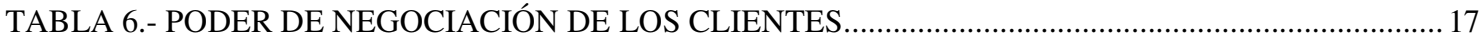

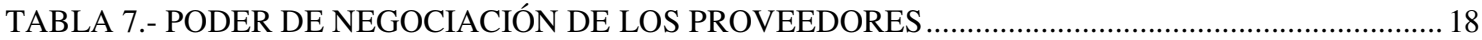

TABLA 8.- PODER DE NEGOCIACIÓN DE LOS POTENCIALES COMPETIDORES ................................. 19

TABLA 9.- PODER DE NEGOCIACIÓN DE PRODUCTOS SUSTITUTOS ............................................20

TABLA 10.- CUADRO RESUMEN DEL PODER DE NEGOCIACIÓN DE CADA UNA DE LAS CINCO

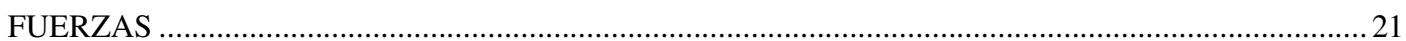

TABLA 11.- UBICACIÓN DE LAS EMPRESAS COMPETIDORAS EN SAN BORJA ...............................22

TABLA 12.- EMPRESAS QUE COMERCIALIZAN ALIMENTO PARA CANES EN SAN BORJA .............23

TABLA 13.- ASPECTOS RELEVANTES EN LA OFERTA DE ALIMENTO PARA CANES ........................25

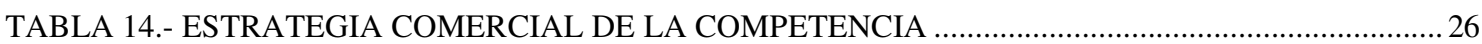

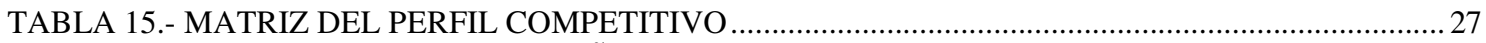

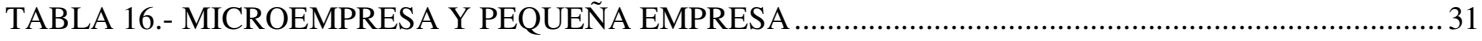

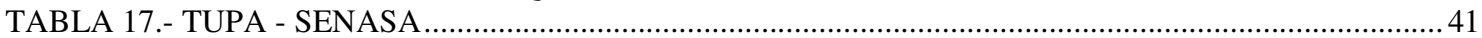

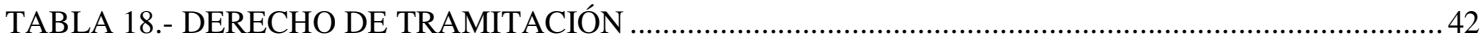

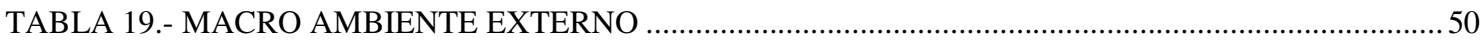

TABLA 20.- TIPOS DE ALIMENTOS QUE CONSUMEN LAS MASCOTAS ............................................5 55

TABLA 21.- ¿CÓMO LLEGÓ LA MASCOTA AL HOGAR? SEGÚN NIVELES SOCIOECONÓMICOS......55

TABLA 22.- DISTRIBUCIÓN DE PERSONAS Y FAMILIAS POR NIVEL SOCIOECONÓMICO DEL DISTRITO DE SAN BORJA - AÑO 2018

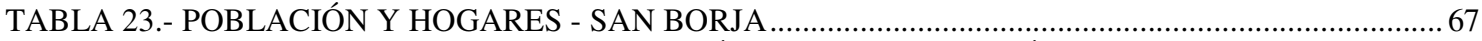

TABLA 24.- LIMA METROPOLITANA: POBLACIÓN Y HOGARES SEGÚN DISTRITOS (EN MILES) $2010 / 2018$

TABLA 25.- DISTRIBUCIÓN DE NSE POR ZONA APEIM 2018 - LIMA METROPOLITANA .................. 69

TABLA 26.- DISTRIBUCIÓN DE LA MUESTRA EN LOS 12 SECTORES DEL DISTRITO PARA LA

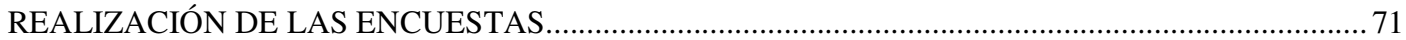

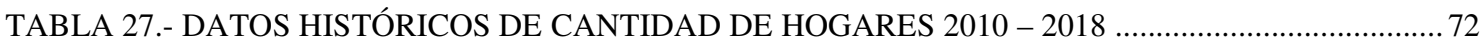

TABLA 28.- MERCADO POTENCIAL. PREGUNTA 1. HOGARES QUE RESIDEN EN DISTRITOS SELECCIONADOS

TABLA 29.- MERCADO POTENCIAL. PREGUNTA 2. HOGARES DE NIVEL SOCIOECONÓMICO ABC

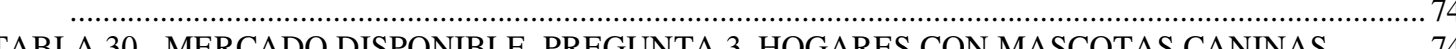

TABLA 31.- PREGUNTA 4. ESTILO DE VIDA PARA IDENTIFICAR EL PERFIL DEL HOGAR DEL

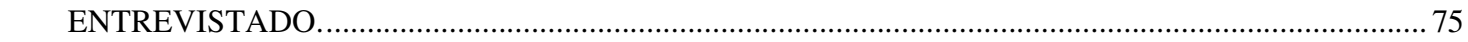

TABLA 32.- PREGUNTA 5. EL TRATO DE LA MASCOTA EN EL HOGAR ........................................ 75

TABLA 33.- PREGUNTA 6. PESO CORPORAL DE LA MASCOTA ….................................................. 76

TABLA 34.- PREGUNTA 7. TIPO DE COMIDA QUE CONSUME LA MASCOTA .......................................76

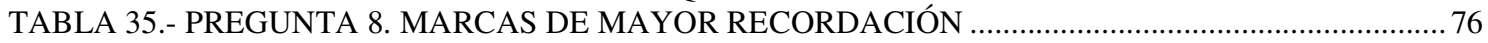

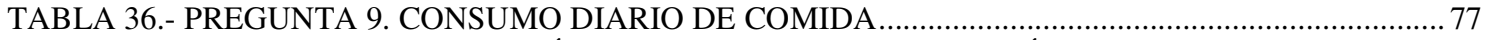

TABLA 37.- PREGUNTA 10. INVERSIÓN MENSUAL EN ALIMENTACIÓN............................................ 77

TABLA 38.- MERCADO EFECTIVO. PREGUNTA 11. ASPECTOS RELEVANTES DEL ALIMENTO IDEAL

TABLA 39.- PREGUNTA 12. INTENCIÓN DE COMPRA DEL ALIMENTO IDEAL ...................................78

TABLA 40.- PREGUNTA 13. PRECIO DISPUESTO A PAGAR POR KILOGRAMO .................................78

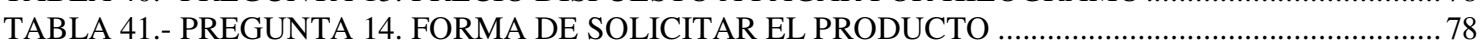

TABLA 42.- PREGUNTA 15. FORMA DE SOLICITAR EL PRODUCTO …........................................... 79

TABLA 43.- PREGUNTA 16. FRECUENCIA DE COMPRA AL MES …................................................ 79

TABLA 44.- MARCO MUESTRAL - CARACTERÍSTICAS POR NIVEL SOCIO ECONÓMICO .................82

TABLA 45.- DATOS HISTÓRICOS DE HOGARES 2010-2018 EXPRESADO EN MILES...........................83

TABLA 46.- DATOS PROYECTADOS DE HOGARES 2019 A 2023 EXPRESADO EN MILES..................8 83

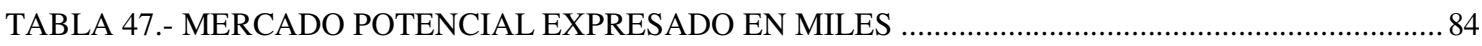


TABLA 48.- MERCADO DISPONIBLE EXPRESADO EN MILES

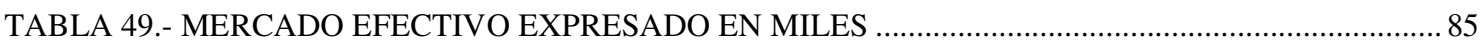

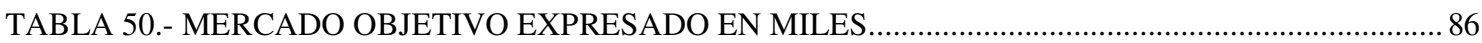

TABLA 51.- CUADRO RESUMEN DEL MERCADO OBJETIVO EXPRESADO EN MILES DE HOGARES

TABLA 52 - BASES PARA LA SEGMENTACIÓN

TABLA 53.- ELEMENTOS DE DIFERENCIACIÓN QUE GENERAN VENTAJAS COMPETITIVAS PARA

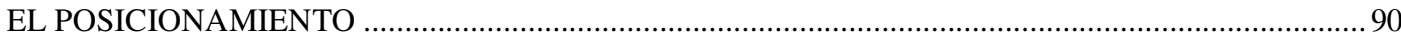

TABLA 54.- ELEMENTOS DE DIFERENCIACIÓN QUE APORTAN AL POSICIONAMIENTO.................91

TABLA 55.- CUADRO COMPARATIVO POR TIPO DE PRODUCTO …………………………………............ 95

TABLA 56.- EFECTOS DE LA COMPOSICIÓN DEL ALIMENTO EN EXCESO, BALANCE O DÉFICIT. 96

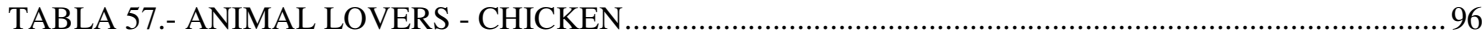

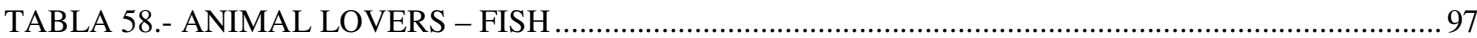

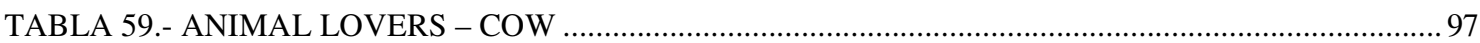

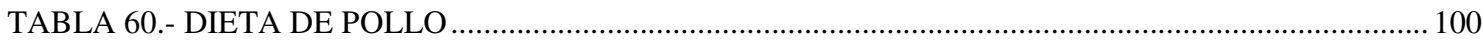

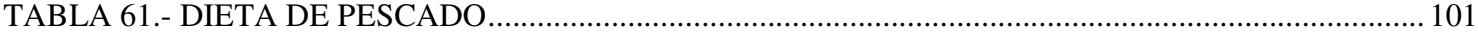

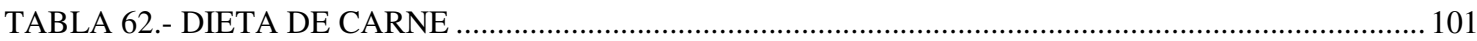

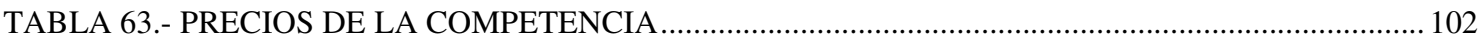

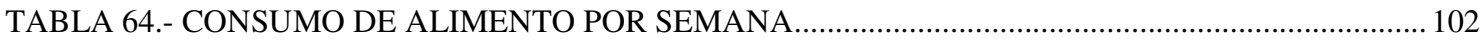

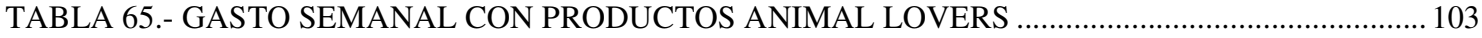

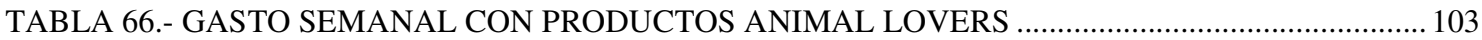

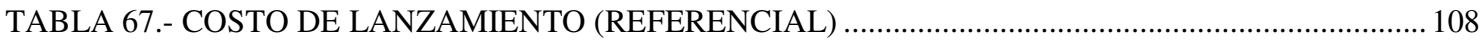

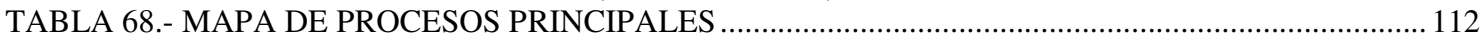

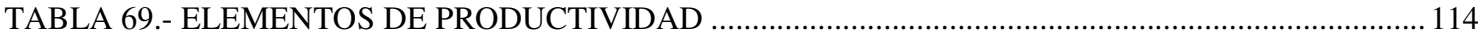

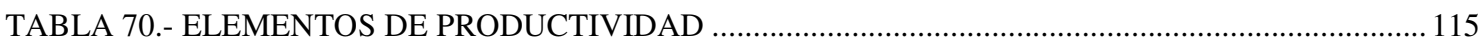

TABLA 71.- MERCADO OBJETIVO CON PROYECCIÓN DE CONSUMO ANUAL, MENSUAL Y DIARIA

TABLA 72 - VENTAS ANUALES EN TONELADAS

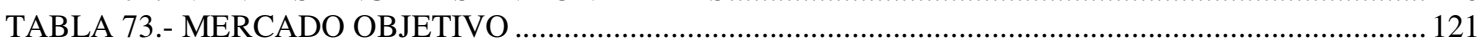

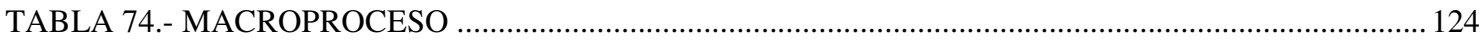

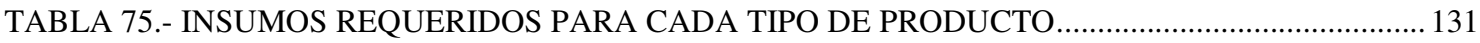

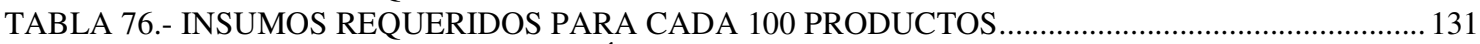

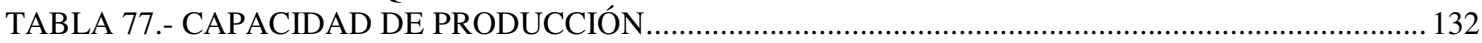

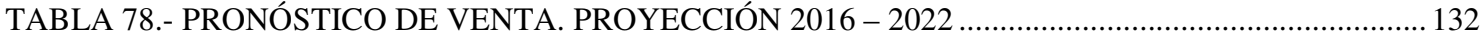

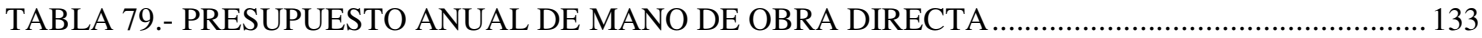

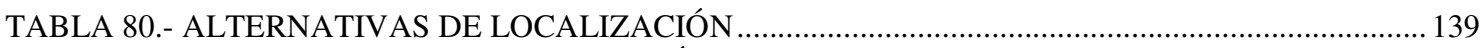

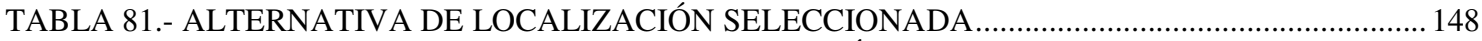

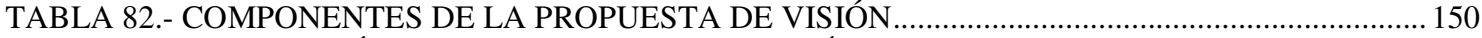

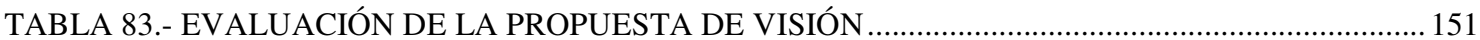

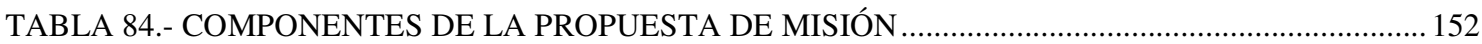

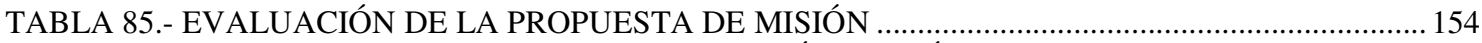

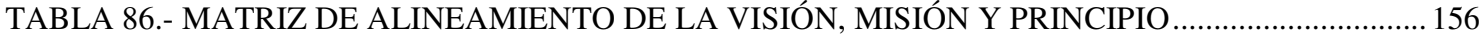

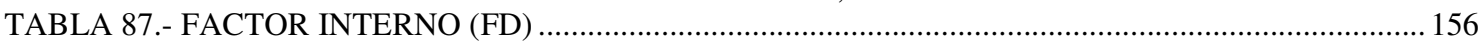

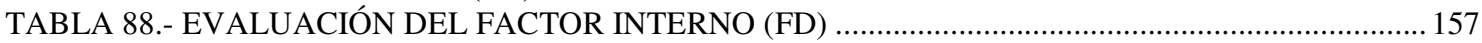

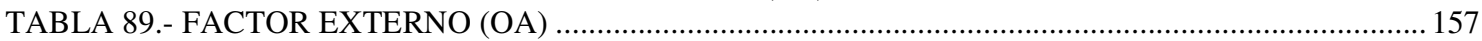

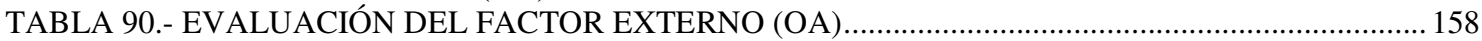

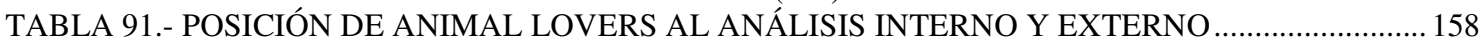

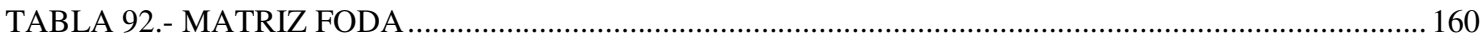

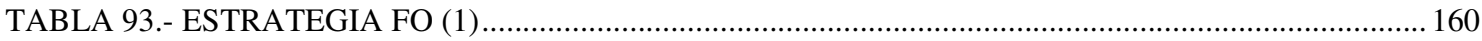

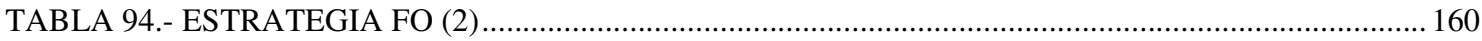

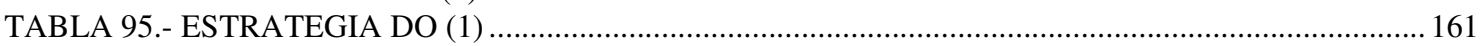

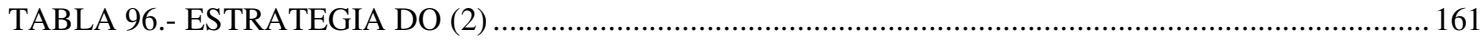

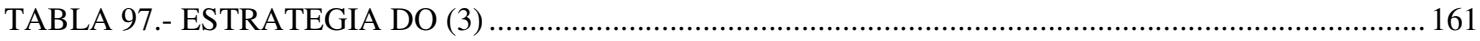

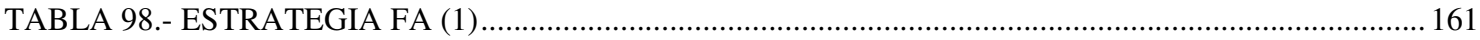

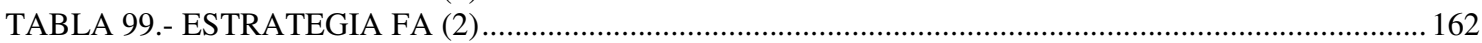

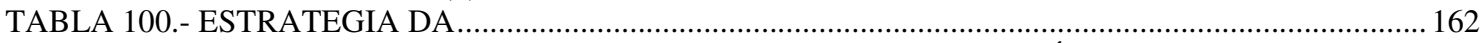

TABLA 101.- CUADRO RESUMEN FODA. ESTRATEGIAS Y META POR ÁREA FUNCIONAL ............ 162

TABLA 102.- ELEMENTOS DE DIFERENCIACIÓN QUE GENERAN VENTAJAS COMPETITIVAS..... 166

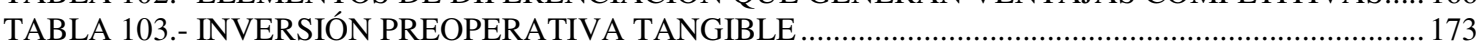

TABLA 104.- INVERSIÓN PREOPERATIVA TANGIBLE - MAQUINARIAS Y EQUIPOS ........................173 
TABLA 105.- INVERSIÓN PREOPERATIVA TANGIBLE - MUEBLES Y ENSERES .............................. 174

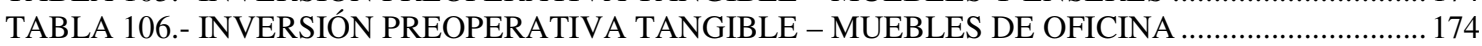

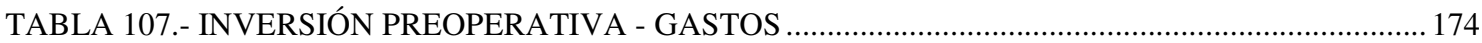

TABLA 108.- INVERSIÓN PREOPERATIVA INTANGIBLE ............................................................ 175

TABLA 109.- INVERSIÓN PREOPERATIVA INTANGIBLE - CONSTITUCIÓN DE EMPRESA .............175

TABLA 110.- INVERSIÓN PREOPERATIVA INTANGIBLE - LICENCIAS Y PERMISOS ...................... 175

TABLA 111.- INVERSIÓN PREOPERATIVA - OTROS (RRHH - SOFTWARE - MARKETING CONTABILIDAD)......

TABLA 112.- INVERSIÓN EN CAPITAL DE TRABAJO

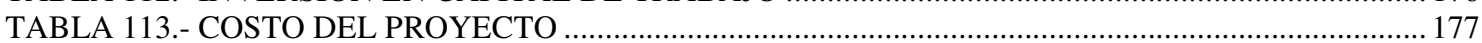

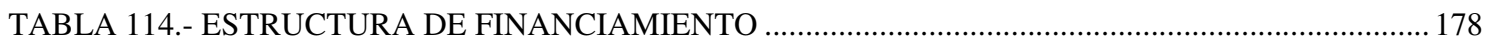

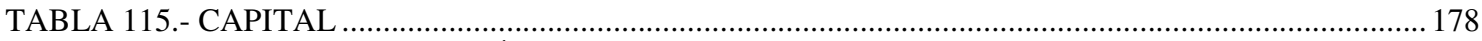

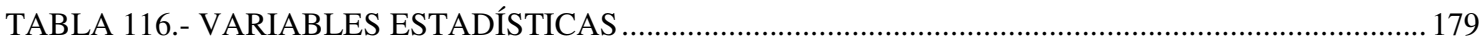

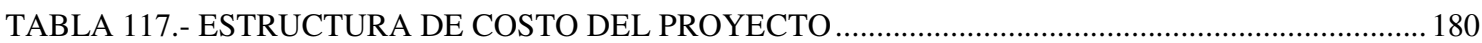

TABLA 118.- ESTRUCTURA DE FINANCIAMIENTO Y TASA DE IMPUESTO A LA RENTA...............180

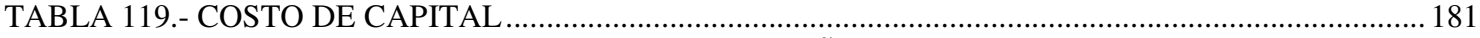

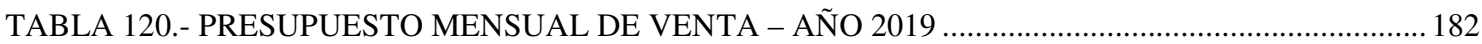

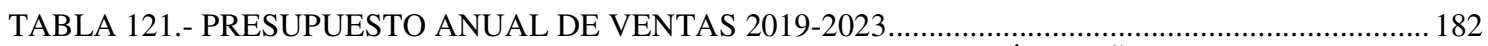

TABLA 122.- PRESUPUESTO MENSUAL DE COSTOS DE PRODUCCIÓN - AÑO 2019 ........................ 182

TABLA 123.- PRESUPUESTO ANUAL DE COSTOS DE PRODUCCIÓN 2019-2023 .............................. 183

TABLA 124.- PRESUPUESTO MENSUAL DE COMPRAS DE MATERIA PRIMA (POLLO) - AÑO 2019

TABLA 125.- PRESUPUESTO MENSUAL DE COMPRAS DE MATERIA PRIMA (PESCADO) - AÑO 2019

TABLA 126.- PRESUPUESTO MENSUAL DE COMPRAS DE MATERIA PRIMA (CARNE) - AÑO 2019

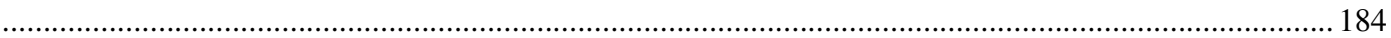

TABLA 127.- PRESUPUESTO MENSUAL DE COMPRAS DE MATERIALES INDIRECTOS - AÑO 2019

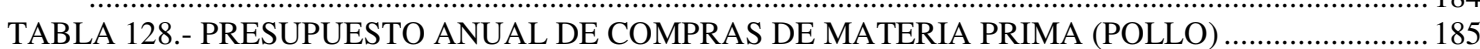

TABLA 129.- PRESUPUESTO ANUAL DE COMPRAS DE MATERIA PRIMA (PESCADO) ................... 185

TABLA 130.- PRESUPUESTO ANUAL DE COMPRAS DE MATERIA PRIMA (CARNE) ....................... 186

TABLA 131.- PRESUPUESTO ANUAL DE COMPRAS DE MATERIALES INDIRECTOS .......................186

TABLA 132.- PRESUPUESTO MENSUAL DE COSTO DE VENTA - AÑO 2019 ..................................... 186

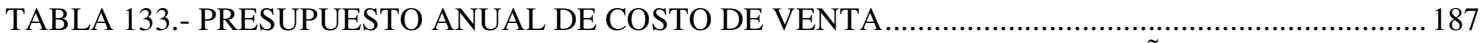

TABLA 134.- PRESUPUESTO MENSUAL DE GASTOS ADMINISTRATIVOS - AÑO 2019..................187

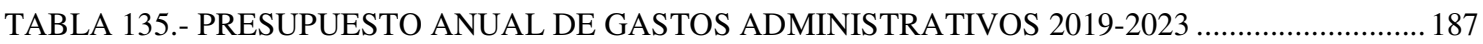

TABLA 136.- PRESUPUESTO MENSUAL DE MARKETING - 2019 ..................................................... 188

TABLA 137.- PRESUPUESTO ANUAL DE MARKETING 2019-2023 …............................................. 188

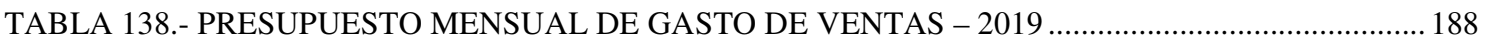

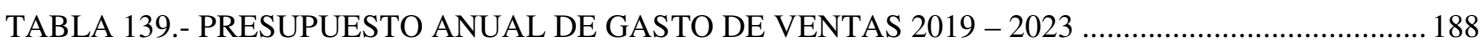

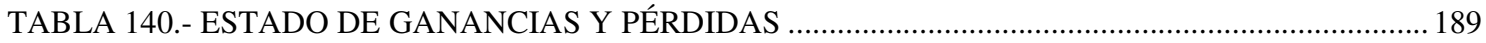

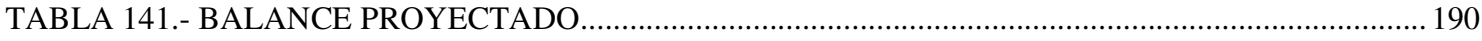

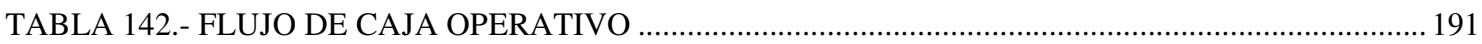

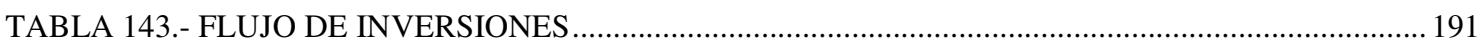

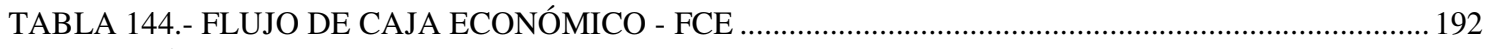

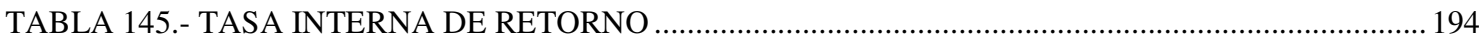

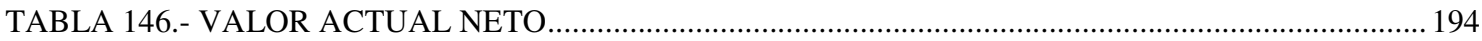

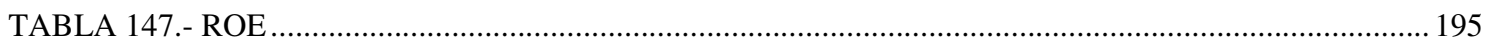

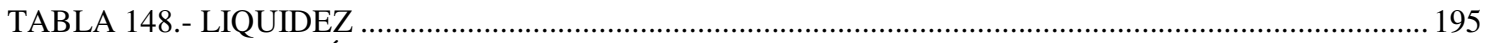

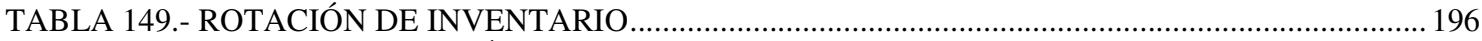

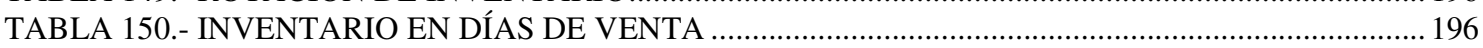

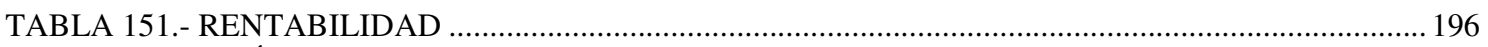

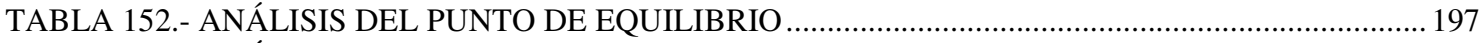

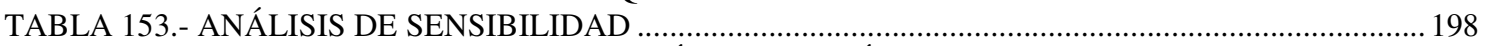

TABLA 154.- VARIACIONES DEL VAN ECONÓMICO, SEGÚN EL CRECIMIENTO PORCENTUAL ANUAL EN VENTAS, A LO LARGO DE TODO EL PROYECTO. 


\section{ÍNDICE DE FIGURAS}

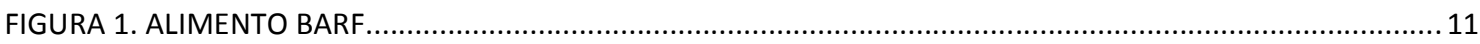

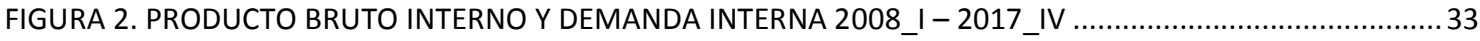

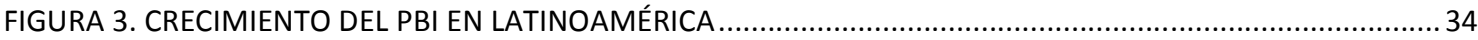

FIGURA 4. VARIACIÓN \% MENSUAL DEL ÍNDICE DE PRECIOS AL CONSUMIDOR DE LIMA METROPOLITANA 2016-

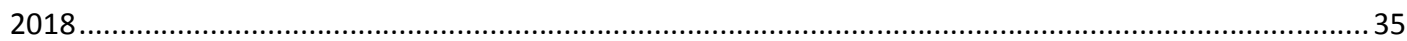

FIGURA 5. EVOLUCIÓN DE LA POBLACIÓN OCUPADA A NIVEL NACIONAL Y DEL ÁREA URBANA........................36

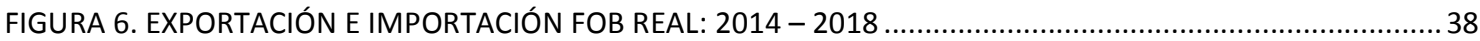

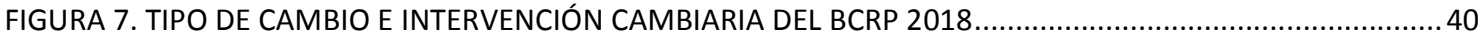

FIGURA 8. CRECIMIENTO DEL MERCADO DE MASCOTAS EN 2017 POR REGIÓN ..........................................43

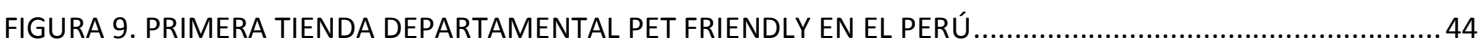

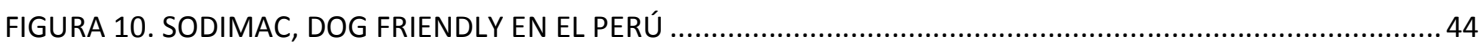

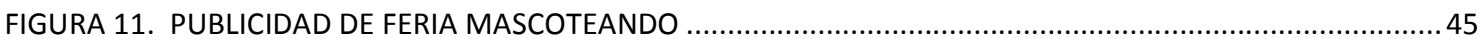

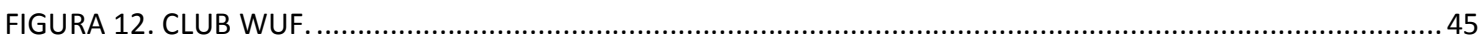

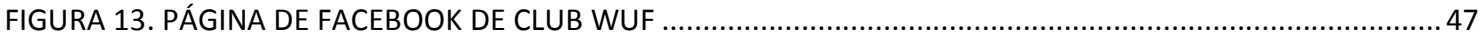

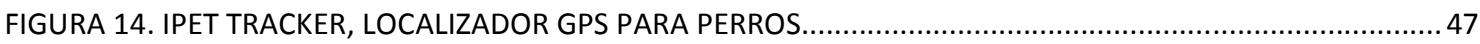

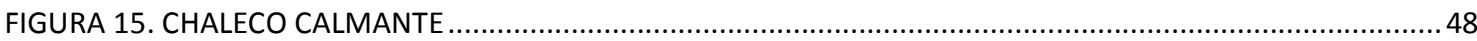

FIGURA 16. DISPENSADOR DE COMIDA PARA PERROS

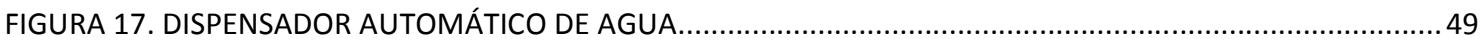

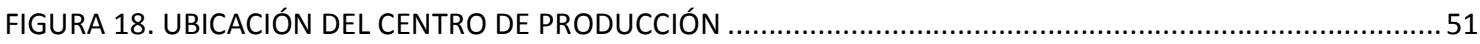

FIGURA 19. ALQUILER POR METRO CUADRADO EN SURQUILLO Y SAN BORJA ...........................................5

FIGURA 20. DISTRIBUCIÓN POR SECTORES DEL DISTRITO DE SAN BORJA …............................................. 52

FIGURA 21. ADAPTADO DE “PLAN ESTRATÉGICO DE GOBIERNO ELECTRÓNICO 2018-2020” POR

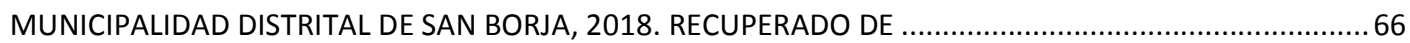

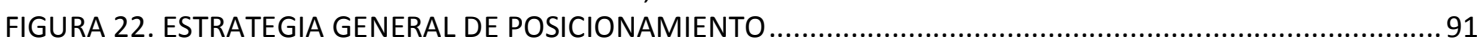

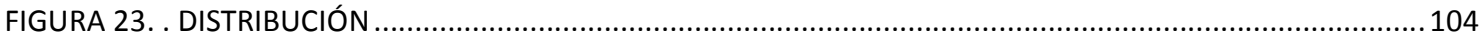

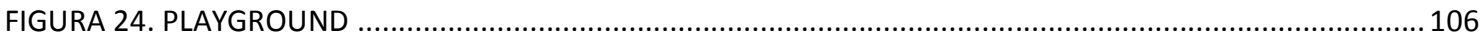

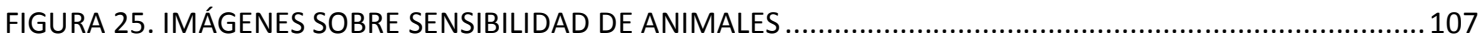

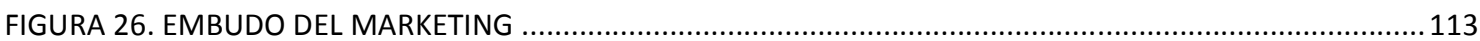

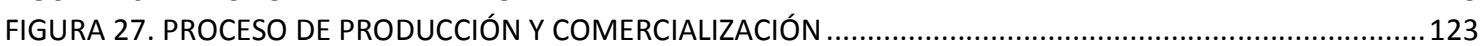

FIGURA 28. EQUIPO EMPLEADO PARA EL CONGELAMIENTO Y CONSERVACIÓN DE CARNES...........................125

FIGURA 29. EQUIPO EMPLEADO PARA LA REFRIGERACIÓN Y CONSERVACIÓN DE VERDURAS..........................125

FIGURA 30. MESA DONDE SE ELABORAN LOS PRODUCTOS. PARA EL TRABAJO INTENSO SE REQUIERE DE ACERO

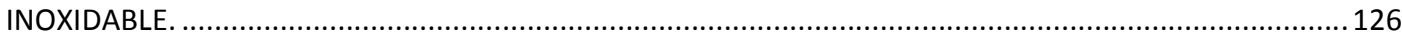

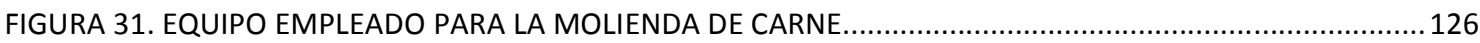

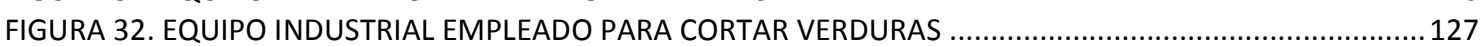

FIGURA 33. . COCINA INDUSTRIAL DE SEIS HORNILLAS PARA LA COCCIÓN DE LOS ALIMENTOS. ....................127

FIGURA 34. EQUIPO PARA MEZCLADO DE CARNES, GRANOS Y VERDURAS. ................................................. 128

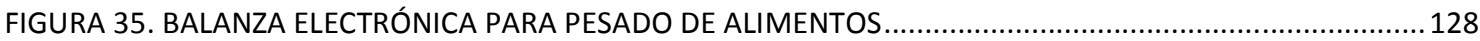

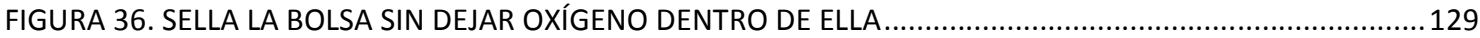

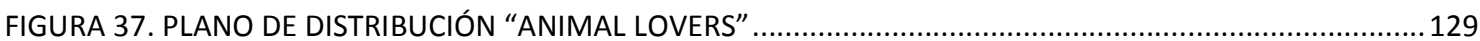

FIGURA 38. ÁREA DE PRODUCCIÓN “ANIMAL LOVERS”.

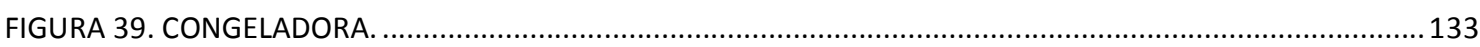

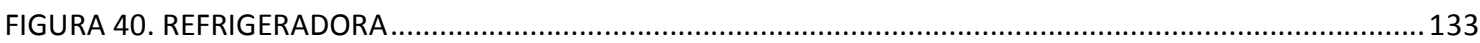

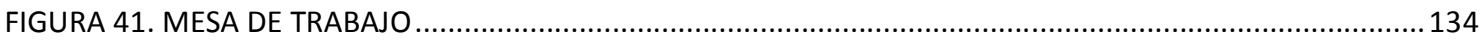

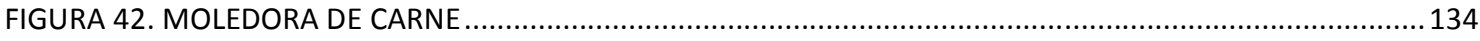

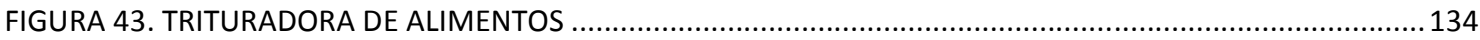

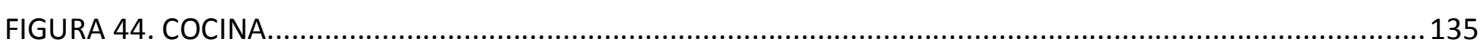

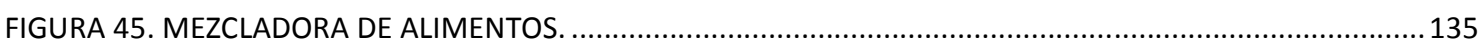

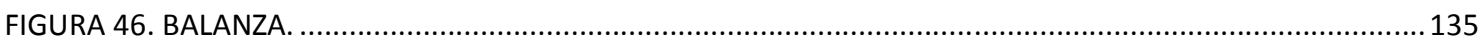

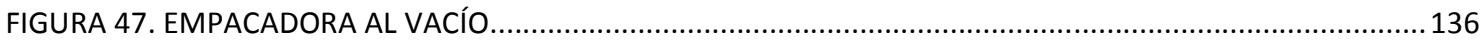

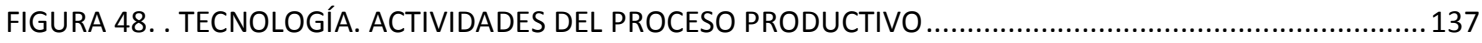

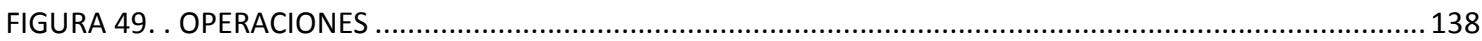

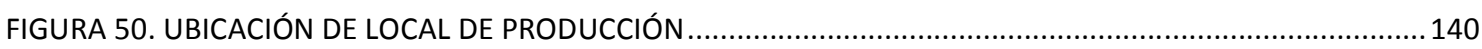

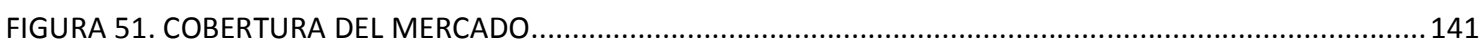

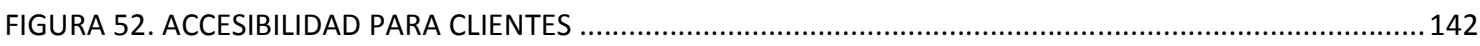


FIGURA 53. UBICACIÓN DE "ANIMAL LOVERS".

FIGURA 54. ORGANIGRAMA ANIMAL LOVERS. 
"ANIMAL LOVERS" 


\section{RESUMEN EJECUTIVO}

En la sociedad se identifican tendencias muy evidentes y el presente trabajo aborda una de estas tendencias. La tendencia referida es aquella que se basa en la sensibilidad de las personas con respecto a los animales traduciéndose en un mayor cuidado para con ellos. Este hecho se traduce en muchos casos en la humanización de los animales que se convierte de manera clara y específica en un especial cariño a los canes y a los gatos, animales domésticos de mayor presencia en los hogares. Esto ha traído como consecuencia, que en el Congreso de la República se haya aprobado una ley contra el maltrato animal que tiene penas privativas de la libertad hacia las personas que actúan de forma cruel con los animales.

Este cariño inusitado por las mascotas ha dado pie a la atención de sus variadas necesidades por parte de los dueños de las mascotas. En consecuencia, surgen diversos servicios que el mercado no contemplaba. Entre estos servicios tenemos a: baños, guardería, paseos en la ciudad, paseos y caminatas de fin de semana, spa, peluquería, escuela, circuito de ejercicios, discoteca, alimentos balanceados, enlatados, galletas, correas, vestido, clínicas veterinarias, viajes en avión, psicólogo canino, entrenador, entre otros muchos servicios.

Bajo esta tendencia se enmarca el siguiente plan de negocios, que consiste en producir y comercializar alimento saludable para mascotas, dado que el consumo es diario, generando una frecuencia de compra que hace atractivo este negocio.

El segmento elegido corresponde a los hogares de NSE A, B y C, conformado por los distritos que tienen el mayor poder adquisitivo en Lima.

La inversión del proyecto equivale a S/ 184,634 de los cuales el 100\% es aportado por los accionistas.

El mercado total considerando los distritos de San Borja, Miraflores, San Isidro y Santiago de Surco es de 206,400 hogares, siendo el mercado objetivo de 1,749 hogares con mascota, lo que representa el $2 \%$. 
La tasa interna de retorno económica (TIRE) es de 46.2\%, no calculándose el costo promedio ponderado de capital (CPPC) por carecer -el proyecto- de financiamiento. De otro lado el costo de oportunidad del inversionista (Ke; $\mathrm{COK}$ ) es de $22.6 \%$, con el que se obtiene un valor actual neto económico (VANE) de S/ 160,728, cifras que demuestran la rentabilidad evaluada a un horizonte de 5 años. 


\section{CAPÍTULO I}

\section{GENERALIDADES}

\subsection{Antecedentes.}

El lobo es reconocido como ancestro del can. Ciertas características del can (Canis lupus familiaris), como vivir en sociedad, elegir un macho alfa como líder, ceder la prioridad para comer primero, dormir en el sitio más cómodo, delimitar el territorio a través del marcaje por orina para dejar huella de jerarquía y así evitar la competencia por alimento, espacio y hembras fértiles, son fiel reflejo de su herencia. El lobo fue domesticado hace más de 15 mil años a.C., gracias a que se acercó a los seres humanos debido a la dificultad para conseguir alimentos, encontrando en las sobras de la comida del hombre, el sustento necesario para subsistir. Este fue el principio de la vida del lobo -más tarde el perro- en la construcción de su relación y convivencia con los seres humanos. El lobo era un animal dedicado a la caza y fundamentalmente carnívoro, no obstante, con la ingesta de vegetales en su dieta, fue modificando su sistema digestivo. El ser humano lo domesticó adaptándolo a sus necesidades, apareciendo de esta forma el perro para la caza, pelea, pastoreo, así como perros de compañía para el hogar. Con el paso del tiempo, el hombre comenzó a manipular su reproducción gestando de esta forma la aparición de nuevas razas. (Yrigoyen, 2014)

En los años setenta, ochenta y noventa (siglo pasado), la industria de los canes aún no era significativa. Todo producto y servicio en el Perú -y en Lima en particular- era inexistente. La alimentación de los canes en aquel entonces, solo se realizaba en base a las sobras de la comida hecha en casa.

Hacia el año 2012, el alimento balanceado para perros mostraba un crecimiento constante durante años recientes con tasas por encima del 10\% anual. Hacia la segunda década, el mercado contaba con treinta (30) marcas de comida para mascotas, concentrando Lima más del 50\% del mercado (Alicorp, 2012). En forma paralela aparecen productos y servicios 
adicionales. Productos y servicios como el vestido, el tratamiento psicológico, paseos para canes y excursiones caninas, entre otros, son en la actualidad una forma rentable de hacer negocio y muestran evidencias del desarrollo en esta industria.

En el actual contexto, el mercado peruano ha experimentado un significativo desarrollo con la aparición de múltiples productos y servicios para mascotas, así como la presencia de una gran cantidad de marcas de alimentos.

De otro lado, según la opinión de veterinarios, la alimentación es uno de los factores más relevantes para brindarles una buena calidad de vida. Por tal motivo, el presente trabajo se enfoca en brindarle calidad de vida al can, a través de productos alimenticios sanos y adecuados para el uso frecuente y cotidiano.

\subsection{Determinación del Problema u Oportunidad.}

El presente proyecto considera dos (2) aspectos: a) la solución del problema con respecto a la alimentación del can; b) la oportunidad de Animal Lovers.

a) La solución del problema con respecto a la alimentación del can.

Con respecto al problema, la comida seca -que predomina en el mercado en un $95 \%$ (Mars, 2018) - posee enzimas de origen animal que cumplen con la fórmula alimenticia y que contiene cierto volumen de carne en su composición (productos de calidad). Este producto está deshidratado y contiene preservantes para una duración aproximada de entre uno o dos años. Con respecto a la solución propuesta por Animal Lovers, esta propuesta le brinda al can un alimento con una cantidad mínima de preservantes para cuidar su salud.

b) La oportunidad de ofrecer un producto balanceado y saludable.

En lo que concierne a la oportunidad, Animal Lovers presenta una propuesta distinta de alimento cuya tendencia está orientada para los próximos años en el incremento de la comida húmeda. Animal Lovers brinda un alimento balanceado, saludable, variado (carne, pollo y 
pescado) y carente de un proceso de producción industrial, con insumos que guardan sus propiedades naturales.

\section{Tabla 1.- Beneficios de Animal Lovers}

\section{Soluciones al problema del Cliente}

- Brindarle calidad de vida a su mascota.

- Evitar preservantes y los efectos posteriores de estos en el can.

\section{Oportunidad de la Empresa}

- Ofrecer un producto balanceado con insumos.

- Proceso no industrial.

- Aprovechar la brecha de oportunidad que ofrece el mercado, considerando según información de mercado:

- $\quad 122,154$ hogares consumen comida balanceada (CPI; 2018).

- $\quad 116,046$ hogares consumen comida seca (95\%). (Gerente de importadora MARS).

- De esta cifra, Animal Lovers desea convertir en clientes a 1,749 hogares que equivalen al $1.5 \%$.

\section{Beneficios de un can con alimentación sana}

- Heces firmes

- Huesos y dientes sanos

- Pelo y piel sanos

Nota: Elaboración propia
- Peso ideal

- Energía

- Vitalidad

\subsection{Justificación del Proyecto.}

Según la información recogida en los últimos años en diversos diarios y a través de fuentes confiables como: Alicorp; Bertha Galdos Jefa de Marca de Purina Nestlé; Jhuliana Alvarez, empresaria; Consultora Maximixe; Ipsos-Perú; entre otros, se observa un mercado con características muy marcadas, como: la fuerte tendencia a la humanización de las mascotas; la preocupación por su alimentación y estado de salud; la presencia mayoritaria de canes en los hogares; un mercado de alimentos en crecimiento; proceso de penetración de ciertas marcas de productos; aumento de la variedad de servicios para las mascotas; concentración del consumo de productos alimenticios en los hogares de Lima (tarea pendiente en provincias) y en general, perspectivas de una industria en franco proceso de consolidación.

A continuación, se realiza una breve reseña de información relevante sobre la industria en estos últimos seis años. 
- Año 2012. Alicorp -que compite con las marcas Mimaskot y Nutricam- indica a través de sus directivos que el mercado -dado el incremento en el cuidado de las mascotas sobre todo de canes- ha generado una oferta diversificada de alimentos con 30 marcas en competencia, además de crecer a tasas por encima del $10 \%$ anual, teniendo Lima concentrado el 50\% del consumo a nivel nacional. En Lima, más del 50\% se vende a través del canal tradicional (mercados y bodegas); les siguen los supermercados, veterinarias y tiendas especializadas en comercialización de alimentos. (Gestión, 2012)

- Año 2013. Según Álvarez, Jefa de Marca de Purina Nestlé las ventas alcanzaron S/ 320 millones con solo un $8 \%$ de la población canina atendida y un total de quince marcas en competencia en alimentos para canes, además de una cultura de tenencia de mascotas, por lo que cada vez la gente se preocupa más por ellos. "Vemos una clase media que está creciendo y una característica de este segmento es tener una mascota en el hogar", subrayó. (Gestión, 2013)

- Año 2014. Solís, gerente general de Es Pa Mascotas indica que, para muchos, las mascotas son parte de la familia, teniendo a sus amos, pendientes de su alimentación, estado de salud y demás cuidados. En lo que se refiere a servicios, existe un fuerte interés por el corte, los baños y la atención veterinaria. La empresaria indica, que existe una fuerte tendencia por adquirir artículos por internet, aunque actualmente todas las transacciones se realizan de manera física a través de las tiendas. No obstante, gran cantidad de productos son importados o se adquieren en el centro de Lima. (Perú 21, 2014)

- Año 2016. Según la consultora Maximixe la producción de alimentos para mascotas creció $12.3 \%$, llegando a 37,634 toneladas métricas y que solo la cuarta parte de canes y gatos se alimenta con nutrientes balanceados, por lo que se aprecia un mercado con un gran potencial de crecimiento. De igual forma, se espera un crecimiento del $10 \%$ para el 
año 2017. No obstante, se refleja claramente en el mundo -al igual que en el Perú- una fuerte tendencia a la humanización de las mascotas.

- Maximixe, indica también, que en el 2015 la producción de alimentos para mascotas llegó a 50,000 TM, muy por debajo de Chile y Argentina. Con respecto a las importaciones, el 2015 éstas crecieron 14.2\% anual en volumen, llegando a alcanzar 18,500 TM, valorizadas en US\$ 26.1 Millones. (Gestión, 2016)

- Año 2017. Ipsos-Perú señala que el 55\% de los hogares de Lima Metropolitana (1.37 millones) cuenta con una mascota en casa. El 74\% tiene un can y el 39\% tiene un gato. Otro dato que arrojo la investigación revela que el limeño tiene interés en alimentar bien a su mascota. El $76 \%$ compra alimento especializado y el $29 \%$ opta por comprar en bodegas. De igual forma, el $70 \%$ lleva sus mascotas al veterinario, un 35\% lo realiza una vez al mes y el 9\% lo realiza con una menor frecuencia. (Perú 21, 2017)

- Año 2018. Mars, dueña de las marcas Pedigree y Whiskas, tiene un agresivo plan para conquistar el liderazgo-en poder de RINTI SA- en los próximos cinco años. Se ha propuesto duplicar el tamaño de sus operaciones hacia el 2020 en Perú. Víctor Pérez, Gerente General de MARS indica que "La base de la alimentación de las mascotas, hoy en día, se da a través del alimento seco. Pero ante la tendencia de 'humanizar' su dieta en cuanto a variedad, el húmedo ha empezado a ganar fuerza". Esto se da a través de los sobres de porción única, que son convenientes por practicidad y precio. (El Comercio, 2018) 


\subsection{Objetivos Generales y Específicos}

- $\quad$ El objetivo general del presente proyecto consiste en elaborar un plan de negocio orientado a atender la necesidad de alimentación de mascotas caninas que constituyen nuestro mercado potencial, a través de una gestión rentable para la organización.

- Del objetivo general se desprenden los objetivos específicos siguientes:

- Calcular el mercado objetivo del proyecto, en los distritos de San Borja, Miraflores, San Isidro y Santiago de Surco, de acuerdo con el mercado meta establecido, para sustentar la viabilidad durante el horizonte de evaluación de 5 años del proyecto.

- Investigar las preferencias del mercado meta para establecer una adecuada combinación precio-valor, donde la propuesta de Animal Lovers ofrezca un alimento novedoso para canes, de calidad superior y a un precio de entrada competitivo para el primer año.

- Establecer una estructura organizacional plana que permita una adecuada gestión administrativa del negocio, con un gasto promedio en remuneraciones, menor al $15 \%$ de las ventas anuales.

- Definir un modelo de gestión basado en objetivos comerciales relevantes con una venta de S/ 500,000 para el primer año del proyecto y que al término del quinto año crezca en $200 \%$.

- Iniciar el proyecto con una capacidad instalada de producción en toneladas al año, que permita atender la demanda (ventas) para los años de duración del proyecto.

- Invertir en el proyecto un aproximado de S/ 150,000, para obtener una rentabilidad aproximada del 20\% para los accionistas al término del quinto año. 


\subsection{Alcances y Limitaciones de la Investigación}

\section{Alcances}

El plan de negocio tiene como radio de acción comercial el distrito de San Borja, que para el 2018 contaba con sus 119 mil habitantes y 38.5 miles de hogares; y de ellos a los hogares que tienen por lo menos a un can en calidad de mascota. La amplitud de la investigación abarca en forma cualitativa -como paso previo a la investigación cuantitativa- a actores relevantes en la industria de la alimentación canina, como:

- Veterinarios en ejercicio profesional activo (cirujanos, nutricionistas, entre otros).

- Familias con mascotas caninas.

Tabla 2.- Lima Metropolitana: población y hogares según distritos - 2018 (en miles)

\begin{tabular}{|c|c|c|c|c|}
\hline \multicolumn{5}{|c|}{$\begin{array}{l}\text { Cuadro } N^{\circ} 8 \\
\text { LIMA METROPOLITANA: POBLACIÓN Y HOGARES } \\
\text { SEGÚN DISTRITOS - } 2018 \text { - (En miles) }\end{array}$} \\
\hline No. & DISTRITO & POBLACION & $\%$ & HOGARES \\
\hline 1 & San Juan de Lurigancho & $1,137.0$ & 11.1 & 279.7 \\
\hline 2 & San Martin de Porres & 733.5 & 7.1 & 177.9 \\
\hline 3 & Ate & 655.8 & 6.3 & 160.8 \\
\hline 4 & Comas & 550.7 & 5.3 & 141.4 \\
\hline 5 & Villa EI Salvador & 482.0 & 4.7 & 117.3 \\
\hline 6 & Villa Maria del Triunfo & 467.8 & 4.5 & 116.5 \\
\hline 7 & San Juan de Miraflores & 422.2 & 4.1 & 109.0 \\
\hline 8 & Los Olivos & 388.7 & 3.8 & 109.0 \\
\hline 9 & Puente Piedra & 366.8 & 3.5 & 89.5 \\
\hline 10 & Santiago de Surco & 364.0 & 3.5 & 109.8 \\
\hline 11 & Chorrillos & 340.7 & 3.3 & 90.7 \\
\hline 12 & Carabayllo & 314.4 & 3.0 & 76.3 \\
\hline 13 & Lima & 287.8 & 2.8 & 94.1 \\
\hline 14 & Santa Anita & 238.2 & 2.3 & 60.8 \\
\hline 15 & Lurigancho & 228.1 & 2.2 & 56.8 \\
\hline 16 & Independencia & 227.0 & 2.2 & 68.9 \\
\hline 17 & El Agustino & 199.8 & 1.9 & 52.8 \\
\hline 18 & La Molina & 181.3 & 1.7 & 48.9 \\
\hline 19 & La Victoria & 180.7 & 1.7 & 57.4 \\
\hline 20 & Rimac & 173.5 & 1.7 & 51.4 \\
\hline 21 & San Miguel & 143.5 & 1.4 & 45.6 \\
\hline 22 & Pachacamac & 134.4 & 1.3 & 32.8 \\
\hline 23 & San Borja & 119.0 & 1.1 & 38.5 \\
\hline
\end{tabular}

Nota: Adaptado de "Perú: población 2018", por CPI, 2018. Recuperado de http://www.cpi.pe/images/upload/paginaweb/archivo/26/mr_poblacional_peru_201 805.pdf

Atender a este segmento se justifica por: su tamaño, crecimiento, rentabilidad, accesibilidad y diferenciación, cuya composición corresponde en un 94.7\% al NSE ABC. 
Tabla 3.-Distribución de NSE por zona APEIM 2018 - Lima metropolitana (\%) HORIZONTALES

\begin{tabular}{|l|c|c|c|c|c|c|c|c|}
\hline \multicolumn{1}{|c|}{ ZONA } & TOTAL & NSEA & NSE B & NSE C & NSE D & NSE E & Muestra & Error (\%) \\
\hline Total & 100 & 4.7 & 23.2 & 41.3 & 24.4 & 6.4 & 4058 & 1.54 \\
\hline Zona 1 (Puente Piedra, Comas, Carabayllo) & 100 & 0.0 & 15.0 & 37.8 & 38.2 & 9.0 & 291 & 5.74 \\
\hline Zona 2 (Independencia, Los Olivos, San Martin de Porras) & 100 & 2.2 & 26.9 & 49.3 & 19.3 & 2.3 & 353 & 5.22 \\
\hline Zona 3 (San Juan de Lurigancho) & 100 & 1.1 & 17.4 & 43.2 & 28.9 & 9.5 & 276 & 5.9 \\
\hline Zona 4 (Cercado, Rimac, Breña, La Victoria) & 100 & 2.5 & 26.7 & 43.0 & 24.1 & 3.8 & 526 & 4.27 \\
\hline $\begin{array}{l}\text { Zona 5 (Ale, Chaclacayo, Lurigancho, Santa Anita, San Luis, } \\
\text { El Agustino) }\end{array}$ & 100 & 1.0 & 10.4 & 45.1 & 33.3 & 10.2 & 331 & 5.39 \\
\hline $\begin{array}{l}\text { Zona 6 (Jesús Maria, Lince, Pueblo Libre, Magdalena, San } \\
\text { Miguel) }\end{array}$ & 100 & 14.4 & 56.0 & 23.9 & 3.9 & 1.8 & 284 & 5.82 \\
\hline Zona 7 (Miraflores, San Isidro, San Borja, Surco, La Molina) & 100 & 34.6 & 46.4 & 13.7 & 4.2 & 1.1 & 338 & 5.33 \\
\hline
\end{tabular}

Nota: Adaptado de "Niveles socioeconómicos 2018" por APEIM, 2018. Recuperado de http://www.apeim.com.pe/wp-content/themes/apeim/docs/nse/APEIM-NSE-2018.pdf

${ }^{a}$ Muestra la alta concentración de los NSE ABC en la zona 7, alcanzando un $94.7 \%$ de la población.

\section{Limitaciones}

Se revelan como limitaciones, la inversión en aspectos relacionados a la investigación, producción, distribución y difusión en medios de comunicación masiva. Además de ello, otra limitación corresponde a las fuentes de información secundaria con que se cuenta. Con respecto a esta última, por lo general no está actualizada o existe de forma escasa.

Finalmente, otra limitante de relevancia es el tiempo pues el lapso entre invertir y obtener ingresos muchas veces determina la sostenibilidad a mediano y largo plazo. 


\section{CAPITULO II}

\section{ESTRUCTURA ECONÓMICA DEL SECTOR}

\subsection{Descripción del Estado Actual de la Industria}

Desde una perspectiva general, la industria del alimento para canes comprende a todos aquellos agentes que participan en calidad de clientes, competidores, proveedores, en calidad de productos sustitutos y como potenciales competidores, sin ningún tipo de segmentación ni clasificación alguna. En tal contexto, la industria en general proyecta para el 2018 un crecimiento aproximado del 10\%, similar a 2017.

\section{Sobre la tenencia de mascotas y sus cuidados.}

El estudio más reciente es el realizado por CPI (2018) el cual indica que un $60 \%$ de los hogares urbanos a nivel nacional posee una mascota, cantidad que es muy similar en todos los niveles socioeconómicos. En el caso de Lima, el 56.5\% de los hogares de Lima Metropolitana tienen mascotas.

Los perros y los gatos tienen la preferencia en los hogares del Perú urbano, con un $79 \%$ y $42 \%$, respectivamente. En los hogares de nivel socioeconómico AB el $87 \%$ tiene por lo menos un perro, en el C el $81 \%$ y en el DE el $74 \%$.

\section{Sobre el tipo de alimento que domina el mercado.}

Con respecto a los alimentos, Pérez, gerente general de MARS (importadora) para la región andina, indica que el alimento seco domina actualmente el mercado con un 95\% y a su vez se experimenta una creciente humanización de las mascotas. "La comida húmeda presenta perspectivas de crecimiento, sin embargo, el alimento especializado será la clave en esta categoría”, comentó. (El Comercio, 2018) 


\section{Sobre los proveedores.}

Tenemos cuatro (4) tipos de proveedores que consideramos relevantes.

- $\quad$ En primer lugar, tenemos a aquellos proveedores que importan alimentos y luego los distribuyen (ejemplo: la importadora MARS).

- $\quad$ En un segundo caso, tenemos a los proveedores que primero producen el alimento para luego distribuirlo, como es el caso de la comida seca no perecible (ejemplo: RINTI S.A.).

- $\quad$ En un tercer caso, tenemos a la comida cruda triturada - perecibles - (BARF por sus siglas en inglés) que se distribuyen bajo una articulada cadena de frio para su conservación.

- En un cuarto caso, el mercado experimenta el surgimiento de ciertas veterinarias especializadas en nutrición, que ofrecen recetas acordes a las necesidades del can, para luego venderles el alimento completamente elaborado (ejemplo: veterinaria Prana).

\section{Sobre los precios.}

Si hablamos de precios, el kilogramo de un producto económico como Bandido de RINTI SA (producción nacional) puede costar S/ 7 en promedio y el kilogramo de un alimento importado super premium como Hill's puede llegar a costar S/ 45 en promedio.

Los productos cuyo precio varía entre $\mathrm{S} / 7$ y S/ 12 por kilogramo son de consumo masivo (en marcas nacionales como: Bandido, Thor, Ricocan y Canbo de RINTI; Dog Chow de Purina, etc.). Estos productos se comercializan en bodegas, mercados y supermercados, donde se pueden encontrar marcas económicas y por lo general de producción nacional. De otro lado, el alimento crudo triturado (BARF) elaborado con carne de pavo, pollo, res. etc. se vende actualmente en algunas veterinarias y supermercados, con un precio entre S/ 14 y S/ 18. En el caso de la empresa RAMBALA tienen un formato de bolsas de 800 grs. aproximadamente.

Otras veterinarias, ofrecen alimento balanceado por prescripción (ejemplo: veterinaria Aurora). 


\section{Sobre los puntos de venta.}

Los puntos de venta son variados. Algunos pertenecen al canal tradicional como los mercados de barrio, las paradas y las bodegas, que ofrecen los productos más económicos.

Otros puntos pertenecen al canal moderno, que están representados por los supermercados (que ofrecen productos no muy caros) y por último tiendas especializadas en alimentos y las veterinarias (productos de mayor calidad) con productos de primera categoría conocidos en el argot popular como premium y super premium. Esta es la forma popular -no ratificada científicamente- de reconocer un producto de calidad.

\section{Sobre los productos.}

En lo que concierne a los alimentos, los puntos de venta ofertan por lo general, comida seca (formato de croquetas embolsadas de 1, 2, 3, 5, 14 o 15 kilogramos), en marcas nacionales e importadas. Estas bolsas de diverso peso se emplean para productos nacionales e importados; para productos de diversas calidades: económicos (baja calidad), denominados premium y super premium (alta calidad).

Los alimentos crudos triturados, conocidos como BARF deben mantenerse refrigerados para su conservación, siendo los pesos de 500 y 800 gramos o cercanos al kilogramo.

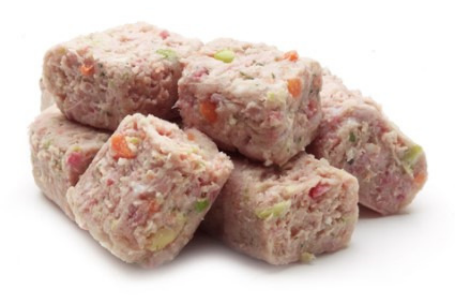

Figura 1. Alimento Barf

Tomado Puro menú, 2018. Recuperado de https://puromenu.es/pages/superior-al-pienso-para-perros-y-gatos-leer-paracreer 
En los puntos de venta (bodegas, mercados, supermercados, tiendas especializadas y veterinarias) de alimento para mascotas, se identifica que el mercado se encuentra dominado por las denominadas croquetas o comida seca (bolas pequeñas, en tonalidades marrones, forma redonda y deshidratadas), las cuales son respaldadas por las continuas investigaciones de las empresas corporativas a nivel internacional que las producen y comercializan; los veterinarios las recomiendan resaltando sus bondades en la composición; el aparato de prensa y publicidad que difunden este tipo de alimento resalta un apropiado balance de nutrientes para la mascota. La presencia de las croquetas se puede catalogar como preponderante en el mercado, más aún, si existen diversos niveles de calidad y precio (más de 30 marcas).

\subsubsection{Segmentación de la industria.}

Basados en la teoría de las cinco fuerzas de Michael Porter, procederemos a indicar quienes son los integrantes de la industria segmentada para el presente proyecto, haciendo alusión que el presente trabajo se centra fundamentalmente en los canes.

- Los competidores directos, representados por:

- Empresas dedicadas a la importación y comercialización de alimento para perros ubicadas en San Borja y los distritos aledaños de: Miraflores, San Isidro y Santiago de Surco (Importadora MARS).

- $\quad$ Empresas que producen comida seca (RINTI S.A.).

- $\quad$ Empresas que producen comida cruda triturada BARF (RAMBALA) de origen nacional.

- Veterinarias que brindan entre sus múltiples servicios, alimentos por prescripción médica (PRANA). 
- Los clientes, representados por los hogares de nivel socioeconómico ABC del distrito de San Borja y distritos aledaños que tienen por lo menos un can en el hogar.

- Los proveedores, que brindan los insumos (carnes, vegetales y suplementos alimenticios) para la producción de los alimentos de Animal Lovers.

- Los productos sustitutos, representados por la comida preparada en casa.

- Los potenciales competidores, empresas, tiendas y veterinarias que de forma complementaria comercializan alimento para canes, no siendo esta su fuente principal de ingresos.

A continuación, ubicará una tabla en donde se resume la información sobre la industria segmentada. 
Tabla 4.-Segmentación de la industria: clientes, competidores directos, proveedores, productos sustitutos y potenciales competidores

\begin{tabular}{|c|c|}
\hline CONCEPTO & VARIABLES DE SEGMENTACIÓN \\
\hline \multirow[t]{4}{*}{ Clientes } & $\begin{array}{l}\text { Segmentación Demográfica } \\
\text { - Hogares de NSE ABC. } \\
\text { - } \quad \text { Hogares con canes. }\end{array}$ \\
\hline & $\begin{array}{l}\text { Segmentación Geográfica } \\
\text { - Hogares con residencia en el distrito de San Borja. }\end{array}$ \\
\hline & $\begin{array}{l}\text { Segmentación Psicográfica } \\
\text { - } \quad \text { Personas con un nivel de educación que les permite considerar el } \\
\text { respeto hacia los animales. } \\
\text { - } \quad \text { Hogares cuyo estilo de vida refleja la tenencia de canes en el } \\
\text { hogar y cierto grado de humanización, considerándolos como } \\
\text { parte de la familia. } \\
\text { - } \quad \text { Contratan diversos servicios para el bienestar de sus mascotas. } \\
\text { - Son personas sociables, respetuosas y empáticas que les gusta } \\
\text { relacionarse con personas que poseen también mascotas. } \\
\text { Laboran en empresas grandes o poseen negocio propio. }\end{array}$ \\
\hline & $\begin{array}{l}\text { Segmentación Conductual } \\
\text { - } \quad \text { Estatus del usuario: usuario actual de comida seca de marcas } \\
\text { conocidas, comida casera o consumidores de ambos tipos de } \\
\text { producto. } \\
\text { - Beneficio buscado: nutrición adecuada y salud para su mascota } \\
\text { canina. } \\
\text { - Frecuencia de uso: consumidor medio e intensivo. }\end{array}$ \\
\hline $\begin{array}{l}\text { Competidores } \\
\text { Directos }\end{array}$ & $\begin{array}{l}\text { Empresas que se dedican a la comercializan de comida seca en el } \\
\text { distrito de San Borja y distritos aledaños: Miraflores, San Isidro y } \\
\text { Santiago de Surco. }\end{array}$ \\
\hline Proveedores & $\begin{array}{l}\text { Clasificados por el tipo de insumo que proveen: } \\
\text { - Centros de beneficio y/o comercio de carne, pollo y pescado. } \\
\text { - Centros de abasto de vegetales. } \\
\text { - Consorcios veterinarios de vitaminas y suplementos alimenticios. }\end{array}$ \\
\hline $\begin{array}{l}\text { Productos } \\
\text { sustitutos }\end{array}$ & Residuos de la comida hecha en casa. \\
\hline $\begin{array}{l}\text { Potenciales } \\
\text { competidores }\end{array}$ & $\begin{array}{l}\text { Pets Shops y Veterinarias, que venden comida seca, pero de manera } \\
\text { complementaria a los servicios que ofrecen. }\end{array}$ \\
\hline
\end{tabular}

Nota: Elaboración propia.

\section{Competidores Directos.}

El poder de negociación de los competidores es de NIVEL ALTO, debido a la gran diversidad de calidades y marcas (tiendas especializadas). 
Tabla 5.-Poder de negociación de los competidores directos

\begin{tabular}{|c|c|c|}
\hline FACTOR & \multicolumn{2}{|c|}{ SUSTENTO } \\
\hline & \multicolumn{2}{|c|}{ ALTO } \\
\hline $\begin{array}{l}\text { Poder de } \\
\text { Negociación }\end{array}$ & $\begin{array}{l}\text { Marcas de comida seca nacionales e } \\
\text { importadas. }\end{array}$ & $\begin{array}{l}\text { Marcas nacionales de alimento crudo } \\
\text { triturado (BARF) y Veterinarias que } \\
\text { ofrecen alimento por prescripción } \\
\text { veterinaria. }\end{array}$ \\
\hline $\begin{array}{l}\text { Drivers para } \\
\text { determinar el poder } \\
\text { de negociación }\end{array}$ & $\begin{array}{l}\text { - El alimento seco es muy conocido, } \\
\text { domina el mercado }(95 \%) \text {. } \\
\text { - Cuenta con el respaldo de la opinión } \\
\text { profesional de los veterinarios. } \\
\text { - Son alimentos que tienen una } \\
\text { percepción positiva: a mayor precio } \\
\text { mayor calidad. } \\
\text { - Se vende al por mayor y menor. } \\
\text { - Variedad de marcas, calidades, pesos } \\
\text { y precios }\end{array}$ & $\begin{array}{l}\text { - Atiende nichos de clientes cuyos } \\
\text { canes rechazan la comida seca, por } \\
\text { ello exploran otras formas de } \\
\text { alimentación. } \\
\text { - Se vende en el canal moderno } \\
\text { (veterinarias). }\end{array}$ \\
\hline Estrategia comercial & $\begin{array}{l}\text { - Variedad de comida seca que se } \\
\text { vende en tiendas especializadas en } \\
\text { alimentos. }\end{array}$ & $\begin{array}{l}\text { - Alimento natural para penetrar el } \\
\text { mercado }\end{array}$ \\
\hline Cantidad de marcas & $\begin{array}{l}\text { - Gran variedad de marcas. Algunos } \\
\text { ejemplos: Taste de of de wild, } \\
\text { Nutram, Pro-Plan, Pro Pac, Hill's, } \\
\text { Eukanuba, Brit, Mio Cane, Science } \\
\text { Diet, entre otros. }\end{array}$ & $\begin{array}{l}\text { - Muy pocas marcas } \\
\text { - Ejemplo: Rambala y Veterinaria } \\
\text { Aurora. }\end{array}$ \\
\hline $\begin{array}{l}\text { Sobre el punto de } \\
\text { venta }\end{array}$ & $\begin{array}{l}\text { Tiendas especializadas en alimentos } \\
\text { para canes }\end{array}$ & $\begin{array}{l}\text { Veterinarias y supermercados muy } \\
\text { orientados al segmento ABC. }\end{array}$ \\
\hline \multirow{3}{*}{$\begin{array}{l}\text { Atención al Cliente } \\
\text { en el punto de venta } \\
\quad \text { (comercial) }\end{array}$} & \multicolumn{2}{|c|}{$\begin{array}{l}\text { - Transaccional. } \\
\text { - Personal con información referencial del producto en el punto de venta, } \\
\text { carente de conocimiento especializado. }\end{array}$} \\
\hline & $\begin{array}{l}\text { - Apoyo de impulsadores de marca en } \\
\text { tiendas especializadas. }\end{array}$ & $\begin{array}{l}\text { - El alimento crudo triturado, no } \\
\text { cuenta con impulsadores. }\end{array}$ \\
\hline & \multicolumn{2}{|c|}{ Pedido: en tienda, por teléfono o a través de internet } \\
\hline Producto & $\begin{array}{l}\text { - Empaque: bolsa } \\
\text { - Estado: pieza deshidratada } \\
\text { - Tipo: Croqueta } \\
\text { - Consistencia: dura } \\
\text { - Cadena de frio: no } \\
\text { - Peso: } 1,2,3,5,13 \text { o } 15 \mathrm{kgs} . \\
\text { - Duración: un año en promedio }\end{array}$ & $\begin{array}{l}\text { - Empaque: bolsa } \\
\text { - Estado: congelado } \\
\text { - Tipo: filete } \\
\text { - Consistencia: dura } \\
\text { - Cadena de frio: si } \\
\text { - Peso: } 800 \text { gramos } \\
\text { - Duración: entre dos (2) y seis (6) } \\
\text { meses }\end{array}$ \\
\hline Precio & $\begin{array}{l}\text { - Entre S/ } 15 \text { y S/ } 45 \text { por kilogramo. } \\
\text { Dependiendo de la relación precio- } \\
\text { calidad, sustentada en la marca. }\end{array}$ & $\begin{array}{l}\text { - A partir de S/ } 10 \text { por kilogramo } \\
\text { - El precio depende del tipo de carne } \\
\text { (pollo, pavo, cordero, entre otros). }\end{array}$ \\
\hline Distribución & \multicolumn{2}{|c|}{ Venta y entrega en tienda o reparto a domicilio } \\
\hline Promoción & $\begin{array}{l}\text { Pauta publicitaria: } \\
\text { - Televisiva, Radial } \\
\text { - Digital }\end{array}$ & $\begin{array}{l}\text { - Volanteo } \\
\text { - Facebook } \\
\text { - Letrero luminoso en punto de venta }\end{array}$ \\
\hline Formato de tienda & \multicolumn{2}{|c|}{ Física y en algunos casos virtual } \\
\hline Ubicación & \multicolumn{2}{|c|}{$\begin{array}{l}\text { - } \quad \text { En el distrito de residencia del público objetivo y aledaños } \\
\text { - } \quad \text { Accesible debido a ubicación céntrica (avenidas) }\end{array}$} \\
\hline Horario & \multicolumn{2}{|c|}{ De acuerdo con la política de cada empresa (algunos atienden las 24 horas) } \\
\hline Forma de pago & \multicolumn{2}{|c|}{ Efectivo, Débito o Crédito } \\
\hline
\end{tabular}

${ }^{a}$ Los factores indicados fueron obtenidos en la investigación en los puntos de venta 
Los establecimientos cuyo producto principal radica en bañar a los canes, vender artículos para mascotas $\mathrm{u}$ ofrecer servicios veterinarios, brindan algunas marcas de calidad, pero con la intención de complementar su oferta comercial, no obstante, vender comida para canes no es su principal fuente de ingreso, por ello no representan una competencia directa pues carecen de la variedad y el volumen de venta necesario. Sin embargo, son posibles competidores, pues conocen las necesidades del cliente, su comportamiento de compra, así como el flujo comercial y la demanda.

\section{Clientes.}

El poder de negociación de los clientes es de NIVEL MEDIO, debido a que no influyen en el precio pues estos se establecen en base al mercado y en correcta proporción a su calidad, aunque los clientes tienen total libertad de optar por otra marca que le brinde el producto adecuado para sus necesidades.

Para el año 2017, los clientes correspondían a todos aquellos hogares del distrito de San Borja y distritos aledaños que tiene un can. (Arce, 2017). Según un estudio realizado por Ipsos Perú un 55\% de hogares (1.37 millones) de Lima Metropolitana cuenta con una mascota en casa, cifra similar a la de CPI. (Perú 21, 2017). De ellos, un $74 \%$ corresponde al can y un $39 \%$ al gato. Un $76 \%$ compra comida especializada y un $29 \%$ lo hace en bodega. Asimismo, el $70 \%$ de los encuestados lleva a sus mascotas al veterinario, siendo el $35 \%$ los que lo hacen mensualmente.

El estudio más reciente es el realizado por CPI en el 2018, el cual indica que un $60 \%$ de los hogares urbanos a nivel nacional posee una mascota, cantidad que es muy similar en todos los niveles socioeconómicos. En el caso de Lima, el 56.5\% de los hogares de Lima Metropolitana tienen mascotas. 
Según Arrese, Gerente de Totally Pets, se aprecia un mayor sentido de responsabilidad en las personas con respecto a los animales, gastando los peruanos un promedio S/ 200 al mes para su cuidado. (Publimetro, 2017)

Las cifras indicadas anteriormente y la información recogida en el ejercicio de investigación inducen a pensar que la industria del alimento para canes ha sido muy bien pensada pues el alimento seco es muy bien considerado por todos los agentes que intervienen desde su producción, importación, distribución, venta y poder de marca.

A continuación, se presenta un cuadro resumen que explica los elementos relevantes con respecto a los clientes.

Tabla 6.- Poder de negociación de los clientes

\begin{tabular}{|c|c|}
\hline FACTOR & SUSTENTO \\
\hline Poder de Negociación & MEDIO \\
\hline $\begin{array}{l}\text { Drivers para determinar el } \\
\text { poder de negociación }\end{array}$ & $\begin{array}{l}\text { - Desconocimiento de la composición del producto } \\
\text { - Consideración de la opinión del veterinario como un referente } \\
\text { - Decisión influenciada por la publicidad en medios } \\
\text { - Relacionan precio y calidad en forma directa }\end{array}$ \\
\hline \multirow{3}{*}{ Tenencia de mascotas } & - Hogares de Lima Metropolitana con mascotas $(60 \%)$ \\
\hline & - Hogares de Lima Metropolitana que tienen canes (57\%) \\
\hline & - Hogares en San Borja para el 2018: 38,500 según CPI. \\
\hline $\begin{array}{l}\text { Tipo de alimento que } \\
\text { compran }\end{array}$ & $\begin{array}{l}\text { - Casera y balanceada: } 54 \% \text { en Lima } \\
\text { - Solo casera: } 32 \% \text { en Lima } \\
\text { - Solo balanceada: } 37 \% \text { en Lima ( } 49 \% \text { en los NSE AB) }\end{array}$ \\
\hline Lugar de compra & $\begin{array}{l}\text { - Físico: especializadas en alimentos, así como veterinarias de San } \\
\text { Borja y distritos aledaños } \\
\text { - Virtual: redes sociales }\end{array}$ \\
\hline
\end{tabular}

Nota: Elaboración propia

${ }^{\text {a }}$ Los factores han sido obtenidos en base a la investigación y las opiniones recogidas en las entrevistas a profundidad realizadas a los dueños de canes en San Borja y aledaños.

\section{Proveedores.}

El poder de negociación de los proveedores es de NIVEL BAJO, debido a que los insumos son en su mayoría sencillos de conseguir pues el producto se compone 
de insumos naturales con escaso o mínimo procesamiento de tipo industrial en su elaboración. Solo para el caso de ciertos componentes y complementos (vitaminas, por ejemplo) se depende de la disponibilidad en el mercado.

Tabla 7.- Poder de negociación de los proveedores

\begin{tabular}{cl}
\hline FACTOR & \multicolumn{1}{c}{ SUSTENTO } \\
\hline Poder de Negociación & \multicolumn{1}{c}{ BAJO } \\
\hline $\begin{array}{c}\text { Drivers para determinar el poder de } \\
\text { negociación }\end{array}$ & $\begin{array}{l}\text { - Insumo principal del producto: carne } \\
\text { - Se cuenta con disponibilidad de proveedores de } \\
\text { carne, vegetales y vitaminas }\end{array}$ \\
\hline Anticipación de pedido & - Anticipación de 24 horas de preferencia \\
\hline Stock & - De acuerdo con disponibilidad del insumo \\
\hline Forma de pedido & - Por teléfono o por correo \\
\hline Volumen de pedido & - De acuerdo con las políticas del proveedor \\
& - En base a disponibilidad del insumo \\
\hline Insumo & En consideración con el grado de perecibilidad \\
\hline - Carnes (res, pescado, pollo, entre otros) \\
\hline Tiempo de reparto del proveedor al \\
centro de producción & - Verduras \\
\hline Forma de pago & - Día siguiente y según disponibilidad de movilidad \\
\hline
\end{tabular}

Nota: Elaboración propia

${ }^{a}$ Los factores corresponden a la estrategia comercial de los proveedores

\section{Potenciales Competidores.}

En base a la Entrevista a Profundidad (2018) realizada al personal que labora en tiendas especializadas en comercializar alimentos y veterinarias que ofrecen productos y servicios variados, se afirma que el poder de negociación de los potenciales competidores es de NIVEL MEDIO.

Los potenciales competidores están representados por aquellos establecimientos que ofrecen servicios de atención médica, baños, alimento para mascotas, algunas medicinas sencillas, accesorios y alimentos de forma complementaria.

Estos establecimientos, al ofrecer variados servicios y generar alto tráfico de clientes, conocen el mercado de las familias con canes, aprendiendo acerca del perfil, 
comportamiento de consumo, procesos de gestión, estrategias de precio, ticket promedio, entre otros factores. Esto les brinda el requisito necesario para convertirse en competidores posteriormente, claro está, siempre y cuando deseen que el alimento para canes cumpla un rol relevante y no simplemente sea una pequeña categoría de complemento en su oferta comercial.

Tabla 8.- Poder de negociación de los potenciales competidores

\begin{tabular}{|c|c|}
\hline FACTOR & SUSTENTO \\
\hline Poder de Negociación & MEDIO \\
\hline $\begin{array}{c}\text { Drivers para determinar el poder de } \\
\text { negociación }\end{array}$ & $\begin{array}{l}\text { - La venta de alimentos complementa su oferta } \\
\text { comercial } \\
\text { - Generan alto tráfico de clientes en sus locales } \\
\text { - Conocen al consumidor y su comportamiento de } \\
\text { compra } \\
\text { - Cumple con los requisitos para convertirse en una } \\
\text { tienda especializada en alimentos }\end{array}$ \\
\hline Conocimiento del mercado & $\begin{array}{l}\text { Conocen: } \\
\text { - El tamaño del mercado } \\
\text { - El segmento y el perfil del consumidor } \\
\text { - Días y horarios de mayor demanda } \\
\text { - El poder adquisitivo de sus clientes } \\
\text { - La forma de fidelizar al cliente } \\
\end{array}$ \\
\hline Gestión comercial & $\begin{array}{l}\text { - Experiencia en ofrecer un servicio (intangible) y un } \\
\text { producto (tangible) } \\
\text { - Manejan categorías de producto } \\
\text { - Aplican estrategia de precios } \\
\text { - Emplean estrategias de atención al cliente }\end{array}$ \\
\hline Gestión logística & $\begin{array}{l}\text { - Gestión eficiente de proveedores } \\
\text { - Manejo de inventarios y stocks } \\
\text { - Fijación de precios y costos }\end{array}$ \\
\hline Manejo de Proveedores & $\begin{array}{l}\text { - Cartera de proveedores } \\
\text { - Negociación de la forma de pago } \\
\text { - Manejo de roturas de stock }\end{array}$ \\
\hline
\end{tabular}

Nota: Elaboración propia.

${ }^{a}$ Los factores corresponden a la estrategia empleada por potenciales competidores. Obtenido en base a las opiniones recogidas en las entrevistas a profundidad realizadas a dichos potenciales competidores

\section{Productos sustitutos.}

Las conclusiones se han obtenido en base a las encuestas realizadas $(2,018)$ a las personas que tienen canes y que a su vez no consumen comida especializada. Se identifica este segmento en estado decreciente, debido a esfuerzos comerciales de la 
empresa RINTI SA (empresa nacional) que está comercializando productos muy económicos, como es el caso de Bandido, que se orienta de manera específica a las personas que desean alimentar a su mascota, pero sin invertir mucho. El precio de venta de este producto es de S/ 7 por kilo.

Se afirma que el poder de negociación es de NIVEL BAJO, debido a que los productos sustitutos son aquellos que, no siendo competencia significativa, satisfacen las necesidades de alimentación de los canes. Este segmento, debe su disminución a factores del estilo de vida de los dueños de los canes. Hábitos como trabajar, estudiar, carga familiar, entre otros factores, consumen el tiempo de las personas y a la vez elimina la oportunidad de atender a sus mascotas, por lo que una de las ventajas principales de la comida seca, radica en usarla sin mayor preparación.

Alimentar con comida casera a los canes puede ser peligroso pues ellos no soportan en su totalidad los alimentos que consume el ser humano -según los veterinarios- $y$, por otro lado, una alimentación carente de un balance nutricional puede perjudicar su salud.

Tabla 9.- Poder de negociación de productos sustitutos

\begin{tabular}{|c|c|}
\hline FACTOR & SUSTENTO \\
\hline Poder de Negociación & Bajo \\
\hline $\begin{array}{c}\text { Drivers para determinar el poder } \\
\text { de negociación }\end{array}$ & $\begin{array}{l}\text { - La comida para la mascota se elabora en base a lo que } \\
\text { consumen en los hogares, por consiguiente, no demanda mayor } \\
\text { esfuerzo. } \\
\text { - Las personas se alimentan por lo general cerca al centro de } \\
\text { labores o estudio. } \\
\text { - Las personas no tienen tiempo para atender a sus mascotas. }\end{array}$ \\
\hline Economía & $\begin{array}{l}\text { - La comida de casa se convierte en el alimento de los canes por } \\
\text { la facilidad y la economía del tiempo. }\end{array}$ \\
\hline Cambio de conciencia & $\begin{array}{l}\text { - La aceptación de la comida preparada se incrementa gracias a } \\
\text { los medios de comunicación masiva y a la recomendación de } \\
\text { los veterinarios. }\end{array}$ \\
\hline
\end{tabular}

Nota: Elaboración propia

${ }^{a}$ Los factores corresponden a la estrategia empleada por los usuarios de productos sustitutos. Obtenido en base a las opiniones recogidas en las entrevistas a profundidad realizadas a dueños de canes 


\section{Poder de negociación.}

Luego de analizar cada uno de los elementos que conforman el sector industrial de alimentos para canes, se procederá a resumir el poder de negociación de cada uno de ellos.

Tabla 10.- Cuadro Resumen del Poder de negociación de cada una de las cinco fuerzas

\begin{tabular}{|c|c|c|c|}
\hline \multirow[b]{2}{*}{ INTEGRANTES } & \multicolumn{3}{|c|}{$\begin{array}{c}\text { PODER DE } \\
\text { NEGOCIACIÓN }\end{array}$} \\
\hline & $\stackrel{\varrho}{\sum^{\natural}}$ & $\frac{\varrho}{2}$ & $\stackrel{0}{\gtrless}$ \\
\hline \multicolumn{4}{|l|}{$\begin{array}{l}\text { Empresas que comercializan: } \\
\text { - Alimentos en formato de comida seca. } \\
\text { - Alimento crudo triturado (BARF por sus siglas en inglés). } \\
\text { - Alimentos por prescripción. }\end{array}$} \\
\hline \multicolumn{4}{|l|}{$\begin{array}{l}\text { Clientes } \\
\text { - Hogares de nivel socioeconómico ABC. } \\
\text { - Residen en San Borja y en distritos aledaños. }\end{array}$} \\
\hline \multicolumn{4}{|l|}{$\begin{array}{l}\text { Potenciales Competidores } \\
\text { - Tiendas especializadas que ofrecen servicios y accesorios para } \\
\text { canes y de forma complementaria ofrecen alimento seco }\end{array}$} \\
\hline $\begin{array}{l}\text { Proveedores } \\
\text { - } \\
\text { - } \\
\text { - }\end{array}$ & & & \\
\hline $\begin{array}{l}\text { Productos Sustitutos } \\
\text { - Comida hecha en casa. Su uso es cada vez menor, debido a que } \\
\text { ocupaciones de estudio y trabajo ocasionan que los miembros de } \\
\text { la familia pasen largas horas fuera de casa, perdiendo la } \\
\text { posibilidad de alimentar a sus mascotas y ocasionando la compra } \\
\text { de comida seca por su duración, practicidad y facilidad para } \\
\text { alimentar a su mascota canina. }\end{array}$ & & & \\
\hline
\end{tabular}

\subsubsection{Empresas que la conforman (ubicación, volumen de ventas, empleados,}

etc.)

Es importante destacar que las marcas representan a los competidores directos, es decir, las marcas nacionales e importadas de comida seca y en menor cuantía de la comida cruda triturada BARF y los alimentos por prescripción veterinaria. No obstante, se toma como referencia a las empresas comercializadoras 
(tiendas), porque ellas representan -a través del volumen de venta- el nivel de aceptación del público por dichas marcas.

Las empresas especializadas en la comercialización de alimentos se segmentan en base a los siguientes criterios de clasificación:

a) Se ubican en el distrito de San Borja, así como en distritos aledaños.

b) Son empresas para quienes la venta de alimento para canes es su principal fuente de ingresos.

c) El tipo de alimento y/o formato que ofertan mayoritariamente es la croqueta.

d) Ofrecen alimentos envasados (en bolsas) de $1 \mathrm{~kg} ., 3 \mathrm{~kg} ., 15 \mathrm{~kg}$., etc. entre otros.

Tabla 11.- Ubicación de las empresas competidoras en San Borja

\begin{tabular}{|c|c|c|c|}
\hline Nombre & Tipo & Dirección & Teléfono \\
\hline Central Pets E.I.R.L. & Veterinario & Av. San Borja Norte. 499 & (01) 2232180 \\
\hline Cat \& Dog & Veterinario & Jr. Daniel Alcides Carrión 102 & (01) 5935298 \\
\hline Clinica Groomers & Hospital veterinario & Av. José Gálvez Barrenechea 819 & (01) 7130707 \\
\hline De Perros, Gatos \& Compañía & Veterinario & Av. De Las Artes Sur 308 & (01) 2252760 \\
\hline DE TODO PET & Tienda de productos & Av. Angamos Este 2517 & (01) 4969826 \\
\hline$\underline{\text { Dog's Garden }}$ & Tienda de productos & Av. San Luis 2632 & 989261042 \\
\hline La Patota Pet Shop & Tienda de productos & Av. Angamos Este 2401 & 941535504 \\
\hline$\underline{\text { Master Kennel }}$ & Tienda de animales & Av. San Borja Sur 643 & (01) 2254626 \\
\hline Pajarería Gianfranco & Tienda de animales & Av. Aviación 3364 & \\
\hline$\underline{\text { Patas, Patitas, Patotas }}$ & $\underline{\text { Veterinario }}$ & $\underline{\text { Miguel Iglesias } 100}$ & (01) 4751124 \\
\hline$\underline{\text { Perros \& Compañía }}$ & Veterinario & Av. Aviación 2566 & (01) 2245540 \\
\hline$\underline{\text { Pet Center }}$ & Cuidados veterinarios & Av. San Luis 2570 & (01) 7177777 \\
\hline Pet's Place & Veterinario & Av. Gálvez Barrenechea 673 & (01) 4750418 \\
\hline Pulguitas Veterinaria & Veterinario & Calle Luis Montero 148 & (01) 5935310 \\
\hline$\underline{\text { Reino Animal }}$ & Veterinario & 3036, Av. Aviación & (01) 7110355 \\
\hline Veterinaria Angelitos E.I.R.L & Veterinario & Av. San Luis 2245 & (01) 6472880 \\
\hline$\underline{\text { Veterinaria Fido's Vet }}$ & Veterinario & Av. San Luis 2080 & (01) 4752290 \\
\hline Veterinaria Gogin & Veterinario & Av. Gálvez Barrenechea 1312 & (01) 3965196 \\
\hline Veterinaria javier prado & Veterinario & Av. San Luis 2670 & 3961320 \\
\hline Veterinaria Las Artes & Veterinario & Av. De Las Artes Sur 363 & (01) 2257832 \\
\hline Veterinaria Salvapatas & Hospital veterinario & 2455, Av. Angamos Este & (01) 4837569 \\
\hline Veterinaria San Luis & Veterinario & Av. San Luis 2205 & (01) 4759656 \\
\hline Villa Mascota Veterinaria & Veterinario & Calle, Calle Jorge Muelle 121 & (01) 2268432 \\
\hline VON DER MEMBLIN & Veterinario & Jr. Andreas Vesalio 481 & (01) 4761880 \\
\hline Zoomanía & Tienda de productos & Av. Aviación & (01) 2258778 \\
\hline
\end{tabular}

${ }^{a}$ Las empresas consideradas son aquellas cuya fuente de ingreso principal, no es necesariamente la venta de alimentos; no obstante, es una categoría que se comercializa 
Tabla 12.- Empresas que comercializan alimento para canes en San Borja

\begin{tabular}{|c|c|c|}
\hline Nombre & Tipo & $\mathbf{N}^{\circ}$ de Empleados \\
\hline Central Pets E.I.R.L. & Veterinario & 2 \\
\hline Cat \& Dog & Veterinario & $>2$ \\
\hline Clinica Groomers & Hospital veterinario & $>2$ \\
\hline De Perros, Gatos \& Compañía & Veterinario & $>2$ \\
\hline DE TODO PET & Tienda de productos & 2 \\
\hline Dog's Garden & Tienda de productos & 2 \\
\hline La Patota Pet Shop & Tienda de productos & 2 \\
\hline Master Kennel & Tienda de animales & $>2$ \\
\hline Pajarería Gianfranco & Tienda de animales & 2 \\
\hline Patas, Patitas, Patotas & Veterinario & $\geq 2$ \\
\hline$\underline{\text { Perros \& Compañía }}$ & Veterinario & $>2$ \\
\hline Pet Center & Cuidados veterinarios & 2 \\
\hline Pet's Place & Veterinario & 2 \\
\hline$\underline{\text { Pulguitas Veterinaria }}$ & Veterinario & $>2$ \\
\hline$\underline{\text { Reino Animal }}$ & Veterinario & 2 \\
\hline Veterinaria Angelitos E.I.R.L & Veterinario & $>2$ \\
\hline Veterinaria Fido's Vet & Veterinario & $>2$ \\
\hline Veterinaria Gogin & Veterinario & $>2$ \\
\hline Veterinaria javier prado & Veterinario & $>2$ \\
\hline$\underline{\text { Veterinaria Las Artes }}$ & Veterinario & $>2$ \\
\hline Veterinaria Salvapatas & Hospital veterinario & $>2$ \\
\hline Veterinaria San Luis & Veterinario & $>2$ \\
\hline Villa Mascota Veterinaria & Veterinario & $>2$ \\
\hline VON DER MEMBLIN & Veterinario & $>2$ \\
\hline Zoomanía & Tienda de productos & 2 \\
\hline
\end{tabular}

Nota: Elaboración propia.

${ }^{a}$ Hogares en San Borja: 38,500. Tienen canes: 21,753. Consumen comida balanceada 8,135 (37.4\%). Consumen comida balanceada y casera: $53.9 \%$, (solo se ha considerado la 5ta parte: 2345 hogares). Total, de hogares que consumen comida balanceada en San Borja: 10,480 hogares. Número de tiendas que comercializan comida para canes: 24 centros de expendio. Cantidad de hogares en promedio que atiende cada empresa: 437 hogares

${ }^{\mathrm{b}}$ Esta información ha sido obtenida en base a la visita a cada punto comercial del distrito.

\subsection{Tendencias de la Industria (crecimiento, inversiones)}

La Industria de la comercialización de alimento para canes, está experimentando ciertos cambios. Euromonitor (2018), identifica perspectivas de las tendencias:

- El consumo está cambiando de comida casera a comida empacada. 
- Los perros pequeños están comenzando a dominar el mercado con una presencia creciente en comparación con perros medianos o grandes.

- $\quad$ El consumo de la comida húmeda para perros está aumentando.

- $\quad$ Los consumidores deciden en base al precio.

- La comida para perros se está ofreciendo con mayor frecuencia en supermercados e hipermercados.

\subsection{Análisis Estructural del Sector Industrial}

Los factores estructurales que hacen atractivo el segmento toman en consideración a los competidores, los clientes y los proveedores.

En el caso de los competidores existen algunos muy fuertes -nacionales e importadosy dinámicos por la mejora constante de sus productos, por ello el mercado está dominado en un $95 \%$ por comida seca (importadora Mars) pero la comida húmeda empieza a incrementar su demanda, configurando esto una gran oportunidad para otras alternativas de alimentación, dentro de las cuales está Animal Lovers.

Los clientes de poder relativo debido a la oferta de variada de alimentos balanceados no ejercen influencia. Recordemos que de los hogares con canes a nivel nacional (62\%) no consume comida balanceada.

Con respecto a los proveedores, no ejercen influencia pues cada insumo tiene variadas opciones de proveeduría.

\subsection{Análisis de la Competencia}

\section{Qué y cómo ofrece la competencia.}

La competencia directa, ofrece alimentos para canes tomando en consideración la infraestructura, la distribución de los productos, el personal, entre otros detalles. 
Tabla 13.- Aspectos relevantes en la oferta de alimento para canes

\begin{tabular}{|c|c|c|}
\hline Ubicación & & $\begin{array}{l}\text { Distrito: San Borja } \\
\text { Ubicación: avenidas principales de alto tránsito. }\end{array}$ \\
\hline Área de terreno aproximada & $\bullet$ & De 30 a $60 \mathrm{~m} 2$ \\
\hline Distribución del local por áreas & & $\begin{array}{l}\text { Counter } \\
\text { Caja } \\
\text { Piso de venta } \\
\text { Almacén }\end{array}$ \\
\hline Tipo de alimento & $\bullet$ & Croquetas (comida seca), BARF, por prescripción \\
\hline Envasado & $\bullet$ & Bolsa \\
\hline Formato de producto & $\bullet$ & Desde $0.5 \mathrm{~kg}$. hasta $15 \mathrm{~kg}$. \\
\hline Procedencia de productos & & $\begin{array}{l}\text { Nacionales } \\
\text { Importados en su mayoría (>=90\%) }\end{array}$ \\
\hline Marcas & & $\begin{array}{ll}\text { Algunos ejemplos: } & \\
\text { Nutran } & \text { Propack } \\
\text { Eukanuba } & \text { Hill's } \\
\text { Taste of the Wild } & \text { Proplan }\end{array}$ \\
\hline Personal & & $\begin{array}{l}\text { Cajero (a) } \\
\text { Counter } \\
\text { Impulsador (a) (enviado por el proveedor) } \\
\text { Vigilante } \\
\text { Almacenero-ayudante (abastece el piso de venta y lleva } \\
\text { la mercadería al auto de los clientes) }\end{array}$ \\
\hline Forma de pago & & $\begin{array}{l}\text { Efectivo } \\
\text { Tarjeta de débito } \\
\text { Tarjeta de crédito }\end{array}$ \\
\hline Estacionamiento & $\bullet$ & En algunos establecimientos \\
\hline Orientación sobre los productos & & A cargo de los impulsadores \\
\hline $\begin{array}{l}\text { Estrategia comercial y } \\
\text { fidelización }\end{array}$ & & $\begin{array}{l}\text { A compras de mayor volumen, el precio por kilogramo } \\
\text { disminuye } \\
\text { Ejemplo: Para una misma marca, comprar una bola de } 15 \\
\text { Kg. es más barato que comprar una bolsa de } 3 \mathrm{Kg} \text {. } \\
\text { Para clientes habituales se les obsequia, muestras gratis } \\
\text { de nuevos productos }\end{array}$ \\
\hline Horario & & $\begin{array}{l}\text { La estrategia de atención al cliente es variada, siendo el } \\
\text { horario un factor que diferencia a cada empresa }\end{array}$ \\
\hline
\end{tabular}

Elaboración propia.

${ }^{a}$ Las características se repiten en las tiendas especializadas en comercializar alimentos

\subsubsection{Empresas que ofrecen el mismo producto o servicio, indicando las semejanzas y diferencias que tienen con el proyecto de la empresa}

Las empresas competidoras tienen elementos comunes, así como elementos que los diferencian. 
Los elementos comunes hacen referencia a las características de infraestructura, distribución de áreas, productos, precios, tipo de servicio, entre otros aspectos (véase tabla 13).

Los elementos que difieren de una empresa a otra se establecen -en este casoen base a la estrategia de tipo comercial.

Tabla 14.- Estrategia comercial de la competencia

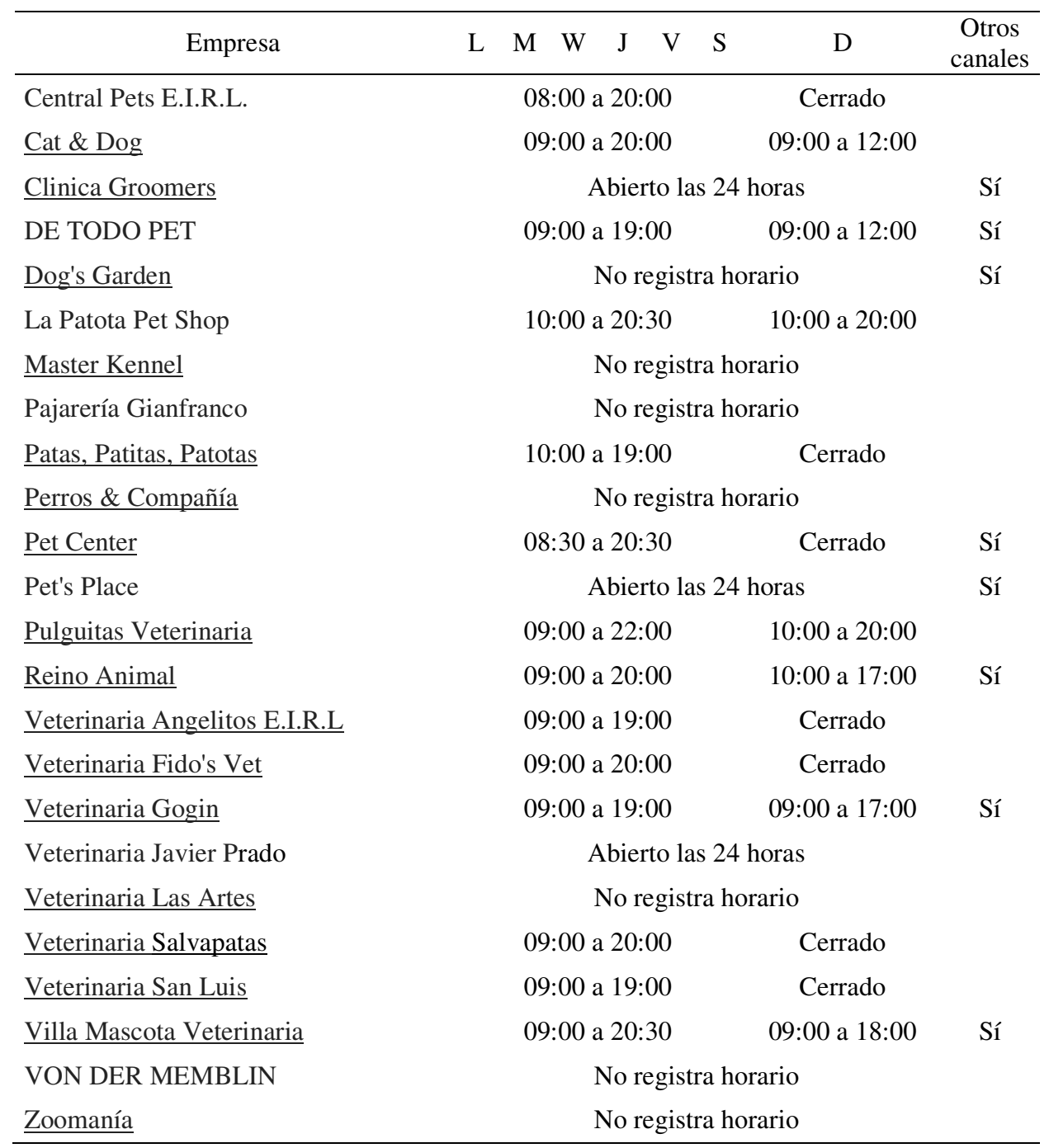

Nota: Elaboración propia.

${ }^{a}$ Cada empresa ostenta su propia estrategia comercial. Esta se hace evidente con el horario de atención establecido y los canales de distribución.

b Tomado de la entrevista a profundidad realizada al personal de algunas de las empresas consignadas en la tabla 


\subsubsection{Participación de mercado de cada uno de ellos}

Cantidad que tiene la empresa en comparación con otras empresas. La cantidad a la que hacemos referencia se relaciona con las ventas, se relaciona con la cantidad de clientes, o con cualquier otra unidad de medida que sea pertinente. Para calcular la participación de mercado actual, se tomará en consideración: la cantidad de clientes de distrito de San Borja (10,480 hogares) y el número de empresas (24), que resulta en promedio a 437 hogares por empresa (4\%).

\subsubsection{Matriz de perfil competitivo}

La matriz toma como base dos marcas representativas de la competencia: Nutran (comida seca) y Rambala (comida cruda triturada).

\section{Tabla 15.- Matriz del perfil competitivo}

\begin{tabular}{l|c|cc|cc|cc}
\hline \multicolumn{1}{c|}{ Factor Crítico } & Ponderació & \multicolumn{2}{c|}{ Animal Lovers } & \multicolumn{2}{c|}{ Nutran } & \multicolumn{2}{c}{ Rambala } \\
& $\mathrm{n}$ & Peso & Puntos & Peso & Puntos & Peso & Puntos \\
\hline Insumos de calidad & 0.1 & 2 & 0.2 & 4 & 0.4 & 2 & 0.2 \\
No preservantes & 0.1 & 4 & 0.4 & 1 & 0.1 & 3 & 0.3 \\
Fórmula balanceada & 0.1 & 2 & 0.2 & 4 & 0.4 & 3 & 0.3 \\
Producción no industrial & 0.1 & 4 & 0.4 & 1 & 0.1 & 2 & 0.2 \\
Alimentos semi cocidos & 0.1 & 4 & 0.4 & 1 & 0.1 & 1 & 0.1 \\
Variedad de sabores & 0.1 & 4 & 0.4 & 2 & 0.2 & 4 & 0.4 \\
Apetencia del can & 0.1 & 4 & 0.4 & 3 & 0.3 & 4 & 0.4 \\
Variados pesos & 0.025 & 1 & 0.025 & 4 & 0.1 & 1 & 0.025 \\
Facilidad de transporte & 0.05 & 2 & 0.1 & 4 & 0.2 & 2 & 0.1 \\
Requiere refrigeración & 0.05 & 1 & 0.05 & 4 & 0.2 & 1 & 0.05 \\
Puntos de venta & 0.05 & 1 & 0.05 & 4 & 0.2 & 2 & 0.1 \\
Reparto a domicilio & 0.025 & 1 & 0.025 & 3 & 0.075 & 1 & 0.025 \\
Marca conocida & 0.1 & 1 & 0.1 & 4 & 0.4 & 2 & 0.2 \\
\hline \multicolumn{1}{c}{ Resultado } & 1 & 2.75 & & 2.775 & \multicolumn{2}{c}{2.4} \\
\hline
\end{tabular}

Nota: Elaboración propia

${ }^{a}$ La estructura del cuadro ha sido elaborada en base a la opinión de profesionales en nutrición canina que día a día se dedican a elaborar fórmulas para el tratamiento de canes.

${ }^{\mathrm{b}}$ El resultado obtenido describe resultados similares entre la comida seca y Animal Lovers, dado que ambas se apoyan en fórmulas balanceadas. La comida cruda triturada no es muy conocida. 


\subsection{Análisis del Contexto Actual y Esperado}

En el contexto actual, el mercado ofrece mayoritariamente, alimentos con el formato de croqueta. Es más, el mercado no solo posee competencia nacional, sino que también cuenta con la presencia de empresas que simplemente importan, siendo este último tipo -de importación- el que se incrementará debido a que el Servicio Nacional de Sanidad Agraria (SENASA) ha eliminado las restricciones para los productos terminados importados, pasando esta función a la Subdirección de Insumos Pecuarios de la Dirección de Insumos Agropecuarios e Inocuidad Agroalimentaria para la regulación de la materia relativa a alimento para animales.

De otro lado, actualmente, ingresar a competir con comida en formato de croqueta es complejo, pues la amplia variedad de la competencia tiene múltiples marcas. No obstante, información actualizada indica que la tasa de penetración del mercado es muy baja (50 mil toneladas al año) en comparación con otros países (500 mil toneladas al año en Argentina).

Es pertinente toma en cuenta que la calidad de servicio es el factor de competitividad que hará rentable la empresa. Factores como identificación, seguimiento y distribución serán los elementos que harán posibles la distinción en el mercado.

\subsubsection{Análisis Político-Gubernamental}

De acuerdo con la coyuntura política que vive el país, es necesario puntualizar información relacionada a:

- $\quad$ La remuneración mínima vital (RMV).

- $\quad$ La unidad impositiva tributaria (UIT).

- $\quad$ La legislación para la micro y pequeña empresa. 


\section{La remuneración mínima vital (RMV).}

La remuneración mínima vital (RMV) se incrementa:

- Desde el 1 de abril de 2018 la Remuneración Mínima Vital (RMV) es modificada de S/ 850 a S/ 930.

- $\quad$ El incremento de la remuneración mínima vital (RMV) para las grandes y medianas empresas entró en vigor desde el 1 de abril de 2018 y desde el 1 de mayo de 2018 para las micro y pequeñas empresas.

- $\quad$ Para el sector formal, la asignación familiar se incrementa a S/ 93 (10\% de la RMV).

- Los que laboran de madrugada verán incrementar su sueldo, que equivale a 1.35 de su RMV. Dicha variante será de S/ 1,255.50

- Las prácticas preprofesionales o subvención por modalidades formativas ascenderán a S/ 930.

- $\quad$ El aporte mínimo a EsSalud es de S/ 83.70.

\section{La Unidad Impositiva Tributaria - UIT}

De acuerdo con el código tributario, la Unidad Impositiva Tributaria (UIT), es un valor referencial determinado por el MEF para el pago de multas, exoneraciones de impuesto y tributos, entre otros usos. El valor para el 2019 es de S/ 4,200, siendo sus efectos inmediatos los siguientes:

- Menor recaudación de impuestos.

- $\quad$ Aumento de las multas o sanciones aplicadas por entidades como: Sunafil, Indecopi, Osiptel, Osinergmin, entre otras.

- $\quad$ Menor pago por impuesto predial y alcabala. 


\section{La legislación para la micro y pequeña empresa}

Para el 2013 se realizaron cambios en la legislación de la micro y pequeña empresa, con el objetivo de solucionar los problemas que enfrentaba las MYPE. (SUNAT 2017).

La ley considera los siguientes elementos:

- La tipificación de la empresa se realizará de acuerdo con el volumen de ventas. Una microempresa podrá contratar las personas que considere conveniente (antes estaba limitada a diez). Desde ahora una microempresa será la que tiene ventas anuales hasta por un máximo de 150 UIT (S/ 555 mil) y una pequeña empresa la que vende desde 150 UIT (S/ 555 mil) hasta 1,700 UIT (S/ 6’290,000).

- En los tres primeros años de inicio de operaciones, las nuevas empresas no serán sancionadas al primer error laboral o tributario, tendrán posibilidad de enmienda sin el pago de multas. Esta norma no aplicará cuando en un lapso de 12 meses la empresa incurra en una infracción similar en dos o más oportunidades.

- Al superar la microempresa el límite de ventas que norma la ley tendrá un año de plazo para pasar como pequeña empresa al régimen laboral especial correspondiente. De la misma forma, si una pequeña empresa vende más de lo establecido tendrá hasta tres años para pasar al régimen general.

- $\quad$ Las empresas micros y pequeñas podrán deducir gastos de capacitación del personal por el $1 \%$ de su planilla anual.

- $\quad$ El Remype pasará a la SUNAT. 
- Las empresas de tipo EIRL, es decir, empresas individuales de responsabilidad limitada podrán estar en el Nuevo RUS (Nuevo Régimen Único Simplificado).

- Las empresas estatales tendrán -según ley- un máximo de 15 días para realizar el pago a sus proveedores de micro y pequeña empresa.

El cuadro detalla los beneficios a nivel laboral para la microempresa.

\section{Tabla 16.- Microempresa y Pequeña empresa}

\begin{tabular}{|c|c|}
\hline Microempresa & Pequeña empresa \\
\hline $\begin{array}{ll}\text { - } & \text { Remuneración Mínima Vital para el } \\
\text { - } & \text { Jorabajador (una RMV) } \\
\text { - } & \text { Descanso semanal y en días feriados } \\
\text { - } & \text { Remuneración por trabajos en } \\
\text { - } & \text { Dobretiempo } \\
\text { - } & \text { Coberanso vacacional de } \mathbf{1 5} \text { días } \\
\text { - } & \text { Indemés del SIS (Seguro Integral de Salud) } \\
& \text { remuneración por despido de } \mathbf{1 0} \text { días de } \\
& \text { un tope de } \mathbf{9 0} \text { días de remuneración) }\end{array}$ & 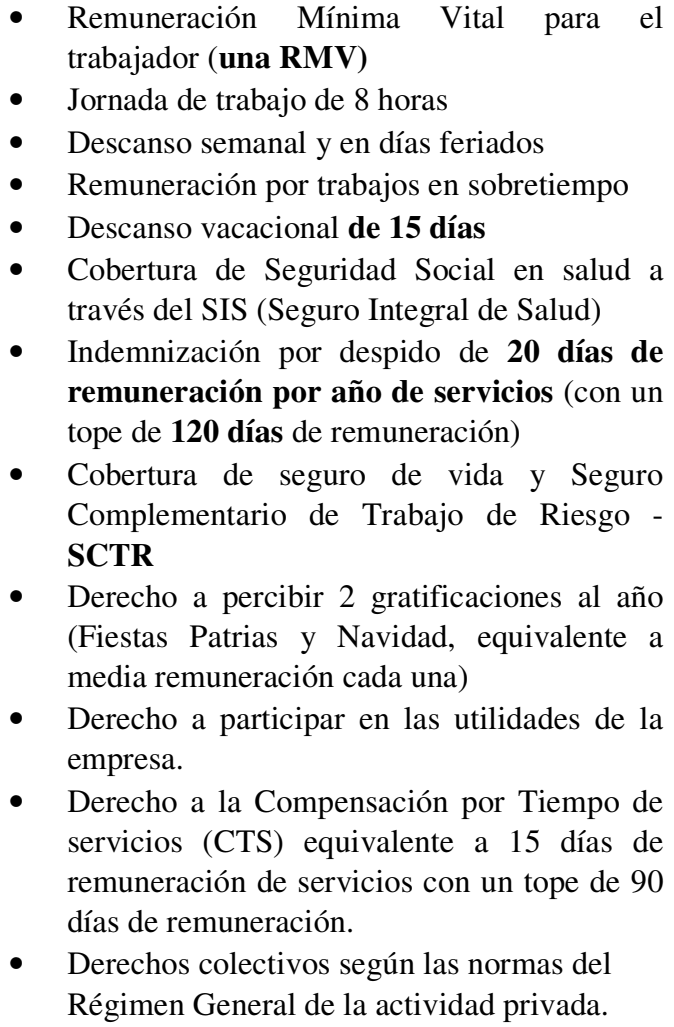 \\
\hline
\end{tabular}

Nota: Elaboración propia. 


\subsubsection{Análisis Económico}

Desde la perspectiva económica son consideradas las variables de influencia, así como las variables que pueden ser utilizadas como referencia para efectos comparativos. Dichas variables son:

- $\quad$ Índice Riesgo País

- $\quad$ Producto Bruto Interno (PBI)

- Inflación

- $\quad$ Población Económicamente Activa (PEA)

- Balanza Comercial

- $\quad$ Tasas de Interés

- $\quad$ Tipo de Cambio

\section{Índice Riesgo País}

Es un indicador que establece el riesgo de un país con respecto a las inversiones extranjeras. Por consiguiente, es un índice que simplifica su situación económica. A mayor riesgo, menor es la capacidad de pago de un país para cumplir con su deuda externa, incrementándose la tasa de interés para préstamos como consecuencia del riesgo que representa financiarlo. Dicho de otra forma, el EMBI + Perú mide la diferencia del rendimiento promedio de los títulos soberanos peruanos frente al rendimiento del bono del tesoro norteamericano. Sobre esta base se define que todo inversor selecciona un país con la intención de maximizar sus ganancias, por ello, se debe prestar atención especial a este índice para proyectar el impacto que tiene sobre ellas. En términos estadísticos, las ganancias se miden sobre el rendimiento esperado y el riesgo sobre la base de la desviación estándar del rendimiento esperado. 
El riesgo país del Perú al 1 de marzo es de 1.14 puntos porcentuales según el EMBI + Perú calculado por el banco de inversión JP Morgan.

\section{Producto bruto interno (PBI)}

El Producto bruto interno es la suma de todos los bienes y servicios producidos en el país durante un año, valorizados a precios de mercado. Tiene varias formas de cálculo: en base a la producción, al gasto, entre otros.

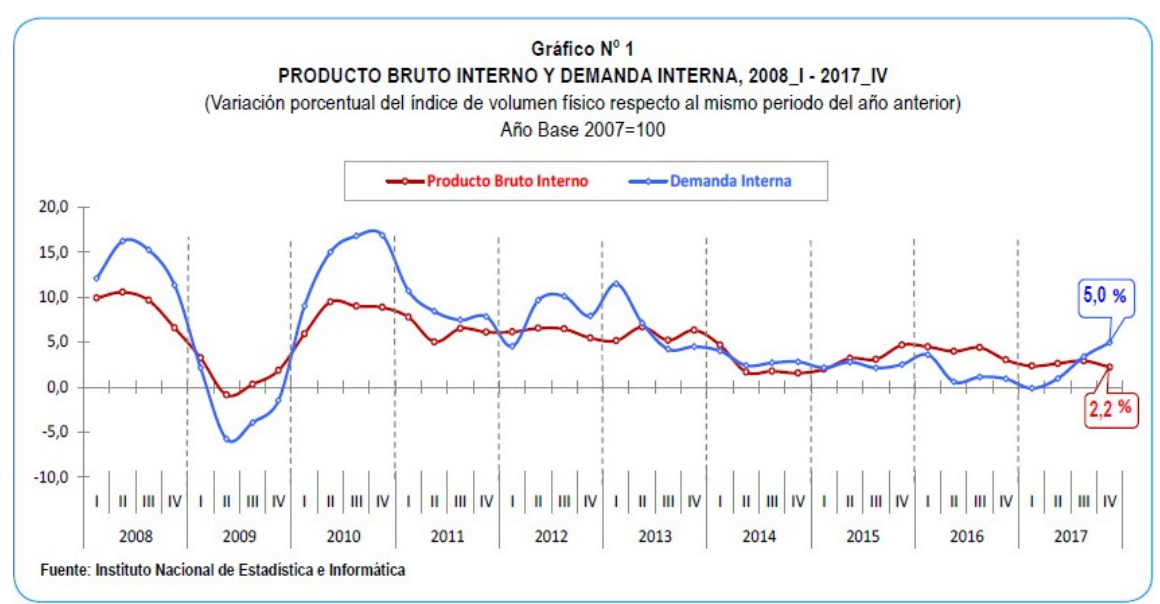

Figura 2. Producto bruto interno y demanda interna 2008_I - 2017_IV

Tomado de "Informe técnico N ${ }^{\circ}$ " por el Instituto Nacional de Estadística e Informática (INEI), 2018. Recuperado de https://www.inei.gob.pe/media/MenuRecursivo/boletines/04-informe-tecnicon04_producto-bruto-interno-trimestral-2017iii.PDF

El crecimiento del PBI ha sido impulsado por la recuperación de la demanda interna. Se espera que esta evolución se mantenga en el horizonte de proyección con tasas de crecimiento más moderadas.

Perú continuará liderando el crecimiento de las economías de la región. 


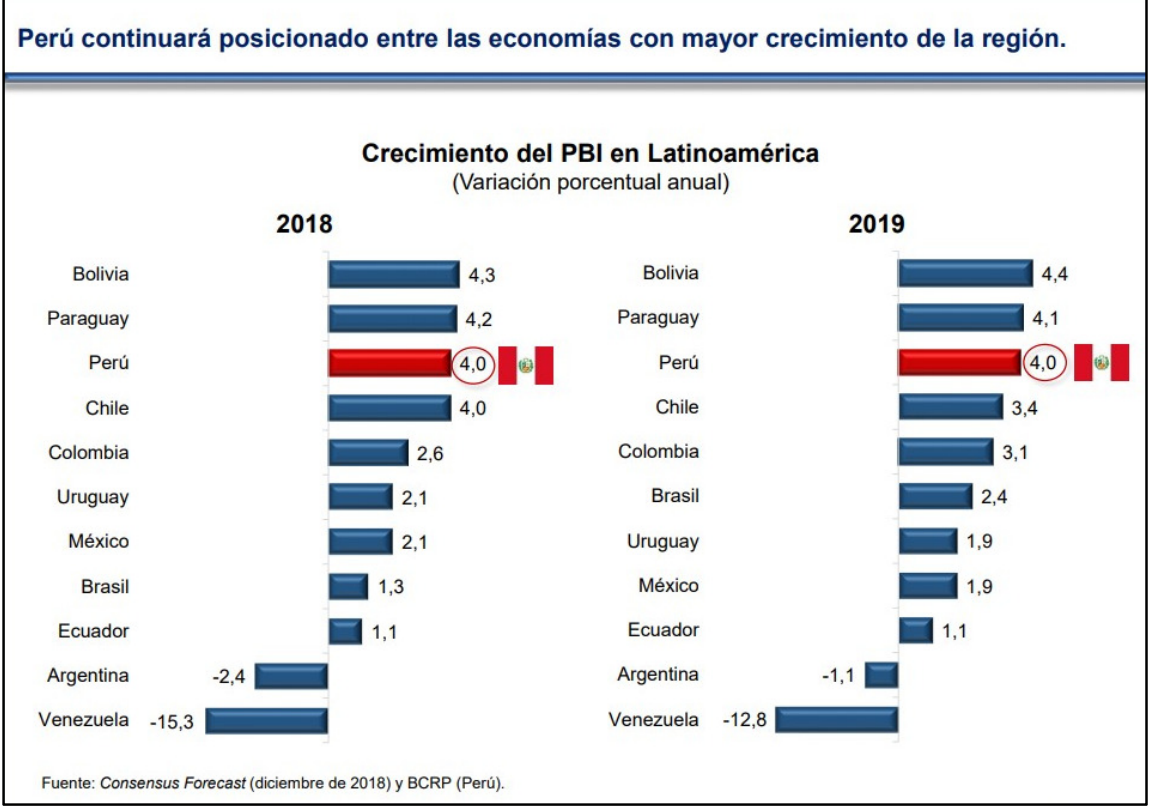

\section{Figura 3. Crecimiento del PBI en Latinoamérica}

Tomado de "Reporte de inflación: panorama actual y proyecciones macroeconómicas 2018-2020" por el Banco Central de Reserva del Perú (BCRP), 2018. Recuperado de http://www.bcrp.gob.pe/docs/Publicaciones/Reporte-

Inflacion/2018/diciembre/reporte-de-inflacion-diciembre-2018-presentacion.pdf

Después de un PBI de $2.6 \%$ en 2017 y de $3.7 \%$ en 2018, se proyecta un crecimiento de 4\% para el 2018, 2019 y 2020, según el reporte de inflación del BCR a diciembre de 2018.

De otro lado el Banco Mundial es mucho más cauto en sus pronósticos, debido a las perspectivas económicas mundiales, donde se indica que el PBI será de $3.8 \%$ para el 2019 y de $3.7 \%$ para 2020.

El informe del Banco Mundial también hace referencia al empleo informal. Indica que es necesario atacar el empleo informal debido a que este tipo de empresas no tributan, ocasionando menor inversión del estado en el empleado y por ende la desigualdad y la pobreza.

Destaca que el empleado de una empresa informal es $75 \%$ menos productivo que un empleado de empresa formal. 


\section{Inflación}

El aumento persistente del nivel general de los precios de la economía, con la consiguiente pérdida del valor adquisitivo de la moneda, se mide generalmente a través de la variación del índice de precios al consumidor (IPC).

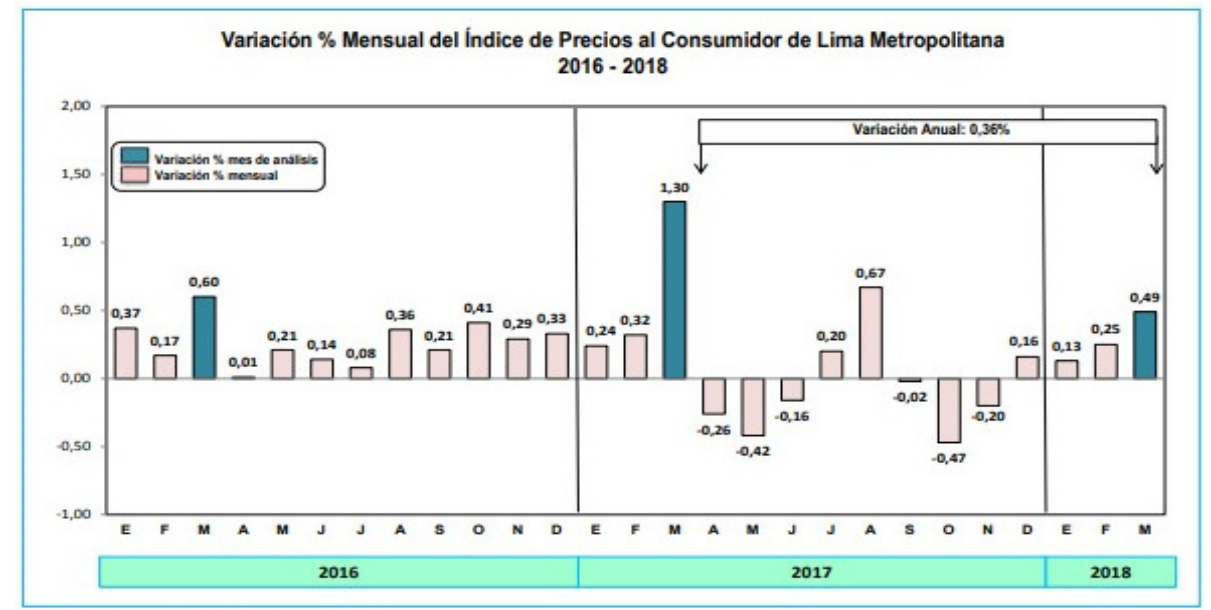

Figura 4. Variación \% mensual del índice de precios al consumidor de Lima metropolitana 2016-2018

Tomado de "Informe técnico $N^{\circ}$ 04" por el Instituto Nacional de Estadística e Informática (INEI), 2018. Recuperado de https://www.inei.gob.pe/media/MenuRecursivo/boletines/04-informe-tecnicon04_precios-mar2018_3.pdf

La inflación en el Perú fue de 1.4\% en el 2017 (tasa más baja desde 2009). Nuestro país proyecta tener la segunda inflación más baja de Latinoamérica con un $2.1 \%$ para el 2018 y 2019.

La inflación del 2018 cerró en 2.2\% (meta del BCR fue entre 1\% y 3\%). El rubro de transportes y comunicaciones ( $16 \%$ en la canasta) subió a $0.94 \%$ (demanda de pasajes hacia el interior). Sin embargo, en el rubro de alimentos y bebidas (38\% en la canasta) la subida de precios solo fue del orden del $0.02 \%$. 


\section{Población Económicamente Activa (PEA)}

La población en edad de trabajar (PET) es aquella que vive en una zona rural o urbana y que a su vez tiene por lo menos 14 años. Se clasifican en dos grandes grupos: Población económicamente Activa (PEA) y la población económicamente inactiva (PEI). A este segundo grupo le corresponde el ama de casa, el estudiante, el jubilado, el rentista, así como las personas que no están en capacidad para trabajar.

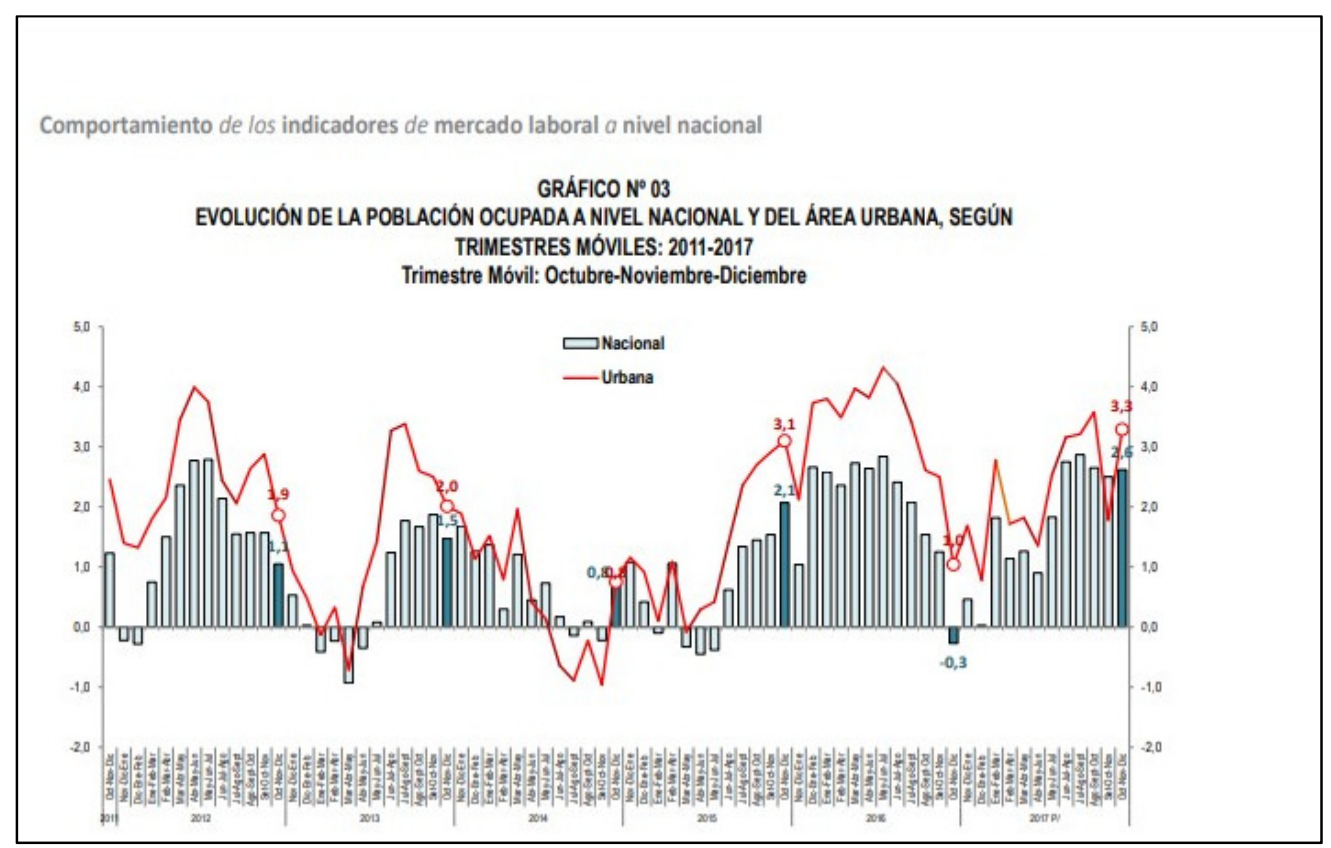

Figura 5. Evolución de la población ocupada a nivel nacional y del área urbana

Según trimestres móviles: 2011 - 2017. Tomado de "Informe técnico $\mathrm{N}^{\circ} 1$ febrero 2018. Comportamiento de los indicadores de mercado laboral a nivel nacional" por Instituto Nacional de Estadística e Informática (INEI), 2018. Recuperado de https://www.inei.gob.pe/media/MenuRecursivo/boletines/01-informe-tecnico-n01_empleonacional_oct-nov-dic2017.pdf

El 34\% de la Población Económicamente Activa (PEA) sigue desempleada. En contraste, más de 11 millones de peruanos laboran en condición de informalidad, pues no perciben gratificaciones, compensación por tiempo de servicios, seguro de salud o pensión de jubilación, según las estadísticas del INEI. 


\section{Balanza comercial}

La Balanza comercial es el resultado de registrar las exportaciones e importaciones del país durante un año. Este saldo tiene relación directa con el precio al que un país vende sus productos a otro país y el precio al cual compra bienes de otro país.

La balanza comercial tiene dos posibles resultados. Superávit y déficit. El superávit se produce cuando las exportaciones son mayores y el déficit cuando las importaciones son mayores.

Algunos factores para tomar en consideración al analizar la balanza comercial se reflejan en:

- Los exportadores, que exigen un tipo de cambio mayor, pues sus clientes del exterior les pagan por lo general en dólares.

- Los exportadores, que brindan puestos de trabajo a los peruanos, siempre y cuando la producción se realice en nuestro país.

- La importación, que puede traer al país productos que les brindan trabajo a personas de otros países.

- Los productos importados pueden ocasionar el deterioro de la industria nacional si ingresan al país con precios muy por debajo de la competencia nacional.

- Entre algunas prácticas de importación encontramos el dumping, que consiste en importar productos por debajo de su precio normal o por debajo de su costo de producción con la intención de eliminar la competencia. El estado se protege del dumping a través de los denominados impuestos, que no son otra cosa que los aranceles. 


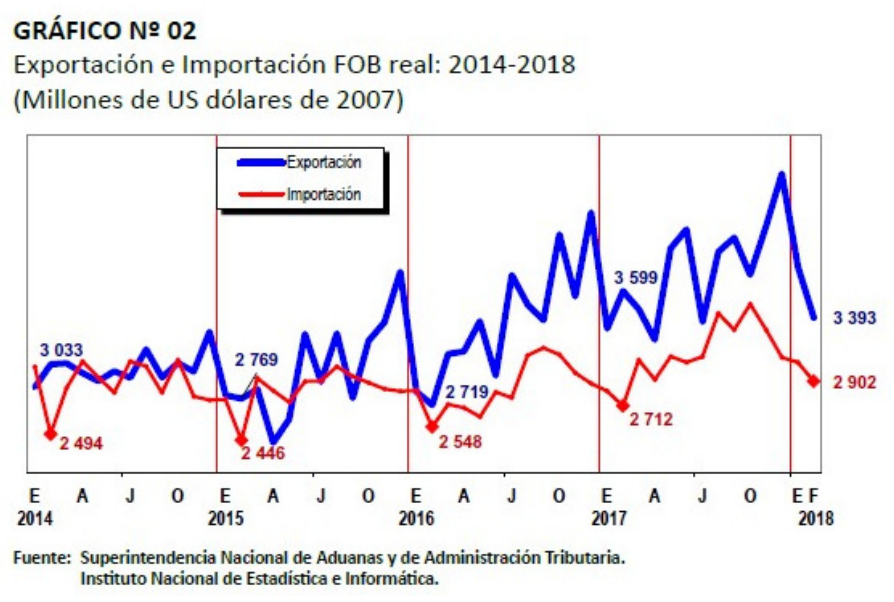

Figura 6. Exportación e importación FOB real: 2014 - 2018

Tomado de "Informe técnico $\mathrm{N}^{\circ} 4$ abril 2018. Evolución de las exportaciones e importaciones" por Instituto Nacional de Estadística e Informática (INEI), 2018. Recuperado de

https://www.inei.gob.pe/media/MenuRecursivo/boletines/04-informetecnico-n04_exportaciones-e-importaciones-ene2018.pdf

La balanza comercial en nuestro país registrará para el primer trimestre de 2019 un superávit de US\$ 1,781 millones registrados, afirmó el banco Scotiabank.

Se espera una evolución negativa de las exportaciones mineras (a excepción del oro) de los productos con menores precios (el índice de precios de exportación IPX lleva cuatro meses consecutivos de caída) esto se compensará con los volúmenes de harina de pescado, según se indicó en el Reporte Semanal del banco.

La caída del precio del petróleo en diciembre impactará positivamente en la balanza comercial, al ser nuestro país un importador asiduo de combustibles.

\section{Tasas de interés referencial}

La tasa de interés referencial es una tasa de interés que el Banco Central de Reserva del Perú fija con la intención de establecer una tasa promedio para las operaciones interbancarias que tienen efecto sobre las tasas de interés que las entidades financieras ofrecen al público. 
El Banco Central de Reserva del Perú (BCR), redujo su tasa de interés de referencia de $3.00 \%$ a $2.75 \%$ para reducir las tasas de crédito en el sistema financiero.

La inflación en febrero continuó disminuyendo, ubicándose en el rango pronosticado de entre $1 \%$ y $3 \%$.

Para marzo se espera una inflación menor a 1\% ubicándose las expectativas de inflación a 12 meses en $2.19 \%$.

Nuestra actividad económica se mantiene por debajo de su potencial en un contexto de baja inflación. No obstante, la economía mundial sigue mostrando indicadores favorables.

\section{Tipo de cambio}

El Banco Central de Reserva (BCR) mostró a inicios del año 2018 sus proyecciones para el tipo de cambio del 2018, 2019 y 2020.

Las proyecciones reflejaban las expectativas para el 2018 con un tipo de cambio ubicado entre S/ 3.23 y S/ 3.28 por dólar.

Los analistas económicos, proyectan que para el 2019, esperan que el precio del dólar se encuentre entre S/ 3.30 y con picos de S/ 3.35. De igual forma, para el 2020, proyectan un precio cercano a los $\mathrm{S} / 3.35$.

Bajo la opinión de las empresas del sistema financiero proyectan para el 2019 una cifra aproximada de S/ 3.25 por dólar, siendo para los siguientes años un valor entre S/ 3.25 y S/ 3.28 .

En resumen, luego de las consultas realizadas por el BCR a diversas entidades y especialistas, se espera que el tipo de cambio llegue al 2020 con un valor ubicado entre los S/ 3.25 y S/ 3.36. 


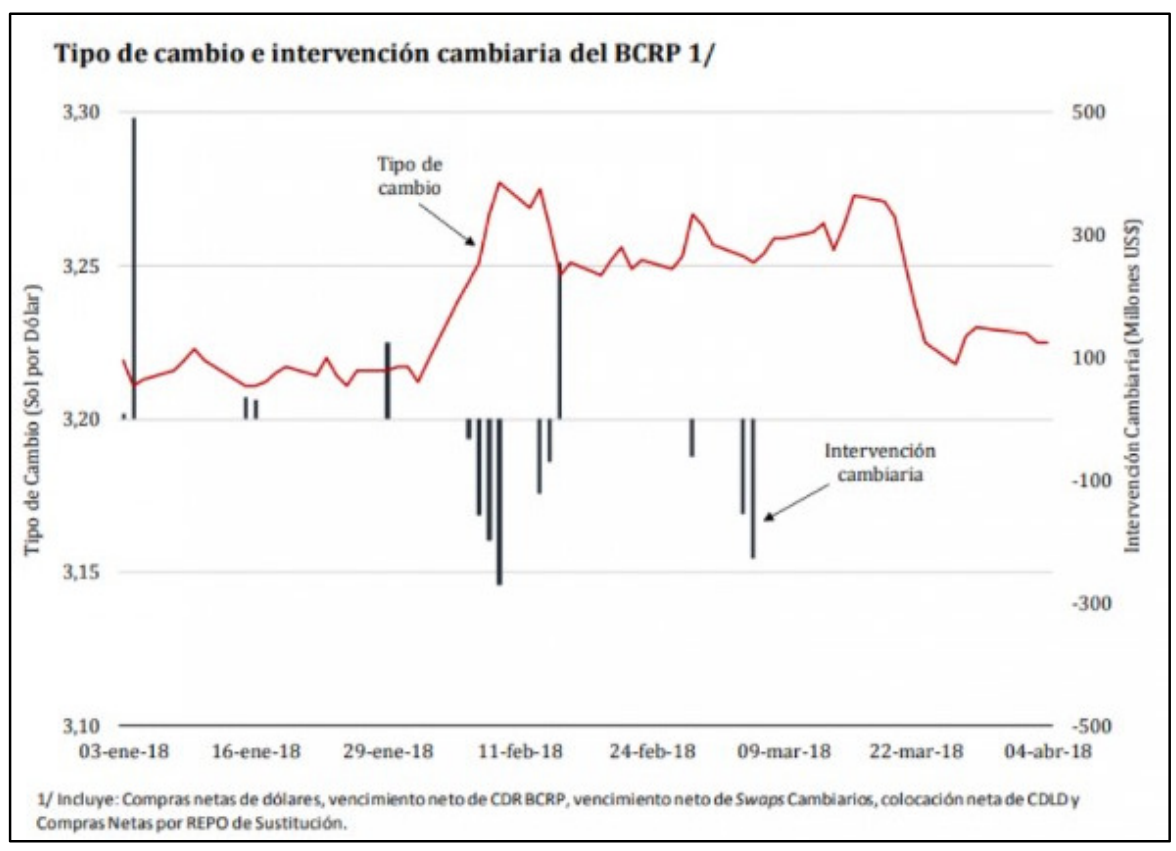

Figura 7. Tipo de cambio e intervención cambiaria del BCRP 2018

Tomado de "Resumen informativo semanal $N^{\circ} 12$ " por Banco Central de Reserva del Perú, 2018. Recuperado de http://www.bcrp.gob.pe/docs/Publicaciones/NotaSemanal/2018/resumen-informativo-12-2018.pdf

\subsubsection{Análisis Legal}

En lo que concierne al análisis legal, el Servicio Nacional de Sanidad Agraria es la institución que aprueba y registra los alimentos para luego proceder con la comercialización de éstos. En tal sentido, esta institución es la que vela por que los alimentos cuenten con un adecuado proceso de producción e inocuidad de calidad. 
Tabla 17.- TUPA - SENASA

\begin{tabular}{|c|c|c|c|}
\hline \multicolumn{4}{|c|}{ TEXTO ÚNICO DE PROCEDIMIENTOS ADMINISTRATIVOS (TUPA) DEL SENASA } \\
\hline \multirow{2}{*}{$\begin{array}{l}\mathrm{N}^{\circ} \mathrm{de} \\
\text { orden }\end{array}$} & \multirow{2}{*}{$\begin{array}{l}\text { Denominación del } \\
\text { procedimiento }\end{array}$} & \multicolumn{2}{|c|}{ Requisitos } \\
\hline & & Número y denominación & $\begin{array}{c}\text { Formulario / Código / } \\
\text { Ubicación }\end{array}$ \\
\hline \multicolumn{4}{|c|}{ INSUMOS PECUARIOS } \\
\hline 01 & $\begin{array}{l}\text { Registro o renovación de } \\
\text { alimentos, premezclas y } \\
\text { aditivos para animales } \\
\text { (excepto alimentos } \\
\text { medicados) } \\
\text { Art. } 17^{\circ} \text { del D. Leg. } N^{\circ} \\
1059 \text { del } 28 / 06 / 2008 \\
\text { Art. } 13^{\circ} \text { del D.S. } 15-98 \text { - } \\
\text { AG del } 22 / 07 / 1998 \\
\text { D.S. } 018-2008 \text {-AG }\end{array}$ & $\begin{array}{l}\text { 1. Solicitud dirigida al Director de Insumos } \\
\text { pecuarios } \\
\text { 2. Proceso de fabricación del producto: } \\
\text { resumen del modo de elaboración. } \\
\text { 3. Presentación } \\
\text { 4. Método de control y evaluación: biológico, } \\
\text { microbiológico, químico, físico, físico - } \\
\text { químico } \\
\text { 5. Duración máxima } \\
\text { 6. Especificar las precauciones para cuando } \\
\text { son alimentos con aditivos } \\
\text { 7. Controles sobre residuos: límite máximo de } \\
\text { residuos (LMR), ingesta diaria admisible } \\
\text { (IDA), período de retiro (aplicable en } \\
\text { alimentos con aditivos) } \\
\text { 8. Conservación correcta del producto } \\
\text { 9. Vencimiento: fecha de expiración } \\
\text { 10. Autorización a tercero, en caso tenga filial } \\
\text { acreditada en el país. } \\
\text { 11. Boleta de pago o validación de pago en el } \\
\text { sistema } \\
\text { Nota: Para la renovación: solicitud y boleta de } \\
\text { pago }\end{array}$ & (Formato cód: IP-01) \\
\hline
\end{tabular}

Nota: Elaboración propia 
Tabla 18.- Derecho de tramitación

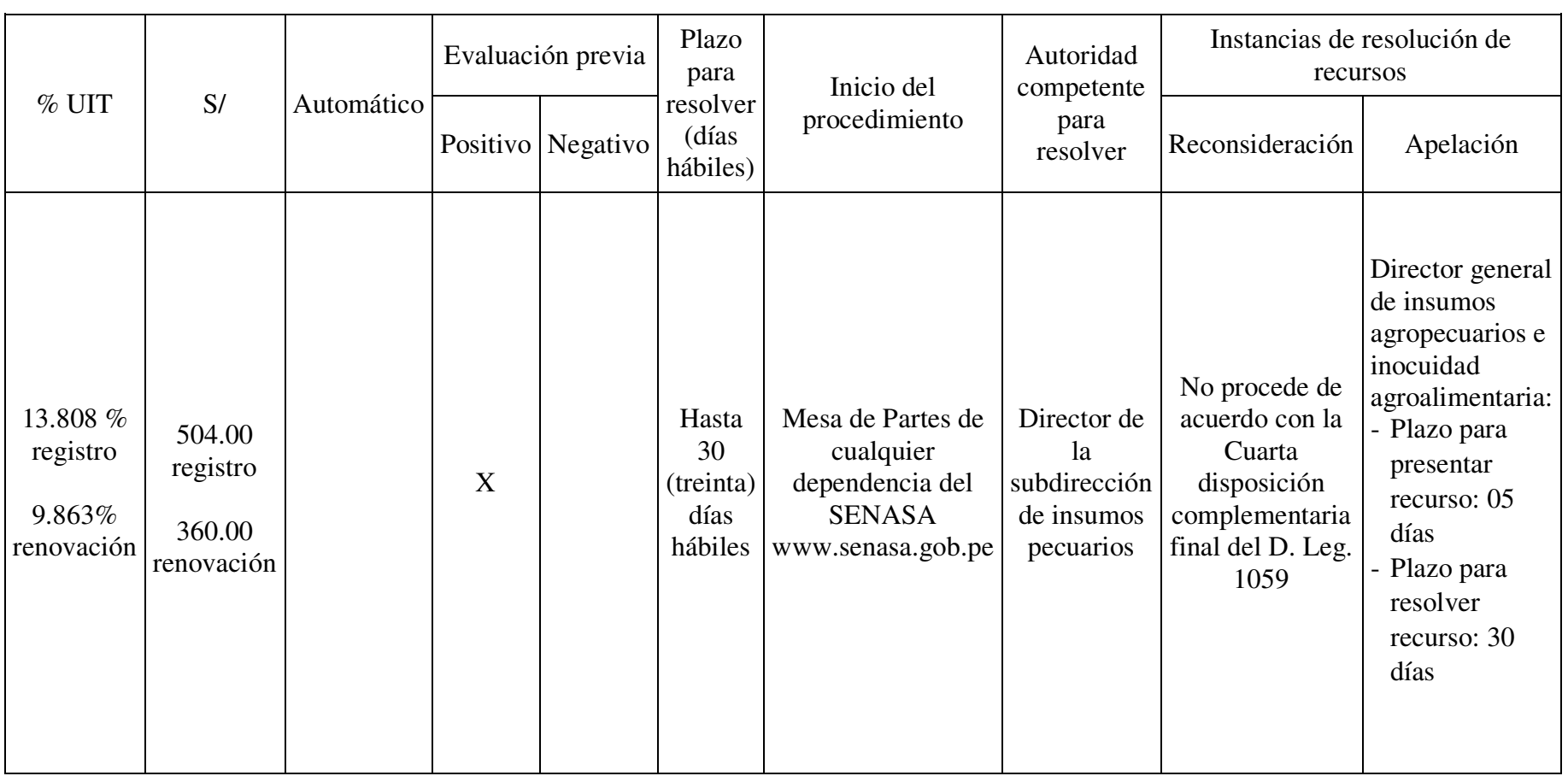

Nota: Elaboración propia 


\subsubsection{Análisis Social y Cultural}

El segmento de mascotas ha sufrido un incremento considerable en los últimos años. Se estima un crecimiento del $2.2 \%$ en la tenencia de mascotas según IBISWorld. Se calcula un crecimiento del $6 \%$ y $8 \%$ anual en los Estados Unidos para la industria de las mascotas con una cifra similar en Latinoamérica, según el reporte emitido por PETCO. (PETmi, 2017)

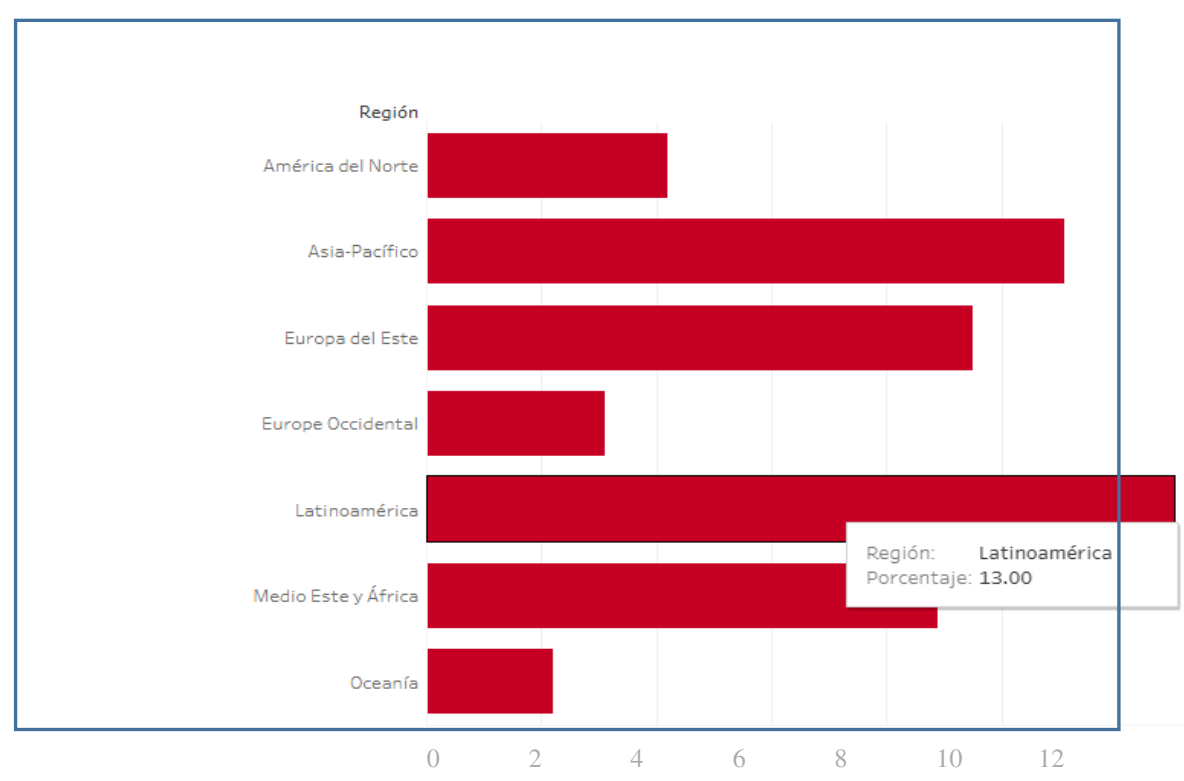

Figura 8. Crecimiento del mercado de mascotas en 2017 por región

Tomado de "Algunas tendencias en el mercado de mascotas en 2017" por Merca2.0, 2017. Recuperado de https://www.merca20.com/algunas-tendenciasen-mercado-mascotas-2017/

\section{Más establecimientos pet friendly}

Las empresas perciben como oportunidad de negocio la autorización para que el cliente visite los establecimientos con sus mascotas. Primeros fueron los cafés, luego las tiendas por departamento (Ripley) y por último las tiendas de retail (Sodimac). Se estima que se incrementarán los locales pet friendly. 


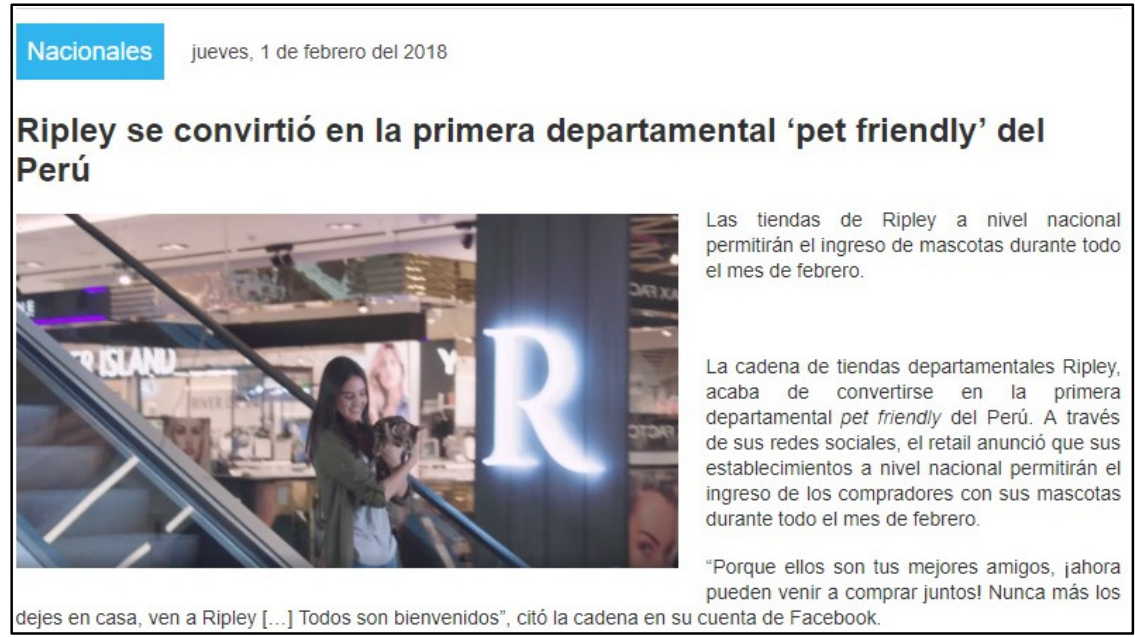

Figura 9. Primera tienda departamental pet friendly en el Perú

Recuperado de https://www.peru-retail.com/ripley-convirtio-primeradepartamental-pet-friendly-peru/

Nacionales martes, 13 de febrero del 2018

Sodimac implementa política 'Dog Friendly' en cuatro de sus tiendas en Perú

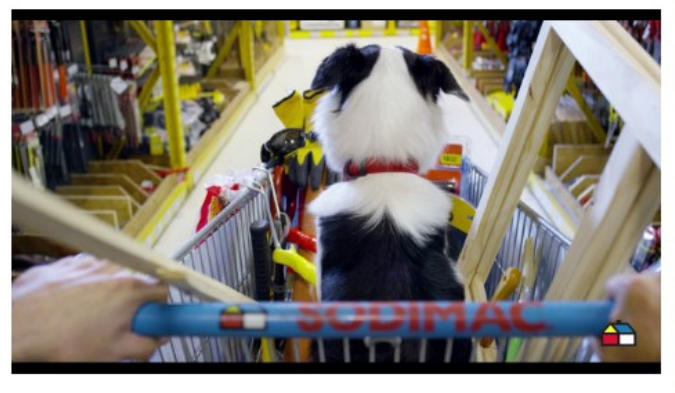

Esta iniciativa se aplicará a las tiendas de Sodimac ubicadas en Ate, Javier Prado, Open Plaza San Miguel y Open Plaza Angamos en Lima.

La cadena de tiendas de mejoramiento del hogar del grupo Falabella, Sodimac, implementó este mes de febrero y por tiempo indefinido la política 'Dog Friendly' en cuatro de sus locales ubicados en Ate, Javier Prado, Open Plaza San Miguel y Open Plaza Angamos, en donde los clientes podrán Angamos, en donde los cllentes podran ingresar a dichos establecimientos en
compañía de sus canes.

Figura 10. Sodimac, dog friendly en el Perú

Recuperado de http://lucidez.pe/negocios/sodimac-implementapolitica-dog-friendly-en-cuatro-de-sus-tiendas-en-peru/

\section{Más Negocios Especializados}

Negocios como veterinarias, clínicas veterinarias, enfocados en baños, ropa, cortes, paseos, adiestramiento, guardería, taxi para mascotas, seguros, entre otros servicios especializados, se incrementarán. 


\section{Clubes de convivencia}

Lugares donde los dueños de las mascotas realizan actividades que fortalecen sus vínculos de lealtad.

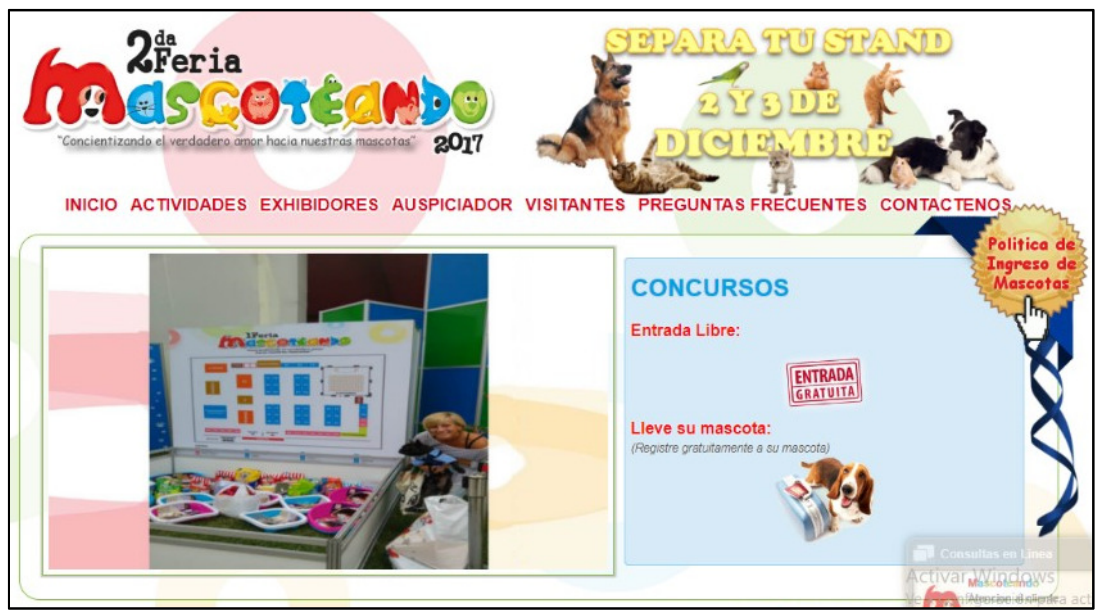

Figura 11. Publicidad de feria Mascoteando

Recuperado de https://www.emprendinauta.com/blog/que-esel-seo-y-por-que-es-publicidad-gratis/

\section{Más información en páginas web y redes sociales}

La web ha sido inundada por información referente a las diversas empresas relacionadas con las mascotas, así como los servicios y concejos que allí se brindan.

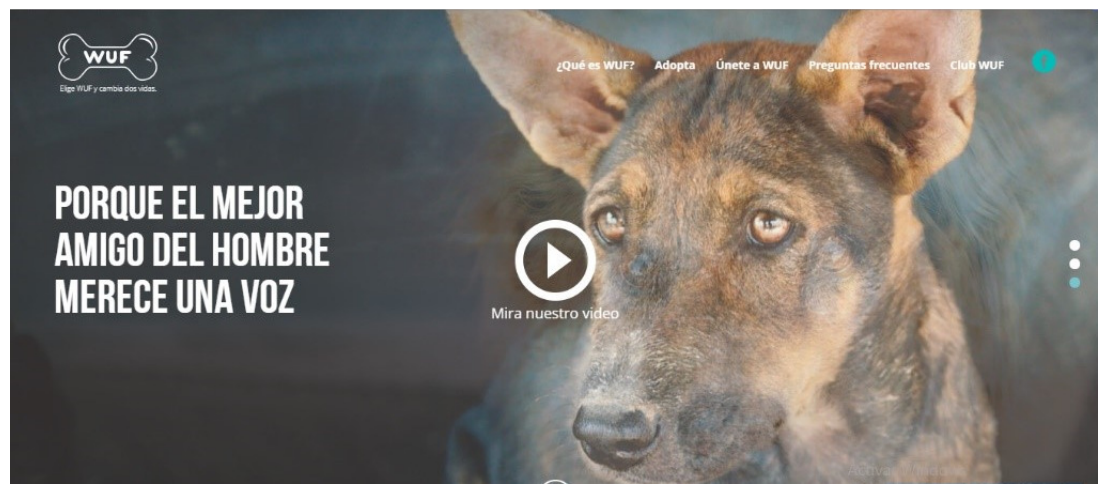

Figura 12. Club WUF.

Recuperado de http://www.wuf.pe/ 


\section{Vínculo emocional entre familias y mascotas}

Según las entrevistas a profundidad realizadas, las familias que tienen mascotas caninas, refieren que sus mascotas son un miembro más de la familia, se preocupan por alimentarlos con productos de calidad, se preocupan por su salud (consultas con veterinarios, realización de análisis, placas y operaciones), duermen con ellos, pasean con ellos en sus autos, los llevan a centros comerciales, los visten, le cortan el pelo en sitios especializados, les ponen collares con su identificación y sus teléfonos, les celebran sus cumpleaños, entre otras características relevantes de su conducta.

Las empresas también están atentas a los cambios del consumidor, en consecuencia, muchas empresas están empezando a permitir el ingreso de clientes con sus mascotas. No se asombre si en un futuro muy cercano, observa que en lugares públicos hagan su aparición los caninos.

\subsubsection{Análisis Tecnológico}

La tecnología tiene una influencia cada vez mayor en la vida de las mascotas. Prueba de esta afirmación es la Comunidad de perros que ha lanzado su propia aplicación (app): Club Wuf.

Club Wuf tiene por objetivo ayudar a crear un mundo mejor para las mascotas (animales sin dueño o que tienen un hogar). Esta aplicación brinda acceso a múltiples producto y servicios, lo único que debe hacer es bajar la aplicación a su móvil y proceder con la afiliación de S/ 20 aproximadamente, que ayudarán a mejorar la calidad de vida en los albergues. La aplicación para dispositivos Club Wuf (app), cuenta con cuatro accesos: el Dato (foro para compartir información entre usuarios) donde además se encuentra la etiqueta Wufcame para colaborar con animales perdidos 
o en proceso de adopción; Lugares (empresas que ofrecen diversos servicios para los canes); Novedades (noticias) y Cuenta (información personalizada del usuario). (El Comercio, 2018)

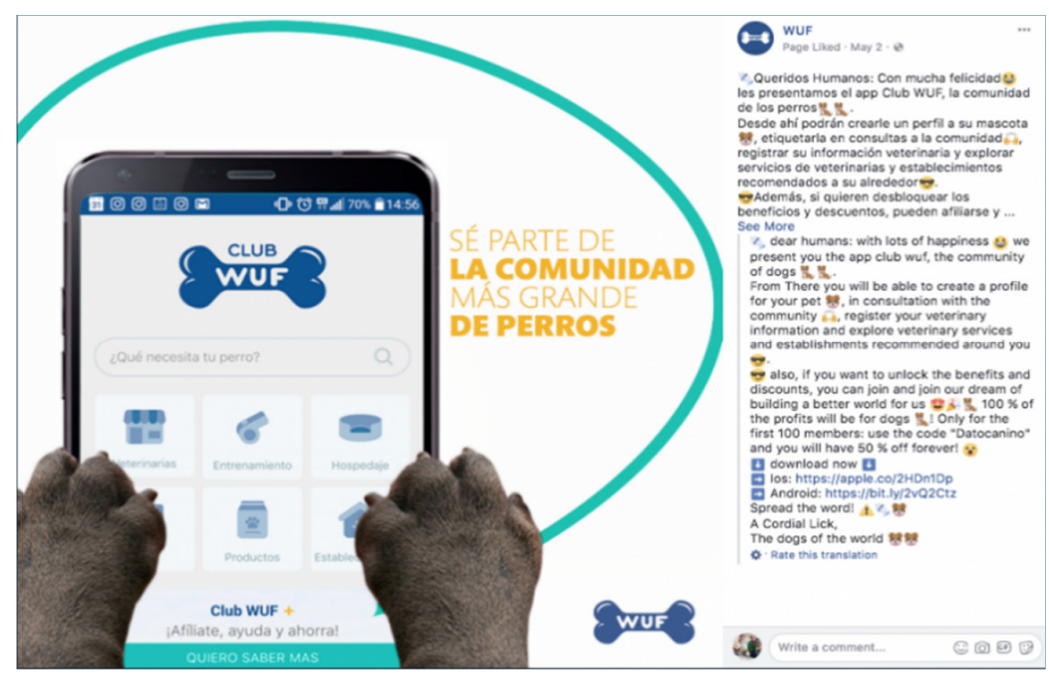

Figura 13. Página de Facebook de Club WUF

Recuperado de https://es-la.facebook.com/WufPeru/

\section{GPS para mascotas}

Este collar es un accesorio que tiene dos funciones:

a) Localiza a tu mascota en caso ésta se extravíe. Tiene una aplicación que envía un correo electrónico en caso la mascota supere los límites de distancia permitida.

b) Mide la actividad realizada para ver si ha cumplido con el ejercicio adecuado para su buena salud.

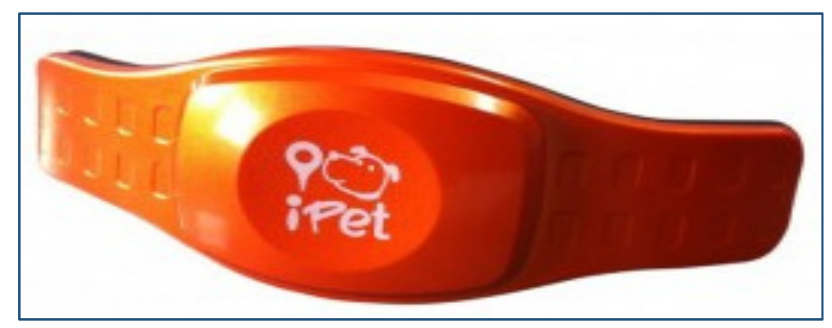

Figura 14. Ipet tracker, localizador GPS para perros

Recuperado de https://ipet.es/localizadores/ipet-tracker-localizadorgps.html 


\section{Chalecos calmantes}

Son chalecos que el can usa y que ante situaciones de estrés se activan ejerciendo presión sobre el perrito, lo cual simula un aparente abrazo que relaja al can disminuyendo su ansiedad. Ideal para ruidos ocasionados por fuegos artificiales y ruidos molestos en general.

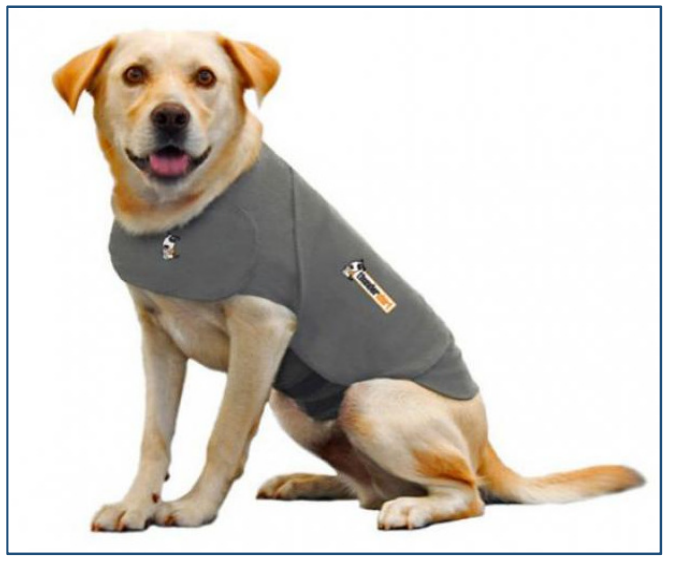

Figura 15. Chaleco calmante

Recuperado de ttps://www.muymascotas.es/accesorios/fotos/accesoriosmodernos-para-mascotas-que-te-sorprenderan/1

\section{Dispensadores de alimentos}

Es una máquina dispensadora de alimentos la cual se puede programar para que, a ciertas horas, pueda expender comida en la ración establecida previamente.

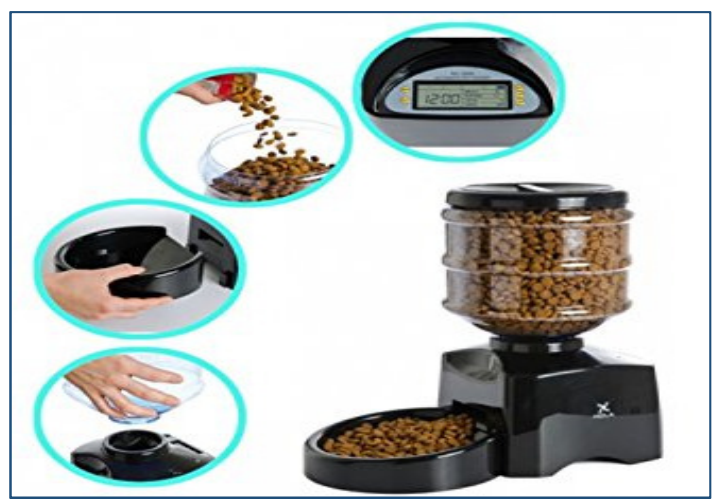

Figura 16. Dispensador de comida para perros

Recuperado de https://www.dispensadorde.net/comida-perros/ 


\section{Dispensador automático de agua}

Contiene agua purificada que en base a filtros de carbono y con la ayuda de una bomba sumergida, ayuda a obtener agua oxigenada y fresca. El diseño del producto evita que el agua salpique al piso.

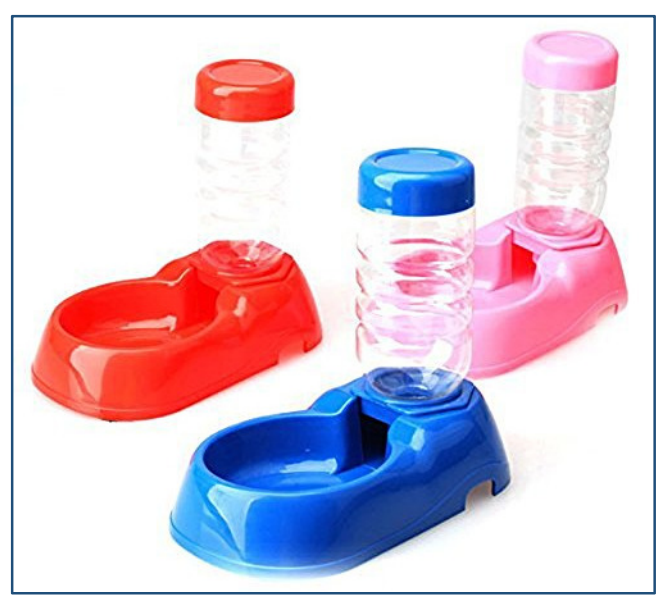

Figura 17. Dispensador automático de agua

Recuperado de https://www.dispensadorde.net/comida-perros/

\subsubsection{Análisis Ecológico}

El desarrollo de la sociedad limeña ha hecho posible un cambio con respecto al medio ambiente, para las personas y de igual forma para los animales.

Los espacios son pequeños para la familia y las mascotas. La nueva forma de vivienda se centra en el uso de un departamento con espacios reducidos. De igual forma sucede con los vehículos cuyo tamaño también es reducido. De una u otra forma se hará frecuente la presencia de razas chicas y medianas, atrás quedaron las casas limeñas antiguas con espacios amplios que incluían grandes perros.

El cambio climático trae consigo, la elevación de las temperaturas y el calor agobiante con los efectos propios sobre las personas y las mascotas. De primera impresión la vista, la piel y las almohadillas de las patas serán las primeras afectadas 
con este factor. Por consiguiente, se requerirá de medicamentos que puedan remediar estas dolencias.

La calidad del agua potable será otro factor, tomando en cuenta que no todos están en capacidad de brindarle a su mascota agua envasada.

La contaminación ambiental, dado que, al vivir en zonas urbanas sobrepobladas, el smog como producto de máquinas y vehículos será mayor conforme avance el tiempo.

La contaminación sonora, corroborada por grandes avenidas que son el escenario diario del tráfico automotriz.

\subsection{Oportunidades}

Tabla 19.- Macro ambiente externo

\section{INVENTARIO DE OPORTUNIDADDES}

\begin{tabular}{|c|c|c|}
\hline FACTOR & IMPACTO & SEMAFORO \\
\hline $\begin{array}{l}\text { El mercado de alimento canino se encuentra } \\
\text { dominado por una gran variedad de alimentos } \\
\text { envasados (tipo croqueta). Tiene una tasa de } \\
\text { penetración del mercado baja en comparación } \\
\text { con el promedio latinoamericano. }\end{array}$ & Alto & Oportunidad \\
\hline $\begin{array}{l}\text { El NSE ABC compra en canales modernos, lo } \\
\text { cual define específicamente el canal de } \\
\text { competencia. }\end{array}$ & Alto & Oportunidad \\
\hline $\begin{array}{l}\text { Elevado precio de productos tipo PREMIUM } \\
\text { (alta calidad) de comida seca. }\end{array}$ & Alto & Oportunidad \\
\hline $\begin{array}{l}\text { Crecimiento anual sostenido, de la venta de } \\
\text { alimento envasado de tipo croqueta en los últimos } \\
\text { años a un ritmo de } 10-12 \% \text { anual. }\end{array}$ & Alto & Oportunidad \\
\hline $\begin{array}{l}\text { Incremento de la sensibilidad social respecto a los } \\
\text { animales, su calidad de vida y humanización, a } \\
\text { través de: redes sociales, canales de televisión, } \\
\text { leyes, veterinarios, clínicas y los múltiples } \\
\text { servicios que se les brinda. }\end{array}$ & Alto & Oportunidad \\
\hline
\end{tabular}




\section{CAPÍTULO III \\ ESTUDIO DE MERCADO}

\subsection{Información sobre el proyecto}

El proyecto responde a la constitución de empresa que se dedicará a producir y comercializar alimentos caninos.

Actividad económica: producción y comercialización de alimento para canes.

Código CIIU: $\quad 1533$-Producción de alimentos para canes.

Razón Social: $\quad$ Fuertes y sanos SAC.

Razón comercial: $\quad$ Animal Lovers, en su versión: Adulto.

Elaboración del proyecto: $\quad$ Año 2018.

Horizonte de evaluación: $\quad$ cinco (5) años. Del 2019 al 2023.

Ubicación del centro de producción: Surquillo, área identificada como el Surquillo comercial, situado en las inmediaciones del parque Fátima (cruce de Miguel Iglesias con Alejandro Peralta).

Factores de ubicación del centro de producción: Rápido acceso a San Borja; alquiler promedio de S/ 2,500 mensuales; acceso rápido a distritos aledaños.

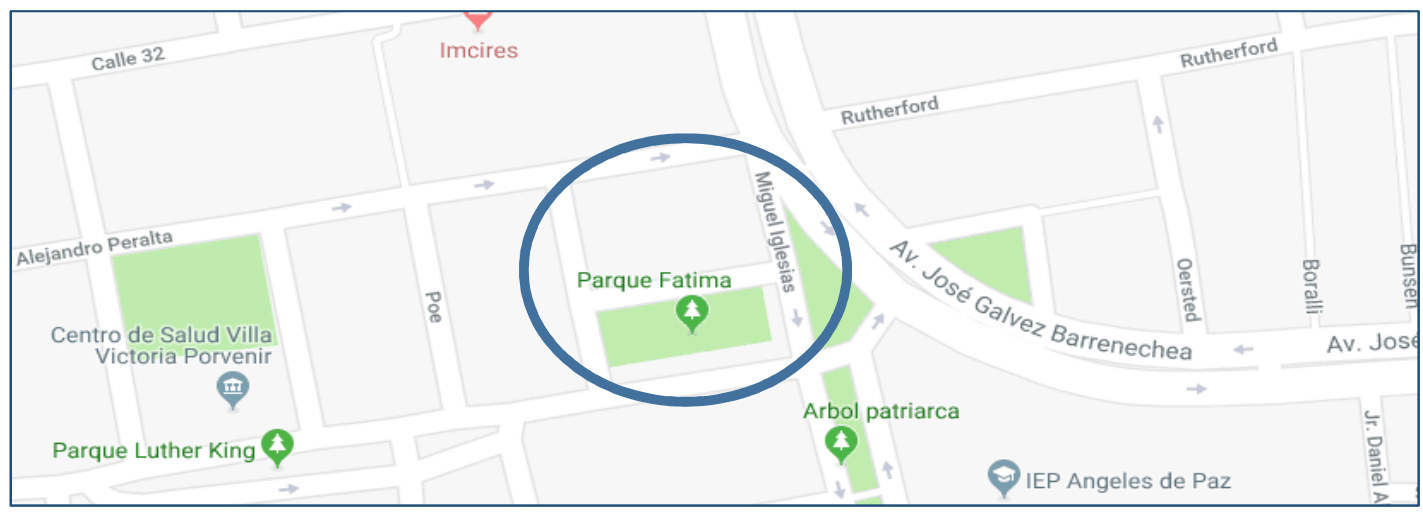

Figura 18. Ubicación del centro de producción

Recuperado de http://planos.paginasamarillas.com.pe/guia-calles-san-borja.asp 


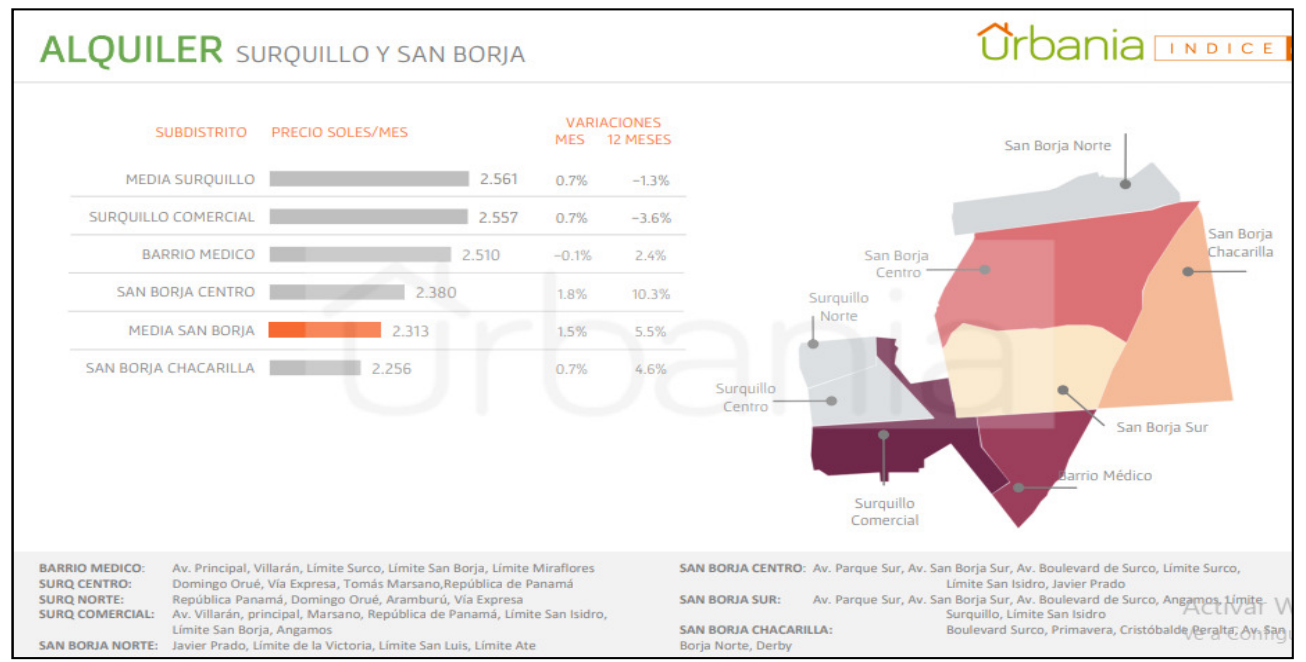

Figura 19. Alquiler por metro cuadrado en Surquillo y San Borja

Tomado de "Departamentos en Lima. Reporte de Mercado. Diciembre 2018" por Urbania, 2018. Recuperado de https://s3.amazonaws.com/wp.prod.urbania.pe/indicem2/wpcontent/uploads/2018/11/04163524/INDICE-M2-DEPARTAMENTOS-LIMA-2018-12.pdf

Ubicación del área de comercialización y reparto: San Borja, distrito donde reside el público objetivo.

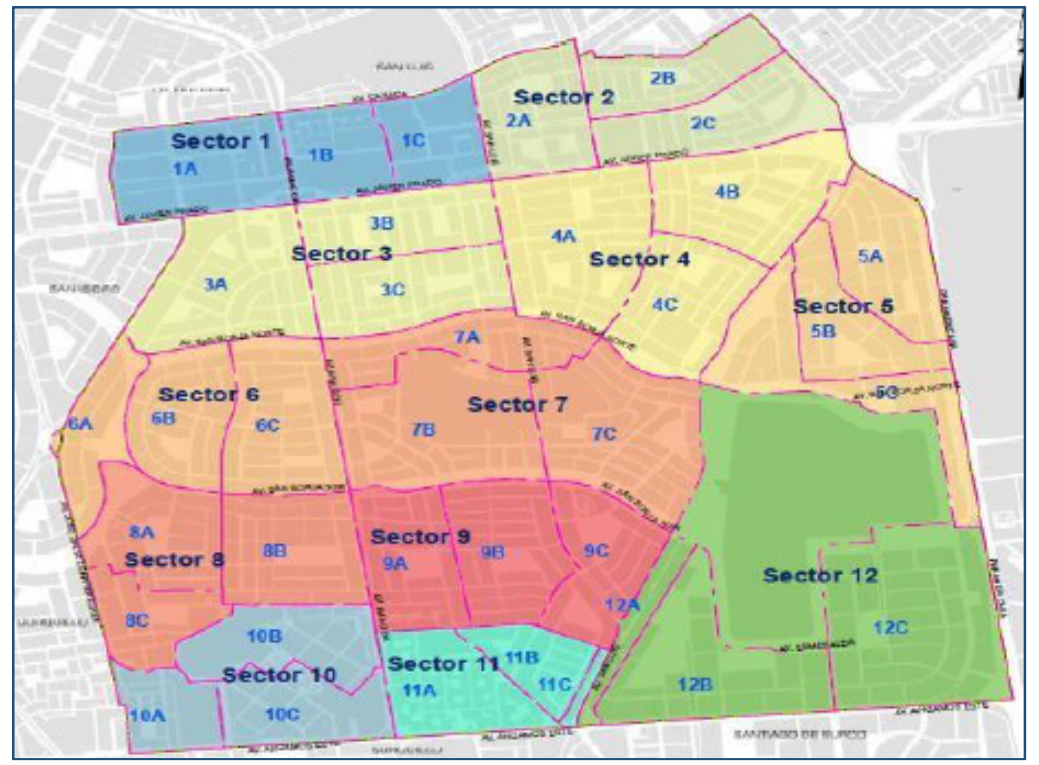

Figura 20. Distribución por sectores del distrito de San Borja

Tomado de "Plan estratégico de gobierno electrónico 2018-2020" por Municipalidad distrital de San Borja, 2018. Recuperado de http://www.munisanborja.gob.pe/dmdocuments/PLAN_GOBIERNO_ELECTRONIC O_SAN_BORJA.pdf 


\subsection{Descripción del servicio o producto}

Animal Lovers busca generar beneficios para el can, para la familia que lo acoge y finalmente, busca fortalecer la relación entre ambos.

El producto tiene dos aspectos: el alimento para el can y la confianza del dueño del can.

\section{El alimento para el can.}

Animal Lovers ofrece un producto con las siguientes características:

- Es un alimento cocido a un nivel que evita perder las ventajas nutricionales que posee y al mismo tiempo facilita la digestión del can.

- Se produce en base a una fórmula balanceada.

- Tiene diversos sabores, lo cual lo hace apetecible por parte del can y de igual forma atiende sus gustos por la comida variada.

- Saludable, por que nutre y no genera efectos colaterales nocivos.

- Se compone de carne (puede ser de pollo, pescado o res), vegetales y suplementos alimenticios.

- Fórmula balanceada para el crecimiento, mantenimiento y cuidado de la salud del can.

- Cumple con todos los requerimientos exigidos según receta de la veterinaria Prana.

- Producto empacado al vacío.

- Se conserva refrigerado.

Este producto pretende afianzar el vínculo psicológico entre el amo y su mascota a través de la generación de lazos afectivos y de protección.

Con respeto a la propuesta de valor, se destacan ciertos parámetros de comparación de aquellas propiedades que generan ventaja de Animal Lovers sobre la comida seca. 


\subsection{Selección del segmento del mercado}

Para la selección del segmento de mercado han sido considerados varios factores (Benassini, 2014), entre los cuales el segmento debe ser:

- Medible (cuantificable), basado en 38.5 mil hogares para el caso de San Borja.

- Accesible a los compradores, dado que residen en el distrito de San Borja.

- $\quad$ Sustancial (suficientemente grande y redituable), de NSE ABC (94.7\%).

- Diferenciable, que tienen un can como mascota al cual le brindan cuidados que exigen una inversión mensual (56.5\% de la población).

- Aplicable, dada la propuesta de una alimentación saludable y balanceada.

\section{Evaluación del segmento de mercado}

La evaluación del segmento elegido (Benassini, 2014) se compone de cuatro elementos:

- Tamaño del segmento.

- $\quad$ Crecimiento del segmento.

- $\quad$ Factores estructurales.

- Recursos y objetivos propios.

\section{Tamaño del segmento}

El segmento está compuesto por 20,600 (56.5\%) hogares de NSE ABC de San Borja. De este grupo, cerca al $90 \%$ consume comida balanceada. Esta cifra representa un mercado que tiene poder adquisitivo y le brinda calidad de vida a su mascota. 
Tabla 20.- Tipos de alimentos que consumen las mascotas

\begin{tabular}{|c|c|c|c|c|c|c|}
\hline & & & & & & Total: $100 \%$ \\
\hline & $\begin{array}{c}\text { Total Perú } \\
\text { Urbano }\end{array}$ & $\begin{array}{l}\text { Lima } \\
\text { Metropolitana }\end{array}$ & $\begin{array}{l}\text { Interior } \\
\text { del Perú } \\
\text { Urbano }\end{array}$ & $A / B$ & C & $\mathrm{D} / \mathrm{E}$ \\
\hline CASERA Y BALANCEADA & 46.3 & 53.9 & 41.7 & 46.1 & 56.1 & 39.9 \\
\hline SÓLO CASERA & 32.3 & 8.7 & 46.7 & 5.2 & 17.9 & 52.2 \\
\hline SólO BALANCEADA & 21.4 & 37.4 & 11.6 & 48.7 & 26.0 & 7.9 \\
\hline
\end{tabular}

Nota: Tomado de "Tenencia de mascotas en los hogares a nivel nacional" por Compañía peruana de estudios de mercados y opinión pública SAC (CPI), 2018. Recuperado de http://cpi.pe/images/upload/paginaweb/archivo/26/mr_mascotas_201808.pdf

Tabla 21.- ¿Cómo llegó la mascota al hogar? según niveles socioeconómicos

\begin{tabular}{|c|c|c|c|c|c|}
\hline & & $\begin{array}{l}\text { Total Perú } \\
\text { Urbano }\end{array}$ & A/B & C & $\mathrm{D} / \mathrm{E}$ \\
\hline 20 & REGALO & 59.0 & 53.1 & 60.2 & 60.7 \\
\hline & COMPRA & 21.5 & 31.8 & 20.5 & 17.7 \\
\hline & ADOPCIÓN & 14.8 & 12.8 & 14.2 & 16.0 \\
\hline 2. & OTROS & 4.7 & 2.3 & 5.1 & 5.6 \\
\hline & REGALO & 56.0 & 46.5 & 50.7 & 60.4 \\
\hline & COMPRA & 9.2 & 8.4 & 9.8 & 9.1 \\
\hline & ADOPCIÓN & 28.8 & 39.2 & 33.4 & 24.6 \\
\hline & OTROS & 6.0 & 5.9 & 6.1 & 5.9 \\
\hline
\end{tabular}

Nota: Tomado de "Tenencia de mascotas en los hogares a nivel nacional" por Compañía peruana de estudios de mercados y opinión pública SAC (CPI), 2018. Recuperado de http://cpi.pe/images/upload/paginaweb/archivo/26/mr_mascotas_201808.pdf

${ }^{\text {a }}$ Muestra las causas que hacen posible el incremento de hogares con canes. Toma en consideración factores relacionados al regalo, compra, adopción y otros. Note además que tanto el regalo como la compra son en promedio el $80 \%$ en todos los niveles socioeconómicos.

\section{Recursos y objetivos propios}

Animal Lovers tiene una propuesta alineada con una alimentación balanceada y saludable. Por ello, una cadena de frio garantiza la duración y mantenimiento del producto. 


\section{Características del segmento elegido}

Las características que definen este segmento son de tipo: geográfico, demográfico, psicográfico y conductual.

Las dos primeras variables -geográfica y demográfica- son cuantificables tomando como base el apoyo de fuentes secundarias.

Las otras dos variables restantes -psicográfica y conductual- permiten identificar con mayor detalle el perfil de los miembros que integran aquellas familias que tienen canes como mascotas.

El perfil del consumidor. Son parejas jóvenes y personas independientes, que viven en un departamento y están iniciando su vida independiente.

Con respecto al perfil del cliente ideal (Buyer Persona) podemos destacar ciertas características atribuibles a una persona como Miguel a manera de ejemplo. Joven de 28 años, es profesional y está estudiando su posgrado, es empleado con un cargo ejecutivo o tiene negocio, su ingreso mensual es mayor a S/ 3,500. Tiene un Smartphone vive conectado a sus redes sociales (FB, IG y TWT) hace todas sus transacciones online. Vive solo, tiene novia hace 3 años y está pensando en casarse, no está muy seguro de querer tener hijos. Tiene a Pirata, un cachorro de $11 \mathrm{~kg}$. que adopto hace 2 años, Pirata es el hijo y mejor amigo de Miguel, en sus tiempos libres salen a correr $10 \mathrm{~K}$ al parque y trata de llevarlo a donde va. Pirata -amigo de Miguel- come Hill's (60-70 soles / semana), pero en los últimos meses su apetito ha disminuido, no está comiendo muy bien, así que Miguel está buscando nuevas opciones para alimentar a su hijo perruno sin que le salga mucho más costoso. 


\section{Marco Muestral}

- Universo: hogares de NSE ABC, que tienen canes en calidad de mascotas.

- Área geográfica: distrito de San Borja y distritos aledaños.

- Población: hogares residentes del distrito.

\section{Unidad Muestral}

La unidad muestral está representada por los hogares de nivel socioeconómico: A, B y $\mathrm{C}$, que residen en el distrito de San Borja.

Tabla 22.- Distribución de personas y familias por nivel socioeconómico del Distrito de San Borja - Año 2018

\begin{tabular}{cccc}
\hline \multicolumn{2}{c}{ Nivel socioeconómico } & Personas & Familias \\
\hline $\mathrm{A}$ & $34.6 \%$ & 41,174 & 13,321 \\
\hline $\mathrm{B}$ & $46.4 \%$ & 55,216 & 17,864 \\
\hline $\mathrm{C}$ & $13.7 \%$ & 16,303 & 5,274 \\
\hline $\mathrm{D}$ & $4.2 \%$ & 4,998 & 1,617 \\
\hline $\mathrm{E}$ & $1.1 \%$ & 1,309 & 423 \\
\hline \multicolumn{2}{c}{ Total, de Personas } & 119,000 & 38,500 \\
\hline
\end{tabular}

Nota: Elaboración propia.

${ }^{\text {a }}$ Según los cálculos basados en las estadísticas de CPI (Compañía peruana de estudios de mercado y opinión pública) y APEIM (Asociación peruana de investigación de mercados) las familias se componen en la actualidad de tres (3) personas en promedio

En base al cálculo del número de personas y familias del año 2018 se proyectará el número de personas y familias de nivel socioeconómico A, B y C para los siguientes años. 


\section{Diseño de la investigación}

El diseño de la investigación corresponde al procedimiento utilizado para recolectar datos y analizar las variables cuyo uso beneficien la investigación del proyecto. El diseño es un modelo de trabajo que ha sido creado para encontrar los resultados esperados en la investigación.

El muestreo es de tipo probabilístico en donde cada unidad de muestra tiene la posibilidad de ser elegida, haciendo uso de un enfoque mixto: enfoque cualitativo y enfoque cuantitativo.

Los métodos empleados en el enfoque cualitativo son: entrevistas a profundidad y grupos de enfoque. Adicionalmente se empleará una prueba de concepto de producto. Y en el enfoque cuantitativo se han utilizado las encuestas.

Con respecto a las fuentes de información secundaria, se ha recurrido a indicadores elaborados por instituciones especializadas en investigación de mercado como: la Asociación Peruana de Empresas de Investigación de Mercado - APEIM, Compañía Peruana de Investigación de Mercado - CPI, Arellano Marketing y cifras del Instituto Nacional de Estadística e InformáticaINEI. Además de datos de instituciones como: el Banco Central de Reserva - BCR; Superintendencia de Banca y Seguros - SBS; Ministerios, entre otros organismos consultados.

\subsection{Investigación Cualitativa}

La investigación cualitativa ha involucrado a personas relacionadas de manera directa con el mercado de los alimentos para canes. Dichas personas cumplen roles en el ámbito profesional de la salud. Por ello, a partir de estas opiniones, se han establecido las ideas a considerar para llevar a cabo la investigación cuantitativa. En virtud de lo expuesto se ha procedido a utilizar dos (2) tipos de herramientas:

- $\quad$ Entrevistas a profundidad

- Grupos de enfoque 


\subsubsection{Muestreo, diseño del instrumento y aplicación de entrevistas a profundidad}

El muestreo se ha realizado en base a personas que tienen relación directa con los servicios que se les brinda a las mascotas por diversos propósitos. El cuestionario ha sido colocado en los anexos del presente trabajo.

En el proceso de muestreo se ha tenido la oportunidad de contar con especialistas. A continuación, encontraremos los datos de dos de ellos.

\section{Profesionales:}

Doctora:

Doctor:

Reategui Blacker, Doris María

Manuel Israel, Cárdenas Rodríguez

Profesión:

Profesión:

Veterinario - Nutricionista - 5210

Veterinario - Cirujano - 5485

A continuación, encontraremos resúmenes de las diversas entrevistas realizadas.

\section{Entrevista $N^{\circ} 1$}

\section{Objetivo general:}

Conocer las necesidades alimenticias de los canes para una debida nutrición y conservación de la salud.

\section{Objetivo específico:}

- Determinar las necesidades alimenticias del can.

- Determinar los componentes de una fórmula balanceada 
- Identificar los ingredientes relevantes en la composición de los productos alimenticios.

\section{Análisis y conclusiones}

- La nutricionista reconoce en el mercado (3) tipos de alimento: comida seca, BARF y comida casera.

- La comida seca tiene una fórmula balanceada, pero es procesada. Y genera efectos adversos en las mascotas.

- $\quad$ El BARF se basa en carne y huesos crudos triturados. Sin embargo, no todos los perros toleran este tipo de alimento.

- La comida casera es natural, pero por lo general no se elabora en base a una formula balanceada. Este alimento por lo general excede o es deficiente en uno o algunos de sus componentes.

- $\quad$ Un buen alimento se elabora en base a una fórmula balanceada.

- Para definir cuál es la dieta correcta de una mascota, se debe determinar la cantidad de calorías que tiene, siendo irrelevante y/o referencial el peso de esta.

- $\quad$ El objetivo es ofrecer al mercado un alimento preparado en forma casera con una fórmula balanceada, con insumos naturales y sabores variados.

- En necesario conservar refrigerado el alimento y ponerlo a punto en baño maría para su consumo. 


\section{Entrevista $\mathbf{N}^{\circ} 2$}

\section{Objetivo general:}

Tener evidencias del estado de salud de las mascotas desde la perspectiva de un médico cirujano.

\section{Objetivo específico:}

- Determinar el estado de salud del can.

- Identificar evidencias del estado de salud.

- $\quad$ Perspectivas de los efectos de la alimentación canina.

\section{Análisis y conclusiones}

- Un médico veterinario habituado a realizar operaciones tiene la oportunidad de revisar los órganos internos de la mascota.

- Identifica que los órganos de los animales que opera presentan formaciones atípicas, siendo éstas -entre otros factores- el resultado de la alimentación.

- $\quad$ Refiere que los animales de la calle no tienen estas formaciones atípicas, pero si los animales de casa.

- Sabe que los animales de casa que trata están alimentados con comida seca de forma considerable.

- Concluye que la alimentación puede ser muy buena, pero de igual forma nociva, debido a que puede ocasionar trastornos en la salud ocasionando una intervención quirúrgica, como paso previo para su curación. 


\subsubsection{Muestreo, diseño del instrumento y aplicación de grupos de enfoque}

En esta parte del presente proyecto se darán a conocer las conclusiones acerca de la información recogida de personas que pertenecen a familias tenedoras de canes.

Los cuestionarios de preguntas empleadas en el grupo de enfoque se ubican en los anexos del presente trabajo.

El proceso de muestreo para realizar reuniones a manera de grupos de enfoque se ha basado en seleccionar personas de NSE ABC que invierten en el bienestar de sus mascotas.

\subsubsection{Análisis y procesamiento de datos}

\section{Análisis y conclusiones}

- Las diversas personas reunidas opinan que consumen comida seca y comida seca mezclada con comida casera.

- $\quad$ Entre las marcas más consumidas están Proplan, Propac, Pedigree, Cambo, Dog Chow. También comentan que consumen Nutran, Hill's Taste of the Wild.

- $\quad$ Las marcas de mayor prestigio son las más caras, pues los clientes asocian el precio con la calidad.

- Los clientes no conocen mucho sobre la composición del alimento, no obstante, la confianza les surge de los veterinarios y el aparato publicitario transmitido por los medios de comunicación masiva. 
- Indican que su mascota llegó a casa como el fruto de un regalo y casi en similar proporción por rescate.

- Consideran a la mascota como un miembro más de la familia por que indican que los acompañan. Suelen hablarles cuando están solos con ellos.

- Hablan con tristeza en el momento de sus futuras partidas.

- Son considerados un miembro más de la casa y como tales tienen ciertos privilegios.

- Manifiestan que no intentan humanizar a la mascota pero que en algunos de los casos pudiera ocurrir.

- $\quad$ Se observa que las mascotas reciben mayores cuidados cuando la familia que las acoge siente la sensación del nido vacío.

- La comunicación con personas que tienen mascotas es muy sencilla pues son personas que demuestran una sensibilidad especial hacia los animales y las personas.

- Los amos son personas sofisticadas, con elevado nivel de estudios, de status e innovadores.

- Una mascota en casa tiene un rol muy especial. Motiva la distención y se vuelve un factor común de preocupación y ocupación, aunque la responsabilidad generalmente es asumida por personas que pasan de los 30 años.

- Las familias les prodigan a sus mascotas, cuidados relacionados a la alimentación, salud, aseo, paseo y en algunos casos diversión. Algunas familias -las que tienen canes pequeños- las llevan a todo lado, incluso a hacer compras.

- Los perros cruzados conocidos como chuscos o criollos tienen organismos más resistentes y son más sanos. Por el contrario, los perros de raza son más débiles, 
presentando problemas de piel, de riñones, de artrosis, de hígado, del corazón, entre otros males.

- $\quad$ Suelen invertir en promedio entre S/ 150 y S/ 350 al mes. El gasto oscila debido a que no todos los meses se visita al veterinario y se compra medicinas. Otro aspecto para resaltar tiene relación con el alimento, las vacunas, los antipulgas, pastillas para la desparasitación, entre otros factores. Sin embargo, los que más invierten en cuidados con productos de calidad son los que tienen perros pequeños.

- $\quad$ Refieren conocer comida seca, algo de comida húmeda y BARF, pero en poca cantidad.

- Algunos refieren que han cambiado varias veces de marca de alimento. Explican que este es el producto de los efectos nocivos en sus mascotas.

- Asocian la calidad del producto con el precio que pagan.

- Indican que la comida seca es muy práctica para comprarla, almacenarla y prepararla para el consumo de la mascota.

- Algunos les dan de comer a su mascota 2 o 3 veces al día, pero se preocupan de ser puntuales en el horario establecido. Invierten desde S/ 40 por semana en alimentos. Esto depende del tamaño de la mascota.

- No conocen de la composición de los alimentos, tan solo refieren que algunos son de elevado precio y que la salud de sus mascotas lo vale. Aunque varios han optado por dejar de consumir comida seca por reacciones adversas en su salud. 


\subsection{Investigación Cuantitativa}

\section{Objetivo de la investigación}

El objetivo principal de la investigación radica en conocer la opinión de los potenciales clientes con respecto a la propuesta de Animal Lovers.

Los objetivos secundarios se cifraron en cuantificar variables identificadas como relevantes en la investigación cualitativa, entre las cuales tenemos: el cuidado de la mascota, el factor de la alimentación y el alimento ideal referido por los hogares tenedores de mascotas.

\section{Área geográfica de realización del estudio}

El área geográfica del presente proyecto considera a los distritos de Miraflores, San Borja, San Isidro y Santiago de Surco. No obstante, a efectos de mostrar el método empleado se utilizará el distrito de San Borja.

San Borja -distrito seleccionado - tiene una extensión territorial de 9,96 km2 dividida en 12 sectores que aportan a la demografía. 


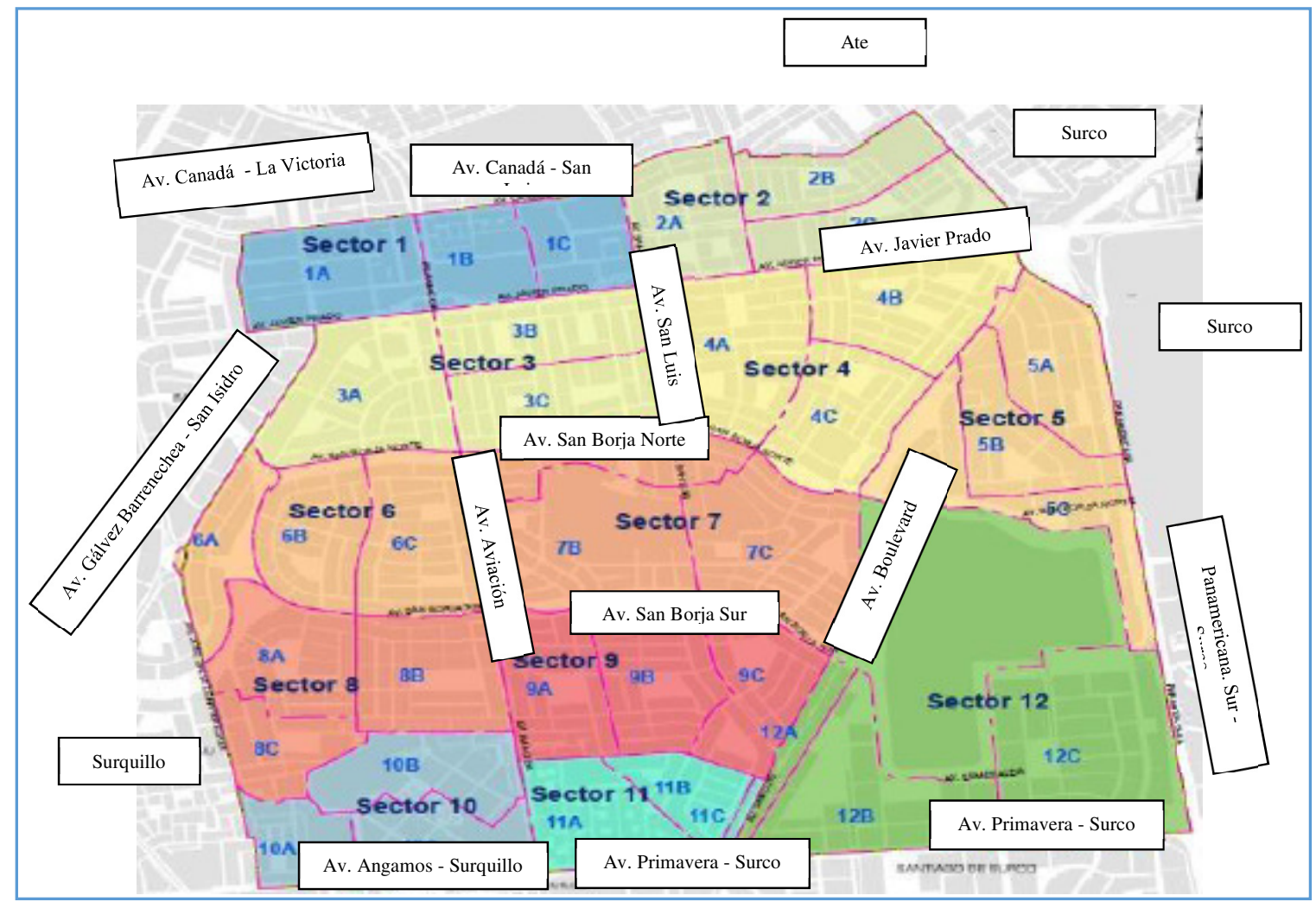

Figura 21. Adaptado de "Plan estratégico de gobierno electrónico 2018-2020" por Municipalidad distrital de San Borja, 2018. Recuperado de http://www.munisanborja.gob.pe/dmdocuments/PLAN_GOBIERNO_ELECTRONICO_SAN_BORJA.pdf

Se muestra la geografía del distrito de San Borja, dividida en sectores. Esta división realizada por la municipalidad responde a la necesidad de realizar acciones focalizadas de acuerdo con la situación de cada sector. 


\section{Población}

Para realizar el cálculo de la proyección de la población, se han empleado fuentes de información secundaria correspondiente a los estudios de CPI e INEI.

Tabla 23.- Población y hogares - San Borja

\begin{tabular}{cccc}
\hline Año & $\begin{array}{c}\text { Población } \\
\text { (miles) }\end{array}$ & $\begin{array}{c}\text { Hogares } \\
\text { (miles) }\end{array}$ & Número de personas por hogar \\
\hline 2010 & 113 & 33.7 & 3.4 \\
2011 & 111.4 & 31.5 & 3.5 \\
2012 & 111.5 & 32.1 & 3.5 \\
2013 & 111.7 & 33.5 & 3.3 \\
2014 & 111.8 & 34 & 3.3 \\
2015 & 111.9 & 27.5 & 4.1 \\
2016 & 114.4 & 37 & 3.1 \\
2017 & 116.7 & 37.8 & 3.1 \\
2018 & 119 & 38.5 & 3.1 \\
\hline
\end{tabular}

Nota: Elaboración propia.

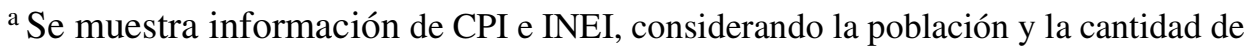
hogares 
Tabla 24.- Lima metropolitana: población y hogares según distritos (en miles) 2010 / 2018

\begin{tabular}{|c|c|c|c|c|c|c|c|}
\hline \multirow{2}{*}{$\mathbf{N}^{\circ}$} & \multirow{2}{*}{ DISTRITO } & \multicolumn{3}{|c|}{2010} & \multicolumn{3}{|c|}{2018} \\
\hline & & Población & $\%$ & Hogares & Población & $\%$ & Hogares \\
\hline 1 & $\begin{array}{l}\text { San Juan de } \\
\text { Lurigancho }\end{array}$ & 969.7 & 10.6 & 262.2 & 1137.0 & 11.1 & 279.7 \\
\hline 2 & San Martín de Porres & 625.7 & 6.8 & 147.8 & 733.5 & 7.1 & 177.9 \\
\hline 3 & Comas & 521.4 & 5.7 & 127.0 & 550.7 & 5.3 & 141.4 \\
\hline 4 & Ate & 516.4 & 5.6 & 156.4 & 655.8 & 6.3 & 160.8 \\
\hline 5 & Villa El Salvador & 411.4 & 4.5 & 98.1 & 482.0 & 4.7 & 117.3 \\
\hline 6 & $\begin{array}{l}\text { Villa María del } \\
\text { Triunfo }\end{array}$ & 408.7 & 4.5 & 106.6 & 467.8 & 4.5 & 116.5 \\
\hline 7 & San Juan de Miraflores & 389.6 & 4.3 & 98.1 & 422.2 & 4.1 & 109.0 \\
\hline 8 & Los Olivos & 343.4 & 3.7 & 101.0 & 388.7 & 3.8 & 109.0 \\
\hline 9 & Lima - (Cercado) & 321.6 & 3.5 & 87.8 & 287.8 & 2.8 & 94.1 \\
\hline 10 & Santiago de Surco & 311.3 & 3.4 & 92.7 & 364.0 & 3.5 & 109.8 \\
\hline 11 & Chorrillos & 310.8 & 3.4 & 82.5 & 340.7 & 3.3 & 90.7 \\
\hline 12 & Puente Piedra & 255.3 & 2.8 & 68.8 & 366.8 & 3.5 & 89.5 . \\
\hline 13 & Carabayllo & 231.9 & 2.5 & 65.3 & 314.4 & 3.0 & 76.3 \\
\hline 14 & Independencia & 222.2 & 2.4 & 62.9 & 227.0 & 2.2 & 68.9 \\
\hline 15 & La Victoria & 206.4 & 2.3 & 53.9 & 180.7 & 1.7 & 57.4 \\
\hline 16 & Santa Anita & 201.7 & 2.2 & 57.1 & 238.2 & 2.3 & 60.8 \\
\hline 17 & El agustino & 196.7 & 2.1 & 49.6 & 199.8 & 1.9 & 52.8 \\
\hline 18 & Rimac & 188.8 & 2.1 & 47.5 & 173.5 & 1.7 & 51.4 \\
\hline 19 & Lurigancho & 181.5 & 2.0 & 52.8 & 228.1 & 2.2 & 56.8 \\
\hline 20 & La molina & 143.0 & 1.6 & 42.0 & 181.3 & 1.7 & 48.9 \\
\hline 21 & San Miguel & 138.9 & 1.5 & 40.3 & 143.5 & 1.4 & 45.6 \\
\hline 22 & San Borja & 113.0 & 1.2 & 33.7 & 119.0 & 1.1 & 38.5 \\
\hline
\end{tabular}

Nota: Elaboración propia. Adaptado de "Market report" por Compañía peruana de estudios de mercados y opinión pública SAC (CPI), 2010; "Market report. Perú: población 2018” por Compañía peruana de estudios de mercados y opinión pública SAC (CPI), 2018. Recuperado de http://www.cpi.pe/images/upload/paginaweb/archivo/26/mr201007-01.pdf;

http://www.cpi.pe/images/upload/paginaweb/archivo/26/mr_poblacional_peru_201805.pdf.

${ }^{a}$ Para el año 2010 la población de San Borja registró 113,000 habitantes y 33,700 hogares. Para el año 2018 la poblaciòn de San Borja registró 119,000 habitantes con 38,500 hogares. El ratio es de 3 personas por cada hogar

Para el cálculo de la población proyectada del 2019 en adelante, se empleó la fórmula de la tasa intercensal que permitió proyectar la población y los hogares para los próximos años. Con la proyección de hogares de San Borja se calcula el universo. Nótese que el público objetivo elegido corresponde a los niveles socioeconómicos $\mathrm{ABC}$ en un $94.7 \%$. 
Tabla 25.- Distribución de NSE por zona APEIM 2018 - Lima metropolitana

\begin{tabular}{|l|c|c|c|c|c|c|c|c|}
\hline \multicolumn{1}{|c|}{ Z\%) HORIZONTALES } & TOTAL & NSE A & NSE B & NSE C & NSE D & NSE E & Muestra & Error (\%) \\
\hline Total & 100 & 4.7 & 23.2 & 41.3 & 24.4 & 6.4 & 4058 & 1.54 \\
\hline Zona 1 (Puente Piedra, Comas, Carabayllo) & 100 & 0.0 & 15.0 & 37.8 & 38.2 & 9.0 & 291 & 5.74 \\
\hline Zona 2 (Independencia, Los Olivos, San Martín de Porras) & 100 & 2.2 & 26.9 & 49.3 & 19.3 & 2.3 & 353 & 5.22 \\
\hline Zona 3 (San Juan de Lurigancho) & 100 & 1.1 & 17.4 & 43.2 & 28.9 & 9.5 & 276 & 5.9 \\
\hline Zona 4 (Cercado, Rímac, Breña, La Victoria) & 100 & 2.5 & 26.7 & 43.0 & 24.1 & 3.8 & 526 & 4.27 \\
\hline $\begin{array}{l}\text { Zona 5 (Ate, Chaclacayo, Lurigancho, Santa Anita, San Luis, } \\
\text { El Agustino) }\end{array}$ & 100 & 1.0 & 10.4 & 45.1 & 33.3 & 10.2 & 331 & 5.39 \\
\hline $\begin{array}{l}\text { Zona 6 (Jesús María, Lince, Pueblo Libre, Magdalena, San } \\
\text { Miguel) }\end{array}$ & 100 & 14.4 & 56.0 & 23.9 & 3.9 & 1.8 & 284 & 5.82 \\
\hline Zona 7 (Miraflores, San Isidro, San Borja, Surco, La Molina) & 100 & 34.6 & 46.4 & 13.7 & 4.2 & 1.1 & 338 & 5.33 \\
\hline $\begin{array}{l}\text { Zona 8 (Surquillo, Barranco, Chorrillos, San Juan de } \\
\text { Miraflores) }\end{array}$ & 100 & 2.0 & 28.8 & 47.4 & 18.1 & 3.7 & 289 & 5.76 \\
\hline $\begin{array}{l}\text { Zona 9 (Villa El Salvador, Villa María del Triunfo, Lurín, } \\
\text { Pachacamác) }\end{array}$ & 100 & 0.4 & 7.2 & 49.2 & 34.0 & 9.3 & 318 & 5.5 \\
\hline $\begin{array}{l}\text { Zona 10 (Callao, Bellavista, La Perla, La Punta, Carmen de } \\
\text { la Legua, Ventanilla,Mi Perú) }\end{array}$ & 100 & 1.3 & 18.7 & 45.7 & 24.6 & 9.8 & 1019 & 3.07 \\
\hline Otros & 100 & 0.0 & 8.8 & 42.6 & 32.8 & 15.7 & 33 & 17.06 \\
\hline
\end{tabular}

Nota: Tomado de "Niveles socioeconómicos 2018" por Asociación peruana de empresas de investigación de mercados (APEIM), 2018. Recuperado de http://www.apeim.com.pe/wp-content/themes/apeim/docs/nse/APEIM-NSE-2018.pdf

${ }^{a}$ La zona 7 que se compone de Miraflores, San Borja, San Isidro y Santiago de Surco, está compuesta en un $94.7 \%$ de los NSE ABC (34.6\%, 46.4\% y $13.7 \%$, respectivamente).

\section{Proceso de Muestreo}

- Muestreo: probabilístico aleatorio con estratificación proporcional por cuotas.

- $\quad$ Extensión: 9.6 km2

- NSE: $\quad \mathrm{ABC}$

\section{Cálculo de la muestra para el distrito de San Borja}

Para realizar el cálculo de la muestra de una población de tipo finita se ha utilizado

la fórmula correspondiente.

Fórmula:

$$
n=\frac{N Z^{2} P Q}{e^{2}(N-1)+Z^{2} P Q}
$$


Donde:

- $\quad$ Nivel de confianza (Z):

$95 \%(1.96)$

- $\quad$ Probabilidad de éxito $(\mathrm{P})$ :

$50 \%$

- $\quad$ Probabilidad de fracaso $(\mathrm{Q})$

$50 \%$

- $\quad$ Tamaño de la población $(\mathrm{N})$ :

38,500

- $\quad$ Margen de error (e):

$6.9 \%$

Reemplazando los valores:

$$
n=\frac{38500 \times 1.96^{2} \times 50 \% \times 50 \%}{0.069^{2} \times(38500-1)+1.96^{2} \times 50 \% \times 50 \%}
$$

Tamaño de la muestra en base a los hogares del año 2018:

$$
n=201 \text { encuestas a hogares }
$$

\section{Tamaño de la muestra}

- Número de hogares:

38,500

- Nivel socio económico ABC:

$94.7 \%$

- Número de hogares de NSE ABC:

36,460

- Tamaño de la muestra:

201 


\section{Distribución de la muestra por sectores}

Tabla 26.- Distribución de la muestra en los 12 sectores del distrito para la realización de las encuestas

\begin{tabular}{|c|c|c|c|c|c|c|c|}
\hline Sector & Hogares & $\begin{array}{c}\mathbf{N}^{\circ} \mathbf{d e} \\
\text { encuestas }\end{array}$ & $\begin{array}{c}\text { Sector } \\
(\boldsymbol{\%})\end{array}$ & Límite 1 & Límite 2 & Límite 3 & Límite 4 \\
\hline $1(\mathrm{~A})$ & 3457 & 20 & $10 \%$ & & Javier Prado & Aviación & Canadá \\
\hline $2(\mathrm{M})$ & 2420 & 14 & $7 \%$ & Circunvalación & Javier Prado & San Luis & Canadá \\
\hline $3(\mathrm{M})$ & 2765 & 16 & $8 \%$ & Del Aire & Javier Prado & San Luis & SB Norte \\
\hline $4(\mathrm{~A})$ & 3457 & 20 & $10 \%$ & Boulevard & Javier Prado & San Luis & SB Norte \\
\hline $5(\mathrm{M})$ & 2420 & 14 & $7 \%$ & Boulevard & $\begin{array}{c}\text { Panamericana } \\
\text { Sur }\end{array}$ & SB Norte \\
\hline $6(\mathrm{M})$ & 2420 & 14 & $7 \%$ & G. Barrenechea & Aviación & SB Sur & SB Norte \\
\hline $7(\mathrm{~A})$ & 3802 & 22 & $11 \%$ & Boulevard & Aviación & SB Sur & SB Norte \\
\hline $8(\mathrm{~A})$ & 3457 & 20 & $10 \%$ & G. Barrenechea & Aviación & SB Sur & Ordoñez \\
\hline $9(\mathrm{~A})$ & 3111 & 18 & $9 \%$ & San Luis & Aviación & SB Sur & La Madrid \\
\hline $10(\mathrm{~A})$ & 3457 & 20 & $10 \%$ & & Aviación & Angamos & Ordoñez \\
\hline $11(\mathrm{~B})$ & 1728 & 10 & $5 \%$ & La Madrid & Aviación & Primavera & \\
\hline $12(\mathrm{~B})$ & 2074 & 12 & $6 \%$ & San Luis & Boulevard & Primavera & \\
\hline & 34566 & 201 & $100 \%$ & & & & \\
\hline
\end{tabular}

Nota: Elaboración propia

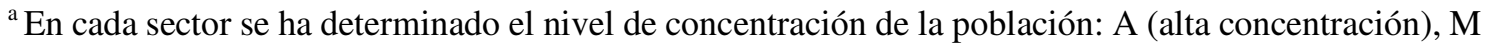
(media concentración) y B (baja concentración).

${ }^{\mathrm{b}}$ El porcentaje con que cada sector aporta a la demografía del distrito se ha establecido en base a un estudio realizado por la municipalidad del distrito, denominado Plan de Gobierno Electrónico San Borja $2018-2020$

\section{Cálculo de la muestra para el mercado del proyecto, que comprende Miraflores, San}

\section{Borja, San Isidro y Santiago de Surco}

En relación con el mercado del proyecto, hasta el momento se ha trabajado en función del distrito de San Borja a efectos de mostrar el método empleado. No obstante, dados los factores favorables como la alta concentración del NSE ABC de los distritos Miraflores, San Isidro y Santiago de Surco -además de San Borja- se hace necesario cuantificar la población de estos cuatro distritos para proceder con un cálculo efectivo del mercado real, incluyendo se reitera- los cuatro distritos. 
Tabla 27.- Datos históricos de cantidad de hogares 2010 - 2018

\begin{tabular}{cccccc}
\hline Hogares & Miraflores & San Borja & San Isidro & Surco & Total \\
\hline 2010 & 33.8 & 33.7 & 19.9 & 92.7 & 180.1 \\
2011 & 25.1 & 31.5 & 16.9 & 89 & 162.5 \\
2012 & 25.1 & 32.1 & 17.1 & 92.4 & 166.7 \\
2013 & 29 & 33.5 & 19.9 & 97.1 & 179.5 \\
2014 & 29.5 & 34 & 20.2 & 98.6 & 182.3 \\
2015 & 20.1 & 27.5 & 13.3 & 84.4 & 145.3 \\
2016 & 33 & 37 & 22.7 & 105.9 & 198.6 \\
2017 & 33.7 & 37.8 & 23.2 & 107.8 & 202.5 \\
2018 & 34.4 & 38.5 & 23.7 & 109.8 & 206.4 \\
\hline
\end{tabular}

Nota: Elaboración propia.

${ }^{a}$ Información obtenida de CPI e INEI

\section{Cálculo de la muestra}

Para realizar el cálculo de la muestra de la población de tipo infinita (población mayor a 100,000 habitantes) se ha utilizado la fórmula correspondiente.

Fórmula:

$$
n=\frac{Z^{2} \times P \times Q}{e^{2}}
$$

Donde:

- $\quad$ Nivel de confianza (Z): $\quad 95 \%(1.96)$

- $\quad$ Probabilidad de éxito $(\mathrm{P})$ : $\quad 50 \%$

- $\quad$ Probabilidad de fracaso (Q): $\quad 50 \%$

- $\quad$ Margen de error (e): $\quad 6.9 \%$

Reemplazando los valores:

$$
n=\frac{1.96^{2} \times 50 \% \times 50 \%}{6.9 \%^{2}}
$$


Tamaño de la muestra en base a los hogares del año 2018:

$$
n=202 \text { encuestas a hogares }
$$

Resultado obtenido:

- Número de hogares:

- Nivel socio económico ABC:

- Número de hogares de NSE ABC:

- $\quad$ Tamaño de la muestra:
206,400

$94.7 \%$

195,461

202

\subsubsection{Diseño del instrumento}

La recolección de la información se realizó mediante encuestas, las cuales se diseñaron a través de un cuestionario estructurado, con preguntas: filtro, abiertas, cerradas, de selección múltiple, entre otros. En esta parte del presente proyecto se darán a conocer los cuestionarios de preguntas empleadas en las encuestas. Dichos cuestionarios se ubican en los anexos del presente trabajo.

\subsubsection{Análisis y procesamiento de datos}

La data fue analizada para determinar la opinión del público encuestado, en base a sus preferencias de consumo con respecto al alimento canino, sus beneficios y sus cuestionamientos. Así como los elementos que constituyen la nueva propuesta de Animal Lovers. 
Tabla 28.- Mercado potencial. Pregunta 1. Hogares que residen en distritos seleccionados.

\begin{tabular}{ccc} 
Residencia & Hogares & Hogares (\%) \\
\hline Miraflores & 35 & $17 \%$ \\
\hline San Borja & 36 & $18 \%$ \\
\hline San Isidro & 23 & $12 \%$ \\
\hline Santiago de Surco & 102 & $50 \%$ \\
\hline Otro distrito & 4 & $2 \%$ \\
\hline Total & $\mathbf{2 0 2}$ & $\mathbf{1 0 0 \%}$ \\
\hline
\end{tabular}

Nota: Elaboración propia

${ }^{\text {a }}$ Pregunta filtro empleada para corroborar que el encuestado reside en uno de los distritos seleccionados para la realización del proyecto.

${ }^{\mathrm{b}} \mathrm{El}$ trabajo de campo indica que el $2 \%$ de los encuestados residían en otro distrito.

Tabla 29.- Mercado potencial. Pregunta 2. Hogares de nivel socioeconómico ABC

\begin{tabular}{ccc}
\hline Nivel socio económico & Hogares NSE ABC & Hogares NSE ABC (\%) \\
\hline A & 89 & $45 \%$ \\
\hline B & 69 & $35 \%$ \\
\hline C & 30 & $15 \%$ \\
\hline Otros & 10 & $5 \%$ \\
\hline Total & $\mathbf{1 9 8}$ & $\mathbf{1 0 0 \%}$ \\
\hline
\end{tabular}

Nota: Elaboración propia

${ }^{a}$ Pregunta para verificar que las personas encuestadas pertenecieran al nivel socioeconómico ABC.

${ }^{\mathrm{b}}$ La encuesta arrojó que el 5\% era del nivel socioeconómico DE, cifra que coincide con las estadísticas de APEIM 2018.

Tabla 30.- Mercado disponible. Pregunta 3. Hogares con mascotas caninas

\begin{tabular}{ccc} 
Tienen mascotas caninas & Hogares con canes & Hogares con canes (\%) \\
\hline $\mathrm{Si}$ & 133 & $71 \%$ \\
\hline No & 55 & $29 \%$ \\
\hline Total & $\mathbf{1 8 8}$ & $\mathbf{1 0 0 \%}$ \\
\hline
\end{tabular}

Nota: Elaboración propia

${ }^{a}$ Pregunta cuyo objetivo era conocer la cantidad de hogares que tenían por lo menos una mascota canina en el seno del hogar

${ }^{\mathrm{b}} \mathrm{El}$ resultado arrojó que el $71 \%$ de los hogares encuestados tiene por lo menos una mascota en el hogar 
Tabla 31.- Pregunta 4. Estilo de vida para identificar el perfil del hogar del entrevistado.

Estilo de vida

Les atrae productos innovadores, así como los nuevos medios de comunicación y compra. Se relacionan con las marcas. Se fijan en el contenido nutricional de los alimentos.

Buscan conveniencia costo-beneficio. Valoran mucho la economía. Están dispuestos a economizar y sacrificar beneficios secundarios. Compran productos de última tecnología de ofertas. Consumen productos tradicionales y modernos, pero no pagan más por la novedad.

El consumo es una actividad entretenida y divertida. Son mujeres a las que les gusta proyectar una buena imagen y cuidar su estética. Les interesa productos que ofrezcan reducir el tiempo y esfuerzo en las labores del hogar evitando hacerlas. Dan prioridad a los beneficios abstractos de los productos que compran. Usan marcas como símbolo de distinción social y calidad.

Son los segundos en adoptar las modas luego de los sofisticados. Prefieren lucir deportivos o casuales. Usan marcas conocidas y ropa de buena apariencia. Gustan de la tecnología. Son machistas en hábitos. No comparte labores del del hogar y no compra artículos de limpieza y alimentos.

Consideran el consumo como una actividad necesaria. Ven a las compras como una necesidad, no como un placer. Las marcas no son importantes. En los alimentos se fijan en la cantidad que reciben, pero también en el beneficio nutricional. Son ahorrativas.

El dinero es escaso. Economizar es importante para cumplir con la canasta básica familiar. Tienen escasa predisposición a comprar productos por la marca. Las compras y posesiones personales tienen un sentido más pragmático que sensorial.

\begin{tabular}{rrrr}
\hline Total & 188 & $100 \%$ \\
\hline
\end{tabular}

Nota: Elaboración propia

${ }^{a}$ Pregunta que indaga sobre la percepción del entrevistado a cerca de su familia.

${ }^{\mathrm{b}}$ Nótese que el mayor porcentaje lo tiene el estilo de vida que corresponde al sofisticado, aunque otros estilos de vida también participan en el NSE ABC.

Tabla 32.- Pregunta 5. El trato de la mascota en el hogar

\begin{tabular}{cc|c|} 
Trato & Hogares & Hogares (\%) \\
\hline Una simple mascota & 26 & $14 \%$ \\
\hline Un miembro de la familia & 162 & $86 \%$ \\
\hline Total & $\mathbf{1 8 8}$ & $\mathbf{1 0 0 \%}$ \\
\hline
\end{tabular}

Nota: Elaboración propia

${ }^{a}$ Pregunta muy relacionada a la humanización de las mascotas.

${ }^{\mathrm{b}} \mathrm{Se}$ observa un alto porcentaje (86\%). Este dato aporta para comprender la gran cantidad de servicios que se les brinda a las mascotas y el desarrollo de este mercado. 
Tabla 33.- Pregunta 6. Peso corporal de la mascota

\begin{tabular}{ccc} 
Peso & Mascotas & Mascotas $(\%)$ \\
$<=5$ & 45 & $24 \%$ \\
\hline$<=10$ & 60 & $32 \%$ \\
\hline$<=15$ & 32 & $17 \%$ \\
\hline$<=20$ & 24 & $13 \%$ \\
\hline$<=25$ & 15 & $8 \%$ \\
\hline$<=30$ & 8 & $4 \%$ \\
\hline$>30$ & 6 & $3 \%$ \\
\hline Total & $\mathbf{1 8 8}$ & $\mathbf{1 0 0 \%}$ \\
\hline
\end{tabular}

Nota: Elaboración propia

${ }^{a}$ El $73 \%$ de las mascotas tienen un peso mediano o menor. Esto permite entender que los hogares de Lima prefieren mascotas más pequeñas debido en gran parte a que el tipo de vivienda más solicitado es el departamento.

Tabla 34.- Pregunta 7. Tipo de comida que consume la mascota

\begin{tabular}{ccc} 
Tipo de comida & Mascotas & Mascotas (\%) \\
Comida balanceada & 83 & $44 \%$ \\
\hline Comida casera & 34 & $18 \%$ \\
\hline Ambas & 71 & $38 \%$ \\
\hline Precio & $\mathbf{1 8 8}$ & $\mathbf{1 0 0 \%}$ \\
\hline
\end{tabular}

Nota: Elaboración propia

${ }^{a}$ La comida seca balanceada tiene un $44 \%$ de clientes. Con más de 30 marcas en el mercado, se infiere que la penetración de este tipo de alimento llegó a su límite. Según opinión del Gerente de la Importadora MARS, es el momento de la comida húmeda.

Tabla 35.- Pregunta 8. Marcas de mayor recordación

\begin{tabular}{ccc}
\hline Marca & Hogares & Hogares (\%) \\
Cambo & 36 & $19 \%$ \\
\hline Proplan & 43 & $23 \%$ \\
\hline Hill's & 23 & $12 \%$ \\
\hline Brit & 19 & $10 \%$ \\
\hline Pedigree & 30 & $16 \%$ \\
\hline Nutram & 19 & $10 \%$ \\
\hline Otros & 19 & $10 \%$ \\
\hline Total & $\mathbf{1 8 8}$ & $\mathbf{1 0 0 \%}$
\end{tabular}

Nota: Elaboración propia 
Tabla 36.- Pregunta 9. Consumo diario de comida

\begin{tabular}{ccc} 
Consumo diario & Hogares & Hogares $(\%)$ \\
\hline$<=100$ gramos & 45 & $26 \%$ \\
\hline$<=200$ gramos & 66 & $35 \%$ \\
\hline$<=300$ gramos & 30 & $16 \%$ \\
\hline$<=400$ gramos & 23 & $12 \%$ \\
\hline$<=500$ gramos & 15 & $8 \%$ \\
\hline$>500$ gramos & 9 & $5 \%$ \\
\hline Total & $\mathbf{1 8 8}$ & $\mathbf{1 0 0 \%}$ \\
\hline
\end{tabular}

Nota: Elaboración propia

${ }^{a}$ El $77 \%$ consume una cantidad no mayor a 300 gramos por día. Si tomamos en consideración que el consumo diario es en promedio, un $2 \%$ del peso del can, se concluye que existe una alta concentración de canes cuyo peso corporal no excede de 15 kilogramos

Tabla 37.- Pregunta 10. Inversión mensual en alimentación

\begin{tabular}{ccc} 
Inversión & Hogares & Hogares (\%) \\
\hline$<=\mathrm{S} / 70$ & 53 & $28 \%$ \\
\hline$<=\mathrm{S} / 130$ & 60 & $32 \%$ \\
\hline$<=\mathrm{S} / 190$ & 43 & $23 \%$ \\
\hline$<=\mathrm{S} / 250$ & 19 & $10 \%$ \\
\hline$>\mathrm{S} / 310$ & 13 & $8 \%$ \\
\hline Total & $\mathbf{1 8 8}$ & $\mathbf{1 0 0 \%}$ \\
\hline
\end{tabular}

Nota: Elaboración propia

Tabla 38.- Mercado efectivo. Pregunta 11. Aspectos relevantes del alimento ideal

\begin{tabular}{ccc} 
Aspectos & Hogares & Hogares (\%) \\
\hline Alimento balanceado & 56 & $30 \%$ \\
\hline Bajo de preservantes & 34 & $18 \%$ \\
\hline Alimento cocido & 17 & $9 \%$ \\
\hline Alimento saludable & 53 & $28 \%$ \\
\hline Refrigerado & 9 & $5 \%$ \\
\hline Otros & 19 & $\mathbf{1 0 0 \%}$ \\
\hline Total & $\mathbf{1 8 8}$ &
\end{tabular}

Nota: Elaboración propia

${ }^{a}$ Pregunta previa que permite determinar el mercado efectivo. El objetivo radica en conocer cuáles son los elementos que valora el usuario en el alimento ideal para las mascotas caninas. 
Tabla 39.- Pregunta 12. Intención de compra del alimento ideal

\begin{tabular}{ccc} 
Respuesta & Hogares & Hogares (\%) \\
\hline Definitivamente no & 19 & $10 \%$ \\
\hline Probablemente no & 23 & $12 \%$ \\
\hline No estoy seguro & 28 & $15 \%$ \\
\hline Probablemente si & 38 & $20 \%$ \\
\hline Definitivamente si & 81 & $43 \%$ \\
\hline Total & $\mathbf{1 8 8}$ & $\mathbf{1 0 0 \%}$
\end{tabular}

Nota: Elaboración propia

${ }^{a}$ Permite calcular el mercado efectivo a partir de la intención de compra del producto considerado como ideal (ver pregunta anterior).

${ }^{\mathrm{b}}$ Nótese que el $63 \%$ tiene expectativas relacionadas al alimento ideal. Con 30 marcas de comida seca en el mercado, es lógico entender que existe una demanda insatisfecha.

Tabla 40.- Pregunta 13. Precio dispuesto a pagar por kilogramo

\begin{tabular}{|c|c|c|}
\hline Respuesta & Hogares & Hogares (\%) \\
\hline$>=\mathrm{S} / 30$ & 18 & $15 \%$ \\
\hline$>=\mathrm{S} / 25$ & 52 & $44 \%$ \\
\hline$>=\mathrm{S} / 20$ & 40 & $34 \%$ \\
\hline$>=S / 15$ & 6 & $5 \%$ \\
\hline$>=\mathrm{S} / 10$ & 2 & $2 \%$ \\
\hline Total & 119 & $100 \%$ \\
\hline
\end{tabular}

Nota: Elaboración propia

${ }^{\text {a }}$ El $73 \%$ está dispuesto a pagar un precio mayor-igual a 20 soles por kilogramo de producto. ${ }^{\mathrm{b}}$ Esto demuestra la poca sensibilidad al precio basada en dos factores: a) Las mascotas pequeñas tienen un consumo muy bajo, lo que reduce el costo del alimento para el hogar; b) El poder adquisitivo permite brindar un alimento que relacione directamente precio y calidad.

Tabla 41.- Pregunta 14. Forma de solicitar el producto

\begin{tabular}{ccc} 
Tipo de acceso & Hogares & Hogares (\%) \\
\hline Celular & 45 & $38 \%$ \\
\hline Redes sociales & 31 & $26 \%$ \\
\hline Tiendas de mascotas & 14 & $12 \%$ \\
\hline Veterinarias & 6 & $5 \%$ \\
\hline Supermercados & 10 & $8 \%$ \\
\hline Otros & 13 & $11 \%$ \\
\hline Total & $\mathbf{1 1 9}$ & $\mathbf{1 0 0 \%}$
\end{tabular}

Nota: Elaboración propia

${ }^{a}$ El 64\% de los hogares prefiere pedir el producto a través de un medio de comunicación masiva, considerando además que esto no reviste un costo adicional. Así mismo, refieren que sería de gran ayuda que la empresa los llamara cuando calcule que se les está por acabar el producto. 
Tabla 42.- Pregunta 15. Forma de solicitar el producto

\begin{tabular}{ccc}
\hline Medio & Hogares & Hogares (\%) \\
\hline Instagram & 39 & $33 \%$ \\
\hline Facebook & 45 & $38 \%$ \\
\hline Twitter & 7 & $6 \%$ \\
\hline LinkedIn & 10 & $8 \%$ \\
\hline Correo electrónico & 18 & $15 \%$ \\
\hline Total & $\mathbf{1 1 9}$ & $\mathbf{1 0 0 \%}$ \\
\hline
\end{tabular}

Nota: Elaboración propia

${ }^{a} \mathrm{El} 71 \%$ de las personas indica que hace uso frecuente de las redes sociales. Las emplean para comunicarse, buscar información, consultar, comprar, vender, etc.

Tabla 43.- Pregunta 16. Frecuencia de compra al mes

\begin{tabular}{ccc}
$\mathrm{N}^{\circ}$ de veces al mes & Hogares & Hogares (\%) \\
\hline 1 & 10 & $8 \%$ \\
\hline 2 & 13 & $11 \%$ \\
\hline 3 & 31 & $26 \%$ \\
\hline 4 & 65 & $55 \%$ \\
\hline Total & $\mathbf{1 1 9}$ & $\mathbf{1 0 0 \%}$ \\
\hline
\end{tabular}

Nota: Elaboración propia

\subsection{Conclusiones y recomendaciones del Estudio Cuantitativo}

El NSE ABC tiene las siguientes características:

- $\quad$ Consumen mayoritariamente comida seca (95\%).

- $\quad$ Prefieren marcas como Nutran, Eukanuba y Hill's (62\%).

- $\quad$ La característica más valorada del alimento: previene enfermedades (47\%).

- Los elementos negativos más significativos son: comida procesada (77\%) presencia de preservantes y químicos (45\%), no se pueden distinguir los insumos (38\%) e insumos inadecuados $(25 \%)$.

- $\quad$ El 80\% compra para perros pequeños en formatos que inician en 100 gramos.

- $\quad$ Compran una o más veces por mes. (81\%).

- $\quad$ Los lugares preferidos de compra son: Pets Shops (57\%). 


\subsection{Perfil del consumidor tipo y sus variantes}

A continuación, se procede a detallar el perfil ideal de nuestro mercado objetivo según características identificadas (Arellano Marketing; 2017).

\section{¿Cómo son?}

Son cosmopolitas. Buscan constantemente la diferenciación. Se basan en su éxito personal. Tienen muy arraigado el estatus.

¿Cómo pasan el tiempo?

Se relajan divirtiéndose y adquiriendo valor informándose en periódicos, revistas y demás medios digitales. Disfrutan el shopping y de los fines de semana. Exhiben moda para sentirse atractivos.

¿Cómo son en el trabajo?

Aspiracionales a tener cargos con niveles de decisión relevantes. Consideran los estudios como necesarios para alcanzar sus metas.

¿Qué les interesa?

Altas expectativas por viajar al exterior y retornar para emprender. El dinero no garantiza la felicidad, pero si el éxito. Grandes aspiraciones para sus hijos. Adquieren constantemente símbolos de estatus. 
¿Qué compran?

Compran modernidad. Productos innovadores y multicanalidad para comprar. Se relacionan con las marcas intensamente. Prestan atención al arreglo y vestir como eje de su imagen personal. Se fijan en el contenido nutricional de los alimentos.

¿Qué expectativas tienen?

A mediano plazo culminar sus estudios, suficiencia económica, los jóvenes trabajar en una empresa importante. Los de mayor edad, independencia laboral. Adquirir activos, vivir en zona agradable y auto de marca diferenciada.

A largo plazo elevar su nivel cultural (postgrado) y ubicarse en el segmento de privilegio. Negocio propio y viajar al extranjero. Sofisticación de su imagen.

El perfil del consumidor es una persona que además de pertenecer al nivel socioeconómico $\mathrm{ABC}$, tiene sensibilidad por los animales y gusta disfrutar de su compañía. Compra comida para su mascota, en representación de su familia. 


\section{CAPÍTULO IV \\ PROYECCIÓN DEL MERCADO OBJETIVO}

\subsection{El ámbito de la proyección}

El mercado ofrece actualmente: Comida seca, alimentos crudos triturados (BARF por sus siglas en inglés), comida preparada por ciertas veterinarias especializadas en nutrición y la comida de casa. En este contexto, el único alimento que tiene el respaldo profesional de los veterinarios es la comida seca. Sin embargo, aun teniendo el mercado dominado por la comida seca, la comida balanceada tiene un $37.4 \%$ de consumidores y un $53.9 \%$ consume algo de comida seca, pero combina también, otras comidas en su alimentación (CPI; 2018).

Animal Lovers, identifica un segmento con características a destacar con respecto a las mascotas caninas: aspecto demográfico (NSE ABC), geográfico (residen en Miraflores, San Borja, San Isidro, Santiago de Surco), psicográfico (sofisticados que tienen mascotas y las consideran miembros de sus familias) y conductual (pagan por veterinarios, medicinas, alimentación, higiene, paseos, entre otros).

A continuación, se aprecian las características de los niveles socioeconómicos ABC.

Tabla 44.- Marco muestral - Características por Nivel Socio Económico

\begin{tabular}{lccc}
\hline \multicolumn{1}{c}{ Concepto } & NSE A & NSE B & NSE C \\
\hline Casa independiente & $45 \%$ & $59 \%$ & $78 \%$ \\
Departamento en edificio & $53 \%$ & $39 \%$ & $18 \%$ \\
Propia, totalmente pagada & $70 \%$ & $65 \%$ & $58 \%$ \\
Tiene TV cable & $95 \%$ & $84 \%$ & $63 \%$ \\
Tiene internet & $96 \%$ & $79 \%$ & $47 \%$ \\
Servicio domestico & $73 \%$ & $15 \%$ & $1 \%$ \\
Auto propio & $88 \%$ & $40 \%$ & $9 \%$ \\
Promedio general de ingreso familiar & $\mathrm{S} / 10,800$ & $\mathrm{~S} / 5,600$ & $\mathrm{~S} / 3,400$ \\
Promedio general de gasto familiar & $\mathrm{S} / 7,300$ & $\mathrm{~S} / 4,200$ & $\mathrm{~S} / 2,800$ \\
\hline
\end{tabular}

Nota: Adaptado de "Niveles socioeconómicos 2018" por Asociación peruana de empresas e investigación de mercados (APEIM), 2018. Recuperado de http://www.apeim.com.pe/wpcontent/themes/apeim/docs/nse/APEIM-NSE-2018.pdf 
Para los distritos de Miraflores, San Borja, San Isidro y Santiago de Surco, se ha aplicado una tasa intercensal anual, debido a que la data histórica de estos distritos no cumple los requerimientos mínimos para efectuar una regresión lineal.

A continuación, se muestran los datos demográficos de los distritos de Miraflores, San Borja, San Isidro y Santiago de Surco.

Tabla 45.- Datos históricos de hogares 2010-2018 expresado en miles

\begin{tabular}{cccccc}
\hline Hogares & Miraflores & San Borja & San Isidro & Surco & Total \\
\hline 2010 & 33.8 & 33.7 & 19.9 & 92.7 & 180.1 \\
\hline 2011 & 25.1 & 31.5 & 16.9 & 89 & 162.5 \\
\hline 2012 & 25.1 & 32.1 & 17.1 & 92.4 & 166.7 \\
\hline 2013 & 29 & 33.5 & 19.9 & 97.1 & 179.5 \\
\hline 2014 & 29.5 & 34 & 20.2 & 98.6 & 182.3 \\
\hline 2015 & 20.1 & 27.5 & 13.3 & 84.4 & 145.3 \\
\hline 2016 & 33 & 37 & 22.7 & 105.9 & 198.6 \\
\hline 2017 & 33.7 & 37.8 & 23.2 & 107.8 & 202.5 \\
\hline 2018 & 34.4 & 38.5 & 23.7 & 109.8 & 206.4 \\
\hline
\end{tabular}

Nota: Elaboración propia

${ }^{a}$ El porcentaje de variación año a año es de $0.2 \%, 1.5 \%, 2 \%$ y $1.9 \%$ para los distritos de Miraflores, San Borja, San Isidro y Santiago de Surco, respectivamente

A continuación, se muestra la proyección de hogares basados en las tasas de crecimiento identificados en los datos históricos.

Tabla 46.- Datos proyectados de hogares 2019 a 2023 expresado en miles

\begin{tabular}{cccccc}
\hline Tasa & $0.2 \%$ & $1.5 \%$ & $2.0 \%$ & $1.9 \%$ & \multirow{2}{*}{ Total } \\
\cline { 1 - 5 } Hogares & Miraflores & San Borja & San Isidro & Surco & \\
\hline 2018 & 34.4 & 38.5 & 23.7 & 109.8 & 206.4 \\
\hline 2019 & 34.5 & 39.1 & 24.2 & 111.9 & 209.6 \\
\hline 2020 & 34.5 & 39.7 & 24.6 & 114.0 & 212.8 \\
\hline 2021 & 34.6 & 40.2 & 25.1 & 116.2 & 216.1 \\
\hline 2022 & 34.7 & 40.8 & 25.6 & 118.4 & 219.5 \\
\hline 2023 & 34.7 & 41.5 & 26.1 & 120.6 & 222.9 \\
\hline
\end{tabular}

Nota: Elaboración propia 


\subsection{Selección de método de proyección}

El método de proyección empleado corresponde a la tasa de crecimiento, la cual para el presente caso es la tasa intercensal.

\subsubsection{Mercado Potencial}

El mercado potencial está representado por toda aquella familia de nivel socioeconómico ABC, que reside en el distrito indicado (Miraflores, San Borja, San Isidro, Santiago de Surco).

\begin{tabular}{|l|}
\hline Mercado Potencial $=$ Hogares $(\mathrm{MIR}+\mathrm{SBJ}+$ SIS+SUR $)$ X NSE ABC \\
\hline Mercado Potencial $=206,400$ X $94.7 \%$ \\
\hline Mercado Potencial $=195,461$ \\
\hline
\end{tabular}

Tabla 47.- Mercado potencial expresado en miles

\begin{tabular}{ccccccc}
\hline & $46.40 \%$ & $34.60 \%$ & $13.70 \%$ & $94.70 \%$ & \\
\hline Año & NSE A & NSE B & NSE C & NSE ABC & UNIVERSO \\
\hline 2018 & 95.8 & 71.4 & 28.3 & 195.5 & 206.4 \\
\hline 2019 & 97.3 & 72.5 & 28.7 & 198.5 & 209.6 \\
\hline 2020 & 98.7 & 73.6 & 29.2 & 201.5 & 212.8 \\
\hline 2021 & 100.3 & 74.8 & 29.6 & 204.6 & 216.1 \\
\hline 2022 & 101.8 & 75.9 & 30.1 & 207.9 & 219.5 \\
\hline 2023 & 103.4 & 77.1 & 30.5 & 211.1 & 222.9
\end{tabular}

Nota: Elaboración propia

\subsubsection{Mercado Disponible}

El mercado disponible se calcula en base al mercado potencial. Este segmento es aquel que tiene en el hogar, un can como mascota y además requiere de productos y servicios pues la consideran como un miembro más de la familia. 


\begin{tabular}{|l|}
\hline Mercado Disponible $=$ Mercado Potencial X Tenencia de canes \\
\hline Mercado Disponible $=195,461 \times 71 \%$ \\
\hline Mercado Disponible $=138,777$ \\
\hline
\end{tabular}

Tabla 48.- Mercado disponible expresado en miles

\begin{tabular}{ccccc}
\hline & $46.40 \%$ & $34.60 \%$ & $13.70 \%$ & $71 \%$ \\
\hline Año & NSE A & NSE B & NSE C & $\begin{array}{c}\text { TENENCIA DE } \\
\text { CANES }\end{array}$ \\
\hline 2018 & 64.4 & 48.0 & 19.0 & 138.8 \\
\hline 2019 & 65.4 & 48.8 & 19.3 & 140.9 \\
\hline 2020 & 66.4 & 49.5 & 19.6 & 143.1 \\
\hline 2021 & 67.4 & 50.3 & 19.9 & 145.3 \\
\hline 2022 & 68.5 & 51.1 & 20.2 & 147.6 \\
\hline 2023 & 69.5 & 51.9 & 20.5 & 149.9 \\
\hline
\end{tabular}

Nota: Elaboración propia

\subsubsection{Mercado Efectivo}

El mercado efectivo toma en cuenta a aquel mercado disponible cuyo interés por nuestro producto impulsa su intención de compra.

\begin{tabular}{|l|}
\hline Mercado Efectivo $=$ Mercado Disponible X Intención de Compra \\
\hline Mercado Efectivo $=138,777$ X 63\% \\
\hline Mercado Efectivo $=87,429$ \\
\hline
\end{tabular}

Tabla 49.- Mercado efectivo expresado en miles

\begin{tabular}{ccccc}
\hline & $46.40 \%$ & $34.60 \%$ & $13.70 \%$ & $63 \%$ \\
\hline Año & NSE A & NSE B & NSE C & $\begin{array}{c}\text { INTENCIÓN DE } \\
\text { COMPRA }\end{array}$ \\
\hline 2018 & 40.6 & 30.3 & 12.0 & 87.4 \\
\hline 2019 & 41.2 & 30.7 & 12.2 & 88.8 \\
\hline 2020 & 41.8 & 31.2 & 12.3 & 90.1 \\
\hline 2021 & 42.5 & 31.7 & 12.5 & 91.5 \\
\hline 2022 & 43.1 & 32.2 & 12.7 & 93.0 \\
\hline 2023 & 43.8 & 32.7 & 12.9 & 94.4 \\
\hline
\end{tabular}

Nota: Elaboración propia 


\subsubsection{Mercado Objetivo}

El mercado objetivo es aquel grupo de hogares obtenido como resultado del cálculo realizado sobre el mercado potencial (segmentación), mercado disponible (tenencia de canes) y mercado efectivo (intención de compra), para finalmente dar paso al mercado final del proyecto (mercado objetivo). Dicho mercado objetivo, responde a la cantidad de hogares que se convertirán en clientes, siendo por consiguiente ésta, la participación de mercado calculada.

\begin{tabular}{|l|}
\hline Mercado Objetivo $=$ Mercado Efectivo X Porcentaje de participación \\
\hline Mercado Objetivo $=87,429$ X $2 \%$ \\
\hline Mercado Objetivo $=1,749$ \\
\hline
\end{tabular}

Tabla 50.- Mercado objetivo expresado en miles

\begin{tabular}{ccccccc}
\hline & $46.40 \%$ & $34.60 \%$ & $13.70 \%$ & $2 \%$ & \\
\hline \multirow{2}{*}{ Año } & NSE A & NSE B & NSE C & CLIENTES & CRECIMIENTO \\
\hline 2018 & 0.81 & 0.60 & 0.24 & 1.75 & \\
\hline 2019 & 0.82 & 0.61 & 0.24 & 1.78 & $1.1 \%$ \\
\hline 2020 & 0.84 & 0.62 & 0.25 & 1.80 & $1.7 \%$ \\
\hline 2021 & 0.85 & 0.63 & 0.25 & 1.83 & $1.6 \%$ \\
\hline 2022 & 0.86 & 0.64 & 0.25 & 1.86 & $1.6 \%$ \\
\hline 2023 & 0.88 & 0.65 & 0.26 & 1.89 & $1.7 \%$ \\
\hline
\end{tabular}

Nota: Elaboración propia

La presente tabla resume los resultados calculados desde el mercado potencial hasta el mercado objetivo. 
Tabla 51.- Cuadro resumen del Mercado objetivo expresado en miles de hogares

\begin{tabular}{ccccccccc}
\hline Fuente & Mercado & Factor & $\%$ & Miraflores & $\begin{array}{c}\text { San } \\
\text { Borja }\end{array}$ & $\begin{array}{c}\text { San } \\
\text { Isidro }\end{array}$ & Surco & Total \\
\hline $\begin{array}{c}\text { CPI - } \\
\text { INEI }\end{array}$ & Total & Universo & $100 \%$ & 34.4 & 38.5 & 23.7 & 109.8 & 206.4 \\
APEIM & Potencial & NSE ABC & $94.7 \%$ & 32.6 & 36.5 & 22.4 & 104.0 & 195.5 \\
Encuestas & Disponible & $\begin{array}{c}\text { Tenencia de } \\
\text { canes }\end{array}$ & $71.0 \%$ & 23.1 & 25.9 & 15.9 & 73.8 & 138.8 \\
Encuestas & Efectivo & $\begin{array}{c}\text { Intención de } \\
\text { compra }\end{array}$ & $63.0 \%$ & 15 & 16 & 10 & 47 & 87.4 \\
Autor & Objetivo & $\begin{array}{c}\text { Porción del } \\
\text { mercado }\end{array}$ & $2 \%$ & 0.30 & 0.32 & 0.20 & 0.94 & 1.76 \\
\hline
\end{tabular}

Nota: Elaboración propia 


\section{CAPÍtULO V}

\section{PLAN DE MARKETING}

El Plan de Marketing para Animal Lovers, está basado en seleccionar a los clientes que se atenderán y la propuesta de valor que se les ofrecerá (Kotler \& Armstrong, 2012).

Con respecto a los clientes, se ha tomado en cuenta la segmentación y el mercado meta. Con respecto a la propuesta de valor, se ha considerado la diferenciación y el posicionamiento.

En relación con la segmentación se consideran a los distritos de Miraflores, San Borja, San Isidro y Santiago de Surco (segmentación geográfica), a las familias de NSE ABC (demográfica), cuyo estilo de vida considera un trato especial a la mascota (psicográfica) y efectúa habitualmente la compra de una serie de productos para su can (conductual).

En relación con el mercado meta, se ha establecido una estrategia de cobertura de mercado diferenciada en la cual, Animal Lovers, se dirige a hogares con las siguientes características:

- $\quad$ Tienen canes que requieren de alimentación balanceada y saludable.

- $\quad$ Tienen canes que están sanos y desean mantener una buena salud.

En relación con la diferenciación, la estrategia se basa en un sencillo proceso de compra semanal, el pago a través del celular (aplicación) y el reparto a domicilio.

En relación con el posicionamiento, la estrategia comunica un producto elaborado con insumos naturales, cocidos parcialmente, procesados artesanalmente y por ello con una duración máxima de dos meses congelado (preservantes al mínimo). 
Tabla 52.- Bases para la segmentación

\begin{tabular}{ccc}
\hline $\mathrm{N}^{\circ}$ & Segmentación & \multicolumn{1}{c}{ Target } \\
\hline $\mathbf{1}$ & Geográfica & Residen en Miraflores, San Borja. San Isidro, Santiago de Surco \\
\hline $\mathbf{2}$ & Demográfica & Familias de nivel socioeconómico ABC \\
\hline $\mathbf{3}$ & Psicográfica & $\begin{array}{l}\text { Estilo de vida con hábito en la tenencia y trato especial hacia las } \\
\text { mascotas }\end{array}$ \\
\hline $\mathbf{4}$ & Conductual & Clientes frecuentes de productos para mascotas \\
\hline
\end{tabular}

Nota: Elaboración propia.

\section{Con respecto a la marca}

La marca es aquel nombre, término, signo, símbolo o diseño que nos permiten identificar bienes y/o servicios, de forma tal que a su vez hagan posible diferenciarlos del resto de productos, vale decir, de la competencia. Identifican al fabricante y lo hacen responsable de las consecuencias de su uso, por consiguiente, genera mayor respaldo y confianza para quienes se deciden por una marca en particular. En consecuencia, no olvidemos que los productos se generan en los centros de producción, pero las marcas se trabajan en la mente de las personas, pues ellas reflejan las interpretaciones y percepciones de los consumidores.

El branding permite gestionar dichos conocimientos y percepciones, con la finalidad de generar estructuras mentales sólidas afines a nuestra marca para influir adecuadamente en el proceso de toma de decisiones de compra y generación de beneficios para la empresa. Por ello es fundamental que se realice un valor añadido que se refleje en el comportamiento del consumidor, con respecto a nuestra marca (alto valor psicológico y financiero). Es así, que el poder de la marca, habita en todo aquel vehículo de información, comunicación, acción, etc. que impacta en el consumidor real o potencial y en las experiencias de tipo directo o indirecto para con la marca (Brand equity). 


\section{Con respecto al posicionamiento}

Se requieren cuatro pasos (Kotler \& Armstrong, 2012):

a) Selección de elementos diferenciados que impulsan ventajas competitivas.

b) Selección de la estrategia general.

c) Elaboración del posicionamiento.

d) Declaración final del posicionamiento.

\section{a) Selección de elementos diferenciados que generan ventajas competitivas}

Las empresas buscan elementos diferenciadores en sus productos, pues estas les generan ventajas competitivas, pero solo algunas de ellas les proporcionarán el posicionamiento deseado.

Tabla 53.- Elementos de diferenciación que generan ventajas competitivas para el posicionamiento

\begin{tabular}{|c|c|c|c|c|c|c|}
\hline \multicolumn{5}{|c|}{ DIFERENCIACIÓN } & \multicolumn{2}{|c|}{ VENTAJA COMPETITIVA } \\
\hline $\mathrm{N}^{\circ}$ & Elementos & Bases & Sustento & Tipo & $\begin{array}{l}\text { ¿Genera } \\
\text { ventajas } \\
\text { competiti } \\
\text { vas? } \\
\end{array}$ & $\begin{array}{c}\text { ¿Son ventajas } \\
\text { competitivas que } \\
\text { aportan al } \\
\text { posicionamiento? }\end{array}$ \\
\hline 1 & $\begin{array}{c}\text { Alimento } \\
\text { balanceado }\end{array}$ & Fórmula & $\begin{array}{l}\text { Nutricionista } \\
\text { canino }\end{array}$ & Importante & No & ----- \\
\hline 2 & No procesada & $\begin{array}{l}\text { Producción } \\
\text { artesanal }\end{array}$ & $\begin{array}{c}\text { Buenas } \\
\text { prácticas de } \\
\text { manufactura }\end{array}$ & Superior & Sí & Sí \\
\hline 3 & $\begin{array}{c}\text { Insumos de } \\
\text { calidad }\end{array}$ & Evidencia & Insumo natural & Comunicable & Sí & Sí \\
\hline 4 & $\begin{array}{l}\text { Preservantes } \\
\text { (mínimo) }\end{array}$ & $\begin{array}{l}\text { Conservación } \\
\text { de la salud }\end{array}$ & $\begin{array}{c}\text { Menor riesgo a } \\
\text { contraer } \\
\text { enfermedades }\end{array}$ & Exclusiva & Sí & Sí \\
\hline 5 & Digestibilidad & $\begin{array}{l}\text { Alimento } \\
\text { cocido }\end{array}$ & $\begin{array}{c}\text { Protege la } \\
\text { digestión del } \\
\text { can }\end{array}$ & Distintiva & No & No \\
\hline 6 & $\begin{array}{c}\text { Requiere } \\
\text { congelamiento } \\
\end{array}$ & Conservación & $\begin{array}{l}\text { Evitar presencia } \\
\text { de bacterias }\end{array}$ & Costeable & No & No \\
\hline 7 & $\begin{array}{c}\text { Biodisponibilida } \\
\mathrm{d}\end{array}$ & $\begin{array}{l}\text { Control en la } \\
\text { cocción del } \\
\text { alimento }\end{array}$ & $\begin{array}{l}\text { Pruebas en } \\
\text { producción }\end{array}$ & Superior & No & No \\
\hline 8 & Confianza & $\begin{array}{l}\text { Satisfacción } \\
\text { psicológica }\end{array}$ & $\begin{array}{l}\text { Encuesta a } \\
\text { dueños de canes }\end{array}$ & Comunicable & $\mathrm{Si}$ & $\mathrm{Si}$ \\
\hline 9 & $\begin{array}{c}\text { Comunicación e } \\
\text { imagen }\end{array}$ & $\begin{array}{l}\text { Propuesta de } \\
\text { valor }\end{array}$ & $\begin{array}{l}\text { Difusión por } \\
\text { redes }\end{array}$ & Comunicable & $\mathrm{Si}$ & No \\
\hline
\end{tabular}

Nota: Elaboración propia 
La ventaja competitiva que aporta al posicionamiento se expresa a continuación.

Tabla 54.- Elementos de diferenciación que aportan al posicionamiento

\begin{tabular}{|c|c|c|c|c|c|c|}
\hline \multicolumn{5}{|c|}{ DIFERENCIACIÓN } & \multicolumn{2}{|c|}{ VENTAJA COMPETITIVA } \\
\hline $\mathbf{N}^{\circ}$ & Elemento & Base & Sustento & Tipo & $\begin{array}{c}\text { ¿Genera } \\
\text { ventajas } \\
\text { competitivas? }\end{array}$ & $\begin{array}{c}\text { ¿Son ventajas } \\
\text { competitivas que } \\
\text { aportan al } \\
\text { posicionamiento? }\end{array}$ \\
\hline 2 & $\begin{array}{c}\text { No } \\
\text { procesada }\end{array}$ & $\begin{array}{c}\text { Producción } \\
\text { artesanal }\end{array}$ & $\begin{array}{l}\text { Buenas prácticas } \\
\text { de manufactura }\end{array}$ & Superior & Sí & Sí \\
\hline 3 & $\begin{array}{l}\text { Insumos de } \\
\text { calidad }\end{array}$ & Evidencia & Insumos naturales & Comunicable & Sí & Sí \\
\hline 4 & $\begin{array}{c}\text { Preservant } \\
\text { es } \\
\text { (mínimo) }\end{array}$ & $\begin{array}{l}\text { Conservació } \\
\mathrm{n} \text { de la salud }\end{array}$ & $\begin{array}{c}\text { Menor riesgo a } \\
\text { contraer } \\
\text { enfermedades }\end{array}$ & Exclusiva & Sí & Sí \\
\hline 8 & Confianza & $\begin{array}{l}\text { Satisfacción } \\
\text { psicológica }\end{array}$ & $\begin{array}{c}\text { Encuesta a } \\
\text { familias con canes }\end{array}$ & Comunicable & Sí & Sí \\
\hline
\end{tabular}

Nota: Elaboración propia

\section{b) Selección de la estrategia general de posicionamiento}

\section{La estrategia de Animal Lovers es: "más por lo mismo".}

- Más, porque ofrece un producto de producción artesanal, con insumos naturales, alimentos cocidos, con un mínimo de preservantes.

- $\quad$ Por lo mismo, porque tiene un precio más competitivo que la competencia.

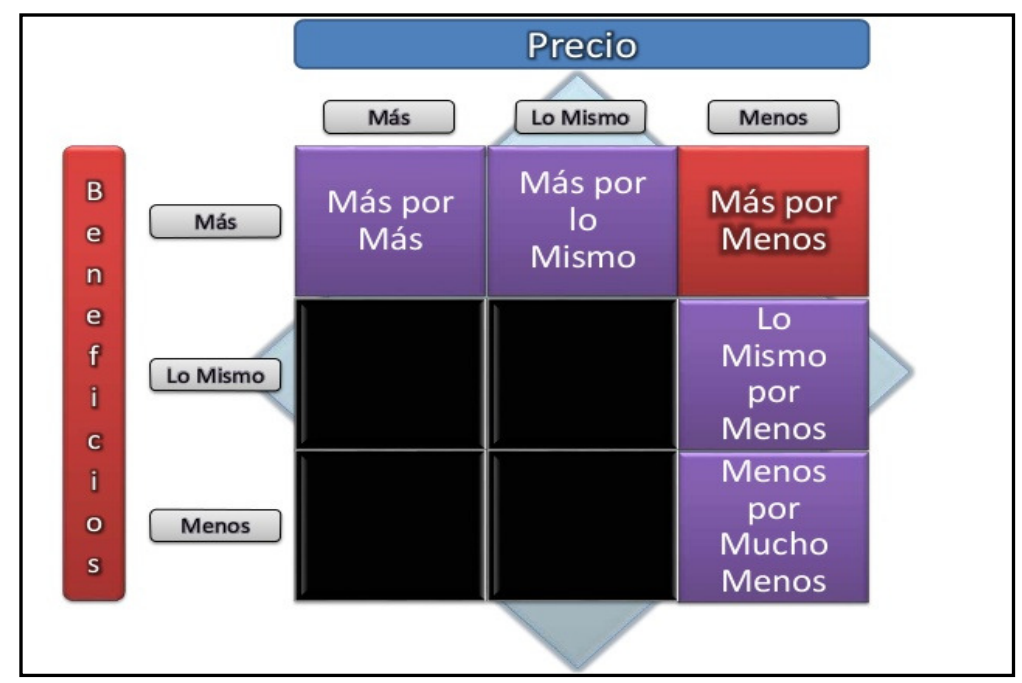

Figura 22. Estrategia general de posicionamiento

Tomado de "Matriz de propuesta de valor" por Bosarreyes (2015). Recuperado de https://es.slideshare.net/lervybosarreyes/matriz-de-propuesta-de-valor 


\section{c) Elaboración de la declaración de posicionamiento}

Estructurada en base a la calidad de vida que se le prodiga a la mascota, puesto de manifiesto gracias a la preocupación en su bienestar.

\section{d) Declaración final del posicionamiento:}

Animal Lovers... ¡Tiernamente saludable!

\subsection{Estrategias de marketing}

La estrategia de marketing se basa en los siguientes argumentos:

Animal Lovers, brinda un producto que dura dos (2) meses, en contraposición a la comida seca que dura un año y el BARF que dura seis (6) meses.

La comida seca se elabora a base de harinas de pollo, cordero, pescado, y si es de baja

calidad, puede componerse de la carcasa del esqueleto, plumas, pico, etc. que al ser de baja calidad proteica y de menor absorción por parte del organismo canino, requiere de un consumo de mayor volumen. En contraste Animal Lovers, ofrece alimentos hechos a base de carne en su contenido proteico, lo cual hará que su mascota, se alimente con insumos de calidad superior.

Los productos Animal Lovers, requieren de una cadena de frio para su conservación y para prepararse simplemente se descongela en baño maría o se hace uso del horno microondas. El proceso de compra, pago y reparto se realiza desde una aplicación sencilla de celular o por la web.

\section{Objetivos de marketing}

Los principales objetivos de marketing son:

- Posicionar Animal Lovers como un alimento balanceado, saludable, elaborado con insumos naturales, cocidos y mínima cantidad de preservantes.

- Brindar un proceso comercial eficiente desde la web y el celular.

- Ofrecer un proceso de distribución basado en una compra semanal. 


\subsubsection{Estrategia de producto}

Se distinguen dos fases:

- $\quad$ Primera fase: la participación de mercado de la comida seca con más de 30 marcas entre nacionales e importadas y con un consumo de un 95\% en Lima, según el Gerente de la importadora MARS.

- Segunda fase: el inicio del dominio de la comida húmeda o similar, representada por el alimento crudo triturado (BARF) y la comida cocida prescrita en veterinarias, elaborada con insumos naturales. Ambas - cruda y cocida requiriendo para su conservación de congelamiento.

Animal Lovers produce un alimento exclusivo para canes, donde la producción se realiza para:

- Canes que requieren de un tratamiento especial a través de recetas por prescripción del nutricionista canino (veterinarias como PRANA nos encargan la elaboración del alimento).

- Fórmulas estandarizadas para todo tipo de can.

Las recetas por prescripción del nutricionista canino contienen en mayor o menor proporción elementos habituales dependiendo de la edad:

- Cachorro (de cero a un año), con nutrientes esenciales para una eficiente absorción, elevada digestibilidad y palatabilidad, para un adecuado crecimiento.

○ Adulto (de uno a seis años), para el equilibrio intestinal, sensibilidad de piel, palatabilidad y antioxidante para un buen estado de salud.

- Adulto mayor (mayor a seis años), para un envejecimiento saludable, antioxidantes, así el cuidado de los huesos y las articulaciones. 
El producto estándar de Animal Lovers contiene los insumos apropiados para los canes adultos. Es un alimento elaborado en base a una fórmula balanceada y nutritiva que emplea insumos naturales y con una mínima cantidad de preservantes, con un nivel de cocción que facilita la digestión del can. Es empacado al vacío y para su adecuada conservación debe mantenerse congelado para luego solo refrigerarse como paso previo para su consumo.

El producto estándar tiene dos presentaciones: de $1 \mathrm{~kg}$. y de 1/2 kg. Cada producto tiene la forma de una lámina rectangular $(10 \mathrm{~cm}$. x $5 \mathrm{~cm}$.) que facilita su descongelamiento.

El tiempo de duración -que por lo general es dos semanas a quince días- está asociado a su condición de producto natural. Tiene varios sabores empleando para el caso de las proteínas: la carne de res, de pescado y de pollo. 
Tabla 55.- Cuadro comparativo por tipo de producto

\begin{tabular}{|c|c|c|c|c|c|}
\hline CONCEPTO & FACTOR & $\begin{array}{l}\text { COMIDA } \\
\text { SECA }\end{array}$ & $\begin{array}{l}\text { COMIDA } \\
\text { HUMEDA }\end{array}$ & $\begin{array}{c}\text { COMIDA } \\
\text { CRUDA } \\
\text { TRITURADA } \\
\text { (BARF) } \\
\end{array}$ & $\begin{array}{l}\text { COMIDA COCIDA } \\
\text { NATURAL }\end{array}$ \\
\hline $\begin{array}{l}\text { Insumos } \\
\text { utilizados }\end{array}$ & $\begin{array}{c}\text { Procesado } \\
\text { industrialmente }\end{array}$ & $\mathrm{X}$ & $\mathrm{X}$ & & \\
\hline \multirow{5}{*}{$\begin{array}{l}\text { Composición } \\
\text { del producto }\end{array}$} & Vitaminas & $\mathrm{X}$ & $\mathrm{X}$ & $\mathrm{X}$ & $\mathrm{X}$ \\
\hline & Minerales & $\mathrm{X}$ & $X$ & $\mathrm{X}$ & $X$ \\
\hline & Proteínas & $\mathrm{X}$ & $\mathrm{X}$ & $\mathrm{X}$ & $\mathrm{X}$ \\
\hline & Omega & $X$ & $X$ & $\mathrm{X}$ & $X$ \\
\hline & Antioxidantes & $X$ & $X$ & $\mathrm{X}$ & $\mathrm{X}$ \\
\hline $\begin{array}{l}\text { Biodisponibilid } \\
\text { ad }\end{array}$ & $\begin{array}{l}\text { Insumo que } \\
\text { conserva sus } \\
\text { propiedades }\end{array}$ & & & & $X$ \\
\hline \multirow{4}{*}{$\begin{array}{l}\text { Beneficios } \\
\text { orgánicos }\end{array}$} & Balanceado & \multirow{8}{*}{\multicolumn{2}{|c|}{$\begin{array}{l}\text { En base a calidad del } \\
\text { insumo }\end{array}$}} & & $\mathrm{X}$ \\
\hline & Digestivo & & & & $\mathrm{X}$ \\
\hline & Hipoalergénico & & & & $X$ \\
\hline & Control de peso & & & & $X$ \\
\hline \multirow{3}{*}{$\begin{array}{l}\text { Beneficios } \\
\text { estéticos }\end{array}$} & $\begin{array}{l}\text { Dientes bien } \\
\text { desarrollados }\end{array}$ & & & $\mathrm{X}$ & $X$ \\
\hline & Pelaje brilloso & & & $\mathrm{X}$ & $X$ \\
\hline & Desarrollo físico & & & $\mathrm{X}$ & $X$ \\
\hline $\begin{array}{c}\text { Investigación y } \\
\text { desarrollo }\end{array}$ & Innovación & & & & Innovación \\
\hline \multirow[b]{2}{*}{ Respaldo } & SENASA & $\mathrm{X}$ & $\mathrm{X}$ & & $X$ \\
\hline & AAFCO & $\begin{array}{r}\text { En base a } \\
\text { ins }\end{array}$ & $\begin{array}{l}\text { calidad del } \\
\text { mo }\end{array}$ & $\mathrm{X}$ & $X$ \\
\hline \multirow{2}{*}{ Presentación } & $<=1 / 2 \mathrm{Kg}$ & Solo : & granel & & $X$ \\
\hline & $>1 / 2 \mathrm{Kg}$ & $\mathrm{X}$ & $\mathrm{X}$ & $\mathrm{X}$ & $\mathrm{X}$ \\
\hline \multirow{2}{*}{$\begin{array}{l}\text { Almacenamient } \\
\text { o }\end{array}$} & $\begin{array}{l}\text { Congelado y } \\
\text { Refrigerado }\end{array}$ & & & $\mathrm{X}$ & $X$ \\
\hline & Perecible & & & $\mathrm{X}$ & $X$ \\
\hline Preservantes & Dosis elevada & Un año e & promedio & & \\
\hline \multirow{2}{*}{ Competencia } & $\mathrm{N}^{\circ}$ de marcas & & 25 & $<=5$ & $<=5$ \\
\hline & Cobertura & Nacional e & nternacional & Lima & San Borja \\
\hline $\begin{array}{c}\text { Público } \\
\text { objetivo }\end{array}$ & Segmentado & & & \multicolumn{2}{|c|}{ Segmentado } \\
\hline Distribución & Canales & Tradiciona & y Moderno & \multicolumn{2}{|c|}{ Moderno } \\
\hline Vigencia & En años & 47 & años & 2 años & Reciente \\
\hline Marketing & Comunicación & Int & gral & Indefinida & Confiable \\
\hline
\end{tabular}

Nota: Elaboración propia.

${ }^{\text {a }}$ Información recopilada a través de nutricionistas caninos de veterinaria PRANA

Balance: nutrición equilibrada 
Tabla 56.- Efectos de la composición del alimento en exceso, balance o déficit

\begin{tabular}{|c|c|c|c|c|c|}
\hline & Proteínas & Grasas & Vitaminas & Minerales & Fibra \\
\hline Exceso & Gases & Sobrepeso & $\begin{array}{c}\text { Problemas } \\
\text { óseos }\end{array}$ & $\begin{array}{l}\text { Cálculos } \\
\text { urinarios }\end{array}$ & $\begin{array}{c}\text { Heces de } \\
\text { mala calidad }\end{array}$ \\
\hline Balance & $\begin{array}{c}\text { Masa } \\
\text { muscular y } \\
\text { crecimiento }\end{array}$ & $\begin{array}{l}\text { Piel y pelo } \\
\text { sanos }\end{array}$ & $\begin{array}{c}\text { Sistema } \\
\text { inmune } \\
\text { fuerte }\end{array}$ & $\begin{array}{c}\text { Huesos y } \\
\text { dientes } \\
\text { fuertes } \\
\end{array}$ & $\begin{array}{c}\text { Buena } \\
\text { digestión }\end{array}$ \\
\hline Deficiencia & $\begin{array}{c}\text { Crecimiento } \\
\text { deficiente }\end{array}$ & $\begin{array}{c}\text { Pelo sin } \\
\text { brillo }\end{array}$ & Fatiga & Debilidad & $\begin{array}{c}\text { Heces de } \\
\text { mala calidad }\end{array}$ \\
\hline
\end{tabular}

Nota: Elaboración propia.

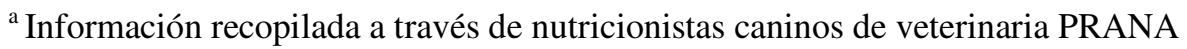

\section{Tabla 57.- Animal Lovers - Chicken}

\begin{tabular}{|c|c|}
\hline Marca: & Animal Lovers - Chicken \\
\hline Nombre del Producto: & Dieta de Pollo \\
\hline \multirow{3}{*}{\multicolumn{2}{|c|}{$\begin{array}{l}\text { Producto elaborado a base de pollo, vegetales y componentes adicionales que hacen de este producto } \\
\text { un alimento balanceado. } \\
\text { Todos sus componentes son naturales. Se produce artesanalmente con un nivel de cocción que } \\
\text { facilita la digestión y la biodisponibilidad de sus insumos. Recomendable cuando se desea un } \\
\text { alimento fácil de digerir y a la vez nutritivo. Debe mantenerse congelado y empacado al vacío para } \\
\text { protegerlo de bacterias y otros agentes contaminantes. } \\
\text { Un día antes de consumirlo, sírvase bajarlo de la nevera a la refrigeradora, para después colocarlo en } \\
\text { baño maría por unos minutos y luego proceder a su consumo. }\end{array}$}} \\
\hline & \\
\hline & \\
\hline Característica principal: & Formula balanceada \\
\hline Calorías: & 1000 calorías \\
\hline Peso (alimento crudo): & $1.017 \mathrm{~kg}$. \\
\hline Empaque: & Bolsa empacada al vacío \\
\hline Ingredientes: & Presentación: \\
\hline $\begin{array}{l}\text { Pollo con grasa, huevo, hígado de pollo, arroz } \\
\text { integral, camote, brócoli, betarraga, zanahoria, } \\
\text { espinaca, col, apio, espinaca, aceite de oliva, } \\
\text { multivitamínico, calcio, zinc, hierro, cobre. }\end{array}$ & 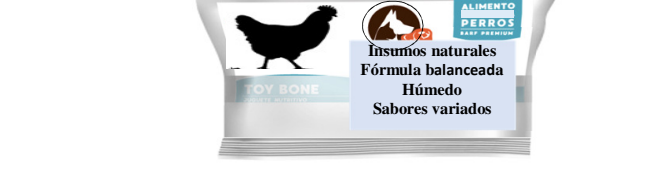 \\
\hline Conservación: & Mantenerse congelado \\
\hline Duración: & Dos (2) meses \\
\hline Certificación: & SENASA \\
\hline
\end{tabular}


Tabla 58.- Animal Lovers - Fish

\begin{tabular}{|c|c|}
\hline Marca: & Animal Lovers - Fish \\
\hline Nombre del Producto: & Dieta de Pescado \\
\hline \multicolumn{2}{|c|}{$\begin{array}{l}\text { Producto elaborado a base de pescado, vegetales y componentes adicionales que hacen de } \\
\text { este producto un alimento balanceado. } \\
\text { Todos sus componentes son naturales. Se produce artesanalmente con un nivel de cocción } \\
\text { que facilita la digestión y la biodisponibilidad de sus insumos. Recomendable cuando se } \\
\text { desea un alimento fácil de digerir y a la vez nutritivo. Debe mantenerse congelado y } \\
\text { empacado al vacío para protegerlo de bacterias y otros agentes contaminantes. } \\
\text { Un día antes de consumirlo, sírvase bajarlo de la nevera a la refrigeradora, para después } \\
\text { colocarlo en baño maría por unos minutos y luego proceder a su consumo. }\end{array}$} \\
\hline Característica principal: & Formula balanceada \\
\hline Calorías: & 1000 calorías \\
\hline Peso (crudo): & 1.106 \\
\hline Empaque: & Bolsa empacada al vacío \\
\hline $\begin{array}{l}\text { Ingredientes: } \\
\text { Pescado blanco, pescado oscuro, } \\
\text { arroz integral, camote, betarraga, } \\
\text { espinaca, aceite de girasol, aceite de } \\
\text { oliva, zanahoria, coliflor, apio, sal, } \\
\text { hierro, zinc, cobre y calcio. }\end{array}$ & $\begin{array}{c}\text { Insumos naturales } \\
\text { Fórumlabalanceada } \\
\text { Húmedo } \\
\text { Sabores variados }\end{array}$ \\
\hline Conservación & Mantenerse congelado y refrigerado \\
\hline Duración & Dos (2) meses \\
\hline Certificación & SENASA \\
\hline
\end{tabular}

Nota: Elaboración propia.

Tabla 59.- Animal Lovers - Cow

\begin{tabular}{|c|c|}
\hline Marca: & Animal Lovers Cow \\
\hline Nombre del Producto: & Dieta de Carne \\
\hline \multirow{3}{*}{\multicolumn{2}{|c|}{$\begin{array}{l}\text { Producto elaborado a base de carne, vegetales y componentes adicionales que hacen de } \\
\text { este producto un alimento balanceado. } \\
\text { Todos sus componentes son naturales. Se produce artesanalmente con un nivel de cocción } \\
\text { que facilita la digestión y la biodisponibilidad de sus insumos. Recomendable cuando se } \\
\text { desea un alimento fácil de digerir y a la vez nutritivo. Debe mantenerse congelado y } \\
\text { empacado al vacío para protegerlo de bacterias y otros agentes contaminantes. } \\
\text { Un día antes de consumirlo, sírvase bajarlo de la nevera a la refrigeradora, para después } \\
\text { colocarlo en baño maría por unos minutos y luego proceder a su consumo. }\end{array}$}} \\
\hline & \\
\hline & \\
\hline Característica principal: & Formula balanceada \\
\hline Calorías: & 1000 calorías \\
\hline Peso (crudo): & 1.014 \\
\hline Empaque & Bolsa empacada al vacío \\
\hline Ingredientes: & 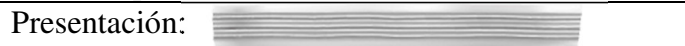 \\
\hline $\begin{array}{l}\text { Malaya, carne con grasa, hígado de } \\
\text { res, corazón de res, pulmón de res, } \\
\text { arroz integral, camote, betarraga, } \\
\text { brócoli, zanahoria, apio, espinaca, } \\
\text { sal, aceite de girasol, vitamina E, } \\
\text { vitamina D, zinc y calcio. }\end{array}$ & $\begin{array}{l}\text { Insumos naturales } \\
\text { Fórmula balanceada } \\
\text { Húmedo } \\
\text { Sabores variados }\end{array}$ \\
\hline Conservación & Congelado \\
\hline Duración & Dos (2) meses \\
\hline Certificación & SENASA \\
\hline
\end{tabular}

Nota: Elaboración propia. 


\subsubsection{Estrategia de precio}

Para elegir la estrategia de fijación de precios antes se deberá analizar las fases que componen la estrategia de selección de una adecuada fijación de precios (Kotler; 2006):

Fase 1: Selección del objetivo del precio. - Donde se identifica que nuestro objetivo sobre la fijación de precio es el de liderazgo del producto, ya que el producto de Animal Lovers será percibido como un producto de calidad superior.

El objetivo del precio radica en ofrecer un producto de calidad a un precio menor en comparación con la competencia, dado que el tipo de producto es nuevo en el mercado, pero en un mercado existente. (Ansoff; 1957)

Fase 2: Cálculo de la demanda. - Se dirige a un nivel socioeconómico $\mathrm{ABC}$, con un estilo de vida sofisticado con una marcada sensibilidad a las mascotas.

Fase 3: Estimación de costos. - Se han calculado y tomado en cuenta los costos fijos y los costos variables.

Con respecto a los costos del primer año se simula:

- $\quad$ Costo fijo $=\mathrm{S} / 181,233 ;$ Costo variable $=\mathrm{S} / 355,283$;

- $\quad$ Número de unidades producidas y vendidas $=44,887$

- $\quad$ Costo unitario en promedio $=\mathrm{S} / 11.82$ 
- $\quad$ Fase 4: Análisis de costo, precios y oferta de la competencia. - Se analizarán los precios y la oferta de la competencia más cercana, en este caso de acuerdo con el perfil competitivo Nutran y Rambala.

Con respecto a la competencia para productos de calidad similar:

Rambala $=$ S/ 13.2; Nutran $=$ S/ 16.7; Propack $=$ S/ 20.8, entre otros .

- Fase 5: Selección de una estrategia de fijación de precios. La fijación de precio de Animal Lovers, se determina en base a cuatro aspectos claves: el costo, la competencia, el valor percibido por el mercado meta y la rentabilidad del proyecto.

Fase 6: Selección del precio final. - Donde se considerarán políticas de precios, en base al tipo de pago, volumen de venta e incentivos.

Según Kotler (20006), la fórmula para calcular el precio es la siguiente:

Precio de venta $=\frac{\text { costo unitario }}{1-\text { rentabilidad esperada sobre las ventas }}$

Precio de venta en promedio $=$ S/ $15($ sin igv); S/ 17.71 (con igv)

Luego, tomando en consideración los precios de la competencia y la estrategia de penetración de mercado, se definen los precios para cada producto:

- $\quad$ Animal Lovers pollo = S/ $9.88(\sin$ igv); S/ $11.65($ con igv)

- $\quad$ Animal Lovers pescado $=\mathrm{S} / 11.7($ sin igv); S/ 13.81 (con igv)

- $\quad$ Animal Lovers carne =S/ $15.44(\sin$ igv); S/ 18.21 (con igv) 
Cabe destacar que el valor percibido se basa en una estrategia de penetración que responde a un producto de mayor calidad, pero a un mismo precio.

De igual forma, sobre la base de los precios indicados se ha procedido a calcular la rentabilidad del proyecto, considerando el crecimiento en unidades vendidas (año 1: 44,887 unidades; año 5: 80,429 unidades).

Tabla 60.- Dieta de pollo

\begin{tabular}{|c|c|c|c|c|}
\hline Producto: & Dieta de Pollo & & Costo S/ : & 4.937 \\
\hline Peso kg (crudo): & 1.017 & Margen de & ntribución S/ : & 4.937 \\
\hline \multirow[t]{2}{*}{ Calorías $\mathrm{x}$ ración: } & 1,000 & & or de venta $S$ / : & 9.874 \\
\hline & & & Precio S/ : & 11.65 \\
\hline Insumo & $\begin{array}{c}\text { Unidad de } \\
\text { Medida }\end{array}$ & $\begin{array}{c}\text { Precio x } \\
\text { Unidad de } \\
\text { Medida }\end{array}$ & Cantidad & Valor S/ \\
\hline Pollo con grasa & $\mathrm{Kg}$. & 3 & 0.15 & 0.45 \\
\hline Pollo sin grasa & Kg. & 6 & 0.1 & 0.6 \\
\hline Huevo & $\mathrm{Kg}$. & 3 & 0.13 & 0.375 \\
\hline Hígado de pollo & $\mathrm{Kg}$. & 8 & 0.07 & 0.56 \\
\hline Arroz integral & $\mathrm{Kg}$. & 3 & 0.2 & 0.6 \\
\hline Camote & $\mathrm{Kg}$. & 1 & 0.1 & 0.1 \\
\hline Brócoli & $\mathrm{Kg}$. & 3 & 0.1 & 0.3 \\
\hline Betarraga & $\mathrm{Kg}$. & 3 & 0.1 & 0.3 \\
\hline Verduras varias & $\mathrm{Kg}$. & 5 & 0.05 & 0.25 \\
\hline Sal & Kg. & 1 & 0.002 & 0.002 \\
\hline Aceite de oliva & Lt. & 20 & 0.02 & 0.4 \\
\hline Complementos & & & & 1 \\
\hline
\end{tabular}

Nota: Elaboración propia. 
Tabla 61.- Dieta de pescado

\begin{tabular}{|c|c|c|c|c|}
\hline Producto: & Dieta de Pescado & & Costo S/ : & 5.85 \\
\hline Peso (crudo): & 1.106 & \multicolumn{2}{|c|}{ Margen de contribución S/ : } & 5.85 \\
\hline Calorías x ración: & 1,000 & \multicolumn{2}{|c|}{ Valor de venta $S /$ : } & 11.7 \\
\hline & & \multicolumn{2}{|c|}{ Precio S/ : } & 13.8 \\
\hline Insumo & $\begin{array}{l}\text { Unidad de } \\
\text { Medida }\end{array}$ & $\begin{array}{l}\text { Precio por } \\
\text { Unidad } \\
\text { de Medida }\end{array}$ & Cantidad & Valor S/ \\
\hline Pescado (carne blanca) & $\mathrm{Kg}$. & 6 & 0.15 & 0.9 \\
\hline Pescado (carne oscura) & $\mathrm{Kg}$. & 6 & 0.15 & 0.9 \\
\hline Arroz integral & Kg. & 3 & 0.3 & 0.9 \\
\hline Camote & $\mathrm{Kg}$. & 1 & 0.2 & 0.2 \\
\hline Espinaca & $\mathrm{Kg}$. & 5 & 0.1 & 0.5 \\
\hline Betarraga & $\mathrm{Kg}$. & 3 & 0.1 & 0.3 \\
\hline Verduras varias & $\mathrm{Kg}$. & 5 & 0.05 & 0.25 \\
\hline Sal & Kg. & 1 & 0.002 & 0.002 \\
\hline Aceite de oliva & Lt. & 20 & 0.04 & 0.8 \\
\hline Aceite de girasol & Lt. & 7 & 0.014 & 0.098 \\
\hline Complementos & & & & 1 \\
\hline
\end{tabular}

Nota: Elaboración propia.

Tabla 62.- Dieta de carne

\begin{tabular}{|c|c|c|c|c|}
\hline Producto: & Dieta de Res & & Costo S/ : & 7.7 \\
\hline Peso (crudo): & 1.014 & Margen de $c$ & atribución $\mathrm{S} /$ : & 7.7 \\
\hline \multirow[t]{2}{*}{ Calorías $\mathrm{x}$ ración: } & 1,000 & Val & r de venta $S$ / : & 15.4 \\
\hline & & & Precio S/ : & 18.2 \\
\hline Insumo & $\begin{array}{l}\text { Unidad de } \\
\text { Medida }\end{array}$ & $\begin{array}{l}\text { Precio por } \\
\text { Unidad de } \\
\text { Medida }\end{array}$ & Cantidad & Valor S/ \\
\hline Malaya & $\mathrm{Kg}$. & 14 & 0.15 & 2.1 \\
\hline Carne $(80 \%)$ & $\mathrm{Kg}$. & 14 & 0.08 & 1.1 \\
\hline Grasa $(20 \%)$ & $\mathrm{Kg}$. & 10 & 0.02 & 0.2 \\
\hline Hígado de res & $\mathrm{Kg}$. & 10 & 0.02 & 0.2 \\
\hline Corazón de res & $\mathrm{Kg}$. & 10 & 0.08 & 0.8 \\
\hline Pulmón de res & $\mathrm{Kg}$. & 10 & 0.03 & 0.3 \\
\hline Arroz integral & $\mathrm{Kg}$. & 3 & 0.2 & 0.6 \\
\hline Camote & $\mathrm{Kg}$. & 1 & 0.2 & 0.2 \\
\hline Betarraga & $\mathrm{Kg}$. & 3 & 0.1 & 0.3 \\
\hline Brócoli & $\mathrm{Kg}$. & 3 & 0.05 & 0.2 \\
\hline Verduras varias & $\mathrm{Kg}$. & 5 & 0.05 & 0.3 \\
\hline Sal & $\mathrm{Kg}$. & 20.00 & 0.02 & 0.40 \\
\hline Aceite girasol & Lt. & 7 & 0.014 & 0.1 \\
\hline Complementos & & & & 1.0 \\
\hline
\end{tabular}

Nota: Elaboración propia. 
El precio de la competencia ha sido analizado para que Animal Lovers se ubique en una posición competitiva favorable.

Tabla 63.- Precios de la competencia

\begin{tabular}{lccrcc}
\hline \multicolumn{1}{c}{ Marca } & Peso & $\begin{array}{c}\text { Unidad de } \\
\text { Medida }\end{array}$ & $\begin{array}{c}\text { Valor de } \\
\text { Venta S/ }\end{array}$ & $\begin{array}{c}\text { IGV } \\
\text { S/ }\end{array}$ & $\begin{array}{c}\text { Precio por } \\
\text { un } \\
\text { Kilogramo } \\
\text { S/ }\end{array}$ \\
\hline (C) Animal Lovers pollo & 1 & $\mathrm{Kg}$. & 9.87 & 1.78 & 11.7 \\
\hline (C) Animal Lovers pescado & 1 & $\mathrm{Kg}$. & 11.7 & 2.1 & 13.8 \\
\hline (B) Rambala de pollo & 0.8 & $\mathrm{Kg}$. & 13.2 & 14.0 & 16.5 \\
\hline (S) Nutran & 15 & $\mathrm{Kg}$. & 249.9 & 14.2 & 16.7 \\
\hline (C) Animal Lovers carne & 1 & $\mathrm{Kg}$. & 15.4 & 2.8 & 18.2 \\
\hline (B) Rambala de res & 0.8 & $\mathrm{Kg}$. & 16 & 16.9 & 20.0 \\
\hline (S) Propack & 12 & $\mathrm{Kg}$. & 249.9 & 17.6 & 20.8 \\
\hline (B) Rambala cordero & 0.8 & $\mathrm{Kg}$. & 19.2 & 20.3 & 24.0 \\
\hline (B) Rambala de pavo & 0.8 & $\mathrm{Kg}$. & 19.2 & 20.3 & 24.0 \\
\hline (S) Proplan & 3 & $\mathrm{Kg}$. & 81.9 & 23.1 & 27.3 \\
\hline (S) Hills & 3.9 & $\mathrm{Kg}$. & 129.9 & 28.2 & 33.3 \\
\hline (S) Eukanuba & 2.3 & $\mathrm{Kg}$. & 79.9 & 29.4 & 34.7 \\
\hline (S) Taste of the wild & 2 & $\mathrm{Kg}$ & 79.9 & 33.9 & 40.0 \\
\hline (B) Comida cruda triturada BARF & & & & \\
(S) Comida seca & & & & & \\
(C) Comida cocida con insumos naturales & & & & & \\
\hline
\end{tabular}

Nota: Elaboración propia.

El valor percibido por el cliente es un trabajo que Animal Lovers debe realizar en la mente del consumidor. Dicho valor es construido a partir de los atributos del producto, en concordancia con un precio competitivo ante un segmento no sensible al precio, pero no por ello carente de exigencia.

Tabla 64.- Consumo de alimento por semana

\begin{tabular}{cccc}
\hline $\begin{array}{c}\text { Peso del can } \\
(\mathrm{Kg} .)\end{array}$ & $\begin{array}{c}\text { Límite inferior } \\
(2 \% \text { del peso })\end{array}$ & $\begin{array}{c}\text { Límite superior } \\
(3 \% \text { del peso })\end{array}$ & $\begin{array}{c}\text { Consumo mínimo } \\
\text { semanal }(\mathrm{kg} .)\end{array}$ \\
\hline 1 & 0.02 & 0.03 & 0.14 \\
\hline 5 & 0.1 & 0.15 & 0.70 \\
\hline 10 & 0.2 & 0.3 & 1.40 \\
\hline 15 & 0.3 & 0.45 & 2.10 \\
\hline 20 & 0.4 & 0.6 & 2.80 \\
\hline 25 & 0.5 & 0.75 & 3.50 \\
\hline 30 & 0.6 & 0.9 & 4.20 \\
\hline 35 & 0.7 & 1.05 & 4.90 \\
\hline
\end{tabular}

Nota: Elaboración propia. 
Tabla 65.- Gasto semanal con productos Animal Lovers

\begin{tabular}{ccccccc}
\hline & & & S/ 11.65 & S/ 13.81 & S/ 18.21 \\
\hline $\begin{array}{c}\text { Peso can } \\
(\text { Kg. })\end{array}$ & $\begin{array}{c}\text { Consumo } \\
(\mathrm{Kg} .)\end{array}$ & $\begin{array}{c}\text { Consumo } \\
\text { semanal } \\
(\mathrm{Kg} .)\end{array}$ & $\begin{array}{c}\text { Compra } \\
\text { semanal } \\
(\mathrm{Kg} .)\end{array}$ & $\begin{array}{c}\text { Pollo } \\
\text { Gasto Semanal } \\
(\mathrm{S} /)\end{array}$ & $\begin{array}{c}\text { Carne } \\
\text { Gasto Semanal } \\
(\mathrm{S} /)\end{array}$ & $\begin{array}{c}\text { Pescado } \\
\text { Gasto Semanal } \\
(\mathrm{S} /)\end{array}$ \\
\hline 1 & 0.02 & 0.14 & 0.50 & 5.8 & 6.9 & 9.1 \\
\hline 5 & 0.1 & 0.70 & 1.00 & 11.7 & 13.8 & 18.2 \\
\hline 10 & 0.2 & 1.40 & 1.50 & 17.5 & 20.7 & 27.3 \\
\hline 15 & 0.3 & 2.10 & 2.50 & 29.1 & 34.5 & 45.5 \\
\hline 20 & 0.4 & 2.80 & 3.00 & 35.0 & 41.4 & 54.6 \\
\hline 25 & 0.5 & 3.50 & 3.50 & 40.8 & 48.3 & 83.7 \\
\hline 30 & 0.6 & 4.20 & 4.50 & 52.4 & 62.1 & 91.0 \\
\hline 35 & 0.7 & 4.90 & 5.00 & 58.3 & 69.0 &
\end{tabular}

Nota: Elaboración propia.

${ }^{\text {a }}$ Los precios indicados incluyen el IGV

\subsubsection{Estrategia de plaza y distribución}

La distribución del producto Animal Lovers se realiza a través de tres canales.

Tabla 66.- Gasto semanal con productos Animal Lovers

\begin{tabular}{cccc}
\hline $\begin{array}{c}\text { Canal 1: } \\
\text { Directo } \\
\text { (un punto de venta) }\end{array}$ & $\begin{array}{c}\text { Animal } \\
\text { Lovers }\end{array}$ & $\begin{array}{c}\text { Punto de Venta: Físico } \\
\text { Local de producción }\end{array}$ & Cliente \\
\hline - & El centro de producción será un punto de venta más & & \\
\hline & Se tendrá un counter donde se le atenderá al cliente para el despacho del producto & \\
\hline Canal 2: & Animal & Punto de Venta: Virtual & Cliente \\
Directo & Lovers & Redes sociales & \\
\hline
\end{tabular}

- Se venderá a través de Facebook y WhatsApp, dos de las redes sociales más consumidas

- Se atenderán consultas y se orientará al cliente potencial a través del chat, envío de mensajes, videos y fotos

- La cancelación del producto se realizará contra entrega (POS) o por deposito a través del App de un banco

$\begin{array}{cccc}\text { Canal 3: } & \text { Animal } & \text { Punto de Venta: Físico } \\ \text { Indirecto } & \text { Nutricionista Canino } & \text { Cliente } \\ \text { (un punto de venta) } & \text { Lovers } & \end{array}$
(un punto de venta)

- La veterinaria realiza el pedido a Animal Lovers

- Animal Lovers reparte a la veterinaria y el cliente lo recoge

- En caso Animal Lovers despache al cliente directamente se cobrará el servicio de reparto a domicilio

$\begin{array}{llll}\text { Canal 4: } & \text { Animal } & \text { Punto de Venta: Físico } & \text { Cliente } \\ \text { Indirecto } & \text { Lovers } & \text { Tiendas especializadas } & \end{array}$
(cuatro puntos de venta)

- La tienda vende el producto que se encuentra disponible en las congeladoras bajo la modalidad de consignación

- La tienda cobra al cliente y paga a Animal Lovers

- Animal Lovers se encarga del recambio de la mercadería y la promoción en el punto de venta

Nota: Elaboración propia. 


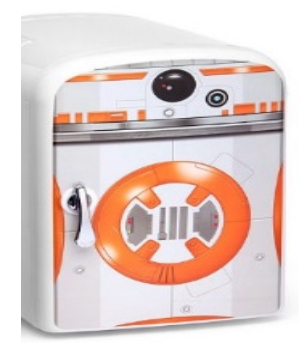

\section{Figura 23. . Distribución}

Elaboración propia

En el corto plazo, la distribución se efectuará en forma selectiva. Es decir, se realizará a través del reparto a domicilio de acuerdo con la demanda del producto en los distritos establecidos como parte de la segmentación. El distrito de partida para dicha distribución será el de San Borja, lugar donde se almacenan los productos. Se realizarán entre tres y cuatro salidas por semana, siguiendo una ruta previamente coordinada en base a los pedidos.

Para esta medida a corto plazo, será necesaria la creación de la fanpage en Facebook para que nuestro público objetivo tenga un canal de comunicación sumamente fluido en el cual realizar sus pedidos, además de construir una comunidad a largo plazo a través de los contenidos útiles que les brindemos.

A mediano plazo, se espera ampliar el espacio de almacenamiento y convertirlo en una tienda de la marca, con mayor cantidad de productos para canes bajo la marca Animal Lovers. No se descarta atraer marcas pequeñas de snacks naturales y saludables, como Natural Prize.

A largo plazo, se implementará un sistema de canales mixtos con el objetivo final de mantener el punto de venta y almacén principal en Surquillo e instalar de manera permanente los equipos de refrigeración en los centros especializados más conocidos de los distritos segmentados. 
En conclusión, la distribución de nuestro producto, además de ser selectiva y apoyarse en la estrategia de jalar (pull) se adaptará al crecimiento de la demanda del producto y la línea de productos que se puedan ofrecer a mediano y corto plazo.

\subsubsection{Estrategia de promoción y publicidad}

La estrategia de promoción y publicidad será completamente digital para el lanzamiento del producto Animal Lovers.

La campaña digital tiene como objetivo principal lanzar nuestro primer producto, Animal Lovers, en la plataforma de Facebook. Esto nos permite desarrollar una campaña de largo alcance, que genere vínculo y compromiso con la marca (engagement) desde nuestro público objetivo a un costo promedio.

Otro objetivo importante de nuestra campaña es que el usuario sea impactado por nuestro contenido a través de videos, notas y diseños gráficos para generar una relación interactiva. En términos cuantitativos, debemos conseguir en dos meses cinco mil seguidores en nuestra fanpage de Facebook.

Lo poco convencional en nuestra estrategia digital es el tono de comunicación a utilizar dentro de la plataforma. Queremos dirigirnos a nuestros usuarios como si sus mascotas escribieran las notas, editaran los videos, tomaran las fotos e hicieran los diseños del canal de comunicación en Facebook (fanpage) y se dirigieran a otras mascotas. Esto último va a desarrollarse en la primera fase de nuestro plan de social media. Este plan se divide en dos fases:

\section{Prelanzamiento:}

La fase de prelanzamiento requiere de la creación de una cuenta en Facebook que ofrezca contenidos escritos, audiovisuales y gráficas para recolectar seguidores de manera orgánica y con inversiones que no sobrepasen los 20 soles semanales. La 
página tendrá el nombre de Animal Lovers, como el producto, y en cuanto a notas tratará temas como:

- 5 lugares para divertirte en familia.

- $\quad$ Cómo mejorar nuestro aliento.

- ¿Te dejaron solo? Encuentra cómo divertirte hasta que lleguen a casa.

- ¿ ¿Te cuesta subir las escaleras? Que bajar de peso no sea una pesadilla.

- ¿Nos vamos de viaje? consejos para viajar cómodo en familia.

Nuestras notas se basarán en información de blogs en internet o medios de prensa. En cuanto al contenido audiovisual se realizarán videos coyunturales al estilo de la página PlayGround que cuenta con casi 5 millones de seguidores.

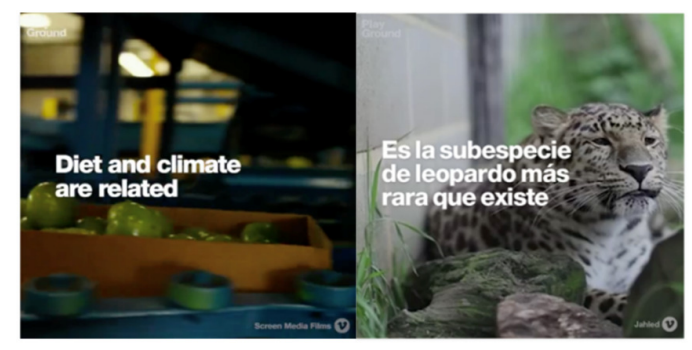

\section{Figura 24. Playground}

Recuperado de https://www.facebook.com/PlayGroundMag/?fref=ts

Estos videos no requieren de grabación. Sólo se crea un texto, como un guion informativo y se usan videos y fotos de apoyo que podemos descargar de YouTube, Vine y otras plataformas audiovisuales. Sin embargo, hay que tomar en cuenta que todo video y audio debe tener su respectivo derecho de autor, como indican las imágenes arriba.

En gráficas utilizaremos aspectos ciertamente ocultos en la mente del consumidor (insights) para componer memes graciosos y utilitarios sobre temas referidos a los engreídos de casa. 


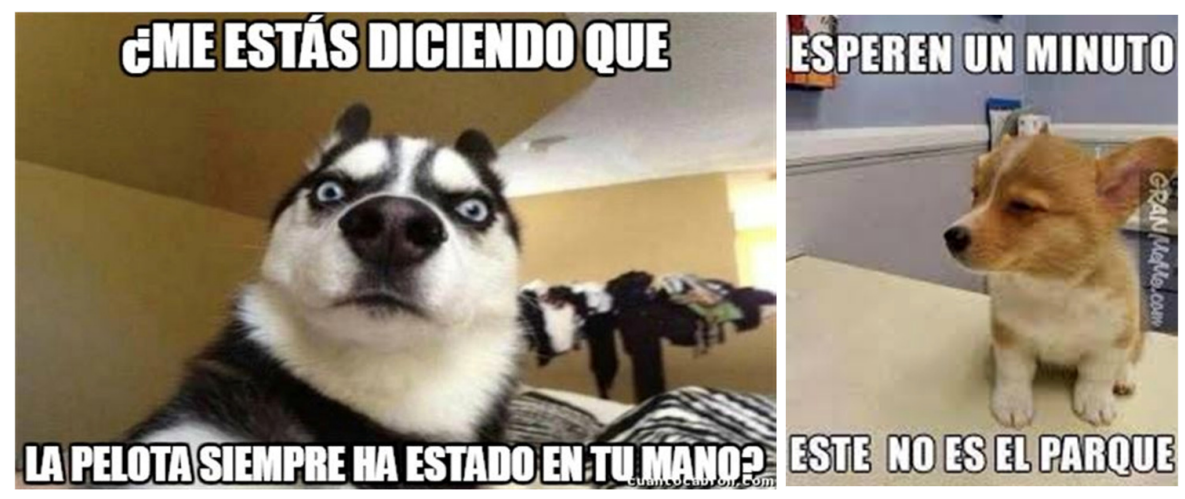

Figura 25. Imágenes sobre sensibilidad de animales

Recuperado de https://www.memegenerator.es/

Es necesario resaltar que todos los contenidos tendrán el slogan de la página relacionado al atributo natural de nuestro producto. Además, los contenidos abordarán sus temas con soluciones e información que proponga el uso de insumos naturales, que no contaminen el medio ambiente, que sean saludables física y mentalmente para de esa forma desarrollar un estilo de vida saludable para las mascotas. Los usuarios irán descubriendo el concepto de campaña de Animal Lovers con la pregunta que inicia nuestros contenidos: “¿Estás listo para algo súper natural?”

\section{Lanzamiento:}

En la segunda fase de la campaña develamos el producto que está detrás del estilo saludable que propone nuestra página en Facebook. Lanzaremos el producto Animal Lovers luego de haber conseguido los cinco mil seguidores y haber generado el vínculo previo con los contenidos del canal de comunicación (fanpage) e intriga con la pregunta relacionada a nuestro concepto.

Daremos a conocer los beneficios del producto mediante notas, gráficas y videos sin dejar de ocasionar un efecto utilitario en ellos. La principal función de los 
contenidos será mantener al tanto al consumidor de que nuestro producto es súper natural.

Las herramientas principales de este lanzamiento serán:

- Una nota a manera de publirreportaje utilitario que nos cuente las principales características de Animal Lovers.

- Un video coyuntural que haga hincapié en los efectos de la industria de alimentos procesados en la naturaleza y en el organismo de nuestras mascotas.

- Una gráfica que contenga el afiche de lanzamiento de Animal Lovers con el slogan "Súper natural, súper engreidor”.

De esta forma, la fanpage que iniciará siendo un sitio de entretenimiento e información, para convertirse en la fanpage oficial de nuestro producto.

Tabla 67.- Costo de lanzamiento (referencial)

\begin{tabular}{ccc}
\hline Tipo de contenido & Cantidad por semana-mes & Pauta en Facebook \\
\hline Texto (Nota) & $7-28$ & S/ 190 \\
\hline Audiovisual & $4-16$ & S/ 320 \\
\hline Gráfico & $6-24$ & S/ 240 \\
\hline Total & 17 semanal -68 mensual & S/ 750 \\
\hline
\end{tabular}

Nota: Elaboración propia.

En el cuadro anterior presentamos el número de contenidos a producirse para la fanpage durante el primer mes. El precio de publicitar en Facebook depende del anunciante. A medida que más inviertas en la pauta publicitaria, podrás segmentar de manera más específica tu contenido. Para los textos hemos destinado 6 soles en publicidad por contenido, para los videos 20 soles en publicidad, puesto que tienen un mayor alcance y son los preferidos por los usuarios, y en gráfica 10 soles en publicidad. 
¿Qué nos asegura y nos brinda este lanzamiento en una plataforma digital?

- Un posicionamiento orgánico de la marca.

- Un vínculo previo con nuestros clientes.

- Un alcance medido y segmentado hacia nuestro público objetivo con una inversión considerablemente inferior al de una campaña en medios tradicionales.

- $\quad$ En líneas generales, una campaña efectiva y poco convencional a bajo costo.

Otra de las estrategias de lanzamiento está referida a la construcción de la marca (branding). En este contexto, la empresa visitará una cantidad determinada de parques (1.5 parques por día) para obsequiar de manera directa al público objetivo una muestra de nuestro producto para explicar sus beneficios y los formatos de presentación ofrecidos. Este ejercicio proporcionará información necesaria para el desarrollo del producto a través del tiempo, así como para su promoción y distribución.

Estas activaciones se realizarán bajo una estrategia orientada a acciones a realizarse en los parques de los distritos de San Borja, Miraflores, San Isidro y Santiago de Surco, luego de las horas de oficina (lunes a viernes) y los fines de semana, momento en el cual los dueños de las mascotas disponen de tiempo para ellos y los sacan a pasear.

\section{Marketing para el desarrollo de la marca}

La programación de las visitas se realizará en razón a lo indicado a continuación. Ejemplo:

\begin{tabular}{ccccc} 
Tiempo & Parque & Total de mascotas & Total de Obsequio & Costo Total \\
\hline 1 día & 1 & 4 canes & 4 X 200 gr. & S/ 8.00
\end{tabular}

Resumen:

\begin{tabular}{lcccc} 
Tiempo & Parques & Mascotas & Total de Obsequio & Costo Total \\
\hline 30 días & 45 & 180 canes por mes & $180 \times 200$ gr. & S/ 360 \\
12 meses & 270 & 1,080 canes por mes & $1,080 \times 200$ gr. & S/ 2,160
\end{tabular}


Dicha cantidad de S/ 2,160 al año, se encuentra registrada en las acciones de Branding, cuyo presupuesto es de S/ 2,400 en total al año.

\subsubsection{Estrategia de personal}

El personal que compone el equipo de Animal Lovers, debe tener ciertas competencias que son esenciales para un adecuado desempeño. Dos factores son importantes para convertirse en colaborador de Animal Lovers:

\section{Factor 1: Pasión por el servicio}

En este aspecto, el colaborador debe tener el perfil de una persona con vocación de servicio.

Los aspectos relevantes en este sentido son:

- $\quad$ Expresión agradable, trato cordial y cálido, para que el cliente se sienta en la confianza de realizar consultas.

- $\quad$ Proactividad para servir, pues el servicio involucra varios aspectos y el colaborador debe estar atento a todos y cada uno de ellos.

- Empatía, para sensibilizarse ante las necesidades del cliente.

- $\quad$ Proactividad para el servicio, pues el cliente no es solo de un área, es de toda la empresa.

- $\quad$ Orientación constante del cliente, sea su área o no la que origina la consulta.

- $\quad$ Escucha activa, para que en caso se realice un reclamo, el cliente agote todos sus argumentos. Recordar quiere el cliente requiere descargarse y el hablar hace posible que paulatinamente mitigue sus emociones. 


\section{Factor 2: Sensibilidad con los animales}

- Trato cálido son las mascotas. Debemos recordar que son un miembro más de la familia.

- Manejo psicológico del can y del amo. Hay que recordar que el niño siente a través del trato que le brinden a su mascota.

- Generación de confianza en la mascota. No hay cliente que regrese si identifica que quienes atienden a su mascota, no tienen la sensibilidad desarrollada.

\section{Factor 3: Construcción de la experiencia}

- Cada punto de contacto con el cliente (físico o virtual) es propicia para desarrollar una experiencia agradable con el cliente.

- El cliente debe percibir el ánimo de colaboración, ayuda, asistencia, orientación y guía para cada uno de sus requerimientos.

- Brindar una experiencia satisfactoria, también depende del nivel de conocimiento de los procesos de atención al cliente, los cuales se basan en procesos de rutina y excepciones.

- Levantamiento constante de información desde la perspectiva del cliente, para saber cuan cerca o lejos estamos del servicio óptimo.

\subsubsection{Estrategia de procesos}

Los procesos están definidos en tres ámbitos:

- $\quad$ Procesos estratégicos (gerencia).

- $\quad$ Procesos principales (cadena de valor para el cliente).

- $\quad$ Procesos secundarios (de soporte). 


\section{De los procesos estratégicos}

Para los primeros años de Animal Lovers, los procesos estratégicos responden a decisiones que involucran la generación, modificación o eliminación de estrategias. Estas estrategias tendrán relación directa con contratar personal, comunicar mejor, vender más, abrir nuevos puntos de venta y coordinar con las empresas que nos permiten comercializar nuestro producto en sus locales.

\section{De los procesos principales}

Estos procesos, impactan directamente en el cliente y son realizados por el personal operativo, es decir, el personal que atiende directamente al cliente.

Estos procesos deben estar muy claros para los colaboradores, de forma tal, que puedan atender al cliente y brindarles soluciones rápidas sin esperar la aprobación de otra instancia, recurriendo a otras áreas para el caso de las excepciones.

\section{Tabla 68.- Mapa de procesos principales}

\begin{tabular}{ccc}
\hline Espacio & Objetivo & Nombre del proceso \\
\hline Local de Animal Lovers & Venta física & Venta en tienda \\
Redes Sociales & Venta virtual & Venta en redes \\
Veterinaria Prana & Venta por demanda & Venta Prana \\
Veterinarias & Venta tercerizada & Venta 3 \\
Despacho & Llevar el producto al cliente & Reparto Domicilio \\
\hline
\end{tabular}

Nota: Elaboración propia.

- Venta en tienda, proceso a través del cual el cliente acude al centro de producción a adquirir el producto.

- Venta en redes, proceso a través del cual el cliente acude al espacio virtual para adquirir el producto. 
- Venta en Prana, proceso a través del cual el cliente solicita la elaboración del alimento en base a la receta brindada por la veterinaria Prana.

- Venta 3, venta tercerizada realizada a través de veterinarias.

- Reparto Domicilio, el reparto de los productos a la dirección indicada por el cliente. Cabe destacar que este reparto se realiza en las mañanas y en las tardes, recordando que los productos se envían en base a compras con periodicidad semanal.

\section{De los procesos de soporte}

Con respecto a los procesos de soporte, se cuenta con uno que es fundamental de acuerdo con las estrategias implementadas. Este proceso es el que se brinda a las redes sociales. La presencia de las redes sociales por su audiencia y bajo costo, es la más atractiva. En este sentido es pertinente manejar las estadísticas de resultado de las campañas lanzadas para afinar estrategias que hagan más efectiva la gestión.

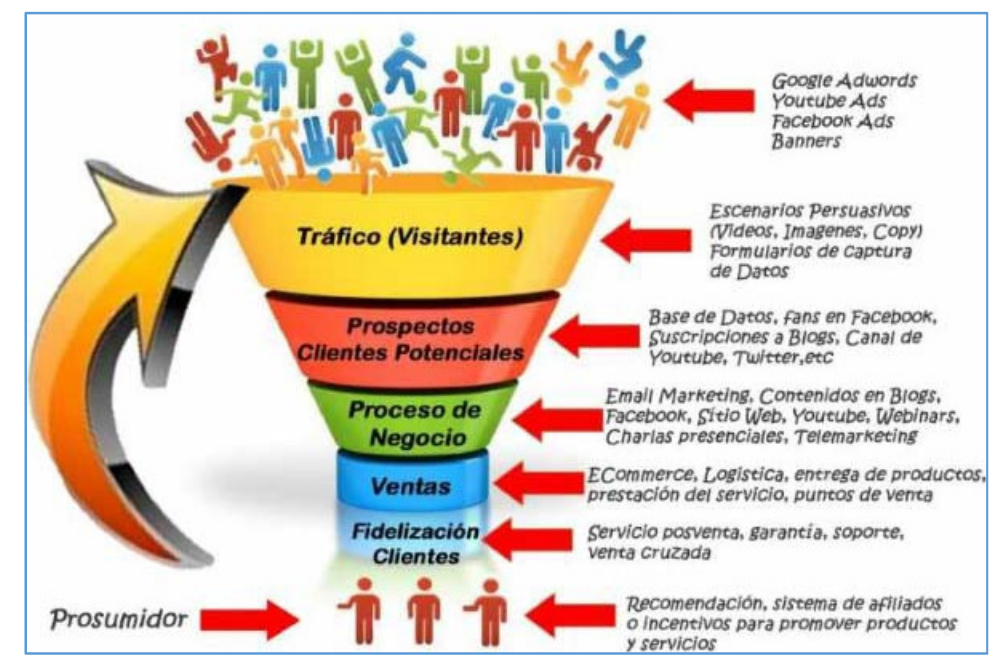

Figura 26. Embudo del marketing

Recuperado de https://www.pinterest.es/pin/417638565437416025/?lp=true 


\subsubsection{Estrategia de Productividad y Calidad}

La estrategia de productividad se centra en analizar la cantidad de productos por cada unidad y/o recurso empleado.

Tabla 69.- Elementos de productividad

\begin{tabular}{cccccc}
\hline ÁREA & PROCESO & \multicolumn{3}{c}{ PRODUCTIVIDAD } & Mora \\
\cline { 3 - 6 } Local de Producción & Producción & $\mathrm{X}$ & $\mathrm{X}$ & $\mathrm{X}$ & $\mathrm{X}$ \\
\hline $\begin{array}{c}\text { Local de Animal } \\
\text { Lovers }\end{array}$ & Venta en tienda & $\mathrm{X}$ & $\mathrm{X}$ & $\mathrm{X}$ & $\mathrm{X}$ \\
\hline Redes Sociales & Venta en redes & $\mathrm{X}$ & $\mathrm{X}$ & $\mathrm{X}$ & $\mathrm{X}$ \\
\hline Veterinaria Prana & Venta Prana & & $\mathrm{X}$ & $\mathrm{X}$ & \\
\hline Veterinarias & Venta 3 & & $\mathrm{X}$ & $\mathrm{X}$ \\
\hline Despacho & $\begin{array}{c}\text { Reparto } \\
\text { Domicilio }\end{array}$ & $\mathrm{X}$ & $\mathrm{X}$ \\
\hline
\end{tabular}

Nota: Elaboración propia

La productividad y la calidad deben ir de la mano. Una eficiencia lograda debe contar con un adecuado margen de valor para el cliente, por ello, en Animal Lovers, los preceptos de calidad Animal Lovers son:

- Calidad en la atención y el servicio al cliente.

- Procesos claros.

- $\quad$ Asistencia constante para con el cliente.

- Consulta rápida ante excepciones.

- Despachos en los horarios establecidos.

- Evitar la generación de expectativas en el cliente.

- $\quad$ Rendimiento sobre el promedio.

- $\quad$ Registrar las tareas realizadas.

- Analizar las tareas realizadas.

- Mejorar las tareas realizadas. 


\subsubsection{Estrategia de Presencia Física}

Basada en aquellos elementos que componen al ambiente físico y que impactan directamente en el cliente.

\subsection{Estrategia de Ventas}

\subsubsection{Plan de Ventas}

Para el primer año de venta se ha estimado una participación de mercado del 2\% (año 2019). Se intenta plantear una cifra realista que sea moderada y a la vez acorde a la realidad.

El cuadro ubicado a continuación refleja el cálculo del consumo promedio de acuerdo con el tamaño de la mascota canina.

Tabla 70.- Elementos de productividad

\begin{tabular}{cccccc}
\hline Tamaño & Peso & $\begin{array}{c}\text { Peso } \\
\text { promedio }\end{array}$ & $\begin{array}{c}\text { Ración diaria } \\
\text { promedio }\end{array}$ & $\begin{array}{c}\text { Ración } \\
\text { Mensual } \\
\text { promedio }\end{array}$ & $\begin{array}{c}\text { Ración } \\
\text { Anual } \\
\text { promedio }\end{array}$ \\
\hline Pequeña & $1-15 \mathrm{~kg}$. & $7.5 \mathrm{~kg}$. & $0.1875 \mathrm{~kg}$ & $5.625 \mathrm{~kg}$. & $67.5 \mathrm{~kg}$. \\
\hline Mediana & $15-30 \mathrm{~kg}$. & $22.5 \mathrm{~kg}$. & $0.5625 \mathrm{~kg}$. & $16.875 \mathrm{~kg}$. & $202.5 \mathrm{~kg}$. \\
\hline Grande & $30-45 \mathrm{~kg}$. & $37.5 \mathrm{~kg}$. & $0.9375 \mathrm{~kg}$. & $28.125 \mathrm{~kg}$. & $337.5 \mathrm{~kg}$. \\
\hline & & Peso en kg. & $1.6875 \mathrm{~kg}$. & $50.625 \mathrm{~kg}$. & $607.5 \mathrm{~kg}$. \\
\hline
\end{tabular}

Nota: Elaboración propia.

Para proyectar una demanda realista se procederá a tomar la cifra de la raza pequeña, la cual tiene un consumo anual promedio de $67.5 \mathrm{~kg}$. 
Tabla 71.- Mercado Objetivo con proyección de consumo anual, mensual y diaria

\begin{tabular}{cccccc}
\hline Año & $\begin{array}{c}\text { Mercado } \\
\text { Objetivo }\end{array}$ & $\begin{array}{c}\text { Consumo de } \\
\text { Kilogramos } \\
\text { al año }\end{array}$ & $\begin{array}{c}\text { Consumo de } \\
\text { Kilogramos } \\
\text { al mes }\end{array}$ & $\begin{array}{c}\text { Consumo de } \\
\text { Kilogramos } \\
\text { al día }\end{array}$ & $\begin{array}{c}\text { Consumo de } \\
\text { Kilogramos } \\
\text { por hora }\end{array}$ \\
\hline 2019 & 1,750 & 114,625 & 9,552 & 318 & 40 \\
\hline 2020 & 1,780 & 116,590 & 9,716 & 324 & 41 \\
\hline 2021 & 1,800 & 117,900 & 9,825 & 328 & 41 \\
\hline 2022 & 1,830 & 119,865 & 9,989 & 333 & 42 \\
\hline 2023 & 1.86 & 121,083 & 10,090 & 336 & 42 \\
\hline
\end{tabular}

Nota: Elaboración propia.

Nuestro plan de ventas está alineado con una proyección de crecimiento basada en un horizonte de 5 años. Comprende cifras reales en base a la capacidad de producción y a una estrategia de mercadeo intensiva.

Tabla 72.- Ventas anuales en toneladas

\begin{tabular}{cccc|cc}
\hline \multirow{2}{*}{ Años } & 2019 & 2020 & 2021 & 2022 & 2023 \\
\cline { 2 - 6 } & Año 01 & Año 02 & Año 03 & Año 04 & Año 05 \\
\hline $\begin{array}{c}\text { Ventas anuales } \\
\text { proyectadas por } \\
\text { Animal Lovers } \\
\text { en toneladas }\end{array}$ & 45 & 54 & 63 & 72 & 80 \\
\hline $\begin{array}{c}\text { Demanda } \\
\text { máxima del } \\
\text { público objetivo } \\
\text { en toneladas }\end{array}$ & 114 & 116 & 117 & 119 & 121 \\
\hline
\end{tabular}

Nota: Elaboración propia.

Es relevante comentar que el mercado nos brinda la posibilidad de comercializar entre 115 y 121 toneladas al año en promedio, no obstante, esta posibilidad está sujeta a nuestra capacidad de financiamiento, inversión, producción, operaciones y en suma, de nuestra capacidad de gestión. 


\subsubsection{Políticas de servicios y garantías}

Es necesaria la generación de un manual de calidad de servicio y garantía de marca para ofrecer un producto de calidad y de igual forma asegurar un servicio de similar nivel.

\section{Proceso de venta:}

- Todos los empaques de Animal Lovers deben contar con la lista de ingredientes y la tabla de valor nutricional.

- Los repartos se realizan entre los distritos de Miraflores, San Borja, Santiago de Surco y San Isidro.

- $\quad$ El tiempo de reparto es de dos (2) veces por semana.

- $\quad$ El reparto se realizará dos veces al día y dependiendo de la demanda entre tres y cuatro veces por semana con fechas y horarios establecidos que serán comunicados en nuestras redes sociales.

- El pago del producto puede realizarse en efectivo, a precio normal y por teléfono.

- Garantizamos el cuidado y proceso natural de nuestros productos en todo sentido.

- Garantizamos el excelente estado del producto hasta la fecha de vencimiento indicada en el empaque.

\section{Procesos de posventa:}

- Un producto en mal estado, en empaque y/o producto, debe ser reportado a cualquiera de nuestros canales de comunicación con una prueba contundente, de ser posible. 
- $\quad$ El producto en mal estado será reemplazado de inmediato, previo proceso de verificación.

- $\quad$ El cliente es responsable del uso inadecuado del producto.

- Garantizamos una atención posventa amable y eficiente.

- Garantizamos un seguimiento exhaustivo en caso hubiera algún inconveniente o disgusto con el producto.

\section{Políticas en red social:}

- Ante una emergencia en red social, nuestro gestor de la comunidad en línea (Community Manager), quien para iniciar será uno de los integrantes, atenderá de forma inmediata, pedirá los datos de la persona que hizo el reclamo, y este se resolverá por interno (in box) para personalizar la atención y resolver de la mejor manera el inconveniente, además de hacerle un seguimiento.

- Garantizamos la calidad y utilidad de nuestros contenidos, aunque deslindamos de cualquier responsabilidad respecto a su mala puesta en práctica.

\section{Garantías generales:}

- Animal Lovers garantiza un alimento natural, no procesado y balanceado de alta calidad.

- Animal Lovers garantiza un servicio de venta y posventa eficiente y efectivo. 


\section{CAPÍtUlO Vi \\ PRONÓSTICO DE VENTAS}

\subsection{Fundamentos y supuestos}

El consumo de comida balanceada de los canes se ha incrementado de manera sostenida a través de los años. La siguiente información, brinda datos específicos sobre el crecimiento de esta industria:

- Según Eduardo Chaman de RINTI SA (Canbo y Ricocan) un crecimiento del 25\% se proyecta este año para el mercado peruano de alimento para mascotas. (América economía, 2014).

- Víctor Pérez, Gerente General de Mars (Pedigree), recuerda que hace 10 años, cuando Pedigree ingresó al mercado, apenas un 5\% de la población les daba croquetas a sus mascotas. Hoy, esto ha cambiado y más del $30 \%$ de peruanos le da de comer alimento procesado a sus mascotas caninas. (El Comercio. Dia 1, 2018)

- Según Euromonitor, el mercado de comida para mascotas llegará a facturar S/ 580 millones en el 2,020, 47\% más que en el 2015. (Semana Económica, 2016)

\subsection{Justificación}

El mercado de alimento para canes tiene más de 30 marcas de comida seca y en una proporción muy reducida, comida cruda triturada (BARF).

En consecuencia, con la cantidad de marcas de comida seca presentes en el mercado (entre nacionales e importadas), con una gran variedad de precios, calidades y formatos, es pertinente concluir en que debido a los cuidados que los hogares les brindan a sus mascotas, la humanización de estas y la inversión que realizan en su bienestar es creciente. Este hecho les obliga a repensar sobre los productos que consumen evaluando el beneficio del alimento sin ocasionar efectos negativos colaterales. 
Por ello, atendiendo a la propuesta de valor de Animal Lovers se ofrece un alimento basado en: una fórmula balanceada (según nutricionistas caninos y bajo estándares de AFFCO) que atiende a las necesidades nutricionales del can para una buena calidad de vida; insumos naturales no manipulados como carnes y vegetales que tienen una cocción mínima para facilitar la digestión de los alimentos; procesos manuales que evitan un proceso industrializado en su preparación para brindar un producto que conserve sus bondades biológicas nutricionales (biodisponibilidad); presencia mínima de preservantes y químicos haciendo uso de preservantes naturales que evitan daños en el organismo del can; sabores (pollo, pescado y res, inicialmente) que faciliten la palatabilidad (gusto del can) para consumir el producto, y la correspondiente cadena de frio para la conservación del producto Animal Lovers.

En base a la exposición de las múltiples razones por las que debemos elegir Animal Lovers, se presenta un mensaje de valor de marca:

“El alimento ideal elaborado con insumos naturales, a una cocción adecuada, de fácil digestión, saludable y nutritivo para tu mascota, se llama Animal Lovers".

La brecha de oportunidad se sustenta en que según CPI (2018) el 56.5\% de los hogares de Lima tiene una mascota y de ellos, más del $80 \%$ tiene un can, en los niveles socioeconómicos ABC. De los hogares con canes que consumen comida balanceada, el 95\% compra comida seca (Importadora MARS). En tal sentido, de los 122,154 hogares que consumen comida balanceada, 116,049 hogares consumen comida seca. De esta cantidad, Animal Lovers desea convertir en hogares 1.5\% (1749 hogares).

El mercado presenta una gran oportunidad, en tanto la comida húmeda -no la secatiene camino por recorrer, dado el incremento del cuidado de las mascotas, como resultado de la creciente humanización de la que son objeto. 
Según la información recopilada, el crecimiento de la industria fue de $15 \%$ anual (2010 al 2015) y del 8\%anual (2016 al 2020). Se ha considerado un escenario moderado del 4\% de crecimiento (2021 al 2023), tal como resume la tabla.

\section{Tabla 73.- Mercado objetivo}

\begin{tabular}{lllllllllllllll}
\hline \multicolumn{10}{c}{ Hogares de NSE A, B y C } \\
\multicolumn{10}{c}{ Distritos de Miraflores, San Borja, San isidro y Santiago de Surco } \\
Crecimiento del mercado 2019-2023 \\
\hline 2010 & 2011 & 2012 & 2013 & 2014 & 2015 & 2016 & 2017 & 2018 & 2019 & 2020 & 2021 & 2022 & 2023 \\
\hline $0 \%$ & $15 \%$ & $15 \%$ & $15 \%$ & $15 \%$ & $15 \%$ & $8 \%$ & $8 \%$ & $8 \%$ & $8 \%$ & $8 \%$ & $4 \%$ & $4 \%$ & $4 \%$
\end{tabular}

Nota: Elaboración propia.

\section{Según Víctor Pérez, Gerente General de Mars (Pedigree):}

La base de la alimentación de las mascotas, hoy en día, se da a través del alimento seco. Pero ante la tendencia de 'humanizar' su dieta en cuanto a variedad, el húmedo ha empezado a ganar fuerza. Ello se da, sobre todo, a través de los sobres de porción única, que suelen ser más convenientes por practicidad y precio.

El alimento húmedo representa un 5\% del consumo, por lo que hay un gran potencial de crecimiento a futuro. La especialización seguirá siendo la clave en esta categoría. (El Comercio. Dia 1, 2018)

\subsection{Aspectos críticos que impactan el pronóstico de ventas}

Los aspectos críticos que impactan en el pronóstico de venta son los siguientes:

- El consumo de alimentos para canes se compone actualmente de un 95\% de comida seca y de un $5 \%$ de comida húmeda. Por tanto, existe potencial de desarrollo de mercado en este aspecto. 
- La especialización del producto será la clave para este segmento.

- La penetración de los productos balanceados va en aumento.

- Hace 10 años solo un $5 \%$ de la población alimentaba a sus canes con croquetas. Hoy en día es cerca del $30 \%$.

- Las marcas de calidad superior son: Nutran, Eukanuba, Hills, Taste of the Wild, entre otras. Proplan, Propack, en el segundo lugar. Y, por último, Cambo, Pedigree.

- Ante el desarrollo del mercado, empresas como Mars están pensando en duplicar su negocio para el 2020.

La proyección de venta tiene también, factores endógenos:

- Nuestra participación de mercado ha sido estimada en un $2 \%$ bajo un escenario moderado, basándonos en la cantidad de clientes.

- Se ha prorrateado lo que consumiría un perro de raza pequeña llegando a la conclusión de que las ventas de Animal Lovers, llegarán a 80 toneladas para el 5to año. 


\section{CAPÍTULO VII}

\section{INGENIERÍA DEL PROYECTO}

\subsection{Estudios de ingeniería}

El estudio de ingeniería del proyecto tiene como misión detallar las actividades de compra de insumos, almacenamiento, producción y distribución de los productos de la empresa Animal Lovers. Este estudio toma en consideración desde las compras que se realizan a los proveedores hasta la colocación del producto en el punto de venta.

\subsubsection{Modelamiento y selección de procesos productivos}

El proceso principal o macroproceso describe como se transforman los insumos en el producto final. Las fases que incluye este macroproceso se detallan a continuación.

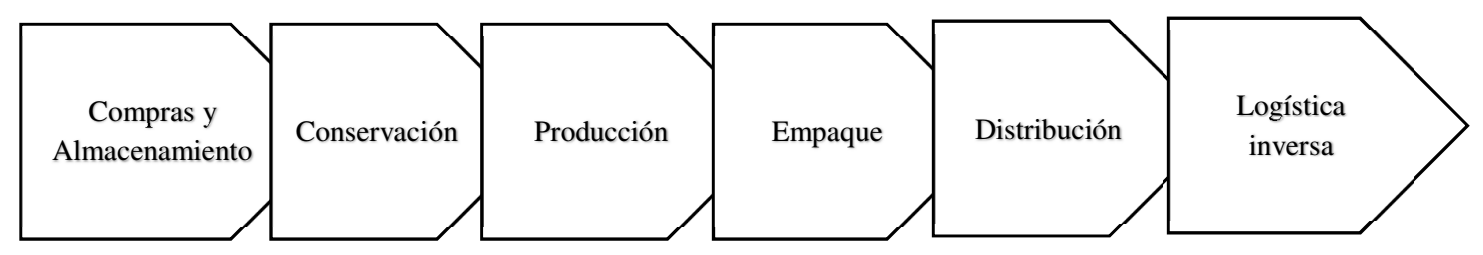

Figura 27. Proceso de producción y comercialización

Elaboración propia 
Tabla 74.- Macroproceso

ACTIVIDAD

DETALLE

Compras

En esta fase la empresa realiza la compra de todos los ingredientes requeridos para el proceso de producción.

\begin{tabular}{|c|c|}
\hline Recepción de mercadería & $\begin{array}{l}\text { En este proceso los insumos son despachados por el proveedor. A través de un proceso } \\
\text { riguroso en la recepción, se atiende el despacho, verificando que los insumos cumplan } \\
\text { en cuanto a: cantidad, calidad, temperatura, grado de conservación y tiempo } \\
\text { proyectado de duración. }\end{array}$ \\
\hline Almacenamiento & $\begin{array}{l}\text { Se procede a almacenar los productos no perecibles en almacén, como el arroz y el } \\
\text { aceite, entre otros. }\end{array}$ \\
\hline Conservación & $\begin{array}{l}\text { Esta fase responde a la necesidad de mantener los insumos perecibles en perfecto } \\
\text { estado, a través de la cadena de frío. Las carnes congeladas y las verduras refrigeradas. }\end{array}$ \\
\hline Trituración & $\begin{array}{l}\text { Las carnes y vegetales se trituran con la intención de que el producto final se encuentre } \\
\text { mezclado, pero a la vez su consistencia tenga trozos de alimento. }\end{array}$ \\
\hline Cocción de carnes & $\begin{array}{l}\text { Tiempo de cocción: de } 15 \text { a } 20 \text { minutos. } \\
\text { Proceso realizado sobre cocinas industriales y ollas de } 40 \text { lts. }\end{array}$ \\
\hline Cocción de vísceras & $\begin{array}{l}\text { Tiempo de cocción: de } 8 \text { a } 10 \text { minutos. } \\
\text { Proceso realizado sobre cocinas industriales y ollas de } 40 \text { lts. }\end{array}$ \\
\hline Cocción de verduras duras & $\begin{array}{l}\text { Tiempo de cocción: de } 10 \text { a } 15 \text { minutos. } \\
\text { Verduras duras: papa, camote, yuca, betarraga, entre otras. } \\
\text { Proceso realizado sobre cocinas industriales y ollas de } 40 \text { lts. }\end{array}$ \\
\hline Cocción de verduras blandas & $\begin{array}{l}\text { Tiempo de cocción: de } 5 \text { a } 10 \text { minutos. } \\
\text { Verduras blandas: espinaca, brócoli, coliflor, entre otras. } \\
\text { Proceso realizado sobre cocinas industriales y ollas de } 40 \text { lts. }\end{array}$ \\
\hline Enfriamiento y secado & $\begin{array}{l}\text { El producto una vez cocido se deja en reposo para el enfriamiento correspondiente. } \\
\text { Cuando el producto en proceso sale de cocción tiene una temperatura mayor a } 100^{\circ} \text { y } \\
\text { agua en una proporción cercana al } 25 \% \text {. }\end{array}$ \\
\hline $\begin{array}{l}\text { Dosificación y pesado de } \\
\text { ingredientes }\end{array}$ & $\begin{array}{l}\text { En esta etapa se preparan todos los ingredientes. Etapa crítica pues de su composición } \\
\text { se deriva un adecuado balance nutricional del alimento. }\end{array}$ \\
\hline Mezclado & $\begin{array}{l}\text { Etapa para brindarle consistencia a la mezcla. Los insumos son mezclados en } \\
\text { proporciones adecuadas de no más de } 10 \text { minutos. Conforme se mezcla, se adicionan } \\
\text { los ingredientes. El coeficiente de variabilidad no debe exceder del } 30 \% \text {. }\end{array}$ \\
\hline Dosificación y pesado & El producto es dividido y pesado en balanza. \\
\hline Empaque al vacío & $\begin{array}{l}\text { El producto es embolsado y se procede a ingresarlo a la empacadora para que se realice } \\
\text { el sellado al vacío. }\end{array}$ \\
\hline Etiquetado & Se le coloca el sticker de la marca. \\
\hline Sello & Se le coloca el sello del lote, fecha y expiración. \\
\hline Conservación & $\begin{array}{l}\text { Esta fase responde a la necesidad de mantener los insumos perecibles en perfecto } \\
\text { estado, a través de la cadena de frío. El producto terminado es congelado. }\end{array}$ \\
\hline
\end{tabular}

Nota: Elaboración propia 


\subsubsection{Selección del equipamiento}

El equipamiento ha sido seleccionado de acuerdo con las exigencias del producto final. El alimento producido contiene insumos cocidos y semi cocidos.

De igual forma, los alimentos de Animal Lovers tendrán una composición similar. En consecuencia, el equipo se refiere a toda la dotación requerida y utilizada en el centro de producción para la preparación de los alimentos, como:

- Congeladoras

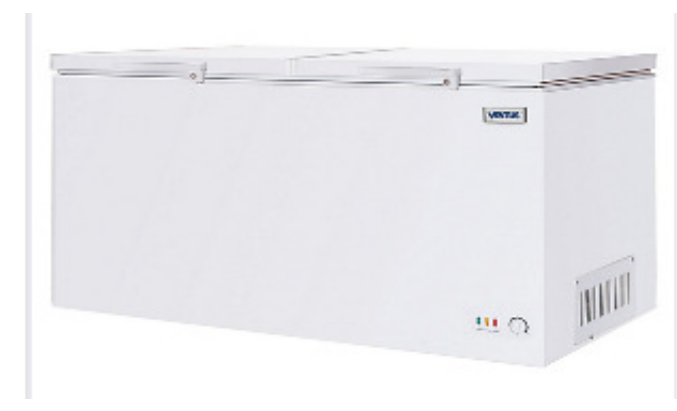

Figura 28. Equipo empleado para el congelamiento y conservación de carnes. Elaboración propia.

- Refrigeradora

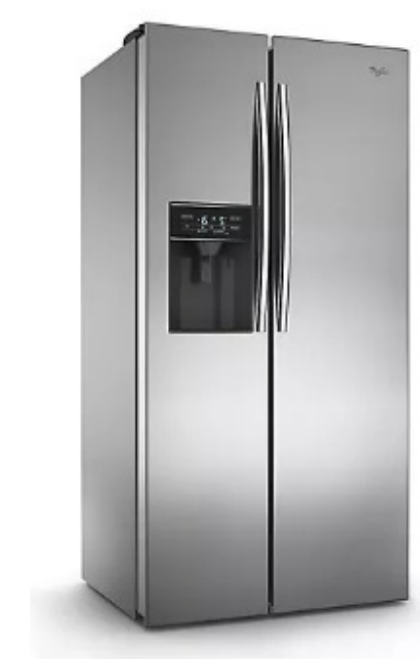

Figura 29. Equipo empleado para la refrigeración y conservación de verduras

Elaboración propia. 
- Mesa de trabajo
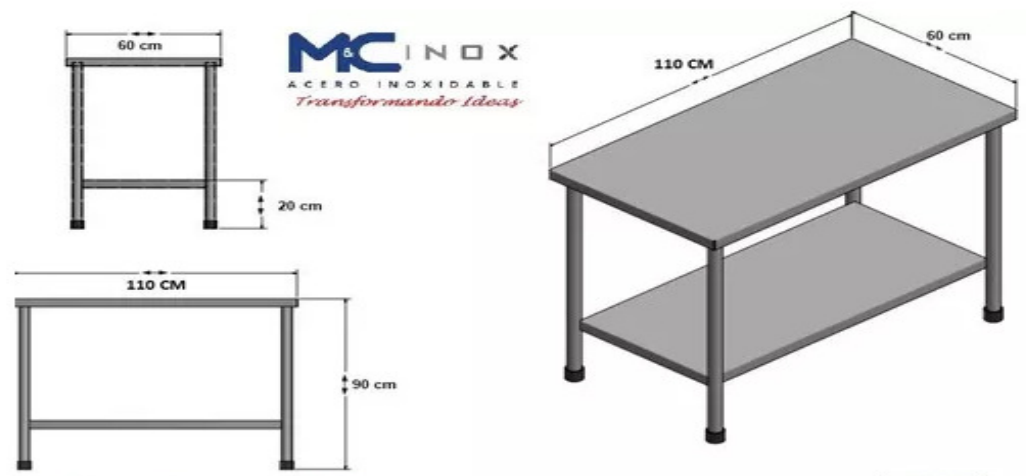

Figura 30. Mesa donde se elaboran los productos. Para el trabajo intenso se requiere de acero inoxidable.

Elaboración propia

- Moledora de carne

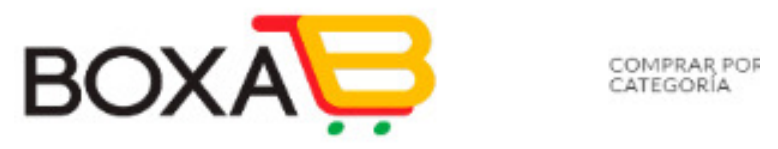

INICIO TIENDA MAQUINARIAOEQUIPOS $\backsim$ BALANZAS $\checkmark$ VISTC

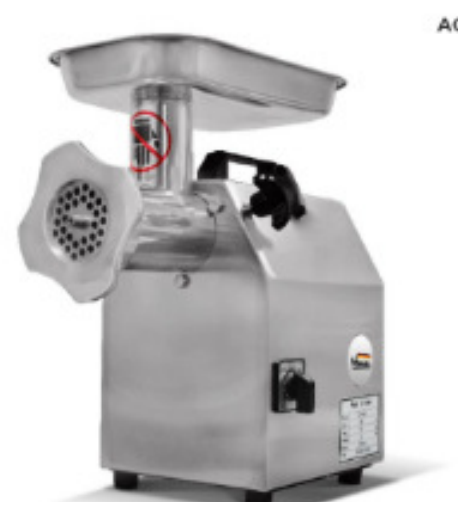

Figura 31. Equipo empleado para la molienda de carne Elaboración propia 
- Trituradora de alimentos

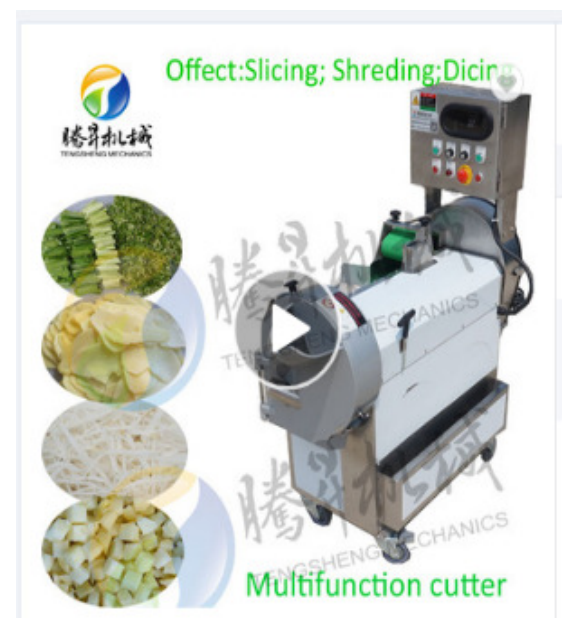

Figura 32. Equipo industrial empleado para cortar verduras

Elaboración propia

- Cocina

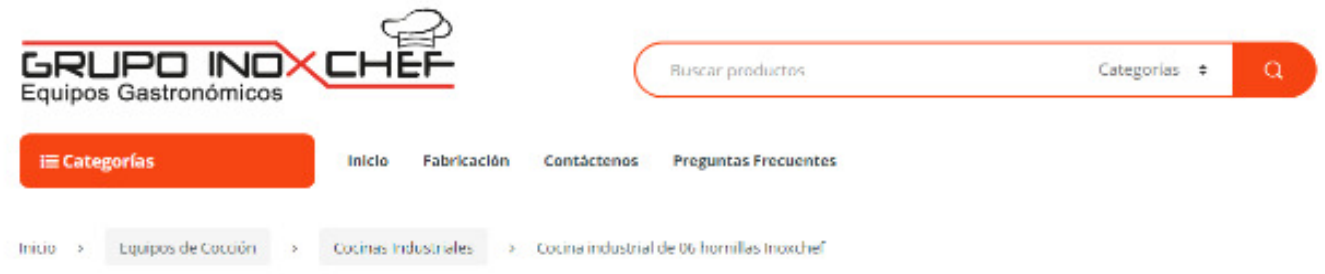

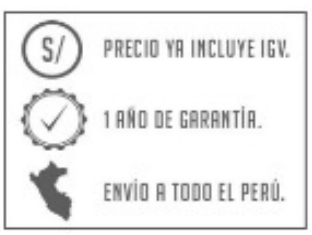

Categorlas de productos

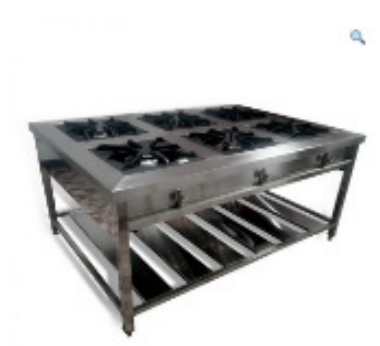

Cocina industrial de 06 hornillas Inoxchef

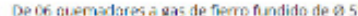

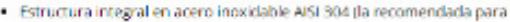

ta hadista gatrom nica:

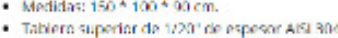

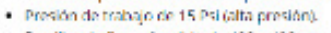

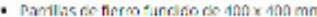

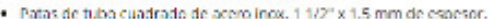

- Pmilsapistor

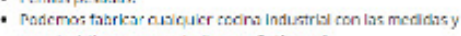

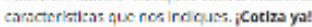

Figura 33. . Cocina industrial de seis hornillas para la cocción de los alimentos. Elaboración propia 
- Mezcladora de alimentos

\section{foodsense}

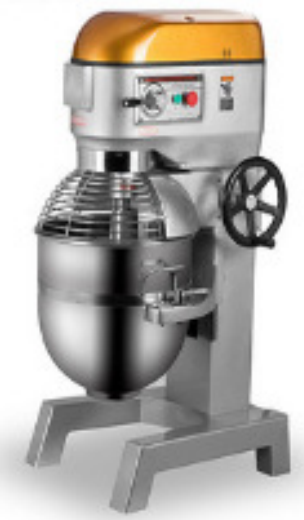

Figura 34. Equipo para mezclado de carnes, granos y verduras.

Elaboración propia.

- Balanza

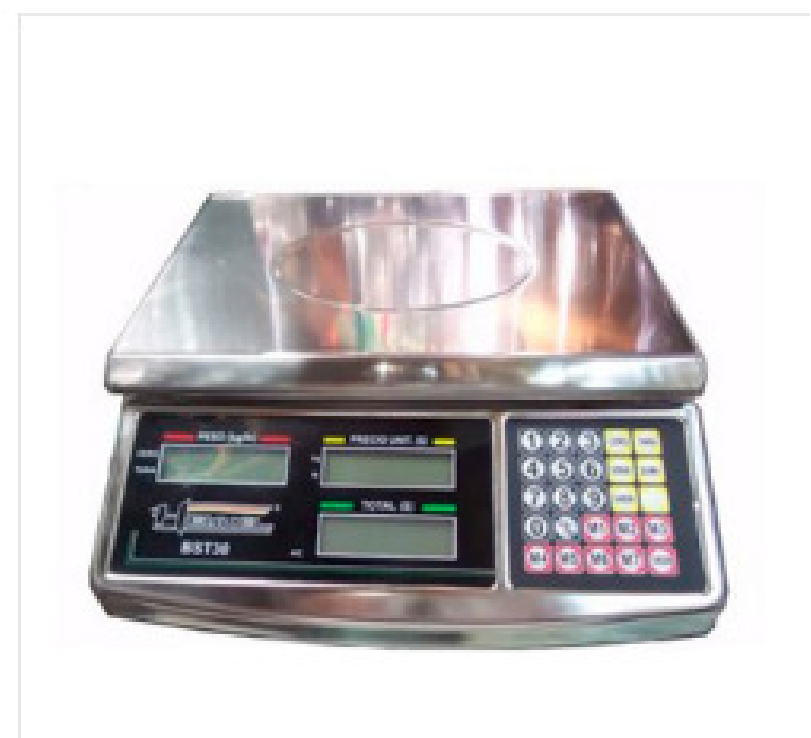

Figura 35. Balanza electrónica para pesado de alimentos . Elaboración propia. 
- Empacadora al vacío

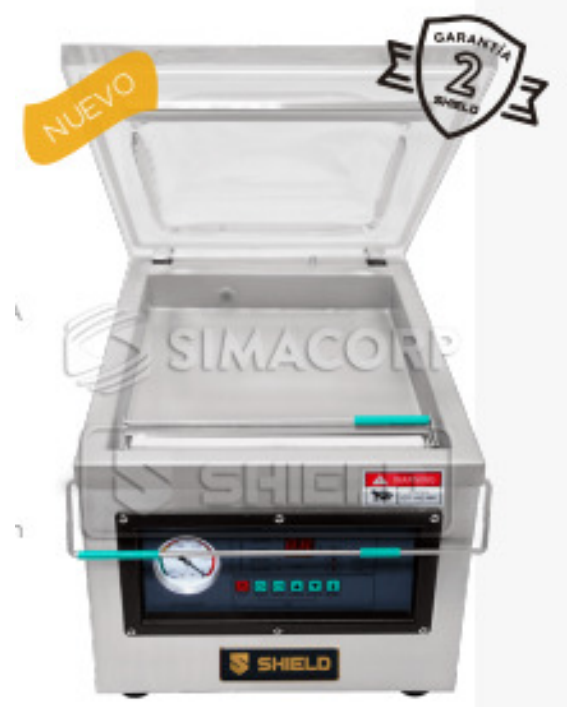

Figura 36. Sella la bolsa sin dejar oxígeno dentro de ella

Elaboración propia.

\subsubsection{Lay out}

Es el Diseño de las áreas: Administrativa, Producción y Distribución en el local que ocupa Animal Lovers.

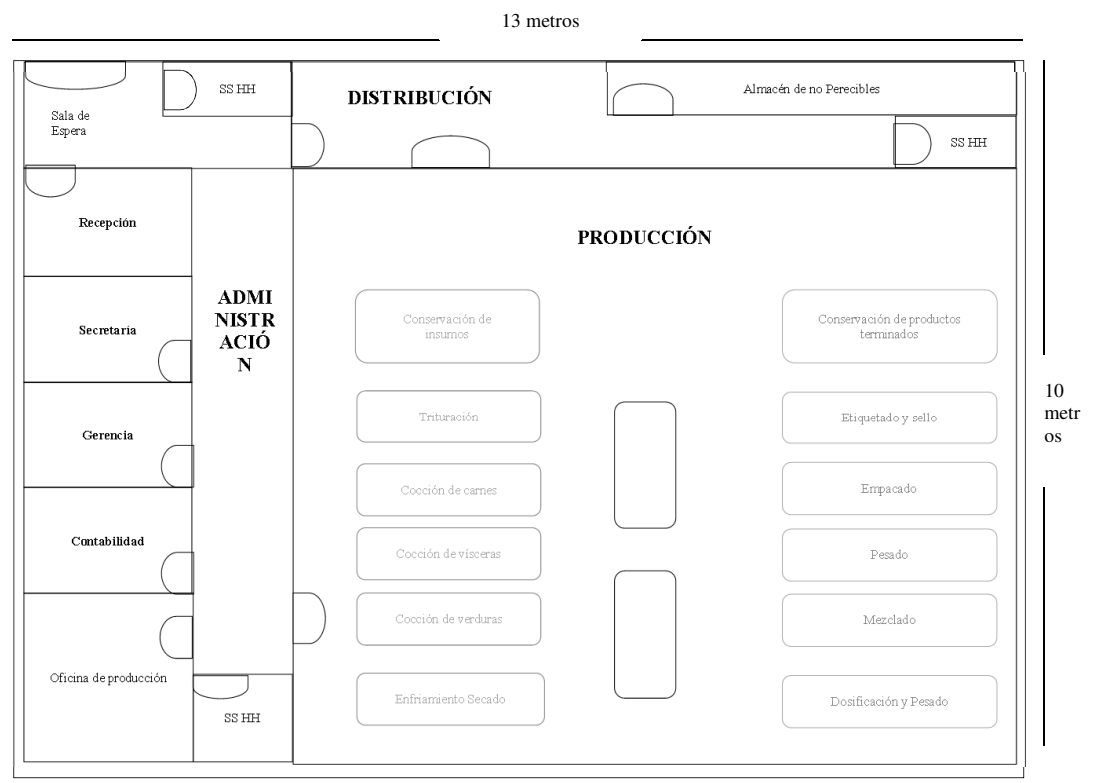

Figura 37. Plano de distribución "Animal Lovers"

Elaboración propia. 


\subsubsection{Distribución de equipos y maquinaria}

La distribución de equipos y maquinaria se diseña para facilitar la operación de preparación de los productos. La distribución en este caso es indicada en la siguiente ilustración.

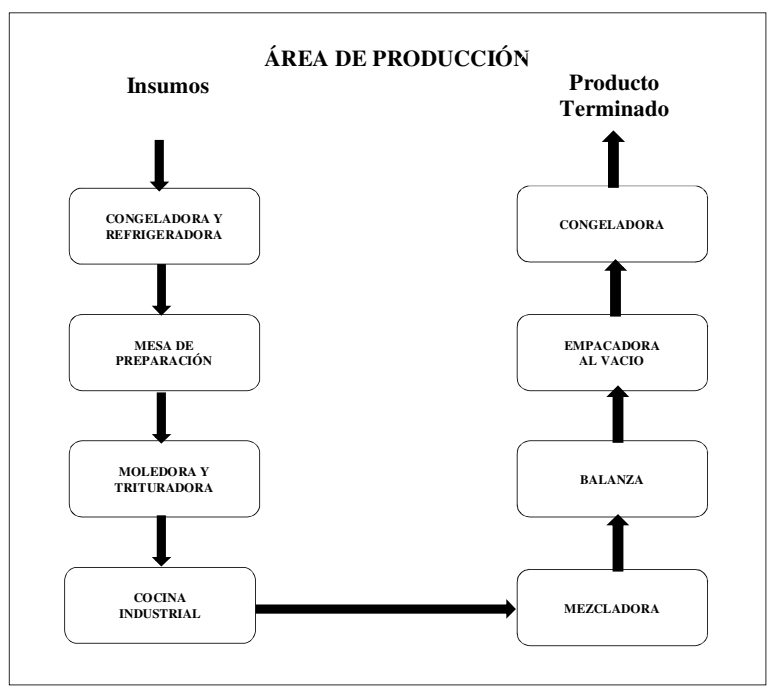

Figura 38. Área de producción "Animal Lovers". Elaboracion propia.

\subsection{Determinación del Tamaño}

Las dimensiones del área de producción se han establecido en base a ciertos factores, como:

- Capacidad instalada.

- Mercado Objetivo, Demanda y capacidad de producción.

- Equipo humano.

En tal sentido las dimensiones del área de producción son: 8 mts. X 10 mts.

\section{Capacidad instalada}

A continuación, se muestra la cantidad de insumos necesarios para la elaboración por cada tipo de producto. 
Tabla 75.- Insumos requeridos para cada tipo de producto

\begin{tabular}{ccccccc}
\hline Producto & Carnes/Vísceras & Arroz & $\begin{array}{c}\text { Verdura } \\
\text { Dura }\end{array}$ & $\begin{array}{c}\text { Verdura } \\
\text { Blanda }\end{array}$ & Huevo & $\begin{array}{c}\text { Total en } \\
\text { Kg. }\end{array}$ \\
\hline Pollo & $0.32 \mathrm{~kg}$. & $0.20 \mathrm{~kg}$. & $0.20 \mathrm{~kg}$. & $0.15 \mathrm{~kg}$. & $0.13 \mathrm{~kg}$. & $1.00 \mathrm{~kg}$. \\
\hline Pescado & $0.30 \mathrm{~kg}$. & $0.30 \mathrm{~kg}$. & $0.30 \mathrm{~kg}$. & $0.15 \mathrm{~kg}$. & & $1.05 \mathrm{~kg}$. \\
\hline Res & $0.38 \mathrm{~kg}$. & $0.20 \mathrm{~kg}$. & $0.30 \mathrm{~kg}$. & $0.10 \mathrm{~kg}$. & & $0.98 \mathrm{~kg}$. \\
\hline
\end{tabular}

Nota: Elaboración propia.

De acuerdo con la estrategia de Animal Lovers, del 100\% de producción, se produce el $50 \%$ de pollo, el $30 \%$ de pescado y el $20 \%$ de res.

La producción anual de los primeros tres años exige una producción de $60 \mathrm{~kg}$. a 100 $\mathrm{kg}$. diarios.

El cuadro ubicado a continuación, muestra la cantidad requerida de insumos para producir $100 \mathrm{~kg}$. de producto.

Tabla 76.- Insumos requeridos para cada 100 productos

\begin{tabular}{ccccccccc}
\hline Producto & $\begin{array}{c}\text { Cantidad por } \\
\text { Tipo de } \\
\text { Producto }(\%)\end{array}$ & $\begin{array}{c}\text { Cantidad por } \\
\text { Tipo de } \\
\text { Producto } \\
(\mathbf{1} \text { kg.) }\end{array}$ & $\begin{array}{c}\text { Carnes / } \\
\text { Vísceras } \\
(\mathbf{k g})\end{array}$ & $\begin{array}{c}\text { Arroz } \\
(\mathbf{k g} .)\end{array}$ & $\begin{array}{c}\text { Verdura } \\
\text { Dura } \\
(\mathbf{k g})\end{array}$ & $\begin{array}{c}\text { Verdura } \\
\text { Blanda } \\
(\mathbf{k g})\end{array}$ & $\begin{array}{c}\text { Huevo } \\
(\mathbf{k g})\end{array}$ & $\begin{array}{c}\text { Total } \\
(\mathbf{k g} .)\end{array}$ \\
\hline Pollo & $50 \%$ & 50 & 16.00 & 10.00 & 10.00 & 7.50 & 6.50 & 50.00 \\
\hline Pescado & $30 \%$ & 30 & 9.00 & 9.00 & 9.00 & 4.50 & 31.50 \\
\hline Res & $20 \%$ & 20 & 7.60 & 4.00 & 6.00 & 2.00 & 19.60 \\
\hline Total & $\mathbf{1 0 0 \%}$ & $\mathbf{1 0 0}$ & $\mathbf{3 2 . 6 0}$ & $\mathbf{2 3 . 0 0}$ & $\mathbf{2 5 . 0 0}$ & $\mathbf{1 4 . 0 0}$ & $\mathbf{6 . 5 0}$ & $\mathbf{1 0 1 . 1 0}$ \\
\hline
\end{tabular}

Nota: Elaboración propia.

El siguiente cuadro muestra la capacidad de producción de Animal Lovers por día, basándose en la capacidad de los equipos. 
Tabla 77.- Capacidad de producción

\begin{tabular}{|c|c|c|c|c|c|c|c|}
\hline Equipo & $\begin{array}{l}\text { Capacidad del } \\
\text { Equipo }\end{array}$ & $\begin{array}{l}\text { Capacidad de } \\
\text { producción } \\
\text { mínima }\end{array}$ & $\begin{array}{l}\text { Capacid } \\
\text { ad de } \\
\text { producci } \\
\text { ón } \\
\text { diaria }\end{array}$ & $\begin{array}{c}\text { Capacidad } \\
\text { de } \\
\text { producción } \\
\text { mensual }\end{array}$ & $\begin{array}{l}\text { Capacidad } \\
\text { de } \\
\text { producción } \\
\text { anual }\end{array}$ & $\begin{array}{c}\mathbf{N}^{\circ} \text { de } \\
\text { equipos }\end{array}$ & $\begin{array}{c}\text { Capacidad de } \\
\text { producción } \\
\text { anual (kg) }\end{array}$ \\
\hline Congeladora & 560 lt. & $250 \mathrm{~kg}$. & $250 \mathrm{~kg}$ & 7,500 & 90,000 & 4 & 360,000 \\
\hline Refrigeradora & 568 lt. & $250 \mathrm{~kg}$. & $250 \mathrm{~kg}$. & 7,500 & 90,000 & 2 & 180,000 \\
\hline Moledora de Carne & $120 \mathrm{~kg} / \mathrm{h}$ & $120 \mathrm{~kg} / \mathrm{h}$ & $960 \mathrm{~kg}$ & 28,800 & 345,600 & 1 & 345,600 \\
\hline $\begin{array}{l}\text { Trituradora de } \\
\text { vegetales }\end{array}$ & $500 \mathrm{~kg} / \mathrm{h}$ & $500 \mathrm{~kg} / \mathrm{h}$ & $4,000 \mathrm{~kg}$ & 120,000 & $1,440,000$ & 1 & $1,440,000$ \\
\hline Cocina Industrial & 6 hornillas & \multirow{2}{*}{$240 \mathrm{~kg}$. } & \multirow{2}{*}{$1,920 \mathrm{~kg}}$. & \multirow{2}{*}{57,600} & \multirow{2}{*}{691,200} & \multirow{2}{*}{1} & \multirow{2}{*}{691,200} \\
\hline Ollas & $40 \mathrm{~kg}$. & & & & & & \\
\hline Mezcladora & $40 \mathrm{lt} / \mathrm{h}$ & $40 \mathrm{lt} / \mathrm{h}$ & $320 \mathrm{~kg}$. & 10,800 & 129,600 & 1 & 129,600 \\
\hline Balanza electrónica & $30 \mathrm{Kg}$. & $30 \mathrm{Kg}$. & $320 \mathrm{~kg}$. & 10,800 & 129,600 & 1 & 129,600 \\
\hline $\begin{array}{l}\text { Empacadora al } \\
\text { vacío }\end{array}$ & $\begin{array}{c}20 \\
\text { empaques/hora }\end{array}$ & $\begin{array}{c}20 \\
\text { empaques/hora }\end{array}$ & $160 \mathrm{~kg}$. & 4,800 & 57,600 & 3 & 172,800 \\
\hline
\end{tabular}

Nota: Elaboración propia

\subsubsection{Proyección de crecimiento}

La proyección de crecimiento se toma sobre los estimados analizados en tablas anteriores.

Tabla 78.- Pronóstico de venta. Proyección 2016 - 2022

\begin{tabular}{cccccc}
\hline Concepto & 2019 & 2020 & 2021 & 2022 & 2023 \\
\hline $\begin{array}{c}\text { Producción real proyectada } \\
\text { (kilogramos) }\end{array}$ & 44,887 & 53,865 & 63,560 & 72,459 & 80,429 \\
\hline $\begin{array}{c}\text { Capacidad máxima de producción } \\
\text { en planta (kilogramos) }\end{array}$ & \multicolumn{3}{c}{129,600 por año } \\
\hline
\end{tabular}

Nota: Elaboración propia

\subsubsection{Recursos}

Los recursos fundamentales para las operaciones de producción corresponden a la mano de obra y los equipos.

En lo que concierne a la mano de obra directa (elaboración del producto) se iniciarán las operaciones con dos (2) personas (un jefe de producción y un operario). Para finalmente culminar el 5 to año con la contratación de cinco (5) personas. 
Tabla 79.- Presupuesto anual de mano de obra directa

\begin{tabular}{lccccccccccc}
\hline & \multicolumn{1}{c}{ Año 1 } & \multicolumn{2}{c}{ Año 2 } & \multicolumn{2}{c}{ Año 3 } & \multicolumn{2}{c}{ Año 4 } & \multicolumn{2}{c}{ Año 5 } \\
\hline Jefe de producción & S/ & 19,137 & S/ & 19,520 & S/ & 19,910 & S/ & 20,308 & S/ & 20,714 \\
\hline Operario de producción & S/ & 18,590 & S/ & 18,962 & S/ & 19,341 & S/ & 19,728 & S/ & 20,123 \\
\hline Ayudante de producción 1 & & & & & S/ & 16,950 & S/ & 17,289 & S/ & 17,635 \\
\hline Ayudante de producción 2 & & & & & & & & S/ & 16,950 \\
\hline Ayudante de producción 3 & & & & & & & & & & \\
\hline Ayudante part time & & & S/ & 8,475 & & & S/ & 8,644 & S/ & 8,817 \\
\hline Costo Total - MOD & S/ & 37,727 & S/ & 46,957 & S/ & 56,201 & S/ & 65,970 & S/ & 84,239 \\
\hline
\end{tabular}

Nota: Elaboración propia

En lo concerniente a los equipos, éstos han sido seleccionados pensando en el precio, la calidad y el potencial de producción que ostentan. A continuación, se presentan algunos recursos con precios y calidad referenciales de mercado.

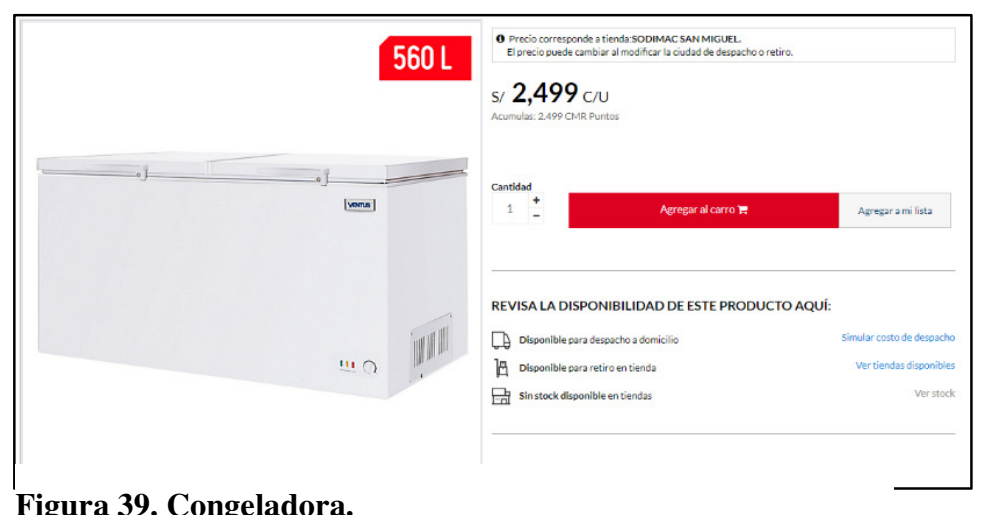

Figura 39. Congeladora.

Recuperado de https://www.sodimac.com.pe/sodimacpe/product/3461092/congelador-horizontal-dual-2-tapas-5671.

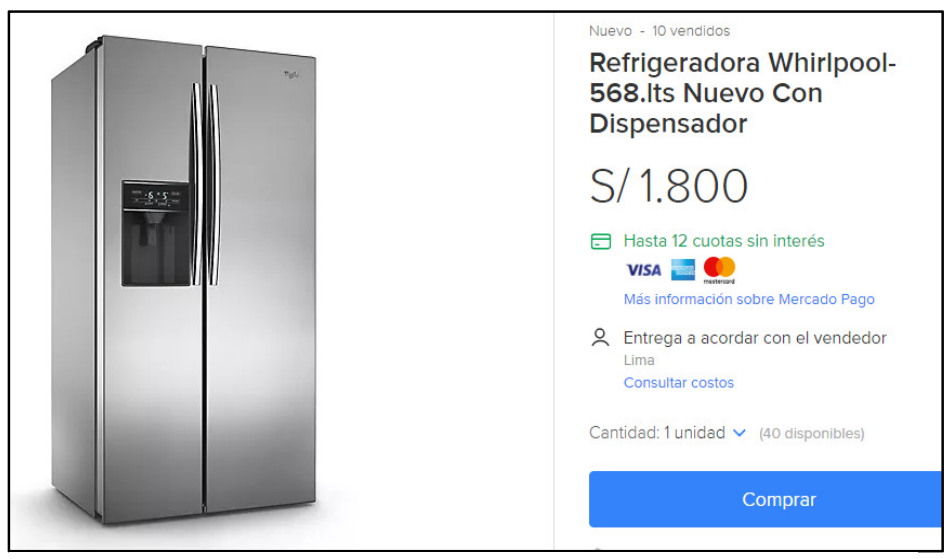

Figura 40. Refrigeradora 
Recuperado de https://articulo.mercadolibre.com.pe/MPE-432059439refrigeradora-whirlpool-5681ts-nuevo-con-dispensador-_JM?quantity=1

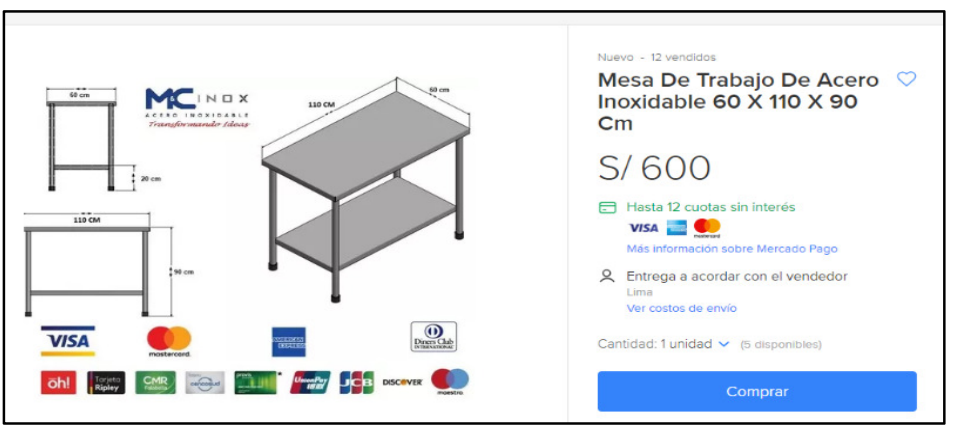

Figura 41. Mesa de trabajo

Recuperado de https://articulo.mercadolibre.com.pe/MPE-425859470mesa-de-trabajo-de-acero-inoxidable-60-x-110-x-90-cm-_JM?quantity=1

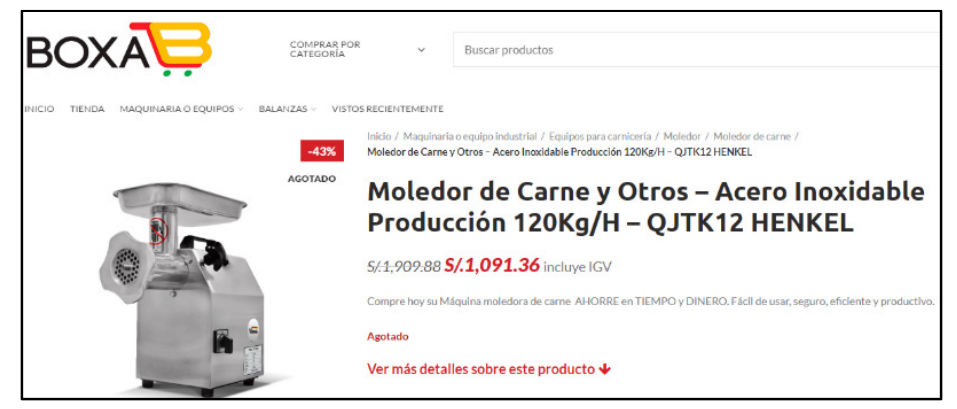

Figura 42. Moledora de carne

Recuperado de https://www.boxa.com.pe/p/moledora-de-carne-120-kg/

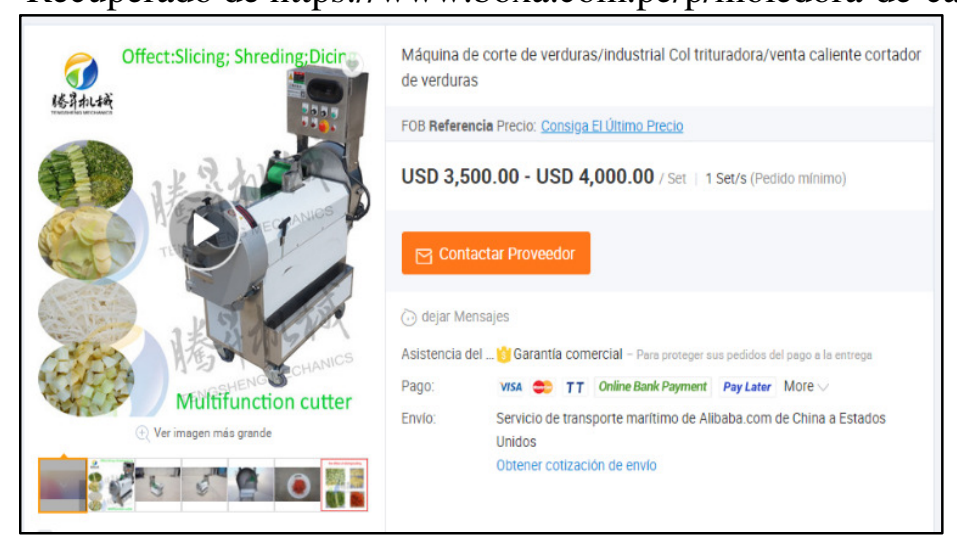

Figura 43. Trituradora de alimentos

Recuperado de https://spanish.alibaba.com/product-detail/vegetablecutting-machine-industrial-cabbage-shredder-hot-sale-vegetable-cutter60579904407.html 


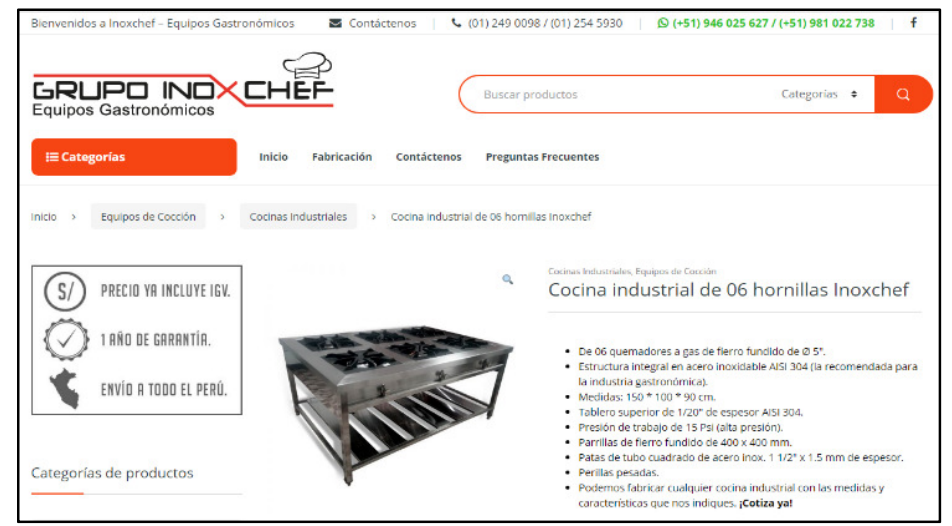

Figura 44. Cocina.

Recuperado de

https://inoxchef.com/producto/cocina-industrial-de-06-hornillas-inoxchef/

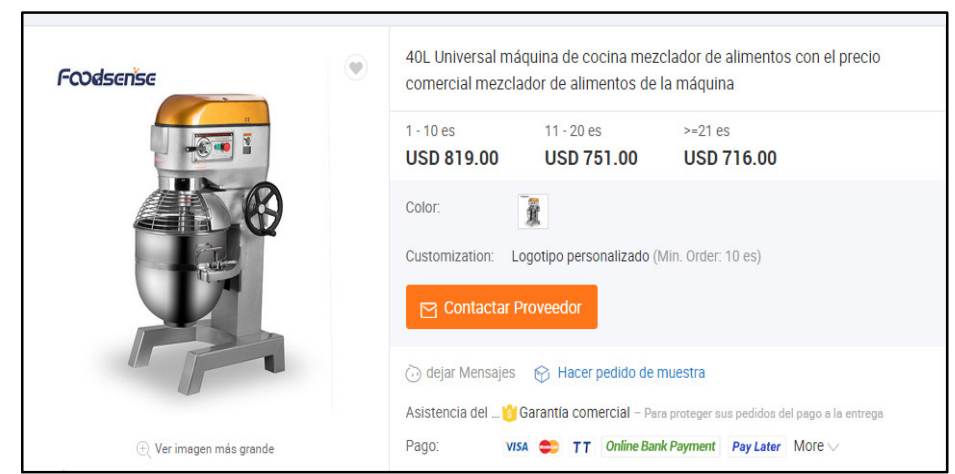

Figura 45. Mezcladora de alimentos.

Recuperado de https://spanish.alibaba.com/product-detail/401-universalkitchen-machine-food-mixer-with-price-commercial-food-mixer-machine50045471624.html?spm=a2700.8699010.normalList.16.fc3b5cb3JAthLx

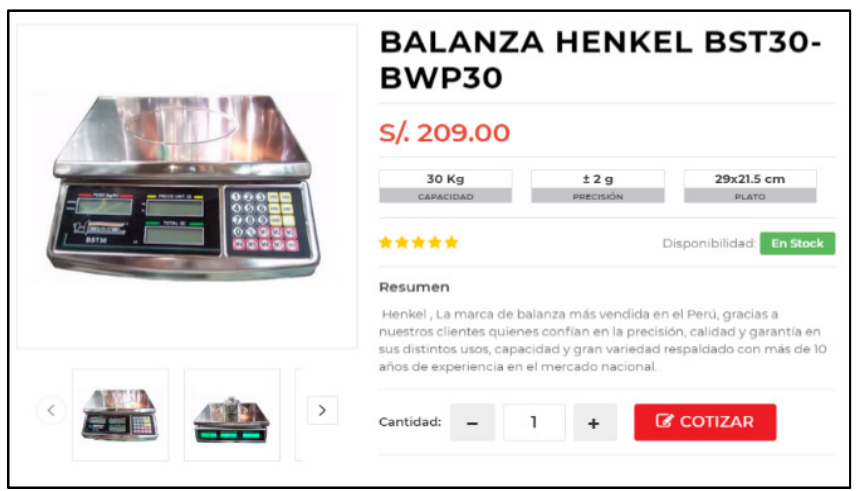

Figura 46. Balanza.

Recuperado de http://www.dbalanzas.com/balanza-henkel-bst30-bwp30 


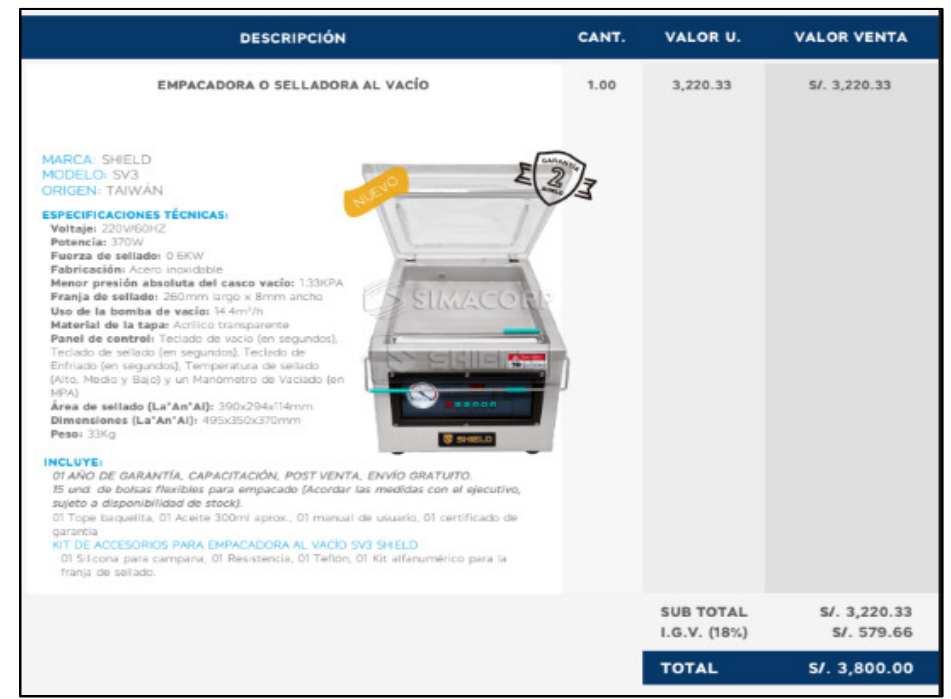

Figura 47. Empacadora al vacío

Recuperado de https://www.simacorp.pe/productos/empacadora-al-vaciosv3-shield/

\subsubsection{Tecnología}

La tecnología empleada en el proceso productivo de los alimentos considera ciertas actividades fundamentales.

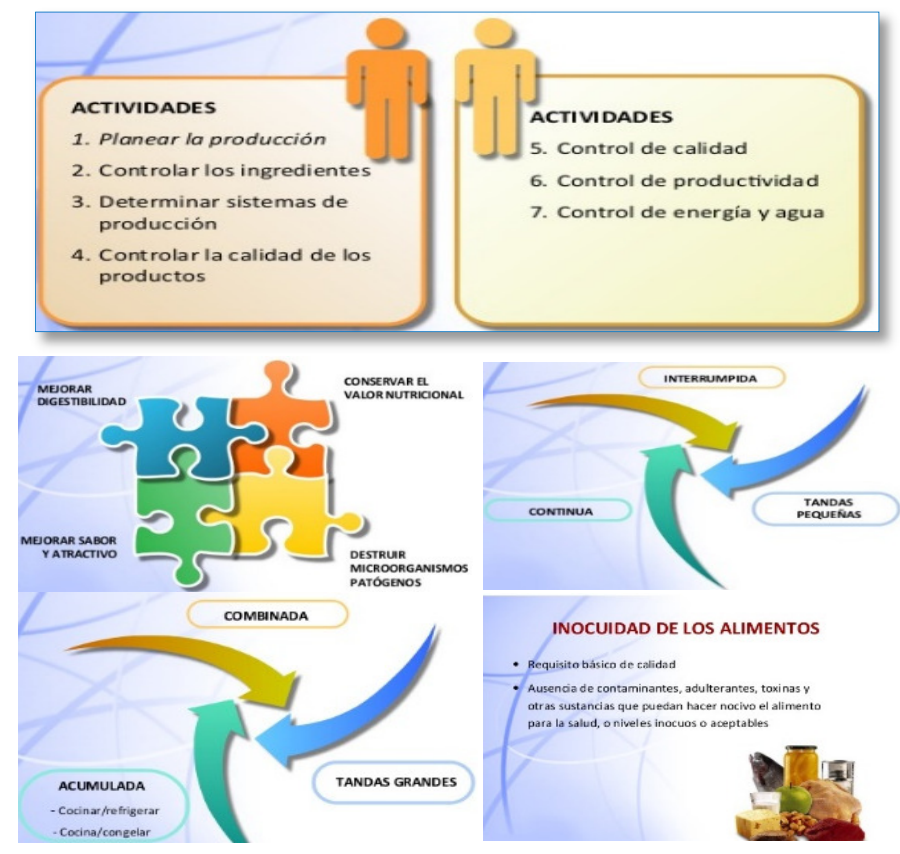


Figura 48. . Tecnología. Actividades del proceso productivo

Elaboración propia

\section{Buenas Prácticas de Manufactura}

Las Buenas Prácticas de Manufactura (BPM), son un conjunto de procedimientos de tipo operativo relacionados con la prevención y el control de los peligros de contaminación, hábitos de higiene y de manipulación, tanto del personal que realiza los procesos, como las instalaciones donde se efectúa el proceso, en los equipos que se utilizan para hacer un producto, en la selección de los proveedores.

La implementación de Buenas Prácticas de Manufactura BPM es una herramienta básica necesaria para la obtención de productos aptos y de calidad seguros para el consumo humano y en este caso para consumo animal, sustentado en la higiene y en la forma de manipulación.

Este Reglamento sobre Vigilancia y Control Sanitario de Alimentos y Bebidas, establece la obligatoriedad del uso de BPM para todos los establecimientos elaboradores industrializadores de alimentos.

\section{Beneficios de implementar BPM}

- Evidencia de una manipulación segura y eficiente de los alimentos.

- Trabajo con Calidad entre los empleados, así como su nivel de capacitación.

- Reducción de reclamos, devoluciones y reprocesos.

- Eficiencia y optimización de los costos.

- Competitividad y de la productividad de la empresa.

- Posicionamiento de la empresa y fidelización de los clientes.

\section{Tiempo implementación de BPM}


Desde el inicio de las operaciones con una orientación de mejora continua.

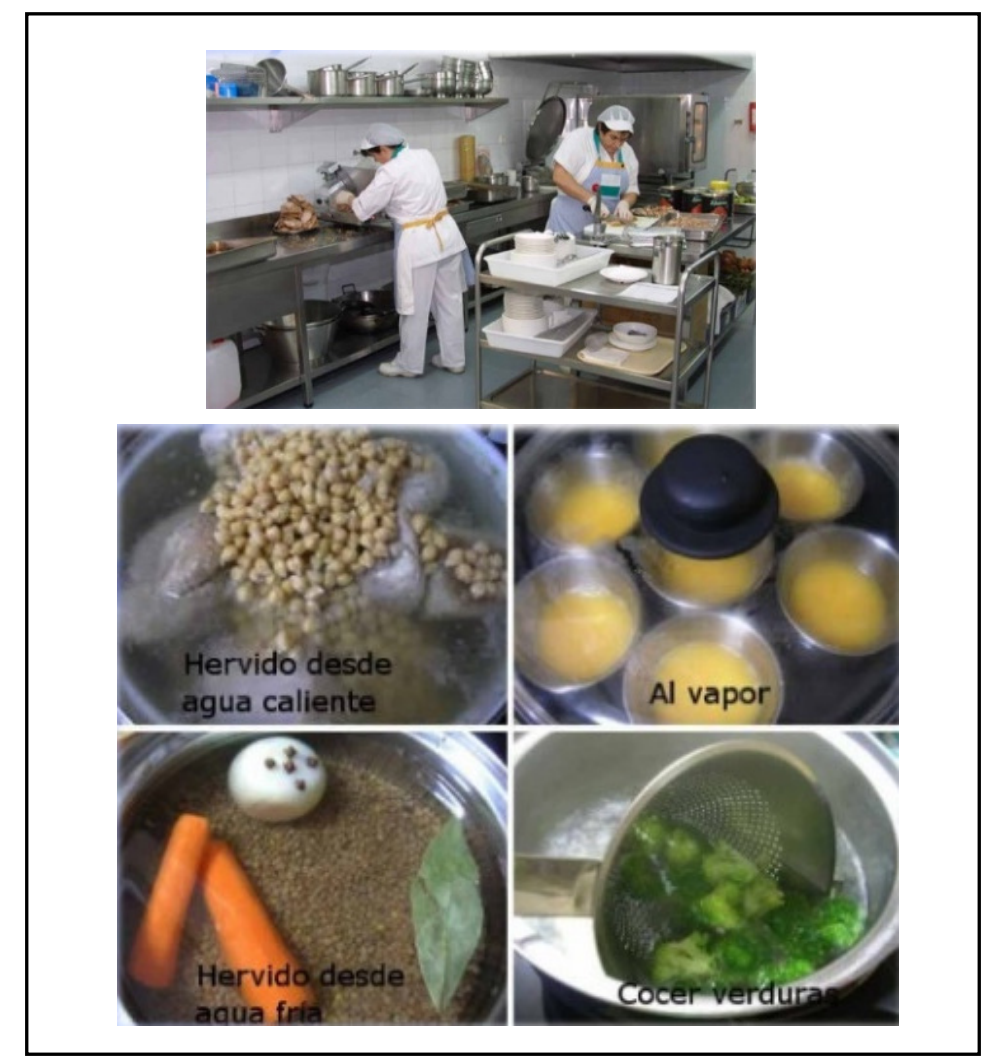

Figura 49. . Operaciones

Elaboración propia

\subsubsection{Flexibilidad}

Flexibilidad para ampliar la capacidad de producción sin pasar por alto las buenas prácticas en la elaboración de los alimentos. Dicha flexibilidad queda evidenciada porque Animal Lovers plantea atender anualmente una demanda de 22 toneladas y la capacidad de los equipos permite más del doble. Sin embargo, es importante destacar la contratación de personal adicional y la ampliación del área de producción. 


\subsubsection{Selección del tamaño ideal}

La dimensión ideal e inicial para el proyecto es de 80 m2 (las dimensiones de dicha área de producción son: 8 mts. x 10 mts.), con lo cual tendremos el espacio ideal de la maquinaria y el espacio que cumpla las normas de seguridad en el proceso de producción.

\subsection{Estudio de Localización}

Animal Lovers se dirige a cuatro (4) distritos: Miraflores, San Borja, San Isidro y Santiago de Surco. En consecuencia, es importante la ubicación estratégica del centro de producción tomando en consideración los siguientes factores:

- $\quad$ La ubicación del público objetivo.

- La ubicación del centro de producción con acceso a los cuatro (4) distritos.

- La selección de los puntos de venta.

\subsubsection{Definición de factores locacionales}

Los factores de localización para elegir una ubicación para el centro de producción tienen relación con el cuadro mostrado a continuación.

Tabla 80.- Alternativas de localización

\begin{tabular}{cccccc}
\hline & \multicolumn{2}{c}{$\begin{array}{c}\text { Surquillo } \\
\text { (límite con San Borja) }\end{array}$} & \multicolumn{2}{c}{$\begin{array}{c}\text { Surquillo } \\
\text { (límite con Miraflores) }\end{array}$} \\
\hline Factor & Peso & Calificación & Ponderado & Calificación & Ponderado \\
\hline Valor del M2 & 0.25 & 3 & 0.75 & 2 & 0.50 \\
\hline Cobertura & 0.45 & 4 & 1.80 & 4 & 1.80 \\
\hline $\begin{array}{c}\text { Distribución } \\
\text { física }\end{array}$ & 0.10 & 3 & 0.30 & 3 & 0.30 \\
\hline Accesibilidad & 0.10 & 3 & 0.30 & 2 & 0.20 \\
\hline Seguridad & 0.10 & 3 & 0.30 & 3 & 0.30 \\
\hline
\end{tabular}

Nota: Elaboración propia

El cuadro muestra que Surquillo es el distrito que se analiza con detalle pues tienen a su alrededor a todos los demás distritos. 
La estrategia se cifró en seleccionar una zona que fuera colindante con San Borja o Miraflores, para mantener siempre el centro estratégico al medio de los distritos seleccionados.

Luego de analizar, se decide por el límite con San Borja, debido a factores de precio, accesibilidad y como centro estratégico de distribución.

\section{Valor del M2}

El predio debe ubicarse en una zona de bajo precio donde los vecinos son en su mayoría personas de nivel socioeconómico DE, pertenecientes al distrito de Surquillo. El precio del alquiler por un área de $100 \mathrm{~m} 2$ es de S/ 2,500 mensuales aproximadamente.

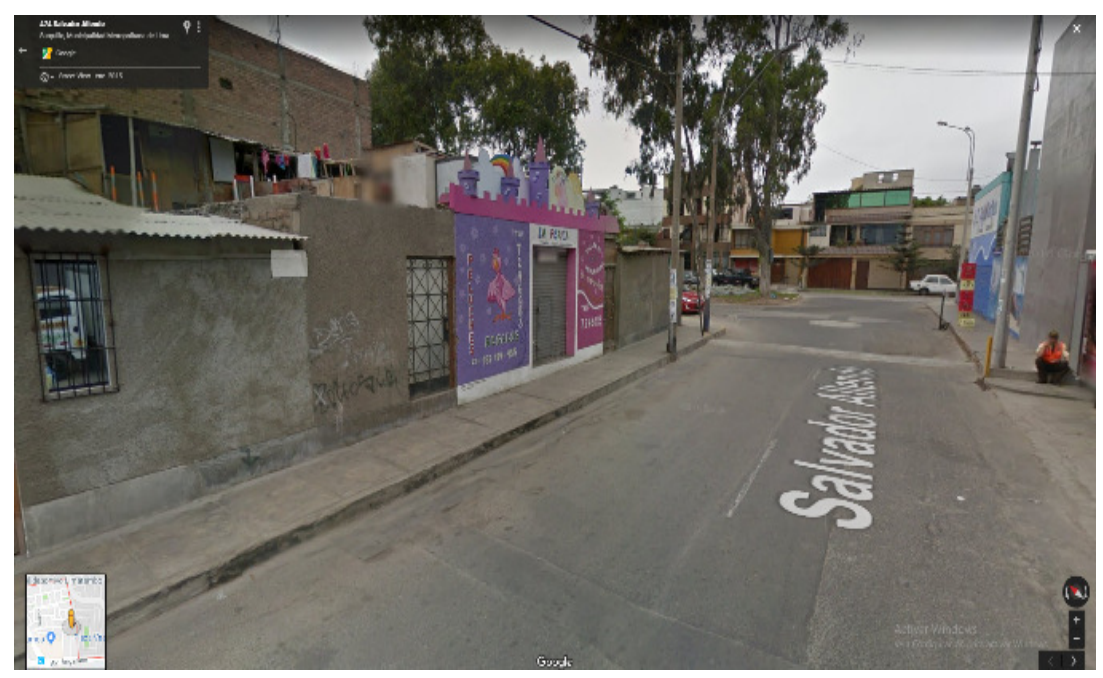

Figura 50. Ubicación de local de producción

Recuperado de https://www.google.com/maps

\section{Cobertura de mercado}


El local debe ubicarse en Surquillo, colindando con Miraflores, San Borja,

San Isidro y Santiago de Surco.

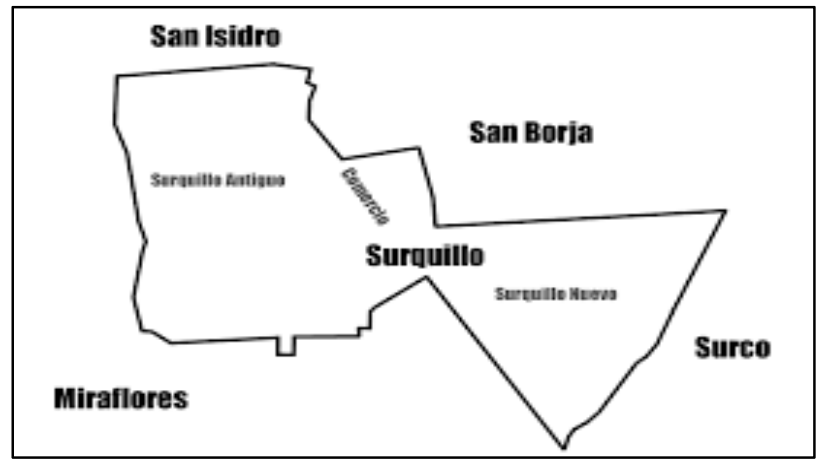

Figura 51. Cobertura del mercado

Elaboración propia. 


\section{Distribución Física}

La accesibilidad a los distritos permite que el local pueda hacer efectiva la distribución tanto en el local de producción como en los puntos de venta de los distritos indicados.

\section{Accesibilidad para el cliente}

La ubicación permite que el cliente tenga un acceso cómodo y rápido, con acceso a avenidas principales.

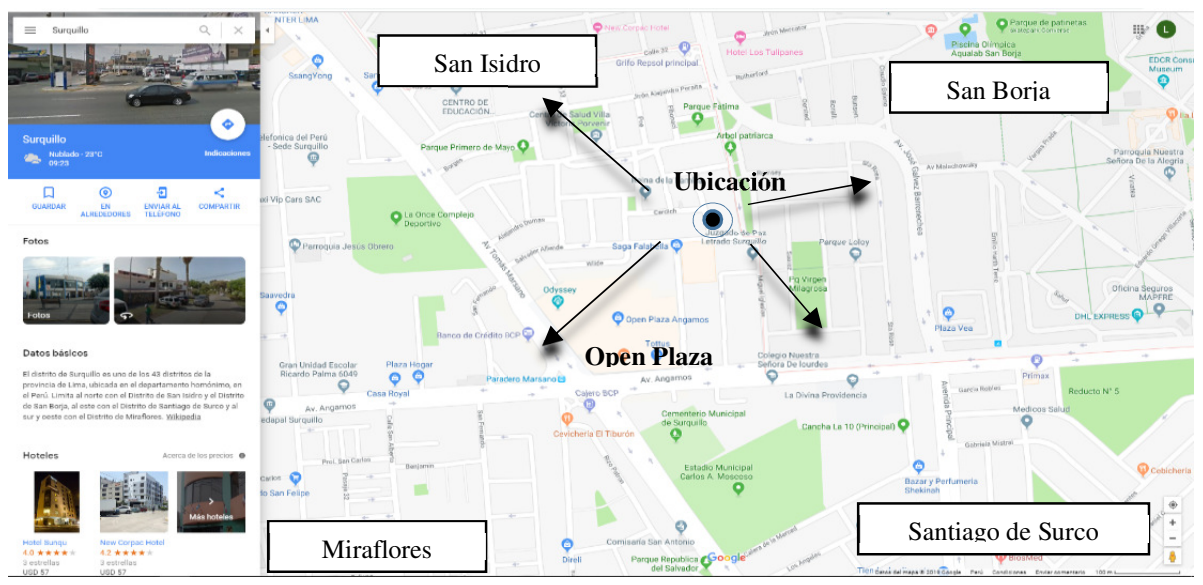

Figura 52. Accesibilidad para clientes

Elaboración propia.

\subsubsection{Consideraciones legales.}

\subsubsection{Identificación del marco legal.}

La legislación laboral peruana para la formación de las Micro y Pequeñas Empresas dispone lo siguiente:

Las ventas anuales son de 150 UIT $(\mathrm{S} / 622,500)$ para la microempresa y 1,700 UIT (S/ 7’055,000) para la pequeña empresa.

El Ministerio de Trabajo norma deberes y derechos de los trabajadores, así como de las empresas. 
La empresa registra a todos sus trabajadores en las planillas de pago dentro de las 72 horas de ingresados a prestar sus servicios, independientemente de que se trate de un contrato por tiempo indeterminado, sujeto a modalidad o tiempo parcial.

La empresa está obligada a conservar sus planillas de pago, el duplicado de las boletas y las constancias correspondientes hasta 5 años después de haber efectuado el pago.

Constituye remuneración para todo efecto legal el integro de lo que el trabajador recibe por sus servicios, en dinero o especie, cualquiera sea la forma o denominación, siempre que sea de su libre disposición. El pago no puede ser inferior al establecido por la RMV (Remuneración mínima vital de S/ 930.00) que marca el ingreso mínimo por jornada ordinaria.

La jornada laboral ordinaria para hombres y mujeres es de 8 horas diarias, pudiendo extenderse hasta un máximo de 48 horas semanales.

El pago de sobre tiempo se abona con un recargo a convenir entre el trabajador y la empresa, pero que no podrá ser menor a $25 \%$ por hora calculado sobre la remuneración ordinaria. También está la posibilidad de acordar el pago de sobretiempo con el otorgamiento de periodos equivalentes de descanso.

Los trabajadores que cumplan una jornada ordinaria mínima de 4 horas tienen derecho a 15 días calendario de descanso vacacional por cada año completo de servicios. 


\subsubsection{Ordenamiento jurídico de la empresa}

\section{Tramitación de RUC}

La SUNAT es la encarga de emitir el RUC. Los requisitos para su obtención son:

- Escritura Pública de constitución en Registros Públicos.

- Documentos de identidad del representante legal.

- Recibos de servicios de los últimos dos meses.

- Inscribirse treinta días antes de la fecha de apertura.

\section{Licencia de Funcionamiento}

La licencia para el funcionamiento de la empresa "Animal Lovers" deberá ser tramitada en la Municipalidad de Surquillo.

Requisitos para el otorgamiento de la licencia de funcionamiento:

- $\quad$ Solicitud de Licencia de Funcionamiento.

- $\quad$ Numero de RUC y DNI del solicitante, tratándose de personas Jurídicas o naturales, según corresponda.

- DNI del representante legal en caso de personas jurídicas, u otros entes colectivos, o tratándose de personas naturales que actúen mediante representación.

- Vigencia de poder de representante legal, en el caso de personas jurídicas u otros entes Colectivos. Tratándose de representación de personas naturales, se requerirá carta poder con firma legalizada.

- Declaración Jurada de Observancia de las Condiciones de Seguridad Básica o Inspección, además de una declaración jurada de inspección técnica de Defensa Civil. 


\section{Inspección Técnicas de Defensa Civil}

La Inspección Técnica de Seguridad en Defensa Civil (ITSDC) es la revisión de las condiciones de seguridad que tiene una edificación, recinto o instalación de todo tipo donde viva, trabaje, o concurra público.

Las ITSDC se encuentran reguladas por el Decreto Supremo $\mathrm{N}^{\circ} 013$ 2000-PCM y el Decreto Supremo Nº74-2005-PCM.

Se debe respetar ciertas normas, tanto técnicas como legales. Las normas técnicas están dadas por distintos entes.

INDECOPI tiene reglamentos sobre señales de seguridad además de las Normas Técnicas Peruanas Obligatorias. El Ministerio de Energía y Mina regula las medidas de seguridad con respecto a la electricidad (ver anexo).

\section{Marcas}

El registro de marca se efectúa en INDECOPI. Una marca es todo signo que sirve para identificar en el mercado los productos o servicios, diferenciándolos de los productos y servicios con los cuales compite. Una marca puede estar conformada por una palabra, combinaciones de las palabras, imágenes, figuras, símbolo, letras, cifras o, incluso formas determinadas de envases, envolturas o de formas de presentación de los productos.

Es importante registrar una marca porque es la única manera de protegerla frente a posibles copias de los demás empresarios que se quieran aprovechar de su prestigio. El registro convierte al titular en el dueño de la marca y es el único autorizado a usarla por los siguientes 10 años a partir de hecho el registro (los cuales pueden ser renovados).

Los pasos para el registro de marca del producto son los siguientes: 
a. Pago del derecho de trámite. El costo es equivalente al 30.60\% de la UIT. Esto debe ser cancelado en las oficinas de INDECOPI.

b. Presentación del formato de solicitud correspondiente a la identificación del solicitante.

c. Se debe precisar cuál es el signo para registrar. Si el signo tiene elementos gráficos, se debe presentar la descripción de este y adjuntar su reproducción.

d. Se debe indicar de manera clara cuales son los productos, servicios y/o actividades económicas que se desea registrar, así como también se debe especificar cuál es la clase en que se solicita dicho registro.

e. La Notificación es entregada después de treinta días hábiles de presentación de la solicitud de registro. Con la notificación se presenta en máximo tres meses, la publicación en El Peruano.

\section{Forma Societaria}

La razón social será “Animal Lovers". Se ha decidido trabajar con este tipo de sociedad por las principales características de una Sociedad Anónima Cerrada, (S.A.C), la cual se encuentra regulada por la Ley General de Sociedades 26887.

- $\quad$ El mínimo es de dos (2) y máximo de veinte (20) accionistas.

- $\quad$ Sus acciones no pueden ser inscritas en el registro Público del Mercado de Valores. El patrimonio personal de los socios no está afecto. Es una sociedad de responsabilidad limitada.

- Los miembros de una Sociedad Anónima Cerrada son: 
- Junta General de Accionistas: es el órgano supremo de la sociedad, está integrado por el total de socios que conforman la empresa.

- Gerente General: es la persona en quien recae la representación legal y de gestión de la sociedad, es quien convoca a la Junta de Accionistas.

También es necesaria la elaboración del Pacto Social, y el Estatuto que regirá las pautas de la persona Jurídica.

El Accionariado estará conformado por:

- $\quad$ Luis Ibarra (33.3\%)

- $\quad$ Ronald Martinez (33.3\%)

- $\quad$ Miguel Serna $\quad(33.3 \%)$

Las personas indicadas son miembros de la Junta General de Accionistas. En consecuencia, aprueban o desaprueban sobre decisiones e inversiones a seguir por la gerencia.

\section{Requisitos para la constitución de la empresa:}

- $\quad$ Elegir el tipo de empresa (EIRL, SRL, SA, SAC, etc.) y de acuerdo con esta los socios.

- Buscar y reservar nombre en RRPP por 30 días.

- Elaborar la minuta con notario dando todos los detalles de aportes.

- Abrir una cuenta bancaria.

- Elevar a Registros Públicos para partida electrónica.

- Inscribir en la Sunat cuando salga la partida electrónica. 


\subsection{Determinación de la localización óptima}

La evaluación ha definido que la ubicación del local de Animal Lovers se encuentre en Surquillo, muy cerca al límite con San Borja.

El valor del $\mathrm{m}^{2}$, cobertura del mercado, accesibilidad, la facilidad para la distribución física y la seguridad hacen posible que este lugar sea el apropiado, alcanzado un puntaje de 3.45

Tabla 81.- Alternativa de localización seleccionada

\begin{tabular}{llcc}
\hline \multicolumn{1}{c}{ Factor } & Peso & Calificación & Resultado \\
\hline Valor del M2 en alquiler & 0.25 & 3 & 0.75 \\
\hline Cobertura de mercado & 0.45 & 4 & 1.80 \\
\hline Distribución física & 0.10 & 3 & 0.30 \\
\hline Accesibilidad para el cliente & 0.10 & 3 & 0.30 \\
\hline Seguridad & 0.10 & 3 & 0.30 \\
\hline
\end{tabular}

Nota: Elaboración propia

La ubicación del local de Animal Lovers se encuentra en el área comprendida entre:

- $\quad$ El mercado de Surquillo situado en la calle Palacios.

- La finalización de la Av. Gálvez Barrenechea.

- $\quad$ A dos (2) cuadras de la salida del estacionamiento del Open Plaza (Jean Paul Sartre).

- $\quad$ Las calles: Méndez, Miguel Iglesias, Salvador Allende, Goethe, (límite de Surquillo son San Borja). 


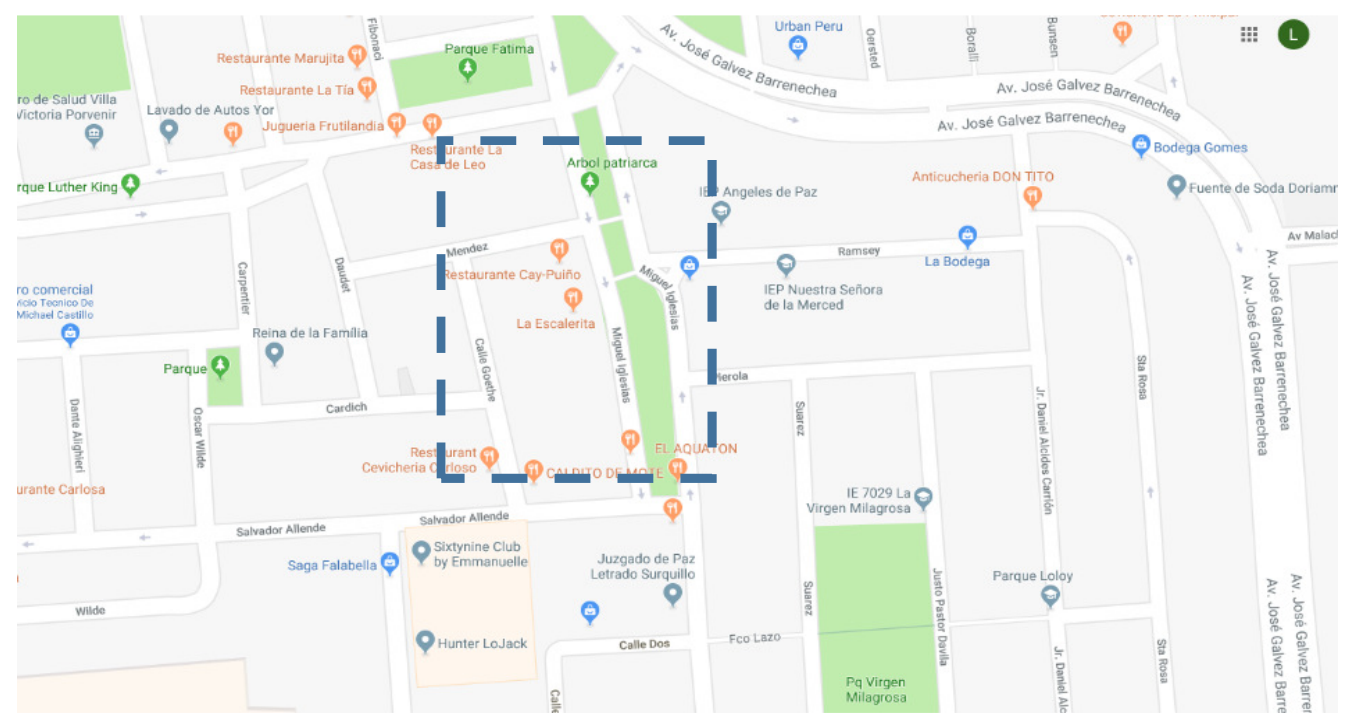

Figura 53. Ubicación de “Animal Lovers".

Recuperado de https://www.google.com/maps 


\section{CAPÍtUlo VIII}

\section{ASPECTOS ORGANIZACIONALES}

\subsection{Características de la cultura organizacional.}

\subsubsection{Visión.}

Es inspiradora e integra un futuro ideal para la organización desde una perspectiva de desarrollo. En virtud de ello, la pregunta a responder es:

¿Qué queremos ser?

Este ejercicio proyecta una visión, cuyos componentes apuntan a construir una sólida imagen empresarial hacia futuro.

Componentes de la propuesta de visión

Tabla 82.- Componentes de la propuesta de visión

\begin{tabular}{|c|c|c|c|c|}
\hline $\mathbf{N}^{\circ}$ & ELEMENTO & BASE & SUSTENTO & $\begin{array}{l}\text { TEXTO DE LA } \\
\text { PROPUESTA }\end{array}$ \\
\hline 1 & Cliente & $\begin{array}{l}\text { Mascotas } \\
\text { caninas }\end{array}$ & Un miembro de la familia & \multirow{3}{*}{$\begin{array}{l}\text { (6) Ser reconocidos, } \\
\text { (5) en el ámbito nacional } \\
\text { (4) como líderes } \\
\text { (2) en la elaboración de } \\
\text { alimento natural, balanceado, } \\
\text { - no procesado industrialmente } \\
\text { (1) para nuestras mascotas, } \\
\text { pequeños miembros de nuestra } \\
\text { familia, } \\
\text { (3) con el respaldo profesional } \\
\text { de nuestros colaboradores }\end{array}$} \\
\hline 2 & $\begin{array}{l}\text { Producto / } \\
\text { Servicio }\end{array}$ & $\begin{array}{l}\text { Alimento } \\
\text { canino }\end{array}$ & $\begin{array}{c}\text { Diseñados en base a } \\
\text { necesidad nutricional con } \\
\text { insumos naturales de } \\
\text { origen animal y vegetal }\end{array}$ & \\
\hline 3 & Tecnología & Experiencia & $\begin{array}{l}\text { Nutricionistas caninos de } \\
\text { reconocido prestigio }\end{array}$ & \\
\hline
\end{tabular}

Nota: Elaboración propia. 


\section{Propuesta de visión}

“Ser reconocidos, en el ámbito nacional como líderes en la elaboración de alimento natural, balanceado, no procesado industrialmente, para nuestras mascotas, pequeños miembros de nuestra familia, con el respaldo profesional de nuestros colaboradores".

\section{Evaluación de la propuesta de la visión}

A continuación, se muestra la evaluación de la visión.

Tabla 83.- Evaluación de la propuesta de visión

\begin{tabular}{cccc}
\hline $\mathbf{N}^{\circ}$ & ELEMENTO & PREGUNTA & CUMPLIMIENTO \\
\hline 1 & Cliente & ¿Se definen los clientes? & $\mathrm{Si}$ \\
\hline 2 & Producto & ¿Se define el producto? & $\mathrm{Si}$ \\
\hline 3 & Tecnología & ¿Se involucra el aspecto \\
tecnológico?
\end{tabular}

Nota: Elaboración propia

\subsubsection{Misión}

¿Cuál es nuestro negocio?

¿Cuál es nuestro core business?

Al ser una nueva empresa, proponemos una misión, poniendo especial énfasis en una imagen empresarial sólida.

\section{Componentes de la propuesta de la misión}


Tabla 84.- Componentes de la propuesta de misión

\begin{tabular}{|c|c|c|c|c|}
\hline $\mathbf{N}^{\circ}$ & ELEMENTO & BASE & SUSTENTACIÓN & MISIÓN PROPUESTA \\
\hline 1 & Cliente & $\begin{array}{l}\text { Mascotas } \\
\text { caninas }\end{array}$ & Amor de los hogares & \multirow{4}{*}{$\begin{array}{l}\text { (2) Brindamos alimento } \\
\text { canino, no procesado, de } \\
\text { calidad. Diseñado en base a } \\
\text { la necesidad nutricional con } \\
\text { insumos naturales de origen } \\
\text { animal y vegetal. } \\
\text { (1) y (3) Nuestro producto } \\
\text { está dirigido al amplio } \\
\text { segmento de hogares que } \\
\text { aman a sus mascotas } \\
\text { caninas. }\end{array}$} \\
\hline 2 & $\begin{array}{l}\text { Productos / } \\
\text { Servicios }\end{array}$ & $\begin{array}{c}\text { Alimento canino } \\
\text { no procesado de } \\
\text { calidad }\end{array}$ & $\begin{array}{c}\text { Diseñado en base a la } \\
\text { necesidad nutricional } \\
\text { con insumos naturales } \\
\text { de origen animal y } \\
\text { vegetal }\end{array}$ & \\
\hline 3 & Mercados & Perú & $\begin{array}{l}\text { Se busca inicialmente } \\
\text { el ámbito nacional }\end{array}$ & \\
\hline 4 & Tecnología & $\begin{array}{l}\text { Know how de } \\
\text { los } \\
\text { nutricionistas } \\
\text { caninos } \\
\end{array}$ & $\begin{array}{l}\text { Valioso aporte en base } \\
\text { al conocimiento y } \\
\text { experiencia profesional }\end{array}$ & \\
\hline 5 & $\begin{array}{l}\text { Rentabilidad y } \\
\text { crecimiento }\end{array}$ & $\begin{array}{l}\text { Logros en } \\
\text { crecimiento y } \\
\text { rentabilidad }\end{array}$ & $\begin{array}{l}\text { Incremento del } \\
\text { flujo de caja }\end{array}$ & \multirow{5}{*}{$\begin{array}{l}\text { (9) Tenemos excelentes } \\
\text { colaboradores } \\
\text { (4) Que ostentan el know } \\
\text { how de nutricionistas } \\
\text { caninos con experiencia en } \\
\text { el diseño de fórmulas } \\
\text { nutricionales. }\end{array}$} \\
\hline 6 & Filosofía & Ética & Producto & \\
\hline 7 & Autoconcepto & $\begin{array}{c}\text { Excelencia en la } \\
\text { gestión }\end{array}$ & $\begin{array}{c}\text { Colaboradores de } \\
\text { primera línea }\end{array}$ & \\
\hline 8 & Imagen pública & $\begin{array}{c}\text { Responsabilidad } \\
\text { social }\end{array}$ & $\begin{array}{l}\text { Crecimiento y } \\
\text { rentabilidad que } \\
\text { permita contribuir con } \\
\text { el desarrollo del país }\end{array}$ & \\
\hline 9 & Colaboradores & $\begin{array}{c}\text { Grupo } \\
\text { seleccionado de } \\
\text { colaboradores }\end{array}$ & $\begin{array}{l}\text { Experiencia en } \\
\text { elaboración de } \\
\text { alimentos }\end{array}$ & \\
\hline
\end{tabular}

Nota: Elaboración propia.

\section{Propuesta de misión}

\section{¿Qué hacemos?}

Ofrecemos alimento canino no procesado, de calidad. Diseñado en base a la necesidad nutricional con insumos naturales de origen animal y vegetal.

Nuestro producto está dirigido al amplio segmento de hogares que aman a sus mascotas caninas. Tenemos excelentes colaboradores con el know how de nutricionistas caninos con experiencia en el diseño de fórmulas nutricionales. 
Buscamos la excelencia en la gestión, que redunde en el crecimiento y rentabilidad que respalde el desarrollo del país.

\section{¿A quiénes servimos?}

Nos dirigimos a los hogares peruanos que aman a sus mascotas caninas.

\section{¿Cómo lo hacemos?}

A través de la excelencia en la gestión.

\section{¿Para qué lo hacemos?}

Para lograr el crecimiento y la rentabilidad que ayuden al desarrollo del país.

\section{¿Con quiénes contamos?}

Contamos con un grupo seleccionado de colaboradores que cuentan con el

know how de nutricionistas caninos con experiencia en el diseño de fórmulas nutricionales.

\section{Evaluación de la propuesta de misión}

A continuación, se procede con la evaluación de la misión para corroborar que cumple con la estructura. 
Tabla 85.- Evaluación de la propuesta de misión

\begin{tabular}{|c|c|c|c|c|}
\hline $\mathbf{N}^{\circ}$ & \multicolumn{2}{|c|}{ ELEMENTO } & PREGUNTA & $\begin{array}{c}\text { CUMPLIMIENT } \\
\text { O } \\
\end{array}$ \\
\hline 1 & \multicolumn{2}{|c|}{ Cliente } & ¿Quiénes son los clientes? & $\mathrm{Si}$ \\
\hline 2 & \multicolumn{2}{|c|}{ Productos } & ¿Cuáles son los productos? & $\mathrm{Si}$ \\
\hline 3 & \multicolumn{2}{|c|}{ Mercado } & $\begin{array}{c}\text { ¿Cuál es el ámbito } \\
\text { geográfico de la } \\
\text { competencia? }\end{array}$ & $\mathrm{Si}$ \\
\hline 4 & \multicolumn{2}{|c|}{ Tecnología } & $\begin{array}{c}\text { ¿Cuál es la perspectiva de } \\
\text { la tecnología? }\end{array}$ & $\mathrm{Si}$ \\
\hline \multirow{3}{*}{5} & \multirow{3}{*}{$\begin{array}{l}\text { Preocupación } \\
\text { por: }\end{array}$} & $\begin{array}{c}\text { Supervivenci } \\
\mathrm{a}\end{array}$ & \multirow{3}{*}{$\begin{array}{l}\text { ¿Busca la solidez } \\
\text { financiera? }\end{array}$} & No \\
\hline & & Crecimiento & & $\mathrm{Si}$ \\
\hline & & Rentabilidad & & $\mathrm{Si}$ \\
\hline 6 & \multicolumn{2}{|c|}{ Filosofía } & $\begin{array}{l}\text { ¿Posee creencias, valores, } \\
\text { aspiraciones y ética? }\end{array}$ & $\mathrm{Si}$ \\
\hline 7 & \multicolumn{2}{|c|}{ Autoconcepto } & $\begin{array}{c}\text { ¿Cuál es su ventaja } \\
\text { competitiva? }\end{array}$ & $\mathrm{Si}$ \\
\hline 8 & $\begin{array}{l}\text { Preocupación } \\
\text { por: }\end{array}$ & $\begin{array}{l}\text { Imagen } \\
\text { pública }\end{array}$ & $\begin{array}{c}\text { ¿Involucra aspectos } \\
\text { sociales, comunitarios y } \\
\text { ambientales? }\end{array}$ & $\mathrm{Si}$ \\
\hline 9 & \multicolumn{2}{|c|}{ Colaboradores } & $\begin{array}{l}\text { ¿Representan un activo } \\
\text { valioso? }\end{array}$ & $\mathrm{Si}$ \\
\hline
\end{tabular}

Nota: Elaboración propia

\subsubsection{Principios.}

\section{Valores}

\section{Liderazgo}

Por qué creemos firmemente, que la mejor manera de alcanzar el éxito es beneficiar a nuestros clientes, a nuestros colaboradores y a nuestros accionistas, trinomio que debe experimentar valor para proporcionarnos el liderazgo que en un primer momento deseamos alcanzar y en un segundo momento, mantener.

\section{Respeto a la persona}

Consideramos que todo esfuerzo debe estar encaminado a lograr el bienestar y desarrollo de la persona en sus diversos aspectos. 


\section{Sensibilidad social}

Consideramos valiosa y necesaria la sensibilidad a toda forma de existencia, más aún si dicha existencia, integra hoy de forma tan significativa, la esencia de la familia peruana.

\section{Integridad}

Buscamos la coherencia sostenida del decir y el hacer.

\section{Innovación}

Innovamos con la finalidad de marcar el paso en el rubro de la alimentación canina, teniendo claro que la excelencia es fruto de la mejora constante. Diseñamos constantemente nuevas fórmulas nutricionales caninas en respuesta a las nuevas necesidades de nuestras queridas mascotas.

\section{Pasión}

Buscamos constantemente nuevas metas.

\section{Servicio}

Estamos al servicio de nuestro país. 
Tabla 86.- Matriz de alineamiento de la visión, misión y principio

\begin{tabular}{|c|c|c|c|c|c|}
\hline $\mathbf{N}^{\circ}$ & COMPONENTE & VISIÓN & MISIÓN & PRINCIPIO & ALINEACIÓN \\
\hline 1 & Cliente & $\mathrm{X}$ & $\mathrm{X}$ & Respeto & Sí \\
\hline 2 & Producto & $\mathrm{X}$ & $\mathrm{X}$ & Integridad & Sí \\
\hline 3 & Mercados & & $\mathrm{X}$ & $\begin{array}{c}\text { Sensibilidad } \\
\text { social }\end{array}$ & Sí \\
\hline 4 & Tecnología & $\mathrm{X}$ & $\mathrm{X}$ & Innovación & Sí \\
\hline \multirow{3}{*}{5} & Supervivencia & & & \multirow{3}{*}{ Pasión } & \multirow{3}{*}{ Sí } \\
\hline & Crecimiento & & & & \\
\hline & Rentabilidad & & & & \\
\hline 6 & Nivel de influencia & $\mathrm{X}$ & & Liderazgo & Sí \\
\hline 7 & Área de Influencia & $\mathrm{X}$ & & Liderazgo & Sí \\
\hline 8 & Imagen pública & $\mathrm{X}$ & $\mathrm{x}$ & Respeto & Sí \\
\hline 9 & $\begin{array}{c}\text { Crecimiento y } \\
\text { rentabilidad }\end{array}$ & & $\mathrm{x}$ & Servicio & Sí \\
\hline 10 & Filosofía & & & & \\
\hline 11 & Autoconcepto & & $\mathrm{x}$ & Integridad & Sí \\
\hline 12 & Colaboradores & & $\mathrm{x}$ & Respeto & Sí \\
\hline
\end{tabular}

Nota: Elaboración propia

\subsection{Formulación de las Estrategias del Negocio}

Todo nuevo emprendimiento requiere no solo de objetivos sino también de estrategias para alcanzarlos. Tomando en cuenta, que dichas estrategias deben estar alineadas con la organización en su conjunto, pues a partir de ellas se realizarán acciones que irán desprendiendo la verdadera esencia de la imagen de la empresa.

Para establecer las estrategias de Animal Lovers, se ha realizado el análisis interno y externo, con sus respectivas matrices para cuantificar el estado actual de ambos.

Tabla 87.- Factor interno (FD)

\begin{tabular}{|l|l|}
\hline \multicolumn{1}{|c|}{ FORTALEZAS } & \multicolumn{1}{c|}{ DEBILIDADES } \\
- & Personal calificado \\
- Calidad de producto & $\bullet \quad$ Capacidad financiera \\
\hline
\end{tabular}

Nota: Elaboración propia. 
Tabla 88.- Evaluación del factor interno (FD)

\begin{tabular}{|c|c|c|c|c|}
\hline $\mathbf{N}^{\circ}$ & Fortaleza & Peso & Ponderación & Puntaje \\
\hline 1 & Personal calificado & 0.20 & 3 & 0.60 \\
\hline 2 & Calidad de producto & 0.40 & 3 & 1.20 \\
\hline \multicolumn{4}{|c|}{ Subtotal } & 1.80 \\
\hline $\mathbf{N}^{\circ}$ & Debilidad & Peso & Ponderación & Puntaje \\
\hline 1 & Capacidad financiera. & 0.40 & 1 & 0.30 \\
\hline \multicolumn{4}{|c|}{ Subtotal } & 0.30 \\
\hline & To & & & 2.10 \\
\hline
\end{tabular}

Nota: Elaboración propia.

La evaluación del factor interno muestra una fortaleza menor (2.10), orientado a ofrecer un producto natural (no procesado industrialmente) y con personal que cumple con la elaboración de un producto relativamente sencillo, pero a la vez rentable.

Tabla 89.- Factor externo (OA)

\begin{tabular}{|c|c|}
\hline $\begin{array}{l}\text { OPORTUNIDADES } \\
\begin{array}{l}\text { Crecimiento del mercado en } 8 \% \text { anual } \\
\text { durante los últimos cinco (5) años }\end{array} \\
\text { - } \quad \text { Sensibilidad social creciente hacia los } \\
\text { canes. } \\
\text { Tope de la penetración de la comida } \\
\text { seca en el mercado. }\end{array}$ & $\begin{array}{l}\text { AMENAZAS } \\
\begin{array}{l}\text { Presencia de } 25 \text { marcas de comida seca } \\
\text { en el mercado. } \\
\text { - Crecimiento del consumo de los } \\
\text { alimentos tipo BARF. }\end{array}\end{array}$ \\
\hline
\end{tabular}

Nota: Elaboración propia. 
Tabla 90.- Evaluación del factor externo (OA)

\begin{tabular}{|c|l|c|c|c|}
\hline $\mathbf{N}^{\circ}$ & \multicolumn{1}{|c|}{ Oportunidad } & Peso & Ponderación & Puntaje \\
\hline $\mathbf{1}$ & $\begin{array}{l}\text { Crecimiento moderado durante los } \\
\text { últimos cinco (5) años. }\end{array}$ & $\mathbf{0 . 2}$ & $\mathbf{4}$ & $\mathbf{0 . 8}$ \\
\hline $\mathbf{2}$ & $\begin{array}{l}\text { Sensibilidad social creciente hacia los } \\
\text { canes. }\end{array}$ & $\mathbf{0 . 2}$ & $\mathbf{4}$ & $\mathbf{0 . 8}$ \\
\hline $\mathbf{3}$ & $\begin{array}{l}\text { Tope de la penetración de la comida } \\
\text { seca en el mercado. }\end{array}$ & $\mathbf{0 . 4}$ & $\mathbf{3}$ & $\mathbf{1 . 2}$ \\
\hline
\end{tabular}

2.8

\begin{tabular}{|c|l|c|c|c|}
\hline $\mathbf{N}^{\circ}$ & \multicolumn{1}{|c|}{ Amenaza } & Peso & Ponderación & Puntaje \\
\hline $\mathbf{1}$ & $\begin{array}{l}\text { Presencia de 30 marcas de comida seca } \\
\text { en el mercado. }\end{array}$ & $\mathbf{0 . 1}$ & $\mathbf{2}$ & $\mathbf{0 . 2}$ \\
\hline $\mathbf{2}$ & $\begin{array}{l}\text { Crecimiento del consumo de los } \\
\text { alimentos tipo BARF. }\end{array}$ & $\mathbf{0 . 1}$ & $\mathbf{2}$ & $\mathbf{0 . 2}$ \\
\hline
\end{tabular}

$\begin{aligned} \text { Subtotal } & 0.4 \\ \text { Total } & 3.2\end{aligned}$

Nota: Elaboración propia.

Las variables definidas como oportunidad y amenazas han sido obtenidas en base al análisis externo PEST y la matriz de perfil competitivo que identifica claramente el impacto de la competencia de Animal Lovers.

Se ha obtenido un puntaje de 3.20, lo que bajo un criterio de opinión de expertos determina un escenario de una oportunidad mayor.

Tabla 91.- Posición de Animal Lovers al análisis interno y externo

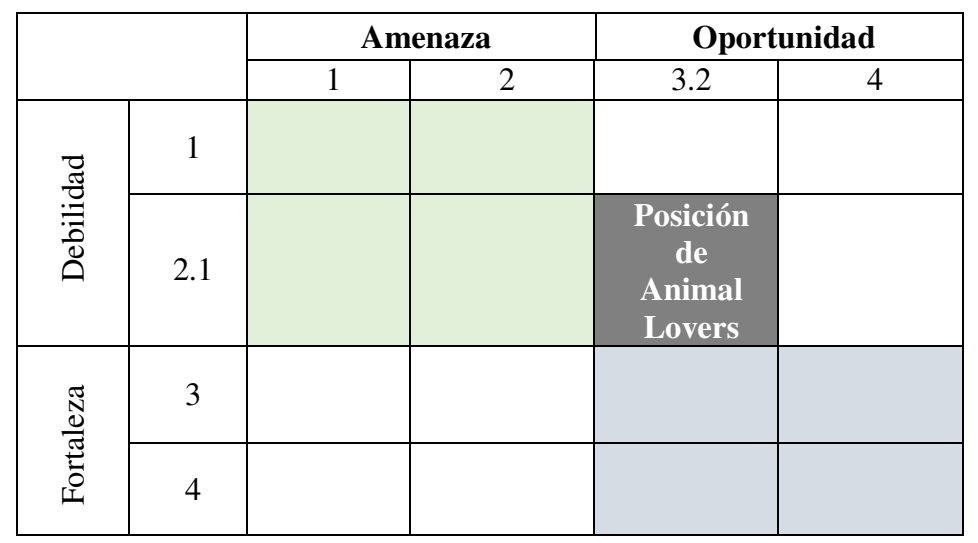

Nota: Elaboración propia. 
La posición de Animal Lovers a nivel interno y externo en conjunto, expresan que existe potencial de desarrollo de Animal Lovers en el mercado, sin embargo, la industria refleja una oportunidad en un mercado que se ha desarrollado con comida seca. Animal Lovers deberá trabajar en dos sentidos:

a. Conquistar al nuevo usuario de comida para canes.

b. Convencer al usuario de comida seca, que la propuesta de Animal Lovers es superior.

De otro lado, la matriz FODA nos permite analizar, las fuerzas internas (fortalezas y debilidades) y las fuerzas externas (oportunidades y amenazas). Con este análisis exploramos acciones que permitan definir estrategias para alcanzar nuestros objetivos.

Las estrategias FO (Fortaleza-Oportunidad) tratan de utilizar las fortalezas para aprovechar las oportunidades del entorno.

Las estrategias DO (Debilidad-Oportunidad) tratan de identificar las debilidades, para luego convertirlas en fortalezas y de esta forma aprovechar las oportunidades del entorno.

Las estrategias FA (Fortaleza-Amenaza) tratan de aprovechar las fortalezas para defenderse de las amenazas del entorno.

Las estrategias DA (Debilidad-Amenaza) tratan de identificar las debilidades, para luego convertirlas en fortalezas, para finalmente defenderse del impacto de las amenazas del entorno. 
Tabla 92.- Matriz FODA

\begin{tabular}{|c|c|}
\hline $\begin{array}{l}\text { FORTALEZAS } \\
\text { 1. } \\
\text { 2. } \\
\text { Personal calificado } \\
\text { Calidad de producto }\end{array}$ & $\begin{array}{l}\text { DEBILIDADES } \\
\text { 1. Capacidad financiera }\end{array}$ \\
\hline $\begin{array}{l}\text { OPORTUNIDADES } \\
\end{array}$ & AMENAZAS \\
\hline $\begin{array}{l}\text { 1. Crecimiento del mercado en } 8 \% \text { anual en } \\
\text { promedio } \\
\text { 2. Humanización de los canes } \\
\text { 3. La venta se concentra en Lima }\end{array}$ & $\begin{array}{l}\text { 1. Presencia de más de } 30 \text { marcas de } \\
\text { comida seca en el mercado } \\
\text { 2. Crecimiento del consumo de los } \\
\text { alimentos tipo BARF }\end{array}$ \\
\hline
\end{tabular}

Nota: Elaboración propia.

Tabla 93.- Estrategia FO (1)

\begin{tabular}{lll}
\multicolumn{1}{c}{ Fortalezas } & \multicolumn{1}{c}{ Oportunidades } & \multicolumn{1}{c}{ Estrategia FO } \\
\hline \multicolumn{1}{c}{$\mathrm{F}(1-2)$} & \multicolumn{1}{c}{$\mathrm{O}(1-2)$} & \multicolumn{1}{c}{ Estrategia $\mathrm{F}(1-2) \mathrm{O}(1-2)$} \\
\hline - Personal calificado. & - $\begin{array}{l}\text { Crecimiento del mercado } \\
\text { en 8\% en promedio. } \\
\text { producto }\end{array}$ & $\begin{array}{l}\text { Comunicar al mercado los } \\
\text { efectos del tipo de alimento, } \\
\text { bajo esta comparación: }\end{array}$ \\
& $\begin{array}{l}\text { Sensibilidad social } \\
\text { creciente hacia los canes. }\end{array}$ & $\begin{array}{l}\text { Comida seca } \neq \text { salud } \\
\text { - Animal lovers = Salud }\end{array}$ \\
\hline
\end{tabular}

Nota: Elaboración propia.

Tabla 94.- Estrategia FO (2)

\begin{tabular}{lcll}
\multicolumn{1}{c}{ Fortalezas } & \multicolumn{1}{c}{ Oportunidades } & \multicolumn{1}{c}{ Estrategia FO } \\
\hline \multicolumn{1}{c}{$\mathrm{F}(1-2)$} & & \multicolumn{1}{c}{$\mathrm{O}(2-3)$} & Estrategia $\mathrm{F}(1-2) \mathrm{O}(2-3)$ \\
\hline - Calidad de & $\bullet$ & Humanización de los canes. \\
producto. & La oferta a nivel nacional se & $\begin{array}{l}\text { Comunicar al mercado de } \\
\text { provincia: } \\
\text { concentra en Lima. }\end{array}$ & Nutrición = Salud \\
\hline
\end{tabular}

Nota: Elaboración propia. 
Tabla 95.- Estrategia DO (1)

\begin{tabular}{ccc} 
Debilidades & \multicolumn{1}{c}{ Oportunidades } & \multicolumn{1}{c}{ Estrategia DO } \\
\hline $\mathrm{D}(1)$ & $\mathrm{O}(1-2)$ & \multicolumn{1}{c}{ Estrategia $\mathrm{D}(1) \mathrm{O}(1-2)$} \\
\hline - Capacidad financiera. & $\begin{array}{l}\text { Crecimiento del } \\
\text { mercado. }\end{array}$ & $\begin{array}{l}\text { Los hogares de Lima con } \\
\text { canes consumen comida } \\
\text { seca en un } 40 \% \\
\text { aproximadamente. }\end{array}$ \\
\hline
\end{tabular}

Nota: Elaboración propia.

Tabla 96.- Estrategia DO (2)

\begin{tabular}{ccc}
\hline Debilidades & \multicolumn{1}{c}{ Oportunidades } & \multicolumn{1}{c}{ Estrategia DO } \\
\hline $\mathrm{D}(1)$ & $\mathrm{O}(1-2)$ & \multicolumn{1}{c}{ Estrategia $\mathrm{D}(1) \mathrm{O}(1-2)$} \\
\hline - Capacidad financiera. & $\begin{array}{l}\text { Humanización de los } \\
\text { canes. }\end{array}$ & $\begin{array}{l}\text { Posicionar: } \\
\text { Comida seca se elabora en } \\
\text { base a deshechos de origen } \\
\text { animal. }\end{array}$ \\
\hline
\end{tabular}

Nota: Elaboración propia.

Tabla 97.- Estrategia DO (3)

\begin{tabular}{ccc} 
Debilidades & Oportunidades & \multicolumn{1}{c}{ Estrategia $\mathrm{DO}$} \\
\hline $\mathrm{D}(1)$ & $\mathrm{O}(2-3)$ & Estrategia $\mathrm{D}(1) \mathrm{O}(2-3)$ \\
\hline - Capacidad financiera. & $\begin{array}{l}\text { Baja penetración en } \\
\text { provincia. }\end{array}$ & $\begin{array}{l}\text { Crecer apalancado en base a la } \\
\text { penetración de mercado en } \\
\text { provincias. }\end{array}$ \\
\hline
\end{tabular}

Nota: Elaboración propia.

Tabla 98.- Estrategia FA (1)

\begin{tabular}{cll}
\hline \multicolumn{1}{c|}{ Fortalezas } & \multicolumn{1}{c}{ Amenaza } & \multicolumn{1}{c}{ Estrategia FA } \\
\hline F (1-3) & \multicolumn{1}{c}{ A (2) } & \multicolumn{1}{c}{ Estrategia F (1-3) A (2) } \\
\hline - Personal calificado. & $\begin{array}{l}\text { Presencia de 25 } \\
\text { marcas de comida } \\
\text { seca en el mercado. }\end{array}$ & $\begin{array}{l}\text { Puntos de distribución en ambos canales } \\
\text { (moderno y tradicional). }\end{array}$ \\
& & $\begin{array}{l}\text { Comunicar al mercado la duración: } \\
\text { Calidad de producto. }\end{array}$ \\
& & Animal Lovers dos meses. \\
& & La comida seca un (1) año. \\
\hline
\end{tabular}

Nota: Elaboración propia. 
Tabla 99.- Estrategia FA (2)

\begin{tabular}{clll} 
Fortalezas & \multicolumn{1}{c}{ Amenaza } & \multicolumn{1}{c}{ Estrategia FA } \\
\hline F (4) & \multicolumn{1}{c}{ A (1) } & \multicolumn{1}{c}{ Estrategia F (4) A (1) } \\
\hline - & Personal calificado. & $\begin{array}{l}\text { Crecimiento del } \\
\text { consumo de los } \\
\text { alimentos tipo BARF. }\end{array}$ & $\begin{array}{l}\text { Comunicar: } \\
\text { "BARF es un tipo de comida } \\
\text { que exige a la digestión } \\
\text { canina". }\end{array}$ \\
\hline
\end{tabular}

Nota: Elaboración propia.

\section{Tabla 100.- Estrategia DA}

\begin{tabular}{|c|c|c|}
\hline Debilidad & Amenaza & Estrategia DA \\
\hline $\mathrm{D}(1)$ & A (1) & Estrategia D (1) A (2) \\
\hline $\begin{array}{l}\text { - Capacidad } \\
\text { financiera. }\end{array}$ & $\begin{array}{l}\text { - Presencia de } 30 \text { marcas de } \\
\text { comida seca en el mercado. } \\
\text { - Crecimiento del consumo } \\
\text { de los alimentos tipo } \\
\text { BARF. }\end{array}$ & $\begin{array}{l}\text { Producción de Animal Lovers: } \\
\text { - "Costos bajos de } \\
\text { producción". } \\
\text { - "Precios competitivos". }\end{array}$ \\
\hline
\end{tabular}

Nota: Elaboración propia.

Tabla 101.- Cuadro resumen FODA. Estrategias y meta por área funcional

\begin{tabular}{|c|c|c|c|}
\hline \multicolumn{2}{|c|}{ Estrategias } & Área Funcional & Meta \\
\hline \multicolumn{2}{|c|}{$\begin{array}{l}\text { Comunicar al mercado limeño y de } \\
\text { provincias: } \\
\text { - Comida Seca } \neq \text { Salud } \\
\text { - Animal lovers = Salud }\end{array}$} & Marketing & $\begin{array}{l}\text { Posicionar: } \\
\text { Comida seca en base } \\
\text { a deshechos de origen } \\
\text { animal. }\end{array}$ \\
\hline $\begin{array}{l}\text { Variedad de } \\
\text { Proveedores }\end{array}$ & \multirow{3}{*}{$\begin{array}{l}\text { Emplear procesos } \\
\text { Estandarizados }\end{array}$} & Logística & $\begin{array}{l}\text { Mantener los insumos } \\
\text { en óptimo estado }\end{array}$ \\
\hline \multirow{2}{*}{$\begin{array}{l}\text { Costos bajos de } \\
\text { producción y } \\
\text { distribución }\end{array}$} & & Producción & $\begin{array}{l}\text { Preservar la calidad } \\
\text { de producto }\end{array}$ \\
\hline & & Distribución & \multirow{2}{*}{$\begin{array}{l}\text { Puntos de venta en } \\
\text { canal tradicional y } \\
\text { canal moderno } \\
\text { en Lima } \\
\text { (inicialmente) y } \\
\text { provincias (después) }\end{array}$} \\
\hline $\begin{array}{l}\text { Accesibilidad al } \\
\text { producto }\end{array}$ & $\begin{array}{c}\text { Precios } \\
\text { competitivos }\end{array}$ & Comercialización & \\
\hline Cambio de producto & Manejo de reclamos & Logística Inversa & $\begin{array}{l}\text { Evitar quejas } \mathrm{y} \\
\text { reclamos en redes } \\
\text { sociales }\end{array}$ \\
\hline $\begin{array}{l}\text { Crecimiento en base a } \\
\text { penetración de } \\
\text { mercado de Lima } \\
\text { (crece a ritmo de } 8 \% \\
\text { anual) }\end{array}$ & $\begin{array}{c}\text { Crecimiento en } \\
\text { base a penetración } \\
\text { de mercado de } \\
\text { Lima ( } 57 \text { toneladas } \\
\text { al año) }\end{array}$ & Finanzas & $\begin{array}{l}\text { Financiamiento } \\
\text { respaldado en el } \\
\text { crecimiento }\end{array}$ \\
\hline
\end{tabular}

Nota: Elaboración propia. 


\subsection{Determinación de las Ventajas Competitivas Críticas.}

\section{¿Cómo se define la diferenciación?}

Las estrategias de diferenciación evitan la oferta de productos básicos (Kotler \& Keller, 2006). Por ello, es aconsejable aprovechar la idea que los consumidores se puedan formar para -a partir de aquí- diferenciar nuestros productos y servicios.

Un elemento clave en el producto: es la diferenciación. En una misma clase de producto, los productos guardan diferencias. Por ejemplo, los potajes a pesar de ser elaborados de la misma forma suelen ser distintos de un restaurante a otro. La diferenciación es, por ello, una estrategia de marketing que resalta las características del producto para que el consumidor las perciba como únicas.

En general, la diferenciación puede darse de varias formas como la innovación, la marca, la publicidad, el servicio, la distribución, los procesos, el rol del participante y la posibilidad de vincularse social o profesionalmente. En consecuencia, las diferencias surgen en base a atributos que generan beneficios percibidos como valor. Con estas acciones se espera tener una propuesta única en el mercado difícil de copiar.

\section{Factores de diferenciación}

Es necesario establecer la(s) variable(s) de diferenciación, así como el posicionamiento en los segmentos meta (Kotler \& Armstrong, 2012). Por ello, se requiere recopilar y analizar los factores de diferenciación claves para la empresa.

Para Animal Lovers los elementos de diferenciación identificados son:

- Confianza porque los insumos son naturales.

- Inocuo para la salud.

- Precios menores a los alimentos de comida seca.

- Fácil de adquirir incluso en veterinarias. 
- $\quad$ Salud y bienestar para las mascotas.

\section{¿Qué es una ventaja competitiva?}

Ventajas que posee una empresa frente a otras empresas del mismo sector o mercado, y que al compararlas se traduce en una posición competitiva de mayor jerarquía en el sector.

\section{¿Cuántas diferencias deberán seleccionar para que una empresa base en ellas su ventaja competitiva?}

- Diferencia que se basa en un solo atributo. De forma tal que genere un único beneficio que a su vez le permita a la empresa posicionarse como la empresa número uno, en ese atributo. Los consumidores podrán reconocer a la empresa por este único beneficio, con mayor razón, si el mercado está plagado de competencia.

- Diferencia que se basa en varios atributos. Esto es válido, en un mercado fragmentado, debido a que pueden surgir varios segmentos y en esta situación, sería propicio ser atractivo para más de un segmento.

Para el caso específico de Animal Lovers, se van trabajan varios elementos de diferenciación. Es decir, de las dos (2) ideas anteriormente nombradas optaremos por elegir más de un atributo, pues, aunque la industria esté fragmentada, también es cierto que las grandes empresas harán esfuerzos denodados por replicar nuestra propuesta de negocio. No obstante, para las grandes corporaciones es más redituable el mercado masivo de consumo humano, con lo cual, ante un producto Animal Lovers, golpearíamos la rentabilidad de sus productos en base a insumos de calidad inferior. 
¿Qué diferencia ha seleccionado Animal Lovers para basar su ventaja competitiva?

Animal Lovers tiene como base de diferenciación, sus insumos, proceso de producción, economía -más por lo mismo- y una buena calidad de vida para su mascota. Por ello, Animal Lovers desea posicionarse en la mente del consumidor como un producto de nivel altamente superior a la comida industrial y/o comercial conocida como comida seca.

\section{¿Cuáles son las diferencias que deben ser seleccionadas?}

Cada diferencia es un atributo que genera beneficios, pero a la vez genera costos. Por tanto, seleccionar una diferencia, implica:

- Importante, la diferencia significa un beneficio muy valioso.

- Distintiva, con respecto a los competidores.

- Superior, la diferencia es superior pues equivale a una mejor forma de obtener el mismo beneficio.

- Comunicable, la diferencia es evidente para los compradores.

- Exclusiva, no empleada por la competencia.

- Costeable, los consumidores deben estar en capacidad de pagar la diferencia del margen.

- $\quad$ Redituable, porque representa una rentabilidad significativa para la empresa. 
Tabla 102.- Elementos de diferenciación que generan ventajas competitivas

\begin{tabular}{|c|c|c|c|c|c|c|}
\hline \multicolumn{5}{|c|}{ DIFERENCIACIÓN } & \multicolumn{2}{|c|}{ VENTAJA COMPETITIVA } \\
\hline $\mathbf{N}^{\circ}$ & Elemento & Base & Sustento & Tipo & $\begin{array}{c}\text { ¿Generan } \\
\text { ventajas } \\
\text { competitivas? }\end{array}$ & $\begin{array}{c}\text { ¿Aportan al } \\
\text { posicionamiento? }\end{array}$ \\
\hline 1 & $\begin{array}{c}\text { Confianza para el } \\
\text { dueño de la } \\
\text { mascota }\end{array}$ & $\begin{array}{l}\text { Insumos } \\
\text { naturales }\end{array}$ & $\begin{array}{l}\text { Trazabilidad del } \\
\text { producto }\end{array}$ & Distintiva & Sí & Sí \\
\hline 2 & $\begin{array}{l}\text { Seguridad para el } \\
\text { dueño de la } \\
\text { mascota }\end{array}$ & $\begin{array}{c}\text { Proceso de } \\
\text { producción no } \\
\text { industrializado }\end{array}$ & $\begin{array}{l}\text { Trazabilidad del } \\
\text { producto }\end{array}$ & Exclusiva & Sí & Sí \\
\hline 3 & $\begin{array}{l}\text { Salud y bienestar } \\
\text { para la mascota }\end{array}$ & $\begin{array}{c}\text { Satisfacción } \\
\text { psicológica } \\
\text { del dueño } \\
\end{array}$ & $\begin{array}{l}\text { Calidad de vida } \\
\text { para la mascota }\end{array}$ & Superior & Sí & Sí \\
\hline 4 & $\begin{array}{c}\text { Inversión en la } \\
\text { alimentación de la } \\
\text { mascota }\end{array}$ & $\begin{array}{c}\text { Precios } \\
\text { competitivos }\end{array}$ & $\begin{array}{l}\text { Precios de la } \\
\text { competencia }\end{array}$ & Costeable & Sí & No \\
\hline 5 & $\begin{array}{l}\text { Accesibilidad } \\
\text { para el dueño de } \\
\text { la mascota }\end{array}$ & $\begin{array}{c}\text { Canal } \\
\text { moderno y } \\
\text { canal } \\
\text { tradicional }\end{array}$ & $\begin{array}{c}\text { Compra } \\
\text { programada y } \\
\text { compra de } \\
\text { ocasión para el } \\
\text { dueño }\end{array}$ & Importante & Sí & Sí \\
\hline
\end{tabular}

Nota: Elaboración propia.

\subsection{Diseño de la estructura organizacional deseada}

La estructura organizacional de Animal Lovers, está basada en un diseño de tipo funcional, aunque la realización de las tareas es en muchos casos de tipo matricial, pues las personas tienen labores de apoyo a las otras áreas, sobre todo en la parte operativa.

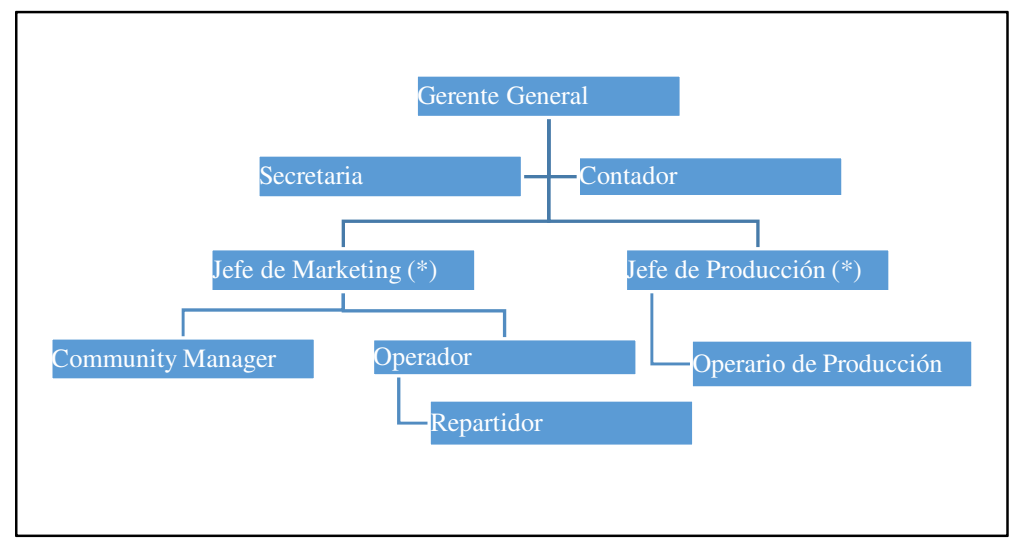

Figura 54. Organigrama Animal Lovers

.Elaboración propia 
El gráfico muestra la estructura del organigrama funcional de la empresa y de los cargos que tienen dichos colaboradores.

Aquellos que tienen un asterisco $(*)$ significa que serán incorporados posteriormente, conforme se incrementen las operaciones.

\subsection{Diseño de los Perfiles de Puestos Clave.}

Los perfiles de los puestos se han establecido en base a las necesidades de planificación, supervisión y control de las operaciones del negocio. Bajo este contexto, se procederá a establecer las características de cada puesto.

\section{a. Gerente General}

- Reporta directamente a Accionistas de la empresa.

- El sueldo aproximado es de S/ 2,800.

- Tiene colaboradores a su cargo.

\section{Objetivos del puesto}

- $\quad$ Supervisar y asesorar a todas las áreas de la empresa.

- Orientar la administración de los recursos humanos, de acuerdo con las políticas y normas vigentes, a fin de establecer y fortalecer un ambiente laboral que promueva y facilite una eficiencia y eficacia cada vez mayor, a todo nivel de la organización.

- Cumplir con la misión de la empresa y compartirla con sus colaboradores y hacerlos participes de esta.

- Establecer las normas de desempeño. Por lo general, una administración áspera o indiferente tendrá un equipo que refleje su comportamiento. De forma similar, una administración cortes y sociable le inspira al colaborador que tiene contacto con el cliente, a tratar a cada cliente de la misma forma. 


\section{b. Secretaria.}

- $\quad$ El sueldo aproximado es de S/ 1,400.

\section{Objetivos del puesto}

- $\quad$ Reportar y soportar en los procesos e indicadores al Gerente general

- Soportar en los procesos de producción, compras y distribución.

- Verificar que se cumplan los procedimientos de seguridad básicos en el local de forma constante.

- $\quad$ Revisar la venta del día anterior en unidades; con esta estadística se proyectará la venta del día de los diferentes ítems podrá tener la información de stock de productos necesarios para el día.

\section{c. Jefe de Marketing}

- $\quad$ El sueldo aproximado es de S/ 1,500.

\section{Objetivos del puesto}

- Verificar la satisfacción del cliente a través de la estrategia de mezcla de marketing.

- Identificar necesidades no atendidas en el mercado.

- Fidelizar al cliente.

\section{d. Jefe de Producción.}

- $\quad$ El sueldo aproximado es de S/ 1,595.

\section{Objetivos del puesto}

- Verificar que los insumos cumplan con los requisitos de calidad establecidos. 
- Supervisar y controlar que todos los procedimientos y procesos de elaboración de los alimentos cumplan según el manual de producción.

- Establecer y revisar el control de mermas, las ventas por canal de distribución.

\subsection{Remuneraciones, compensaciones e incentivos}

Los trabajadores perciben una remuneración por los servicios que brindan para la empresa, derecho respaldado por la Ley Articulo 24 "El trabajador tiene derecho a una remuneración equitativa y suficiente, que procure, para él y su familia, el bienestar material y espiritual. Las remuneraciones mínimas se regulan por el Estado con participación de las organizaciones representativas de los trabajadores y de los empleadores".

Tienen derecho a percibir, por lo menos, la remuneración mínima vital referenciada en el Decreto Supremo No 022-2007-TR, que indica a 930.00 nuevos soles mensuales. Los días de descanso, feriados, también serán remunerados. Por otro lado, el personal, después de un año de trabajo, recibirá quince días de vacaciones remunerada equivalente a la mitad de una remuneración mensual.

\subsection{Política de recursos humanos}

La empresa contará con un personal idóneo para su correcto funcionamiento. Por ello se realizará un proceso de reclutamiento y selección para conocer si las personas están capacitadas para el puesto vacante. Tomando como referencia la legislación laboral, existen dos tipos de contratos que respaldan al trabajador, uno es el contrato determinado, el cual fija un plazo acordado de trabajo del empleado y debe ser llevado ante el Ministerio de Trabajo; y el otro, es el contrato indefinido, en el cual los trabajadores pueden ser contratos por meses, años indefinidos y no es necesario llevarlo al Ministerio de Trabajo. Se decidió que todos los empleados contarán con un contrato determinado y en base a su desenvolvimiento, desempeño, trabajo, compromiso y responsabilidad, renovaremos y extenderemos el contrato, 
caso contrario, procederemos a eliminar el vínculo laboral. Todos nuestros empleados pasarán a formar parte de planilla como lo exige la ley, de manera que, contarán con todos los derechos y beneficios sociales.

La empresa tendrá la definición de Microempresa, porque su constitución abarcará un ingreso que corresponde a esta definición. Por esta razón, la empresa se encontrará dentro del régimen laboral especial de la Microempresa, que se encarga de fomentar la formalización, desarrollo y mejorar las condiciones laborales de los trabajadores.

El régimen laboral comprende: remuneración, jornada de trabajo, horario de trabajo y trabajo en sobre tiempo, descanso semanal, descanso vacacional, descanso por días feriados, despido injustificado, seguro social de salud (SIS) y régimen pensionario (en coordinación y aprobación, siempre y cuando el trabajador desea aportar a la ONP). Las ventas anuales brutas no deben sobrepasar los 150 UIT, según ley $\mathrm{N}^{\circ} 28015$.

\section{Ley de Promoción y Formalización de la Micro y Pequeña Empresa.}

\section{Horario de trabajo}

La jornada laboral, estipulada por ley, es de 8 horas efectivas sin refrigerio, dando un total de 50 horas semanales. El trabajador también tiene derecho de descansar una vez a la semana de acuerdo con lo indicado por la empresa.

Si el trabajador sobrepasa las horas de trabajo preestablecidas, deberá ser remunerado por las horas extras. De sobrepasarse 2 horas se le pagará un $25 \%$ más del pago por hora promedio, las 3 horas siguientes se les pagará $35 \%$. Así lo dispone La Constitución Política vigente. 
Todo empleador sujeto este régimen laboral, debe poseer un registro permanente de control de asistencia de sus trabajadores, para el correcto pago de sus remuneraciones. En este registro se deben incluir datos como: Nombre o razón social del empleador, nombre y número del documento, fecha, hora y minutos de ingreso y salida, minutos de permanencia fuera de la jornada de trabajo. El registro no necesita de autorización o legalización notarial, pero se puede realizar. No es necesario llevar un cuaderno con toda esta información, también se puede realizar a través de tarjetas mecánicas, entre otros. Según ley el refrigerio de los trabajadores no debe ser menor a 45 minutos, aun cuando se tenga el consentimiento del empleado.

\section{Conducta del colaborador}

En Animal Lovers queremos brindar a nuestros colaboradores un ambiente de trabajo agradable, que les permita trabajar con tranquilidad y cumplir con sus funciones de la mejor manera. En tal sentido existe una política de respeto mutuo entre colaboradores, el buen trato, las buenas costumbres y los buenos modales son parte de ello y se aplican para todos los niveles jerárquicos en el restaurante.

\section{Refrigerio}

- El colaborador está facultado a recibir un refrigerio diario.

- $\quad$ El menú de personal y los horarios de refrigerio de personal son de manejo exclusivo de cada administración.

\section{Sanciones disciplinarias}

- Con la finalidad de hacer de conocimiento del colaborador las sanciones por infringir las reglas expuestas, referente a las obligaciones básicas, políticas en contra de la discriminación, hostigamiento sexual, normas de higiene, incumplimiento de 
procedimientos, tardanzas, inasistencias, indisciplina, entre otros, la Administración recomienda la siguiente modalidad de sanciones a escala.

- $\quad$ Primera vez: Llamada de atención verbal. Se registra en el legajo de personal.

- Segunda vez: Amonestación por escrito.

- $\quad$ Tercera vez: Amonestación por escrito y suspensión de acuerdo con la gravedad de la falta.

- Cuarta vez: Despido de acuerdo con la ley.

\section{Beneficios Sociales}

- La empresa brindara a sus empleados de acuerdo con la ley, vacaciones y descansos remunerados: quince días pagados luego de un año de trabajo.

- $\quad$ SIS: El aporte mensual por cada trabajador, el equivalente a S/ 83.00 nuevos soles.

- Afiliación al Sistema Nacional de Pensiones o Sistema Privado de Pensiones a elección del trabajador. 


\section{CAPÍTULO IX}

\section{PLANIFICACIÓN FINANCIERA}

\subsection{La Inversión}

\subsubsection{Inversión preoperativa}

Se detallarán los costos previos al inicio de las operaciones, los cuales se dividen en activos tangibles e intangibles.

Los activos tangibles se encuentran expresados en soles. Se detallan a continuación.

Tabla 103.- Inversión preoperativa tangible

\begin{tabular}{|c|c|c|c|c|c|c|}
\hline \multicolumn{7}{|c|}{ INVERSIÓN PREOPERATIVA - TANGIBLE } \\
\hline & \multicolumn{2}{|c|}{ Subtotal } & \multicolumn{2}{|c|}{ IGV } & \multicolumn{2}{|r|}{ Total } \\
\hline Maquinarias y Equipos & S/ & 74,779 & $\mathrm{~S} /$ & 13,460 & $\mathrm{~S}$ & 88,240 \\
\hline Muebles y enseres & S/ & 19,347 & S/ & 3,483 & $\mathrm{~s}$ & 22,830 \\
\hline Muebles de Oficina & S/ & 8,286 & S/ & 1,491 & $\mathrm{~s}$ & 9,778 \\
\hline Inversión - Gastos Preoperativos & S/ & 31,000 & $\mathrm{~S} /$ & 5,580 & $\mathrm{~S}$ & 36,580 \\
\hline $\begin{array}{l}\text { Total Activo Tangible } \\
\end{array}$ & S/ & 133,413 & S/ & 24,014 & $\mathrm{~s}$ & 157,427 \\
\hline
\end{tabular}

Nota: Elaboración propia

Tabla 104.- Inversión preoperativa tangible - maquinarias y equipos

\begin{tabular}{|c|c|c|c|c|c|c|c|c|c|c|}
\hline Área & Tipo & Concepto & Cantidad & Importe & & sbtotal & \multicolumn{2}{|c|}{ IGV } & \multicolumn{2}{|c|}{ Total } \\
\hline Producción & Maquinaria & Lavadero & 2 & S/ 805 & S/ & 1,611 & S/ & 290 & S/ & 1,901 \\
\hline Producción & Maquinaria & Congeladora Ventus 560 1ts & 4 & 804 & S/ & 3,218 & S/ & 579 & S & 3,797 \\
\hline Producción & Maquinaria & Refrigeradora Whirpool 568 1ts & 2 & S/ 1,800 & S/ & 3,601 & S/ & 648 & S/ & 4,249 \\
\hline Producción & Maquinaria & Cocina semi-industrial & 1 & S/ 1,500 & S/ & 1,500 & S/ & 270 & S/ & 1,770 \\
\hline Producción & Maquinaria & Moledora de carne & 1 & S/ 2,559 & S/ & 2,559 & S/ & 461 & S/ & 3,020 \\
\hline Producción & Maquinaria & Licuadora industrial & 2 & S/ 1,144 & S/ & 2,288 & S/ & 412 & S & 2,700 \\
\hline Producción & Maquinaria & Empacadora al vacio & 3 & S/ 3,220 & S/ & 9,661 & S/ & 1,739 & S/ & 11,400 \\
\hline Producción & Maquinaria & 1000 bolsas nylon 70 micras $13 \times 15$ (anc * lar) & 2 & S) 292 & S/ & 585 & S/ & 105 & S/ & 690 \\
\hline Producción & Maquinaria & Balanza Henkel & 2 & S/ 3,220 & S/ & 6,440 & S/ & 1,159 & S/ & 7,599 \\
\hline Producción & Maquinaria & Ollas & 6 & S/ $\quad 99$ & $\mathrm{~S} /$ & 593 & S/ & 107 & S & 700 \\
\hline
\end{tabular}

Nota: Elaboración propia 
Tabla 105.- Inversión preoperativa tangible - muebles y enseres

\begin{tabular}{|c|c|c|c|c|c|c|c|c|c|c|}
\hline Área & Tipo & Concepto & Cantidad & Importe & \multicolumn{2}{|c|}{ Subtotal } & \multicolumn{2}{|c|}{ IGV } & \multicolumn{2}{|c|}{ Total } \\
\hline Producción & Muebles y enseres & Botas industriales para agua & 36 & 18 & $\mathrm{~S} /$ & 638 & $\mathrm{~S} /$ & 115 & $\mathrm{~S} /$ & 752 \\
\hline Producción & Muebles y enseres & Mandiles protectores & 36 & 11 & S/ & 381 & S/ & 69 & S/ & 450 \\
\hline Producción & Muebles y enseres & Javas & 48 & 13 & S/ & 610 & S/ & 110 & S/ & 720 \\
\hline Producción & Muebles y enseres & Mascarillas X 100 unidades & 48 & 19 & S/ & 891 & S/ & 160 & S/ & 1,051 \\
\hline Producción & Muebles y enseres & Caja de guantes X 100 pares & 48 & 19 & S/ & 895 & S/ & 161 & S/ & 1,056 \\
\hline Producción & Muebles y enseres & Caja de gorros X 100 & 48 & 8 & S/ & 407 & S/ & 73 & S/ & 480 \\
\hline Producción & Muebles y enseres & Uniforme de trabajo & 48 & 51 & S/ & 2,441 & S/ & 439 & S/ & 2,880 \\
\hline Producción & Muebles y enseres & Extintores & 12 & 59 & S/ & 711 & S/ & 128 & S/ & 839 \\
\hline Vestuario & Muebles y enseres & Espejo & 12 & 85 & S/ & 1,017 & S/ & 183 & S/ & 1,200 \\
\hline Vestuario & Muebles y enseres & Dispensador antibacterial & 48 & 30 & S/ & 1,424 & S/ & 256 & S/ & 1,680 \\
\hline Vestuario & Muebles y enseres & Dispensador de jabón espuma & 48 & 43 & S/ & 2,054 & S/ & 370 & S/ & 2,424 \\
\hline Vestuario & Muebles y enseres & Dispensador de papel higiénico & 12 & 97 & S/ & 1,169 & S/ & 211 & S/ & 1,380 \\
\hline Vestuario & Muebles y enseres & Estanteria metálica & 24 & 110 & S/ & 2,644 & S/ & 476 & S/ & 3,120 \\
\hline Vestuario & Muebles y enseres & Gabinete para vestuario & 24 & 169 & S/ & 4,066 & S/ & 732 & S/ & 4,798 \\
\hline & & & & Total & S/ & 19,347 & S/ & 3,483 & S/ & 22,830 \\
\hline
\end{tabular}

Nota: Elaboración propia

Tabla 106.- Inversión preoperativa tangible - muebles de oficina

\begin{tabular}{|c|c|c|c|c|c|c|c|c|c|c|}
\hline Área & Tipo & Concepto & Cantidad & Importe & \multicolumn{2}{|c|}{ Subtotal } & \multicolumn{2}{|c|}{ IGV } & \multicolumn{2}{|c|}{ Total } \\
\hline Administrativa & Muebles de oficina & Escritorio de melamina & 1 & S/ 339 & S/ & 339 & S/ & 61 & S/ & 400 \\
\hline Administrativa & Muebles de oficina & Silla giratoria & 1 & 508 & S/ & 508 & S/ & 92 & S & 600 \\
\hline Administrativa & Muebles de oficina & Estante-archivador & 1 & 169 & S/ & 169 & S/ & 31 & S/ & 200 \\
\hline Administrativa & Muebles de oficina & Laptop & 1 & S/ 1,525 & S/ & 1,525 & S/ & 275 & S/ & 1,800 \\
\hline Administrativa & Muebles de oficina & Caja fuerte & 1 & S/ 508 & S/ & 508 & S/ & 92 & S/ & 600 \\
\hline Administrativa & Muebles de oficina & Escritorio de melamina & 2 & 219 & S/ & 439 & S/ & 79 & S/ & 518 \\
\hline Administrativa & Muebles de oficina & Sillas & 2 & 254 & S/ & 508 & S/ & 91 & S/ & 600 \\
\hline Administrativa & Muebles de oficina & Estante-archivador & 2 & 169 & S/ & 339 & S/ & 61 & S/ & 400 \\
\hline Administrativa & Muebles de oficina & Computadora personal & 2 & S/ 1,695 & S/ & 3,390 & S/ & 610 & S/ & 4,000 \\
\hline Administrativa & Muebles de oficina & Mesa para impresora & 1 & S/ $\quad 110$ & S/ & 110 & S/ & 20 & S/ & 130 \\
\hline Administrativa & Muebles de oficina & Impresora & 1 & 424 & S/ & 424 & S/ & 76 & S/ & 500 \\
\hline Administrativa & Muebles de oficina & Reloj de pared & 1 & S) $\quad 25$ & S/ & 25 & S/ & 5 & S) & 30 \\
\hline & & & & Total & S/ & 8,286 & S/ & 1,491 & S/ & 9,778 \\
\hline
\end{tabular}

Nota: Elaboración propia

Tabla 107.- Inversión preoperativa - gastos

\begin{tabular}{|c|c|c|c|c|c|c|c|c|c|}
\hline Área & Entidad & Concepto & Cantidad & Importe & Subtotal & \multicolumn{2}{|c|}{ IGV } & \multicolumn{2}{|c|}{ Total } \\
\hline Empresa en General & Persona Natural & Alquiler del local & 2 & S/ 2,500 & S/ $\quad 5,000$ & $\mathrm{~S} /$ & 900 & S/ & 5,900 \\
\hline Empresa en General & Varios & Acondicionamiento del local & 2 & $\mathrm{~S} / 12,000$ & S/ 24,000 & S/ & 4,320 & S/ & 28,320 \\
\hline Empresa en General & SEDAPAL & Agua & 2 & S/ $\quad 250$ & 500 & S/ & 90 & S/ & 590 \\
\hline Empresa en General & EDELNOR & Luz & 2 & 570 & 1,140 & S/ & 205 & S/ & 1,345 \\
\hline Empresa en General & Telefónica & Trio (telefono, cable e internet) & 2 & S/ $\quad 180$ & 360 & S/ & 65 & S/ & 425 \\
\hline & & & & Total & S/ 31,000 & S/ & 5,580 & S/ & 36,580 \\
\hline
\end{tabular}

Nota: Elaboración propia

Los activos intangibles, que se encuentran en soles y sin IGV, son indicados a continuación. 
Tabla 108.- Inversión preoperativa intangible

\begin{tabular}{|c|c|c|c|c|c|c|}
\hline \multicolumn{7}{|c|}{ INVERSIÓN PREOPERATIVA - INTANGIBLE } \\
\hline & \multicolumn{2}{|c|}{ Subtotal } & \multicolumn{2}{|c|}{ IGV } & \multicolumn{2}{|c|}{ Total } \\
\hline Constitución de Empresa & $\mathrm{S} /$ & 13,300 & $\mathrm{~S} /$ & 2,394 & $\mathrm{~S} /$ & 15,694 \\
\hline Licencias y permisos & S/ & 10,800 & S/ & 1,944 & S/ & 12,744 \\
\hline Otros & S/ & 21,360 & S/ & 3,845 & S/ & 25,205 \\
\hline Total Activo Intangible & S/ & 45,460 & S/ & 8,183 & S/ & 53,643 \\
\hline
\end{tabular}

Nota: Elaboración propia

Tabla 109.- Inversión preoperativa intangible - constitución de empresa

\begin{tabular}{|c|c|c|c|c|c|c|c|c|c|c|c|}
\hline Area & Entidad & Concepto & Cantidad & \multicolumn{2}{|c|}{ Importe } & & ubtotal & \multicolumn{2}{|c|}{ IGV } & \multicolumn{2}{|c|}{ Total } \\
\hline Empresa en General & $\mathrm{BCP}$ & Apertura de cuenta corriente & 1 & & & & & & & & \\
\hline Empresa en General & CEPEFODES & Elaboración de minuta & & & & & & & & & \\
\hline Empresa en General & CEPEFODES & Elevación de escritura a registros públicos & & & & & & & & & \\
\hline Empresa en General & CEPEFODES & Inscripción de RUC & 1 & S/ & 1,500 & S/ & 1,500 & S/ & 270 & S/ & 1,770 \\
\hline Empresa en General & CEPEFODES & Autorización de planilla de pago & & & & & & & & & \\
\hline Empresa en General & CEPEFODES & Derecho de inscripción en notaria & & & & & & & & & \\
\hline Empresa en General & Diseñador gráfico & Elaboración de logotipo & 4 & S/ & 950 & S/ & 3,800 & S/ & 684 & S/ & 4,484 \\
\hline Empresa en General & INDECOPI & Marcas, Nombre y Lema Comercial & 10 & S/ & 800 & $\mathrm{~S} /$ & 8,000 & S/ & 1,440 & $\mathrm{~S} /$ & 9,440 \\
\hline & & & & & Total & S/ & 13,300 & $\mathrm{~S} /$ & 2,394 & S/ & 15,694 \\
\hline
\end{tabular}

Nota: Elaboración propia

Tabla 110.- Inversión preoperativa intangible - licencias y permisos

\begin{tabular}{|c|c|c|c|c|c|c|c|c|c|c|}
\hline Área & Entidad & Concepto & Cantidad & Importe & & btotal & & GV & & otal \\
\hline Empresa en General & Municipalidad de Surquillo & Derecho de revisión de bomberos & 1 & S/ 300 & $\mathrm{~S} /$ & 300 & S/ & 54 & S/ & 354 \\
\hline Empresa en General & Municipalidad de Surquillo & Derecho de licencia & 1 & S/ 2,000 & S/ & 2,000 & S/ & 360 & S/ & 2,360 \\
\hline Empresa en General & Municipalidad de Surquillo & Licencia de funcionamiento & 1 & S/ 2,500 & S/ & 2,500 & S/ & 450 & S/ & 2,950 \\
\hline Empresa en General & Municipalidad de Surquillo & Carne de sanidad & 1 & S/ 200 & S/ & 200 & S/ & 36 & S/ & 236 \\
\hline Empresa en General & INDECI & Certificado de Defensa Civil & 1 & 500 & S/ & 500 & S/ & 90 & S/ & 590 \\
\hline Empresa en General & . & Certificado de Seguridad de Defensa Civil & 1 & 300 & S/ & 300 & S/ & 54 & S/ & 354 \\
\hline Empresa en General & DIGESA & Registro sanitario & 1 & S/ $\quad 500$ & S/ & 500 & S/ & 90 & S/ & 590 \\
\hline Empresa en General & DIGESA & Validación Técnica Oficial del Plan HACCP. & 1 & S/ 4,500 & S/ & 4,500 & S/ & 810 & S/ & 5,310 \\
\hline & & & & Total & S/ & 10,800 & S/ & 1,944 & S/ & 12,744 \\
\hline
\end{tabular}

Nota: Elaboración propia

Tabla 111.- Inversión preoperativa - Otros (RRHH - Software - Marketing - Contabilidad)

\begin{tabular}{|c|c|c|c|c|c|c|c|c|c|c|}
\hline Área & Entidad & Concepto & Cantidad & Importe & & btotal & \multicolumn{2}{|c|}{ IGV } & \multicolumn{2}{|c|}{ Total } \\
\hline Contabilidad & Notaria Becerra Sosaya & Legalización de libros contables & 1 & S/ 400 & S/ & 400 & S/ & 72 & S/ & 472 \\
\hline Contabilidad & Imprenta & Talonario de facturas y boletas & 1 & S/ $\quad 560$ & S/ & 560 & S/ & 101 & S/ & 661 \\
\hline Recursos Humanos & E1 Comercio & Publicación de anuncio (fin de semana) & 3 & S/ 1,800 & S: & 5,400 & S/ & 972 & S/ & 6,372 \\
\hline Marketing & Staff Digital & Página web & 1 & S/ 5,000 & S/ & 5,000 & S/ & 900 & S/ & 5,900 \\
\hline Marketing & Redes Sociales & Publicidad & 1 & S/ 5,000 & $\mathrm{~S} /$ & 5,000 & S/ & 900 & S/ & 5,900 \\
\hline Software & Microsoft Office & Software de oficina & 2 & S/ 2,500 & S/ & 5,000 & S/ & 900 & S/ & 5,900 \\
\hline & & & & Total & S/ & 21,360 & S/ & 3,845 & S/ & 25,205 \\
\hline
\end{tabular}

Nota: Elaboración propia

La inversión total sin IGV en activos (tangibles e intangibles) es de S/ 184,634

(incluye el capital de trabajo). El financiamiento responde a un $100 \%$ de capital propio por consiguiente carece de financiamiento. 


\subsubsection{Inversión en capital de trabajo}

El capital de trabajo corresponde a los recursos a corto plazo que necesitará la empresa para operar. Para la obtención del monto se aplicará el método del máximo déficit acumulado.

El método del máximo déficit acumulado se calcula mes a mes durante el primer año de realizado el proyecto. Para cada mes se calcula la diferencia entre ingresos y egresos. El resultado de cada mes es llevado al resultado del mes siguiente, hasta completar el año, obteniendo el cálculo del déficit acumulado, anual.

Luego de efectuar los cálculos indicados se determina la necesidad de contar con S/ 5,761 para emplearlo como capital de trabajo.

Tabla 112.- Inversión en Capital de trabajo

\begin{tabular}{|c|c|c|c|c|c|c|c|c|c|c|c|c|c|}
\hline & & Mes 1 & Mes 2 & Mes 3 & Mes 4 & Mes 5 & Mes 6 & Mes 7 & Mes 8 & Mes 9 & Mes 10 & Mes 11 & Mes 12 \\
\hline Producto: Pollo & $\mathrm{S} /$ & 9,688 & S/ 10,464 & S/ 11,301 & S/ 12,205 & S/ 13,303 & S/ 14,766 & S/ 16,391 & S/ 18,194 & S/ 20,377 & $\mathrm{~S} / 22,822$ & S/ 25,789 & S/ 29,142 \\
\hline Producto: Pescado & $\mathrm{S} /$ & 8,045 & S/ $\quad 8,689$ & S/ $\quad 9,384$ & $\mathrm{~S} / 10,134$ & S/ 11,046 & $\mathrm{~S} / 12,261$ & S/ 13,610 & S/ 15,107 & S/ 16,920 & S/ 18,951 & S/ 21,414 & S/ 24,198 \\
\hline Producto: Res & $\mathrm{S} /$ & 7,076 & S/ 7,642 & S/ 8,253 & S/ 8,914 & S/ 9,716 & S/ 10,785 & S/ 11,971 & S/ 13,288 & S/ 14,882 & S/ 16,668 & S/ 18,835 & S/ 21,283 \\
\hline INGRESO TOTAL & $\mathrm{S}$ & 24,809 & S/ 26,794 & S/ 28,937 & S/ 31,252 & S/ 34,065 & S/ 37,812 & S/ 41,972 & S/ 46,589 & S/ 52,179 & S/ 58,441 & S/ 66,038 & S/ 74,623 \\
\hline Costo de materia prima & $\mathrm{S} /$ & 12,405 & $\mathrm{~S} / 13,397$ & S/ 14,469 & S/ 15,626 & $\mathrm{~S} / 17,033$ & $\mathrm{~S} / 18,906$ & S/ 20,986 & S/ 23,294 & S/ 26,090 & $\mathrm{~S} / 29,220$ & S/ 33,019 & S/ 37,311 \\
\hline Costo de mano de obra directa & $\mathrm{S} /$ & 3,144 & S/ $\quad 3,144$ & $\mathrm{~S} / \quad 3,144$ & S/ $\quad 3,144$ & S/ $\quad 3,144$ & S/ $\quad 3,144$ & S/ $\quad 3,144$ & S/ $\quad 3,144$ & S/ $\quad 3,144$ & S/ $\quad 3,144$ & S/ $\quad 3,144$ & S/ $\quad 3,144$ \\
\hline Costo indirecto de fabricación & $\mathrm{S} /$ & 4,673 & S/ 4,832 & S/ $\quad 5,003$ & S/ $\quad 5,186$ & S/ $\quad 5,406$ & S/ $\quad 5,694$ & S/ 6,013 & S/ 6,365 & S/ $\quad 6,789$ & S/ 7,261 & S/ 7,831 & 8,473 \\
\hline COSTO DE VENTA & $-\mathrm{S} /$ & 20,222 & $-\mathrm{S} / 21,373$ & $-\mathrm{S} / 22,615$ & $-\mathrm{S} / 23,956$ & $-\mathrm{S} / 25,583$ & -S/ 27,744 & $-\mathrm{S} / 30,143$ & $-\mathrm{S} / 32,803$ & -S/ 36,022 & -S/ 39,625 & -S/ 43,994 & -S/ 48,929 \\
\hline UTILIDAD BRUTA & $\mathrm{S} /$ & 4,587 & 5,421 & S/ 6,322 & S/ 7,296 & S/ $\quad 8,482$ & $\mathrm{~S} / 10,068$ & S/ 11,829 & S/ 13,785 & S/ 16,157 & S/ 18,815 & S/ 22,044 & $\mathrm{~S} / 25,694$ \\
\hline Gasto - Administracion & $\mathrm{S} /$ & 5,654 & 5,654 & S/ $\quad 5,654$ & S/ $\quad 5,654$ & S/ $\quad 5,654$ & 5,654 & S/ $\quad 5,654$ & S/ $\quad 5,654$ & S/ $\quad 5,654$ & S/ $\quad 5,654$ & S/ $\quad 5,654$ & 5,654 \\
\hline Gasto - Marketing & $\mathrm{S} /$ & 4,817 & S/ $\quad 4,817$ & S/ $\quad 4,817$ & S/ $\quad 4,817$ & S/ 4,817 & S/ $\quad 4,817$ & S/ $\quad 4,817$ & S/ $\quad 4,817$ & S/ 4,817 & S/ $\quad 4,817$ & S/ $\quad 4,817$ & 4,817 \\
\hline Gasto - Venta & $\mathrm{S} /$ & 1,671 & S/ $\quad 1,671$ & S/ 1,671 & S/ $\quad 1,671$ & S/ $\quad 1,671$ & S/ $\quad 1,671$ & S/ $\quad 1,671$ & S/ $\quad 1,671$ & S/ $\quad 1,671$ & S/ $\quad 1,671$ & S/ $\quad 1,671$ & 1,671 \\
\hline GASTOS & $-\mathrm{S} /$ & 12,142 & -S/ 12,142 & $-\mathrm{S} / 12,142$ & -S/ 12,142 & -S/ 12,142 & -S/ 12,142 & -S/ 12,142 & -S/ 12,142 & -S/ 12,142 & $-\mathrm{S} / 12,142$ & $-\mathrm{S} / 12,142$ & -S/ 12,142 \\
\hline UTILIDAD OPERATIVA & $-\mathrm{S} /$ & 7,555 & 6,721 & $-\mathrm{S} / \quad 5,820$ & -S/ 4,846 & -S/ 3,660 & -S/ $\quad 2,074$ & $-\mathrm{S} /$ & S/ 1,643 & S/ 4,015 & S/ 6,673 & S/ 9,902 & S/ 13,552 \\
\hline \multicolumn{14}{|l|}{ GASTOS FINANCIEROS } \\
\hline UTILIDAD ANTES DE IMPUESTOS & $-\mathrm{S} /$ & 7,555 & 6,721 & 5,820 & 4,846 & $-\mathrm{S} / \quad 3,660$ & 2,074 & 313 & 1,643 & S/ 4,015 & 6,673 & 9,902 & S/ 13,552 \\
\hline IMPUESTO A LA RENTA & & & & & & & & & -S/ 484.66 & $-\mathrm{S} / 1,184.39$ & $-\mathrm{S} / 1,968.56$ & $-\mathrm{S} / 2,921.03$ & $-\mathrm{S} / 3,997.90$ \\
\hline INGRESO MENOS EGRESO & $-\mathrm{S} /$ & 7,555 & 6,721 & -S/ $\quad 5,820$ & -S/ 4,846 & -S/ $\quad 3,660$ & -S/ 2,074 & 313 & S/ $\quad 1,158$ & S/ $\quad 2,830$ & S/ 4,705 & S/ $\quad 6,981$ & $\mathrm{~S} / \quad 9,554$ \\
\hline SALDO ACUMULADO & $-\mathrm{S}$ & 7,555 & $-\mathrm{S} / 14,276$ & -S/ 20,096 & -S/ 24,942 & $-\mathrm{S} / 28,602$ & $-\mathrm{S} / 30,676$ & $-\mathrm{S} / 30,990$ & -S/ 29,831 & $-\mathrm{S} / 27,001$ & -S/ 22,296 & -S/ 15,316 & $-\mathrm{S} / \quad 5,761$ \\
\hline CAPITAL DE TRABAJO & $\mathrm{S} /$ & 5,761 & & & & & & & & & & & \\
\hline
\end{tabular}




\subsubsection{Costo del proyecto.}

El costo del proyecto es de S/ 184,634. Esta inversión se divide en 25\% de activo fijo intangible, $72 \%$ de activo tangible y $3 \%$ de capital de trabajo.

Tabla 113.- Costo del proyecto

\begin{tabular}{|c|c|c|c|}
\hline \multicolumn{4}{|l|}{ INVERSIÓN PREOPERATIVA - INTANGIBLE } \\
\hline Constitución de Empresa & $\mathrm{S} / 13,300$ & & \\
\hline Licencias y permisos & S/ 10,800 & & \\
\hline Otros (RRHH- Software - Marketing - Contabilidad) & S/ 21,360 & & \\
\hline Total Activo Intangible & & S/ 45,460 & $25 \%$ \\
\hline \multicolumn{4}{|l|}{ INVERSIÓN PREOPERATIVA - TANGIBLE } \\
\hline Maquinarias y Equipos & S/ 74,779 & & \\
\hline Muebles y enseres & S/ 19,347 & & \\
\hline Muebles de Oficina & S/ 8,286 & & \\
\hline Inversión - Gastos Preoperativos & S/ 31,000 & & \\
\hline Total Activo Tangible & & S/ 133,413 & $72 \%$ \\
\hline \multicolumn{4}{|l|}{ INVERSION - CAPITAL DE TRABAJO } \\
\hline Capital de trabajo & $\mathrm{S} / \quad 5,761$ & $\mathrm{~S} / \quad 5,761$ & $3 \%$ \\
\hline INVERSIÓN TOTAL & & S/ 184,634 & $100 \%$ \\
\hline
\end{tabular}

Nota: Elaboración propia

\subsubsection{Inversiones futuras}

Para las inversiones futuras a partir del 2023, la empresa evaluará el incremento del equipamiento, ya que hasta el año indicado (año 5) la capacidad instalada puede atender la demanda proyectada.

\subsection{Financiamiento}

La empresa considera un financiamiento del $0 \%$ del costo del proyecto y un $100 \%$ de aporte de los socios.

\subsubsection{Endeudamiento y condiciones}

La empresa no financiará préstamo alguno. Sin embargo, en el supuesto caso de financiamiento, la tasa seleccionada correspondería a INTERBANK con un $19.12 \%$ TEA para nuevas empresas.

Se utilizarán garantías hipotecarias, las que recaerán sobre el inmueble en que se realice la operación productiva, ya que es propiedad de uno de los socios 
accionistas, el cual ha cedido como garantía dicha propiedad valorizada en US\$ $60,000$.

Tabla 114.- Estructura de financiamiento

\begin{tabular}{lrrrrc} 
& $100 \%$ & \multicolumn{1}{c}{$100 \%$} & \multicolumn{1}{c}{$0 \%$} \\
\hline & & \multicolumn{1}{c}{ Total } & \multicolumn{1}{c}{ Aporte } & Préstamo \\
\hline Activo Intangible & S/ & 45,460 & S/ & 45,460 & 0 \\
Activo Tangible & S/ & 133,413 & S/ & 133,413 & 0 \\
Capital de Trabajo & S/ & 5,761 & S/ & 5,761 & 0 \\
\hline \multicolumn{1}{c}{ Total } & S/ & 184,634 & S/ & 184,634 & 0 \\
\hline
\end{tabular}

Nota: Elaboración propia.

\subsubsection{Capital y costo de oportunidad}

El capital será aportado por los tres socios, por el monto de S/ 184,634 donde cada uno contribuirá con un tercio que corresponde a S/ 61,545.

Tabla 115.- Capital

\begin{tabular}{crr}
\multicolumn{3}{c}{ Aporte por Socios } \\
\hline Aportantes & \multicolumn{2}{c}{ Aportes } \\
\hline Socio 1 & S/ & 61,545 \\
Socio 2 & S/ & 61,545 \\
Socio 3 & S/ & 61,545 \\
\hline Total & S/ & 184,634 \\
\hline
\end{tabular}

Nota: Elaboración propia

El costo de oportunidad del inversionista (Ke) equivale a la tasa mínima de rendimiento para un proyecto de inversión.

Para calcular el costo de oportunidad se utilizarán variables relacionadas al mercado estadounidense. De igual forma, se utilizará el método del Capital Asset Pricing Model (CAPM). Este método se basa en la teoría del portafolio que involucra en el riesgo de una inversión, la existencia de una relación entre el riesgo y el retorno.

Se considera el supuesto de que la única fuente de riesgo que afecta la rentabilidad de las inversiones es el riesgo del mercado, por lo que se toma en cuenta el factor beta, que relaciona el riesgo del proyecto con el riesgo del mercado, donde este corresponde a las acciones de la industria americana de procesamiento de 
alimentos con un 0.61 (Damodaran). Este valor indica la sensibilidad del sector a las variaciones del mercado, logrando ser una industria estable donde la demanda no se verá afectada significativamente. La industria presenta una volatilidad mediana, que garantiza la inversión que se realice en ella.

El índice obtenido del mercado americano cuenta con las bolsas de valores de mayor envergadura a nivel internacional (Nasdaq, Euronext), ubicadas en el estado de Nueva York, donde cotizan las principales empresas y organizaciones de todo el mundo, siendo esta una buena razón para obtener los indicadores del mercado americano, que están dados por su volatilidad y variabilidad. Para el cálculo del Ke en Perú, se cuenta con la siguiente relación de indicadores.

Tabla 116.- Variables estadísticas

\begin{tabular}{|c|c|}
\hline Variables Estadisticas & Valor \\
\hline Beta no apalancado del sector ${ }^{(a)}$ & 0.61 \\
\hline Rendimiento de mercado de valores ${ }^{(b)}$ & $7.51 \%$ \\
\hline Tasa libre de riesgo (10 años) ${ }^{(c)}$ & $1.78 \%$ \\
\hline Inflación USA $2019^{(\mathrm{d})}$ & $1.76 \%$ \\
\hline Riesgo Pais Perú (e) & $1.67 \%$ \\
\hline Prima de riesgo adicional del inversionista & $6.00 \%$ \\
\hline Inflación Perú $2019^{(8)}$ & $2.10 \%$ \\
\hline Inflación Perú anualizada (alimentos) ${ }^{(\mathrm{g})}$ & $3.63 \%$ \\
\hline
\end{tabular}

Nota: Elaboración propia

(a) Betas totales por sector (para calcular los costos de capital de la empresa privada). Procesamiento de alimentos. Beta no apalancado. EE. UU. (2019; enero). Aswath Damodaran. Recuperado de http://people.stern.nyu.edu/adamodar/New_Home_Page/datafile/totalbeta.html

(c) Curva de tasas de rendimiento diarias del tesoro. Departamento del tesoro de Estados Unidos. Web site del gobierno de los Estados Unidos. (2019; 29 de noviembre) -

Recuperado de https://www.treasury.gov/resource-center/data-chart-center/interestrates/pages/TextView.aspx?data=yieldYear\&year=2019 
(d) Inflación de Estados Unidos. Índice de precios al consumo (IPC). Tasas Globales. (2019; 30 de noviembre). Triami Media BV

Utrecht, Nederland. Recuperado de

https://es.global-rates.com/estadisticas-economicas/inflacion/indice-de-precios-al-

consumo/ipc/estados-unidos.aspx

(g) Proyección de inflación 2019-2020. Reporte de Inflación. Inflación en alimentos

2010-18. Banco Central de Reserva del Perú

(2019; Septiembre). Recuperado de

http://www.bcrp.gob.pe/docs/Publicaciones/Reporte-Inflacion/2019/setiembre/reportede-inflacion-setiembre-2019-presentacion.pdf

(e) Spreads predeterminados del país y primas de riesgo. Riesgo país (2019; enero).

Aswath Damodaran. Recuperado de

http://people.stern.nyu.edu/adamodar/New_Home_Page/datafile/ctryprem.html

(b) Valor económico agregado por sector (USA). Procesamiento de alimentos. Costo de equidad (2019; 30 de noviembre) - Recuperado de

http://people.stern.nyu.edu/adamodar/New_Home_Page/

datafile/EVA.htm

Tabla 117.- Estructura de costo del proyecto

\begin{tabular}{ccr}
\hline D/C & Monto & Porcentaje \\
\hline Deuda & 0 & $0 \%$ \\
Capital & S/ 184,634 & $100 \%$ \\
\hline Total & S/ 184,634 & $\mathbf{1 0 0 \%}$ \\
\hline
\end{tabular}

Nota: Elaboración propia.

Tabla 118.- Estructura de financiamiento y tasa de impuesto a la renta

\begin{tabular}{ccc}
\hline \multicolumn{3}{c}{ Estructura de Financiamiento } \\
\hline Deuda (D) & Capital (C) & Total \\
\hline 0 & $100 \%$ & $100 \%$ \\
0 & S/ 184,634 & S/ 184,634 \\
\hline Total & $\mathbf{1 0 0 \%}$ \\
\hline \multicolumn{3}{l}{} \\
\hline \multicolumn{2}{l}{ Impuesto a la renta } & $\mathbf{2 9 . 5 \%}$ \\
\hline
\end{tabular}

Nota: Elaboración propia. 
Tabla 119.- Costo de capital

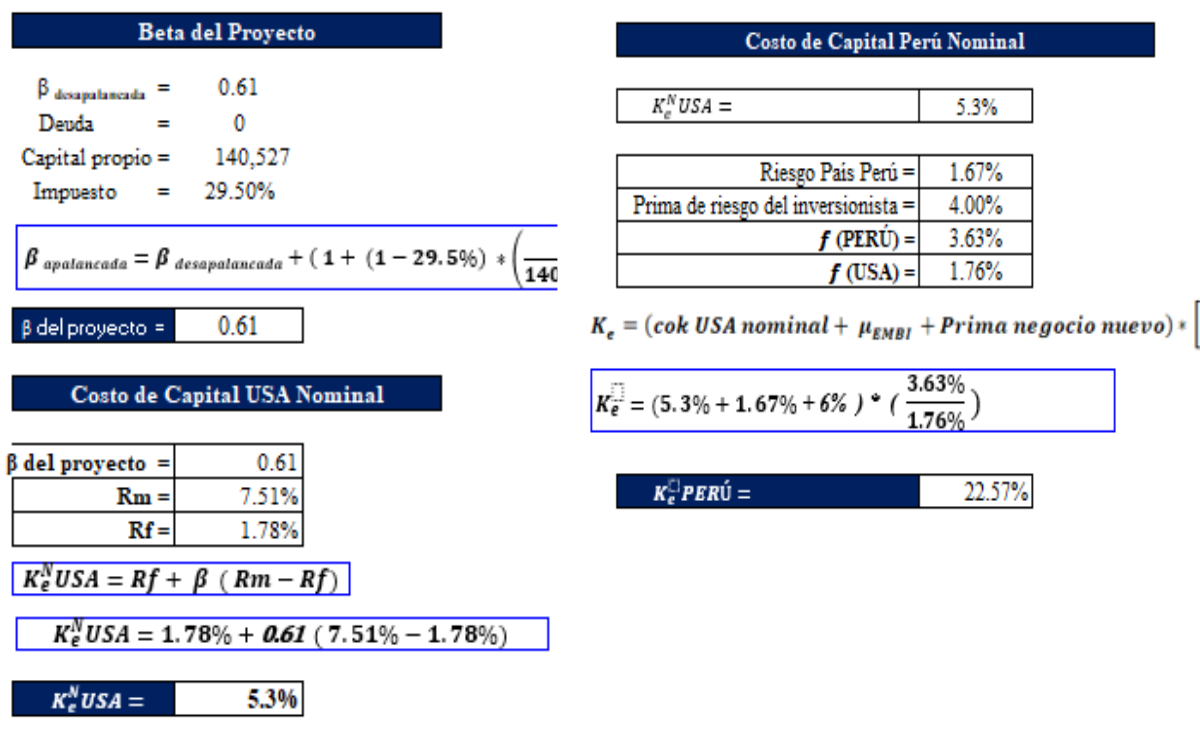

Nota: Elaboración propia.

\subsubsection{Costo de capital promedio ponderado}

Debido a que toda la inversión será realizada con capital propio, no se aplicará el costo promedio ponderado de capital. En tal sentido, el flujo de caja económico será descontado con el costo de oportunidad del inversionista $(\mathrm{Ke})$.

\subsection{Presupuesto Base}

\subsubsection{Presupuesto de venta}

A continuación, se presenta el presupuesto de ventas y de ingresos para cada año del horizonte. 
Tabla 120.- Presupuesto mensual de venta - Año 2019

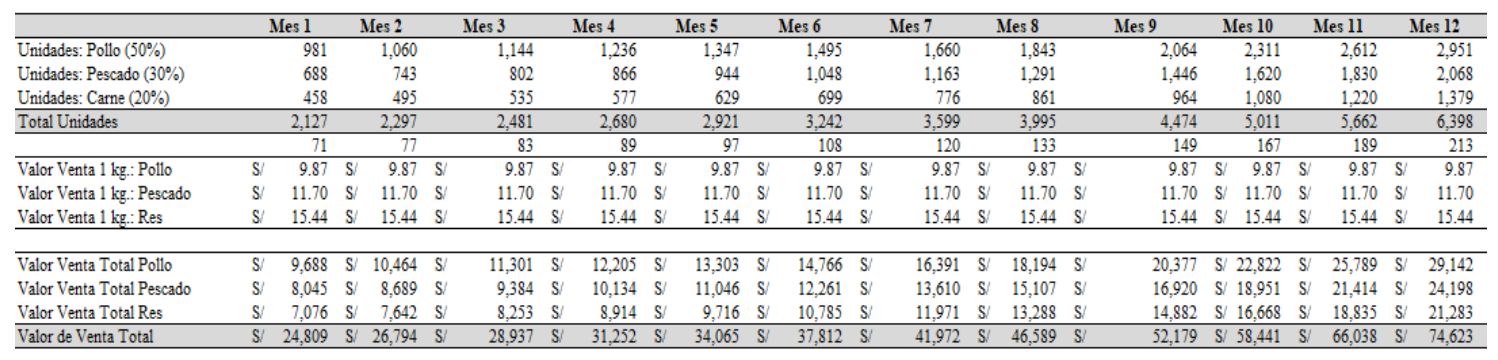

Nota: Elaboración propia.

Tabla 121.- Presupuesto anual de ventas 2019-2023

\begin{tabular}{|c|c|c|c|c|c|c|c|c|c|c|}
\hline & \multicolumn{2}{|c|}{ Año 2019} & \multicolumn{2}{|c|}{ Año 2020} & \multicolumn{2}{|c|}{ Año 2021} & \multicolumn{2}{|r|}{ Año 2022} & \multicolumn{2}{|r|}{ Año 2023} \\
\hline Unidades: Pollo (50\%) & & 20,705 & & 24,846 & & 29,318 & & 33,423 & & 37,099 \\
\hline Unidades: Pescado (30\%) & & 14,509 & & 17,411 & & 20,545 & & 23,422 & & 25,998 \\
\hline Unidades: $\operatorname{Res}(20 \%)$ & & 9,673 & & 11,608 & & 13,697 & & 15,614 & & 17,332 \\
\hline Total Unidades & & 44,887 & & 53,865 & & 63,560 & & 72,459 & & 80,429 \\
\hline Valor de Venta por $1 \mathrm{~kg} .:$ Pollo & $\mathrm{S}$ & 9.87 & S/ & 10.37 & S/ & 10.89 & S/ & 11.43 & $\mathrm{~S} /$ & 12.00 \\
\hline Valor de Venta por $1 \mathrm{~kg}$.: Pescado & $\mathrm{s}$ & 11.70 & S/ & 12.29 & S/ & 12.90 & S: & 13.54 & S/ & 14.22 \\
\hline Valor de Venta por $1 \mathrm{~kg}$.: Res & S & 15.44 & S/ & 16.21 & S/ & 17.02 & $\mathrm{~S} /$ & 17.87 & S/ & 18.76 \\
\hline Valor de Venta: Pollo & $\mathrm{s}$ & 204,441 & & 257,595 & S/ & 319,160 & $\mathrm{~S} /$ & 382,035 & $\mathrm{~S} /$ & 445,262 \\
\hline Valor de Venta: Pescado & S & 169,760 & & 213,898 & S/ & 265,019 & S/ & 317,228 & S/ & 369,729 \\
\hline Valor de Venta: Res & S & 149,311 & & 188,132 & S & 233,096 & $\mathrm{~S}$ & 279,016 & S & 325,193 \\
\hline Valor de Venta Total & S & 523,512 & & 659.625 & $\mathrm{~S}$ & 817,276 & S & 978.279 & & $1,140,184$ \\
\hline
\end{tabular}

Nota: Elaboración propia.

\subsubsection{Presupuesto de costo de producción}

Se hallará el costo unitario de producción. Se considerará para tal efecto, la materia prima, mano de obra directa y los costos indirectos de fabricación.

Tabla 122.- Presupuesto mensual de costos de producción - Año 2019

\begin{tabular}{|c|c|c|c|c|c|c|c|c|c|c|c|c|c|c|c|c|c|c|c|c|c|c|c|}
\hline $\mathrm{CIF}$ & & Les 1 & & Mes 2 & & Les 3 & & Mes 4 & & Les 5 & & Les 6 & & 47 & & Mes 8 & & Mes 9 & & les 10 & & les 11 & Mes 12 \\
\hline Alquiler del local & S/ & 2,000 & S/ & 2,000 & S/ & 2,000 & S/ & 2,000 & S/ & 2,000 & S/ & 2,000 & S/ & 2,000 & S/ & 2,000 & S/ & 2,000 & S/ & 2,000 & S/ & 2,000 & S/ $\quad 2,000$ \\
\hline Gas & S/ & 300 & S/ & 311 & S/ & 321 & S/ & 333 & S & 344 & S/ & 356 & S & 369 & S/ & 382 & S/ & 395 & S/ & 409 & S/ & 423 & 438 \\
\hline Luz & S/ & 216 & S/ & 220 & S/ & 225 & S/ & 229 & S/ & 234 & S/ & 238 & S/ & 243 & S/ & 248 & S/ & 253 & S/ & 258 & S/ & 263 & 269 \\
\hline Agua & S/ & 160 & S/ & 160 & S/ & 160 & S/ & 160 & S/ & 160 & S/ & 160 & S/ & 160 & S/ & 160 & S/ & 160 & S/ & 160 & S/ & 160 & 160 \\
\hline Bolsa de empaque & S/ & 734 & S/ & 793 & S/ & 856 & S/ & 924 & S/ & 1,008 & S/ & 1,119 & S/ & 1,242 & S/ & 1,378 & S/ & 1,544 & S/ & 1,729 & S/ & 1,953 & 2,207 \\
\hline Bolsa Bilaminada Alum $12 \times 15 \mathrm{~cm}$ & S) & 638 & S/ & 689 & S/ & 744 & S/ & 804 & S/ & 876 & S/ & 973 & S/ & 1,080 & S & 1,198 & S/ & 1,342 & S/ & 1,503 & S/ & 1,699 & 1,920 \\
\hline Sticker & S/ & 425 & S/ & 459 & S/ & 496 & S/ & 536 & S/ & 584 & S/ & 648 & S/ & 720 & S/ & 799 & S/ & 895 & S/ & 1,002 & S/ & 1,132 & S/ $\quad 1,280$ \\
\hline Otros & S/ & 200 & S/ & 200 & S/ & 200 & S/ & 200 & S/ & 200 & S/ & 200 & S) & 200 & S/ & 200 & S/ & 200 & S/ & 200 & S/ & 200 & 200 \\
\hline Costo Total - CIF & S/ & 4,673 & S/ & 4,832 & S/ & 5,003 & S/ & 5,186 & S/ & 5,406 & S/ & 5,694 & S/ & 6,013 & S/ & 6,365 & S/ & 6,789 & S/ & 7,261 & S/ & 7,831 & S/ $\quad 8,473$ \\
\hline Costo total de producción & S) & 20,222 & S/ & 21,373 & S/ & 22,615 & S/ & 23,956 & S/ & 25,583 & S/ & 27,744 & S/ & 30,143 & S) & 32,803 & S) & 36,022 & S/ & 39,625 & S/ & 43,994 & S/ 48,929 \\
\hline Costo unitario de producción & & 9.51 & & 9.30 & & 9.11 & & 8.94 & & 8.76 & & 8.56 & & 8.38 & & 8.21 & & 8.05 & & 7.91 & & 7.77 & 7.65 \\
\hline
\end{tabular}

Nota: Elaboración propia. 
Tabla 123.- Presupuesto anual de costos de producción 2019-2023

\begin{tabular}{|c|c|c|c|c|c|c|c|c|c|}
\hline & & 2019 & & 2020 & & 2021 & 2022 & & 2023 \\
\hline \multicolumn{10}{|l|}{ Materia Prima } \\
\hline Costo de Materia Prima: Pollo & S/ & 102,220 & $\mathrm{~S} /$ & 128,798 & S/ & 159,580 & S/ $\quad 191,018$ & S/ & 222,631 \\
\hline Costo de Materia Prima: Pescado & S/ & 84,880 & S/ & 106,949 & S/ & 132,510 & S/ $\quad 158,614$ & S/ & 184,865 \\
\hline Costo de Materia Prima: Res & $\mathrm{S} /$ & 74,656 & S/ & 94,066 & S/ & 116,548 & S/ $\quad 139,508$ & $\mathrm{~S} /$ & 162,597 \\
\hline Costo Total - Materia Prima & $\mathrm{S} /$ & 261,756 & $\mathrm{~S} /$ & 329,813 & S/ & 408,638 & S/ $\quad 489,139$ & S: & 570,092 \\
\hline \multicolumn{10}{|l|}{ Mano de Obra Directa } \\
\hline Jefe de produccion & $\mathrm{S} /$ & 19,137 & S/ & 19,520 & $\mathrm{~S} /$ & 19,910 & 20,308 & S/ & 20,714 \\
\hline Operario de produccion & S/ & 18,590 & S/ & 18,962 & S/ & 19,341 & 19,728 & S/ & 20,123 \\
\hline Ayudante de produccion 1 & & & & & S/ & 16,950 & 17,289 & S/ & 17,635 \\
\hline Ayudante de produccion 2 & & & & & & & & S/ & 16,950 \\
\hline \multicolumn{10}{|l|}{ Ayudante de produccion 3} \\
\hline Ayudante a tiempo parcial & & & S/ & 8,475 & & & 8,644 & S/ & 8,817 \\
\hline Costo Total - Mano de Obra Directa & $\mathrm{S} /$ & 37,727 & $\mathrm{~S} /$ & 46,957 & $\mathrm{~S} /$ & 56,201 & 65,970 & $\mathrm{~S} /$ & 84,239 \\
\hline \multicolumn{10}{|l|}{ CIF } \\
\hline Alquiler del local & S/ & 24,000 & S/ & 24,000 & S/ & 25,200 & 25,200 & S/ & 26,460 \\
\hline Gas & S/ & 4,381 & S/ & 5,608 & S/ & 7,180 & 9,193 & S/ & 11,770 \\
\hline Luz & S/ & 2,897 & S/ & 2,955 & S/ & 3,014 & 3,074 & S/ & 3,136 \\
\hline Agua & S/ & 1,920 & S/ & 3,103 & S/ & 5,013 & 8,101 & S/ & 13,091 \\
\hline Bolsa de empaque & S: & 15,486 & S/ & 15,711 & S/ & 18,853 & 22,246 & S/ & 25,361 \\
\hline Bolsa Bilaminada Alum $12 \times 15 \mathrm{~cm}$ & S/ & 13,466 & S/ & 13,466 & S/ & 16,159 & 19,068 & S/ & 21,738 \\
\hline Sticker & S/ & 8,977 & S/ & 8,977 & S/ & 10,773 & 12,712 & S/ & 14,492 \\
\hline Otros & $\mathrm{S} /$ & 2,400 & S/ & 2,400 & $\mathrm{~S} /$ & 2,400 & 2,448 & S/ & 2,448 \\
\hline Costo Total - CIF & S/ & 73,527 & S/ & 76,220 & S/ & 88,593 & S/ $\quad 102,043$ & S/ & 118,494 \\
\hline Costo total de producción & S/ & 373,011 & S/ & 452,989 & S/ & 553,432 & S/ 657,152 & S/ & 772,825 \\
\hline Costo unitario de producción & & 8.31 & & 8.41 & & 8.71 & 9.07 & & 9.61 \\
\hline
\end{tabular}

Nota: Elaboración propia.

\subsubsection{Presupuesto de compras}

Se detallan las compras de materia prima directa e indirecta.

Tabla 124.- Presupuesto mensual de compras de materia prima (pollo) - Año 2019

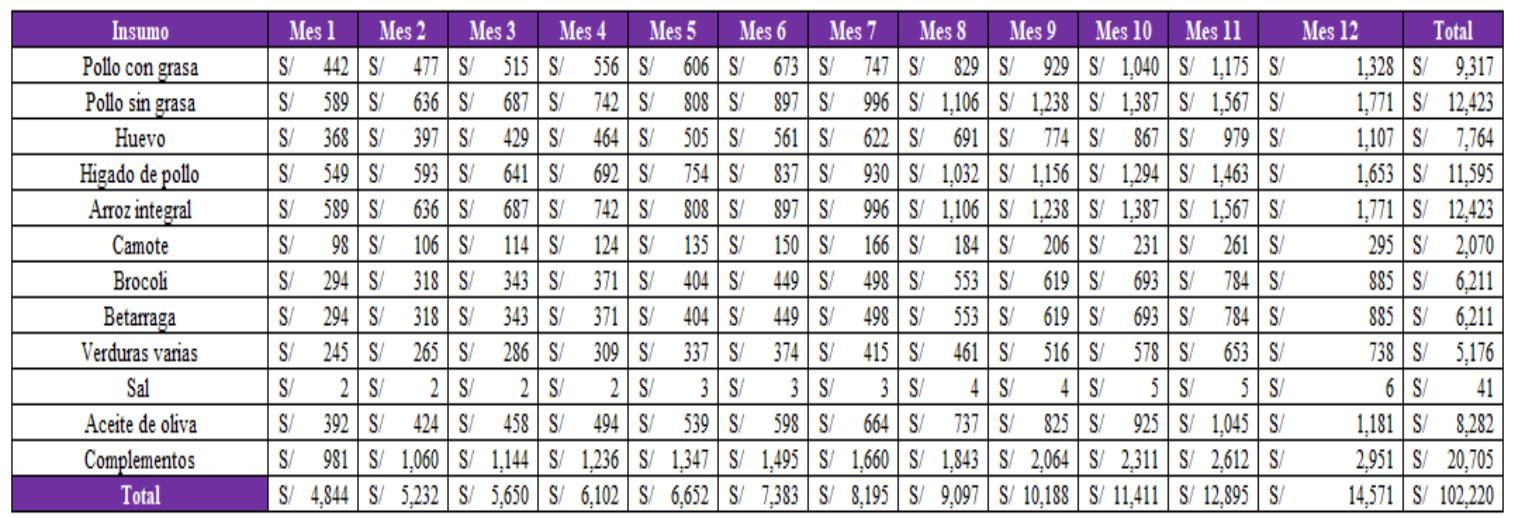

Nota: Elaboración propia 
Tabla 125.- Presupuesto mensual de compras de materia prima (pescado) - Año 2019

\begin{tabular}{|c|c|c|c|c|c|c|c|c|c|c|c|c|c|}
\hline & Mes 1 & Mes 2 & Mes 3 & Mes 4 & Mes 5 & Mes 6 & Mes 7 & Mes 8 & Mes 9 & Mes 10 & Mes 11 & Mes 12 & Total \\
\hline Pescado (came blanca) & S/ 619 & 668 & S/ 722 & S/ $\quad 780$ & 850 & S/ $\quad 943$ & S/ 1,047 & S/ 1,162 & S/ 1,302 & S/ 1,458 & S/ $\quad 1,647$ & S/ $\quad 1,861$ & S/ 13,058 \\
\hline Pescado & 619 & 668 & 722 & 780 & 850 & 943 & S/ 1,047 & S/ 1,162 & S/ 1,302 & S/ 1,458 & S/ $\quad 1,647$ & S/ $\quad 1,861$ & S/ 13,058 \\
\hline & 619 & 668 & 722 & 780 & 850 & 943 & S/ 1,047 & S/ 1,162 & S/ $\quad 1,302$ & S/ 1,458 & S/ $\quad 1,647$ & S/ $\quad 1,861$ & S/ 13,058 \\
\hline & 138 & 149 & 160 & 173 & 189 & 210 & $\mathrm{~S} / \quad 233$ & S/ 258 & 289 & 324 & S/ $\quad 366$ & S/ $\quad 414$ & S/ $\quad 2,902$ \\
\hline & 344 & 371 & 401 & 433 & 472 & 524 & 582 & 646 & 723 & 810 & 915 & S/ 1,034 & S/ $\quad 7,255$ \\
\hline & 206 & 223 & 241 & 260 & 283 & 314 & 349 & 387 & 434 & 486 & 549 & S/ 620 & S/ $\quad 4,353$ \\
\hline & 172 & 186 & 201 & 217 & 236 & 262 & 291 & 323 & 362 & 405 & 458 & 517 & S/ $\quad 3,627$ \\
\hline & $\mathrm{S} /$ & $\mathrm{S} /$ & $\mathrm{S} /$ & S/ & $\mathrm{S} /$ & S/ & $\mathrm{S} /$ & $\mathrm{S} /$ & $\mathrm{S} /$ & $\mathrm{S} /$ & $\mathrm{S} /$ & S/ & $\mathrm{S} /$ \\
\hline Acei & 550 & 594 & 642 & 693 & 755 & 838 & 931 & S/ 1,033 & S/ $\quad 1,157$ & S/ $\quad 1,296$ & S/ $\quad 1,464$ & S/ $\quad 1,655$ & S/ 11,608 \\
\hline & 67 & 73 & $\mathrm{~S} /$ & 85 & 93 & S/ $\quad 103$ & S/ $\quad 114$ & S/ $\quad 127$ & S/ $\quad 142$ & S/ $\quad 159$ & S/ $\quad 179$ & S/ 203 & S/ $\quad 1,422$ \\
\hline Comple & S/ 688 & $\mathrm{~S} / \quad 743$ & S/ $\quad 802$ & S/ $\quad 866$ & S/ $\quad 944$ & S/ 1,048 & $\mathrm{~S} / \quad 1,163$ & S/ 1,291 & S/ 1,446 & S/ 1,620 & S/ $\quad 1,830$ & S/ 2,068 & S/ 14,509 \\
\hline Total & S/ $\quad 4,022$ & S/ $\quad 4,344$ & S/ 4,692 & S/ $\quad 5,067$ & S/ $\quad 5,523$ & S/ $\quad 6,131$ & S/ $\quad 6,805$ & S/ 7,554 & S/ $\quad 8,460$ & S/ $\quad 9,475$ & S/ 10,707 & S/ 12,099 & S/ 84,880 \\
\hline
\end{tabular}

Nota: Elaboración propia.

Tabla 126.- Presupuesto mensual de compras de materia prima (carne) - Año 2019

\begin{tabular}{|c|c|c|c|c|c|c|c|c|c|c|c|c|c|}
\hline Insumo & Mes 1 & Mes 2 & Mes 3 & Mes 4 & Mes 5 & Mes 6 & Mes 7 & Mes 8 & Mes 9 & Mes 10 & Mes 11 & Mes 12 & Total \\
\hline Malaya & S/ $\quad 963$ & S/ $\quad 1,040$ & S/ 1,123 & S/ 1,213 & S/ 1,322 & S/ 1,467 & S/ 1,629 & S/ 1,808 & S/ 2,025 & S/ 2,268 & S/ 2,562 & S/ 2,895 & $\mathrm{~S} / 20,313$ \\
\hline Carne (80\%) & 513 & S/ $\quad 554$ & S/ 599 & S/ 647 & S/ 705 & S/ 782 & S/ $\quad 869$ & S/ $\quad 964$ & S/ 1,080 & S/ 1,209 & S/ 1,367 & S/ 1,544 & S/ 10,834 \\
\hline Grasa (20\%) & 92 & 99 & 107 & 115 & 126 & 140 & 155 & 172 & S/ 193 & S/ 216 & S/ $\quad 244$ & S/ 276 & S/ 1,935 \\
\hline Higado de res & 92 & 99 & 107 & 115 & 126 & 140 & 155 & 172 & 193 & 216 & 244 & S/ 276 & S/ 1,935 \\
\hline Corazón de res & 367 & 396 & 428 & 462 & 504 & 559 & 620 & 689 & 771 & 864 & 976 & S/ 1,103 & S/ 7,738 \\
\hline Pulmón de res & 138 & 149 & 160 & 173 & 189 & 210 & 233 & 258 & 289 & 324 & 366 & S/ 414 & S/ 2,902 \\
\hline Arroz integral & 275 & 297 & 321 & 346 & 378 & 419 & 465 & 516 & 578 & 648 & 732 & 827 & S/ 5,804 \\
\hline Camote & 92 & 99 & 107 & 115 & 126 & 140 & 155 & 172 & 193 & 216 & 244 & 276 & S/ $\quad 1,935$ \\
\hline Betarraga & 138 & 149 & 160 & 173 & 189 & 210 & 233 & 258 & 289 & 324 & 366 & 414 & S/ 2,902 \\
\hline Brocoli & 69 & 74 & 80 & 87 & 94 & 105 & 116 & 129 & 145 & 162 & 183 & 207 & S/ 1,451 \\
\hline Verduras varias & 115 & 124 & 134 & 144 & 157 & 175 & 194 & 215 & 241 & 270 & 305 & 345 & S/ 2,418 \\
\hline Sal & 183 & 198 & 214 & 231 & 252 & 279 & 310 & 344 & 386 & 432 & 488 & 552 & S/ $\quad 3,869$ \\
\hline Aceite girasol & 45 & 49 & 52 & 57 & 62 & 68 & 76 & 84 & $\mathrm{~S} /$ & S/ $\quad 106$ & S/ $\quad 120$ & S/ $\quad 135$ & S/ $\quad 948$ \\
\hline Complementos & S/ 458 & S/ 495 & S/ $\quad 535$ & S/ 577 & S/ $\quad 629$ & S/ 699 & S/ $\quad 776$ & S/ $\quad 861$ & S/ $\quad 964$ & S/ 1,080 & S/ 1,220 & S/ 1,379 & S/ $\quad 9,673$ \\
\hline Total & S/ 3,538 & S/ 3,821 & S/ 4,127 & S/ 4,457 & S/ 4,858 & S/ 5,392 & S/ $\quad 5,985$ & S/ 6,644 & S/ 7,441 & S/ 8,334 & S/ 9,417 & S/ 10,642 & S/ 74,656 \\
\hline
\end{tabular}

Nota: Elaboración propia.

Tabla 127.- Presupuesto mensual de compras de materiales indirectos - Año 2019

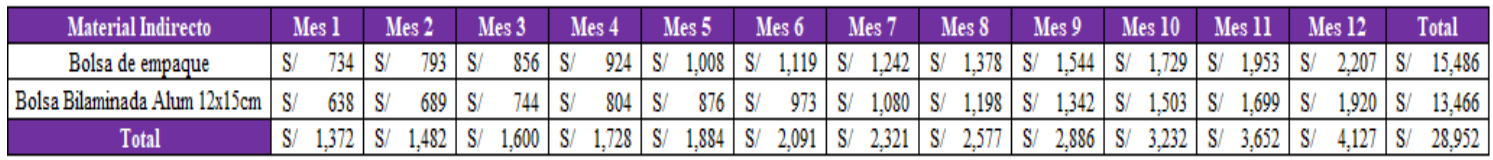

Nota: Elaboración propia. 
Tabla 128.- Presupuesto anual de compras de materia prima (pollo)

\begin{tabular}{|c|}
\hline Insumo \\
\hline Pollo con grasa \\
\hline Pollo sin grasa \\
\hline Huevo \\
\hline Higado de pollo \\
\hline Arroz integral \\
\hline Camote \\
\hline Brocoli \\
\hline Betarraga \\
\hline Verduras varias \\
\hline Sal \\
\hline Aceite de oliva \\
\hline Complementos \\
\hline Total \\
\hline
\end{tabular}

\begin{tabular}{|c|c|c|c|c|c|}
\hline \multicolumn{2}{|c|}{2019} & 2020 & 2021 & 2022 & \\
\hline & 9,31 & 11,740 & S/ 14, & S/ 17,411 & S/ 20 \\
\hline & & 1 & S/ 1 & $\mathrm{~S} / 2$ & $\mathrm{~S} /$ \\
\hline & & & $\mathrm{S} / 1$ & $\mathrm{~S} / \mathrm{1}$ & $\mathrm{S} /$ \\
\hline & & $\mathrm{S} / \quad 14,0$ & $\mathrm{~S} / 18$ & S/ 2 & $\mathrm{~S} /$ \\
\hline & & S/ 15, & $\mathrm{~S} / 19$ & $\mathrm{~S} / 23$ & $\mathrm{~S} /$ \\
\hline & & S/ $\quad 2,609$ & $\mathrm{~S} / 3$ & $\mathrm{~S} / 3$ & $\mathrm{~S} /$ \\
\hline & & 826 & $\mathrm{~S} /$ & $\mathrm{S} /$ & $\mathrm{S} /$ \\
\hline & & 7,826 & & $\mathrm{~S} / \mathrm{1}$ & $\mathrm{S} /$ \\
\hline & 5 & 522 & & $\mathrm{~S} / \mathrm{s}$ & $\mathrm{S} /$ \\
\hline & & $\mathrm{S} /$ & & 77 & $\mathrm{~S} /$ \\
\hline & & S/ 10,435 & $\mathrm{~S} / \mathrm{12}$ & S/ $\quad 15,476$ & $\mathrm{~S} /$ \\
\hline & $20,7 \mathrm{C}$ & S/ 26,0 & $\mathrm{~S} / 32$, & S/ $\quad 38,691$ & $\mathrm{~S} /$ \\
\hline & & S/ 12 & $\mathrm{~S} / 15$ & $\mathrm{~S} / 19$ & \\
\hline
\end{tabular}

Nota: Elaboración propia.

Tabla 129.- Presupuesto anual de compras de materia prima (pescado)

\begin{tabular}{|c|}
\hline Insumo \\
\hline Pescado (carne blanca) \\
\hline Pescado (carne oscura) \\
\hline Arroz integral \\
\hline Camote \\
\hline Espinaca \\
\hline Betarraga \\
\hline Verduras varias \\
\hline Sal \\
\hline Aceite de oliva \\
\hline Aceite de girasol \\
\hline Complementos \\
\hline Total \\
\hline
\end{tabular}

\begin{tabular}{|lr|rr|lr|lr|l|l|}
\hline \multicolumn{2}{|c|}{2019} & \multicolumn{2}{c|}{$\mathbf{2 0 2 0}$} & \multicolumn{2}{c|}{$\mathbf{2 0 2 1}$} & \multicolumn{2}{|c|}{$\mathbf{2 0 2 2}$} & \multicolumn{2}{|c|}{2023} \\
\hline $\mathrm{S} /$ & 13,058 & $\mathrm{~S} /$ & 16,454 & $\mathrm{~S} /$ & 20,386 & $\mathrm{~S} /$ & 24,402 & $\mathrm{~S} /$ & 28,441 \\
\hline $\mathrm{S} /$ & 13,058 & $\mathrm{~S} /$ & 16,454 & $\mathrm{~S} /$ & 20,386 & $\mathrm{~S} /$ & 24,402 & $\mathrm{~S} /$ & 28,441 \\
\hline $\mathrm{S} /$ & 13,058 & $\mathrm{~S} /$ & 16,454 & $\mathrm{~S} /$ & 20,386 & $\mathrm{~S} /$ & 24,402 & $\mathrm{~S} /$ & 28,441 \\
\hline $\mathrm{S} /$ & 2,902 & $\mathrm{~S} /$ & 3,656 & $\mathrm{~S} /$ & 4,530 & $\mathrm{~S} /$ & 5,423 & $\mathrm{~S} /$ & 6,320 \\
\hline $\mathrm{S} /$ & 7,255 & $\mathrm{~S} /$ & 9,141 & $\mathrm{~S} /$ & 11,326 & $\mathrm{~S} /$ & 13,557 & $\mathrm{~S} /$ & 15,800 \\
\hline $\mathrm{S} /$ & 4,353 & $\mathrm{~S} /$ & 5,485 & $\mathrm{~S} /$ & 6,795 & $\mathrm{~S} /$ & 8,134 & $\mathrm{~S} /$ & 9,480 \\
\hline $\mathrm{S} /$ & 3,627 & $\mathrm{~S} /$ & 4,570 & $\mathrm{~S} /$ & 5,663 & $\mathrm{~S} /$ & 6,778 & $\mathrm{~S} /$ & 7,900 \\
\hline $\mathrm{S} /$ & 29 & $\mathrm{~S} /$ & 37 & $\mathrm{~S} /$ & 45 & $\mathrm{~S} /$ & 54 & $\mathrm{~S} /$ & 63 \\
\hline $\mathrm{S} /$ & 11,608 & $\mathrm{~S} /$ & 14,625 & $\mathrm{~S} /$ & 18,121 & $\mathrm{~S} /$ & 21,691 & $\mathrm{~S} /$ & 25,281 \\
\hline $\mathrm{S} /$ & 1,422 & $\mathrm{~S} /$ & 1,792 & $\mathrm{~S} /$ & 2,220 & $\mathrm{~S} /$ & 2,657 & $\mathrm{~S} /$ & 3,097 \\
\hline $\mathrm{S} /$ & 14,509 & $\mathrm{~S} /$ & 18,282 & $\mathrm{~S} /$ & 22,651 & $\mathrm{~S} /$ & 27,113 & $\mathrm{~S} /$ & 31,601 \\
\hline $\mathrm{S} /$ & 84,880 & $\mathrm{~S} / 106,949$ & $\mathrm{~S} / 132,510$ & $\mathrm{~S} /$ & 158,614 & $\mathrm{~S} /$ & 184,865 \\
\hline
\end{tabular}

Nota: Elaboración propia. 
Tabla 130.- Presupuesto anual de compras de materia prima (carne)

\begin{tabular}{|c|}
\hline Insumo \\
\hline Malaya \\
\hline Carne ( $80 \%)$ \\
\hline Grasa (20\%) \\
\hline Higado de res \\
\hline Corazón de res \\
\hline Pulmón de res \\
\hline Arroz integral \\
\hline Camote \\
\hline Betarraga \\
\hline Brocoli \\
\hline Verduras varias \\
\hline Sal \\
\hline Aceite girasol \\
\hline Complementos \\
\hline Total \\
\hline
\end{tabular}

\begin{tabular}{|c|c|c|c|c|c|}
\hline \multicolumn{2}{|c|}{2019} & 2020 & 2021 & 2022 & 2023 \\
\hline S/ & 20,313 & S/ 25,595 & S/ 31,712 & S/ $\quad 37,959$ & S/ $\quad 44,241$ \\
\hline & & S/ 13,650 & S/ 16, & S/ 20,2 & $\mathrm{~S} /$ \\
\hline & & S/ $\quad 2,438$ & S/ $\quad 3,020$ & 3,615 & S/ $\quad 4,213$ \\
\hline & & 2,438 & 20 & $\mathrm{~S} /$ & $\mathrm{S} /$ \\
\hline & & 9,750 & S/ 12, & S/ 14, & S/ 10 \\
\hline & 02 & 3,656 & S/ 4, & S/ $\quad 5,4$ & $\mathrm{~S} /$ \\
\hline & 304 & 7,313 & $\mathrm{~S} /$ & $\mathrm{S} / 10,8$ & $\mathrm{~S} / \mathrm{1}$ \\
\hline & 935 & 2,438 & S/ & 3,615 & S/ \\
\hline & & 3,656 & $\mathrm{~S} /$ & S/ & $\mathrm{S} /$ \\
\hline$S$ & & 1,828 & $\mathrm{~S} /$ & $\mathrm{S} /$ & $\mathrm{S} /$ \\
\hline$S$ & 2,418 & 3,047 & $\mathrm{~S} /$ & $\mathrm{S} /$ & 5,267 \\
\hline$S$ & 3,869 & 4,875 & 6,040 & 7,230 & 8,427 \\
\hline S & 948 & 1,194 & $\mathrm{~S} / \quad 1,480$ & S/ $\quad 1,771$ & 2,065 \\
\hline S & 9,673 & $\mathrm{~S} / \quad 12,188$ & S/ 15,101 & S/ 18,076 & S/ $\quad 21,067$ \\
\hline & 74,656 & $\mathrm{~S} / 94,066$ & $\mathrm{~S} / 116,548$ & $\mathrm{~S} / 139,508$ & $\mathrm{~S} / 162,597$ \\
\hline
\end{tabular}

Nota: Elaboración propia.

Tabla 131.- Presupuesto anual de compras de materiales indirectos

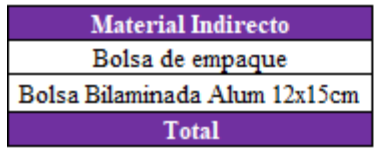

\begin{tabular}{|c|c|c|c|c|c|}
\hline & 019 & 2020 & 2021 & 2022 & 2023 \\
\hline $\mathrm{S} /$ & 15,486 & S/ $\quad 19,513$ & S/ 24,176 & S/ 28,939 & S/ 33,728 \\
\hline $\mathrm{S} /$ & 13,466 & S/ $\quad 16,967$ & $\mathrm{~S} / 21,023$ & S/ 25,164 & 29,329 \\
\hline $\mathrm{S} /$ & 28,952 & $\mathrm{~S} / \quad 36,480$ & $\mathrm{~S} / \quad 45,199$ & $\mathrm{~S} / \quad 54,103$ & 63,057 \\
\hline
\end{tabular}

Nota: Elaboración propia.

\subsubsection{Presupuesto de costo de venta}

Se detallan los costos del producto a nivel mensual.

Tabla 132.- Presupuesto mensual de costo de venta - Año 2019

\begin{tabular}{|c|c|c|c|c|c|c|c|c|c|c|c|c|c|c|c|c|c|c|}
\hline & & Mes 1 & & Mes 2 & & Mes 3 & & Mes 4 & & Ies 5 & & Les 6 & Mes 7 & Mes 8 & Mes 9 & Mes 10 & Mes 11 & Mes \\
\hline IPT & & & $0 \mathrm{~S}$ & 506 & S/ & 534 & S/ & 565 & 8 & 599 & & 640 & S/ $\quad 694$ & S/ 754 & S/ $\quad 820$ & $\begin{array}{ll}\text { S/ } \quad 901 \\
\end{array}$ & & S/ 1,1 \\
\hline & S & 12,405 & SI & 13,397 & S/ & 14,469 & S/ & 15,626 & & 17,033 & & 18,906 & S/ 20,986 & S/ 23,294 & S/ 26,090 & S/ 29,220 & S/ 33,019 & $5 / 3,3$ \\
\hline & & & S/ & 3,1 & 5 & & S/ & & & & & & S/ 3,144 & S/ 3,144 & S/ 3,144 & S/ 3 , & S/ 3,144 & 3,1 \\
\hline & s & & S/ & 4,832 & s & & S/ & 5,186 & & & & & S/ 6,013 & S/ 6,365 & S/ 6,789 & 7,261 & S/ 7,831 & \\
\hline Inventario Final PT & $-S \mid$ & 506 & $-S$ & 534 & $-S /$ & 565 & $-S /$ & 599 & $-S /$ & 640 & -4 & 694 & S/ 754 & -S) $\quad 820$ & -S) $\quad 901$ & & S/ 1,100 & S/ 9,32 \\
\hline
\end{tabular}

Nota: Elaboración propia. 
Tabla 133.- Presupuesto anual de costo de venta

\begin{tabular}{|c|c|c|c|c|c|c|c|c|c|}
\hline & \multicolumn{2}{|c|}{ Año 2019} & \multicolumn{2}{|r|}{ Año 2020} & \multicolumn{2}{|r|}{ Año 2021} & Año 2022 & \multicolumn{2}{|c|}{ Año 2023} \\
\hline Inventario Inicial PT & & & S/ & 9,325 & S/ & 11,325 & S/ 13,836 & $\mathrm{~s}$ & 16,429 \\
\hline Materia Prima & S/ & 261,756 & S/ & 329,813 & S: & 408,638 & S/ 489,139 & $\mathrm{~s}$ & 570,092 \\
\hline Mano de Obra Directa & S/ & 37,727 & S/ & 46,957 & S/ & 56,201 & S/ $\quad 65,970$ & $\mathrm{~s}$ & 84,239 \\
\hline CIF & S/ & 73,527 & S/ & 76,220 & s/ & 88,593 & S/ 102,043 & s & 118,494 \\
\hline$(-)$ Inventario Final PT & $-S /$ & 9,325 & $-S /$ & 11,325 & $-S /$ & 13,836 & -S/ $\quad 16,429$ & & 0 \\
\hline & & 363,685 & S/ & 450,990 & $\mathrm{~S} /$ & 550,921 & S/ 654,559 & & 789,254 \\
\hline
\end{tabular}

Nota: Elaboración propia.

\subsubsection{Presupuesto de gastos administrativos}

Los gastos administrativos se incrementarán en un 5\% anual para provisionar escenarios de futuros incrementos en el costo de vida, así como del sector alimentos.

Tabla 134.- Presupuesto mensual de gastos administrativos - Año 2019

\begin{tabular}{|c|c|c|c|c|c|c|c|c|c|c|c|c|c|c|c|c|c|c|c|c|c|c|c|c|}
\hline & & Mes 1 & & Ies 2 & & Mes 3 & & Ies 4 & & Ies 5 & & les 6 & & les 7 & & les 8 & & Les 9 & & es 10 & & Ies 11 & & Les 12 \\
\hline Gerente General & SI & 2,734 & S/ & 2,734 & S/ & 2,734 & S/ & 2,734 & S/ & 2,734 & S/ & 2,734 & S/ & 2,734 & S/ & 2,734 & S/ & 2,734 & S/ & 2,734 & S/ & 2,734 & S/ & 2,734 \\
\hline Contador & s & 600 & S & 600 & S/ & 600 & S & 600 & S/ & 600 & S/ & 600 & S & 600 & S/ & 600 & S/ & 600 & S/ & 600 & S/ & 600 & S/ & 600 \\
\hline Secretaria & SI & 1,412 & S/ & 1,412 & S/ & 1,412 & S/ & 1,412 & S/ & 1,412 & S/ & 1,412 & S/ & 1,412 & S/ & 1,412 & S/ & 1,412 & S/ & 1,412 & S/ & 1,412 & S/ & 1,412 \\
\hline Alquile & S & 400 & S & 400 & S/ & 400 & S/ & 400 & SI & 400 & S/ & 400 & S & 400 & S/ & 400 & S/ & 400 & S/ & 400 & S/ & 400 & S/ & 400 \\
\hline Luz & s & 100 & SI & 100 & S/ & 100 & S/ & 100 & S/ & 100 & S/ & 100 & S/ & 100 & S/ & 100 & SI & 100 & S/ & 100 & S/ & 100 & S/ & 100 \\
\hline Agra & s & 40 & S & 40 & S/ & 40 & S/ & 40 & S/ & 40 & S/ & 40 & S/ & 40 & S/ & 40 & S/ & 40 & S/ & 40 & S/ & 40 & S/ & 40 \\
\hline Comuni & s & 180 & S/ & 180 & S/ & 180 & S/ & 180 & S/ & 180 & S/ & 180 & S/ & 180 & S/ & 180 & S/ & 180 & S/ & 180 & S/ & 180 & S/ & 180 \\
\hline Hojas 1 & $S$ & 28 & S & 28 & S & 28 & s & 28 & s & 28 & S) & 28 & S/ & 28 & S/ & 28 & S/ & 28 & S/ & 28 & S/ & 28 & S/ & 28 \\
\hline Tinta para impresora & S & 60 & S/ & 60 & S/ & 60 & S & 60 & S/ & 60 & \$ & 60 & S/ & 60 & S/ & 60 & S/ & 60 & S/ & 60 & S/ & 60 & S/ & 60 \\
\hline Otros útiles de oficina & SI & 100 & S/ & 100 & S/ & 100 & S/ & 100 & S/ & 100 & S) & 100 & S) & 100 & S/ & 100 & S/ & 100 & S/ & 100 & S/ & 100 & S/ & 100 \\
\hline Gasto Total Administrativo & S & 5,654 & S) & 5,654 & S/ & 5,654 & S/ & 5,654 & S/ & 5,654 & S/ & 5,654 & S) & 5,654 & S/ & 5,654 & S/ & 5,654 & S/ & 5,654 & & 5,654 & & 5,654 \\
\hline
\end{tabular}

Nota: Elaboración propia.

Tabla 135.- Presupuesto anual de gastos administrativos 2019-2023

\begin{tabular}{|c|c|c|c|c|c|}
\hline & Año 2019 & Año 2020 & Año 2021 & Año 2022 & Año 2023 \\
\hline Gerente General & S/ 32,806 & S/ 34,447 & S/ 36,169 & S/ 37,977 & S/ 39,876 \\
\hline Contador & 7,200 & 7,560 & 7,938 & 8,335 & 8,752 \\
\hline Secretaria & S/ 16,950 & S/ 17,797 & S/ 18,687 & S/ 19,622 & S/ 20,603 \\
\hline Alquiler del local & 4,800 & 5,040 & 5,292 & 5,557 & 5,834 \\
\hline Luz & 1,200 & 1,260 & 1,323 & 1,389 & 1,459 \\
\hline Agua & 480 & 504 & 529 & 556 & 583 \\
\hline Comunicación (teléfono+internet+cable) & 2,160 & 2,268 & 2,381 & 2,500 & 2,625 \\
\hline Hojas Bond & 336 & 353 & 370 & 389 & 408 \\
\hline Tinta para impresora & 720 & 756 & 794 & 833 & 875 \\
\hline Otros útiles de oficina & S/ $\quad 1,200$ & S/ $\quad 1,260$ & S/ $\quad 1,323$ & 1,389 & 1,459 \\
\hline Gasto Total Administrativo & S/ $\quad 67,852$ & S/ 71,245 & S/ 74,807 & S/ 78,547 & S/ 82,475 \\
\hline
\end{tabular}

Nota: Elaboración propia. 


\subsubsection{Presupuesto de marketing y ventas}

Los gastos de marketing y ventas se incrementarán en un 5\% anual para

provisionar escenarios de futuros incrementos en el costo de vida, así como del

sector alimentos.

Tabla 136.- Presupuesto mensual de marketing - 2019

\begin{tabular}{|c|c|c|c|c|c|c|c|c|c|c|c|c|c|c|c|c|c|c|c|c|c|c|c|c|}
\hline \multirow[b]{2}{*}{ Jefe } & \multicolumn{2}{|c|}{ Mes 1} & \multicolumn{2}{|c|}{ Mes 2} & \multicolumn{2}{|c|}{ Mes 3} & \multicolumn{2}{|c|}{ Mes 4} & \multicolumn{2}{|c|}{ Mes 5} & \multicolumn{2}{|c|}{ Mes 6} & \multicolumn{2}{|c|}{ Mes 7} & \multicolumn{2}{|c|}{ Mes 8} & \multicolumn{2}{|c|}{ Mes 9} & \multicolumn{2}{|c|}{ Mes 10} & \multicolumn{2}{|c|}{ Mes 11} & \multicolumn{2}{|c|}{ Mes 12} \\
\hline & S/ & 1,534 & S & 1,534 & $\mathrm{~S} /$ & 1,534 & S/ & 1,534 & S/ & 1,534 & S/ & 1,534 & S/ & 1,534 & S/ & 1,534 & S/ & 1,534 & S/ & 1,534 & $\mathrm{~S} /$ & 1,534 & S & 1,534 \\
\hline Community & S/ & 1,063 & S/ & 1,063 & S & 1,063 & S/ & 1,063 & S/ & 1,063 & S & 1,063 & S/ & 1,063 & S/ & 1,063 & S & 1,063 & S/ & 1,063 & S/ & 1,063 & S/ & 1,063 \\
\hline Alquiler del local & S/ & 100 & S/ & 100 & S & 100 & S/ & 100 & S/ & 100 & S & 100 & S/ & 100 & S/ & 100 & S/ & 100 & S/ & 100 & S/ & 100 & S/ & 100 \\
\hline Luz & S/ & 40 & S: & 40 & S/ & 40 & S/ & 40 & S/ & 40 & S/ & 40 & S/ & 40 & S/ & 40 & S/ & 40 & S/ & 40 & S/ & 40 & S) & 40 \\
\hline Agua & S/ & 40 & S/ & 40 & S/ & 40 & S/ & 40 & S/ & 40 & S/ & 40 & S/ & 40 & S/ & 40 & S/ & 40 & S/ & 40 & S/ & 40 & S/ & 40 \\
\hline Campaña & S/ & 900 & S & 900 & S/ & 900 & S/ & 900 & S/ & 900 & S/ & 900 & S/ & 900 & S/ & 900 & S/ & 900 & S/ & 900 & S/ & 900 & S/ & 900 \\
\hline Banner & S/ & 100 & S/ & 100 & S/ & 100 & S/ & 100 & S/ & 100 & S/ & 100 & S/ & 100 & S/ & 100 & S/ & 100 & S/ & 100 & S/ & 100 & S & 100 \\
\hline Branding 1 & S/ & 100 & S/ & 100 & S/ & 100 & S/ & 100 & S/ & 100 & S/ & 100 & S/ & 100 & S/ & 100 & S/ & 100 & S/ & 100 & S/ & 100 & S) & 100 \\
\hline Branding 2 & S/ & 100 & S/ & 100 & S/ & 100 & S/ & 100 & S/ & 100 & S/ & 100 & S/ & 100 & S/ & 100 & S/ & 100 & S/ & 100 & S/ & 100 & S/ & 100 \\
\hline Redes sociales & S/ & 750 & S/ & 750 & S/ & 750 & S/ & 750 & S/ & 750 & S/ & 750 & S/ & 750 & S/ & 750 & S/ & 750 & S/ & 750 & S/ & 750 & S) & 750 \\
\hline Mercahndising & S/ & 90 & S/ & 90 & S/ & 90 & S/ & 90 & S/ & 90 & S/ & 90 & S/ & 90 & S/ & 90 & S/ & 90 & S/ & 90 & S/ & 90 & S & 90 \\
\hline Total & S/ & 4,817 & S! & 4,817 & S/ & 4,817 & S/ & 4,817 & S/ & 4,817 & S/ & 4,817 & S/ & 4,817 & S/ & 4,817 & S/ & 4,817 & S/ & 4,817 & S/ & 4,817 & S & 4,817 \\
\hline
\end{tabular}

Nota: Elaboración propia.

Tabla 137.- Presupuesto anual de marketing 2019-2023

\begin{tabular}{|c|c|c|c|c|c|c|c|c|c|c|}
\hline \multirow[b]{2}{*}{ Jefe } & \multicolumn{2}{|c|}{ Año 2019} & \multicolumn{2}{|c|}{ Año 2020} & \multicolumn{2}{|c|}{ Año 2021} & \multicolumn{2}{|c|}{ Año 2022} & \multicolumn{2}{|c|}{ Año 2023} \\
\hline & S/ & 18,408 & S/ & 19,328 & S/ & 20,295 & S/ & 21,309 & S/ & 22,375 \\
\hline Community & S/ & 12,758 & S/ & 13,396 & S/ & 14,066 & S/ & 14,769 & S/ & 15,507 \\
\hline Alquiler del local & S/ & 1,200 & S/ & 1,260 & S/ & 1,323 & S/ & 1,389 & S/ & 1,459 \\
\hline Luz & S/ & 480 & S/ & 504 & S/ & 529 & S/ & 556 & S/ & 583 \\
\hline Agua & S/ & 480 & S/ & 504 & S/ & 529 & S/ & 556 & S/ & 583 \\
\hline Campaña & S/ & 10,800 & S/ & 11,340 & S/ & 11,907 & S/ & 12,502 & S/ & 13,127 \\
\hline Banner & S/ & 1,200 & S/ & 1,260 & S/ & 1,323 & S/ & 1,389 & S/ & 1,459 \\
\hline Branding 1 & S/ & 100 & S/ & 105 & S/ & 110 & S/ & 116 & S/ & 122 \\
\hline Branding 2 & S/ & 100 & S/ & 105 & S/ & 110 & S/ & 116 & S/ & 122 \\
\hline Redes sociales & S/ & 9,000 & S/ & 9,450 & S/ & 9,923 & S/ & 10,419 & S/ & 10,940 \\
\hline Mercahndising & S/ & 1,080 & S/ & 1,134 & S/ & 1,191 & S/ & 1,250 & S/ & 1,313 \\
\hline Total & & 55,606 & & 58,386 & & 61,306 & & 64,371 & & 67,589 \\
\hline
\end{tabular}

Nota: Elaboración propia.

Tabla 138.- Presupuesto mensual de gasto de ventas - 2019

\begin{tabular}{|c|c|c|c|c|c|c|c|c|c|c|c|c|c|c|c|}
\hline & & es 1 & Mes? & Mes & 83 & Mes 4 & Mes & es 5 & Mes 6 & Mes 7 & Mes 8 & Mes 9 & Mes 10 & Mes 11 & Mes 12 \\
\hline Operador & S & $911 \mathrm{~s}$ & $\begin{array}{ll}\text { S } & 911\end{array}$ & S & $911 \mathrm{~s}$ & $\begin{array}{ll}\text { S } & 911\end{array}$ & S/ & $911 \mathrm{~S}$ & $\begin{array}{ll}\text { S) } & 911\end{array}$ & S) 911 & S/ 911 & \$ $\quad 911$ & \$ 911 & \$ $\quad 911$ & $\begin{array}{ll}\mathrm{S} & 911\end{array}$ \\
\hline Repartidor & S & $759 \mathrm{~s}$ & 759 & S & 759 & 759 & S/ & 759 & 759 & 759 & 759 & 759 & 759 & 759 & 759 \\
\hline Total & S & $1,671 \mathrm{~S}$ & 1,671 & S & $1,671 \mathrm{~S}$ & 1,671 & $\mathrm{~S}$ & $1,671 \mathrm{~S}$ & 1,671 & 1,671 & 1,671 & 1.671 & 1,671 & 1,671 & $\begin{array}{ll}\text { S } & 1,671\end{array}$ \\
\hline
\end{tabular}

Nota: Elaboración propia.

Tabla 139.- Presupuesto anual de gasto de ventas 2019 - 2023

\begin{tabular}{|c|c|c|c|c|c|}
\hline & Año 2019 & Año 2020 & Año 2021 & Año 2022 & Año 2023 \\
\hline Operador & S/ $\quad 10,935$ & S/ $\quad 11,482$ & S/ $\quad 12,056$ & S/ $\quad 12,659$ & S/ $\quad 13,292$ \\
\hline Repartidor & 9,113 & 9,568 & 10,047 & 10,549 & 11,077 \\
\hline Total & 20,048 & 21,051 & 22,103 & S/ $\quad 23,208$ & S/ $\quad 24,369$ \\
\hline
\end{tabular}

Nota: Elaboración propia. 


\subsubsection{Presupuesto de gastos financieros}

El proyecto no cuenta con intereses generados por préstamo bancario. En consecuencia, no se tienen gastos de tipo financiero.

\subsection{Presupuestos de Resultados}

\subsubsection{Estado de ganancias y pérdidas proyectado}

Tabla 140.- Estado de ganancias y pérdidas

\begin{tabular}{|c|c|c|c|c|c|c|c|c|c|}
\hline \multirow{2}{*}{$\begin{array}{l}\text { ESTADO DE GANANCLAS Y PÉRDIDAS } \\
\text { Venta }\end{array}$} & \multicolumn{2}{|c|}{2019} & \multicolumn{2}{|c|}{2020} & \multicolumn{2}{|c|}{2021} & \multicolumn{2}{|c|}{2022} & 2023 \\
\hline & $\mathrm{S} /$ & 523,512 & $\mathrm{~S} /$ & 659,625 & $\mathrm{~S} /$ & 817,276 & $\mathrm{~S} /$ & $978,279 \quad \mathrm{~S} /$ & $1,140,184$ \\
\hline Costo de Venta & $-\mathrm{S} /$ & 363,685 & $-\mathrm{S} /$ & 450,990 & $-\mathrm{S} /$ & 550,921 & $-\mathrm{S} /$ & $654,559-\mathrm{S} /$ & 789,254 \\
\hline Utilidad Bruta & $\mathrm{S} /$ & 159,827 & $\mathrm{~S} /$ & 208,635 & $\mathrm{~S} /$ & 266,355 & $\mathrm{~S} /$ & $323,720 \quad \mathrm{~S} /$ & 350,930 \\
\hline Gastos de Marketing & $-\mathrm{S} /$ & 55,606 & $-\mathrm{S} /$ & 58,386 & $-\mathrm{S} /$ & 61,306 & $-\mathrm{S} /$ & $64,371 \quad-\mathrm{S} /$ & 67,589 \\
\hline Gastos de Venta & $-\mathrm{S} /$ & 20,048 & $-\mathrm{S} /$ & 21,051 & $-\mathrm{S} /$ & 22,103 & $-\mathrm{S} /$ & $23,208 \quad-\mathrm{S} /$ & 24,369 \\
\hline Utilidad Operativa & $\mathrm{S} /$ & 16,321 & $\mathrm{~S} /$ & 57,954 & $\mathrm{~S} /$ & 108,139 & $\mathrm{~S} /$ & $157,594 \quad \mathrm{~S} /$ & 176,497 \\
\hline \multicolumn{10}{|l|}{ Amortizacion } \\
\hline Gastos Financieros & \multicolumn{2}{|c|}{0} & \multicolumn{2}{|c|}{0} & \multicolumn{2}{|r|}{0} & \multicolumn{2}{|r|}{0} & 0 \\
\hline Utilidad antes de Impuestos & $-\mathrm{S} /$ & 4,162 & $\mathrm{~S} /$ & 37,471 & $\mathrm{~S} /$ & 87,657 & $\mathrm{~S} /$ & $137,111 \quad \mathrm{~S} /$ & 156,015 \\
\hline Impuesto a la Renta & & & $-\mathrm{S} /$ & 11,054 & $-\mathrm{S} /$ & 25,859 & $-\mathrm{S} /$ & $40,448 \quad-\mathrm{S} /$ & 46,024 \\
\hline UTILIDAD NETA & $-\mathrm{S} /$ & 4,162 & $\mathrm{~S} /$ & 26,417 & $\mathrm{~S} /$ & 61,798 & $\mathrm{~S} /$ & $96,663 \mathrm{~S} /$ & 109,990 \\
\hline
\end{tabular}

Nota: Elaboración propia. 


\subsubsection{Balance proyectado}

Tabla 141.- Balance proyectado

\begin{tabular}{|c|c|c|c|c|c|c|}
\hline & Año $(0)$ & 2,019 & 2,020 & 2,021 & 2,022 & 2,023 \\
\hline \multicolumn{7}{|l|}{ ACTIVO } \\
\hline \multicolumn{7}{|l|}{ ACTIVO CORRIENTE } \\
\hline Caja y bancos & 5,761 & 21,717 & 66,867 & 145,663 & 209,491 & 307,804 \\
\hline Cuentas por cobrar comerciales & & & 2,100 & 5,289 & 31,746 & 47,722 \\
\hline Otras cuentas por cobrar accionistas & & 10,123 & 10,699 & 10,248 & 32,455 & 42,240 \\
\hline Mercaderia & & 730 & 1,848 & 4,642 & 11,388 & 20,590 \\
\hline $\begin{array}{l}\text { TOTAL ACTIVO CORRIENTE } \\
\text { ACTIVO NO CORRIENTE }\end{array}$ & 5,761 & 32,570 & 81,514 & 165,842 & 285,080 & 418,356 \\
\hline \multicolumn{7}{|l|}{ Otros activos financieros } \\
\hline Inmuebles, maquinarias y equipos & 133,413 & 112,930 & 92,448 & 71,965 & 51,483 & 31,000 \\
\hline Activos intangibles (neto) & 45,460 & 45,460 & 44,551 & 43,660 & 42,787 & 41,931 \\
\hline \multicolumn{7}{|l|}{ Otro activos } \\
\hline TOTAL ACTIVO NO CORRIENTE & 178,873 & 158,390 & 136,999 & 115,625 & 94,269 & 72,931 \\
\hline TOTAL ACTIVO & 184,634 & 190,960 & 218,513 & 281,467 & 379,349 & 491,287 \\
\hline \multicolumn{7}{|l|}{ PASIVO Y PATRIMONIO } \\
\hline \multicolumn{7}{|l|}{ PASIVO CORRIENTE } \\
\hline Prestamos bancarios & & 0 & 0 & 0 & 0 & 0 \\
\hline Cuentas por pagar comerciales & & 0 & 0 & 0 & 0 & 0 \\
\hline Tributos, remuneraciones y participaciones & & 10,487 & 11,624 & 12,780 & 13,998 & 15,946 \\
\hline TOTAL & & 10,487 & 11,624 & 12,780 & 13,998 & 15,946 \\
\hline \multicolumn{7}{|l|}{ PASIVO NO CORRIENTE } \\
\hline Obligaciones financieras a largo plazo & & 0 & 0 & 0 & 0 & 0 \\
\hline TOTAL & - & 0 & 0 & 0 & 0 & 0 \\
\hline \multicolumn{7}{|l|}{ PATRIMONIO } \\
\hline Capital Social & 184,634 & 184,634 & 184,634 & 184,634 & 184,634 & 184,634 \\
\hline Resultado del Ejercicio & & 4,162 & 26,417 & 61,798 & 96,663 & 109,990 \\
\hline Resultado Acumulado & & (9) & 4,162 & 22,255 & 84,053 & 180,716 \\
\hline TOTAL & 184,634 & 180,472 & 206,889 & 268,687 & 365,350 & 475,341 \\
\hline TOTAL PASIVO Y PATRIMONIO & 184,634 & 190,960 & 218,513 & 281,467 & 379,349 & 491,287 \\
\hline
\end{tabular}

Nota: Elaboración propia.

\subsubsection{Flujo de caja proyectado}

\section{Flujo de caja operativo}

Construido en base a las ventas, costos y gastos del proyecto (materia prima, mano de obra directa e indirecta, costos indirectos de fabricación, gastos de ventas, gastos de administración e impuesto a la renta). 
Tabla 142.- Flujo de caja operativo

\begin{tabular}{|c|c|c|c|c|c|c|c|c|c|c|}
\hline \multirow{2}{*}{ INGRESOS } & \multicolumn{2}{|c|}{2019} & \multicolumn{2}{|c|}{2020} & \multicolumn{2}{|c|}{2021} & \multicolumn{2}{|r|}{2022} & \multicolumn{2}{|r|}{2023} \\
\hline & & & & & & & & & & \\
\hline Ingreso & $\mathrm{S} /$ & 523,512 & $\mathrm{~S} /$ & 659,625 & $\mathrm{~S} /$ & 817,276 & $\mathrm{~S} /$ & 978,279 & $\mathrm{~S} /$ & $1,140,184$ \\
\hline Total Ingresos & S/ & 523,512 & $\mathrm{~S} /$ & 659,625 & $\mathrm{~S} /$ & 817,276 & $\mathrm{~S} /$ & 978,279 & S/ & $1,140,184$ \\
\hline \multicolumn{11}{|l|}{ EGRESOS } \\
\hline Mano de Obra Directa & $-\mathrm{S} /$ & 37,727 & $-\mathrm{S} /$ & 46,957 & $-\mathrm{S} /$ & 56,201 & $-\mathrm{S} /$ & 65,970 & $-\mathrm{S} /$ & 84,239 \\
\hline Gastos de Administración & $-\mathrm{S} /$ & 67,852 & $-\mathrm{S} /$ & 71,245 & $-\mathrm{S} /$ & 74,807 & $-\mathrm{S} /$ & 78,547 & $-\mathrm{S} /$ & 82,475 \\
\hline Gastos de Marketing & $-\mathrm{S} /$ & 55,606 & $-\mathrm{S} /$ & 58,386 & $-\mathrm{S} /$ & 61,306 & $-\mathrm{S} /$ & 64,371 & $-\mathrm{S} /$ & 67,589 \\
\hline Gasto de ventas & $-S /$ & 20,048 & $-S /$ & 21,051 & $-S /$ & 22,103 & $-\mathrm{S} /$ & 23,208 & $-\mathrm{S} /$ & 24,369 \\
\hline Costo Fijo & $-S /$ & 181,233 & $-S /$ & 197,638 & $-S /$ & 214,417 & $-\mathrm{S} /$ & 232,096 & $-S /$ & 258,672 \\
\hline Materia Prima & $-\mathrm{S} /$ & 261,756 & $-\mathrm{S} /$ & 329,813 & $-\mathrm{S} /$ & 408,638 & $-\mathrm{S} /$ & 489,139 & $-\mathrm{S} /$ & 570,092 \\
\hline CIF & $-\mathrm{S} /$ & 73,527 & $-\mathrm{S} /$ & 76,220 & $-\mathrm{S} /$ & 88,593 & $-\mathrm{S} /$ & 102,043 & $-\mathrm{S} /$ & 118,494 \\
\hline Impuesto a la Renta & $\mathrm{S} /$ & - & $\mathrm{S} /$ & 11,054 & $\mathrm{~S} /$ & 25,859 & $\mathrm{~S} /$ & 40,448 & $\mathrm{~S} /$ & 46,024 \\
\hline Costo Variable & $-\mathrm{S} /$ & 335,283 & $-\mathrm{S} /$ & 394,979 & $-S /$ & 471,372 & $-\mathrm{S} /$ & 550,735 & $-S /$ & 642,562 \\
\hline Total Egresos & $-\mathrm{S} /$ & 516,517 & $-\mathrm{S} /$ & 592,617 & $-\mathrm{S} /$ & 685,789 & $-\mathrm{S} /$ & 782,831 & $-\mathrm{S} /$ & 901,234 \\
\hline EBIT & $\mathrm{S} /$ & 6,995 & $\mathrm{~S} /$ & 67,008 & $\mathrm{~S} /$ & 131,487 & $\mathrm{~S} /$ & 195,448 & $\mathrm{~S} /$ & 238,951 \\
\hline Depreciación & $\mathrm{S} /$ & 20,483 & $\mathrm{~S} /$ & 20,483 & $\mathrm{~S} /$ & 20,483 & $\mathrm{~S} /$ & 20,483 & $\mathrm{~S} /$ & 20,483 \\
\hline Amortización & & 0 & & 0 & & 0 & & 0 & & 0 \\
\hline FLUJO DE CAJA OPERATIVO & $\mathrm{S} /$ & 27,478 & $\mathrm{~S} /$ & 87,491 & $\mathrm{~S} /$ & 151,969 & $\mathrm{~S} /$ & 215,931 & $\mathrm{~S} /$ & 259,433 \\
\hline
\end{tabular}

Nota: Elaboración propia.

\section{Flujo de inversiones}

En el año cero se desembolsa S/ 184,634 para invertir en activo fijo tangible, activo fijo intangible y capital de trabajo.

Tabla 143.- Flujo de inversiones

\begin{tabular}{|c|c|c|c|c|c|c|c|c|c|c|}
\hline FLUJO DE INVERSIONES & Año $(0)$ & & 2019 & 2020 & & 2021 & & 2022 & & 2023 \\
\hline Activo Fijo Intangible & S/ $\quad 45,460$ & & & & & & & & & \\
\hline Activo Fijo Tangible & S/ 133,413 & & & & & & & & & \\
\hline Capital de Trabajo & - S/ $\quad 5,761$ & $-S /$ & 5,761 & S/ 20,624 & $-\$ /$ & 6,306 & $-S /$ & 6,440 & & \\
\hline Valor en liquidación en Capital de Trabajo & & & & & & & & & \$/ & 6,440 \\
\hline Valor de Rescate - Activos Fijos & & & & & & & & & \$/ & 41,931 \\
\hline FLUJO DE INVERSIONES & -S/ 184,634 & $-S /$ & 5,761 & -S/ 20,624 & $-\$ /$ & 6,306 & $-\$ /$ & 6,440 & \$/ & 48,371 \\
\hline
\end{tabular}

Nota: Elaboración propia. 


\section{Flujo de caja económico proyectado}

Integra las cantidades correspondientes al flujo de caja operativo y el flujo de caja de la inversión. Los resultados obtenidos constituyen el Flujo de Caja Económico (FCE).

El año 2019 se tiene un resultado adverso que mejora de manera sostenida desde el año 2020 al 2023.

Tabla 144.- Flujo de Caja Económico - FCE

\begin{tabular}{|c|c|c|c|c|c|c|c|c|c|c|}
\hline FLUJO DE CAJA ECONOMMCO & Año $(0)$ & & 2019 & & 2020 & 2021 & & 2022 & & 2023 \\
\hline Flujo de caja operativo & & S/ & 27,478 & S/ & 87,491 & S/ 151,969 & \$/ & 215,931 & S/ & 259,433 \\
\hline Flujo de caja de & 184,634 & $-8 /$ & 5,761 & $-S /$ & 20,624 & 6,306 & $-\$ /$ & 6,440 & \$/ & 48,371 \\
\hline FLUJO DE CAJA ECONÓMICO & -\$/ 184,634 & S/ & 21,717 & S/ & 66,867 & \$/ 145,663 & S/ & 209,491 & \$/ & 307,804 \\
\hline
\end{tabular}

Nota: Elaboración propia.

\section{Flujo de caja de la deuda}

Debido a que el proyecto carece de financiamiento no se efectúa el flujo de servicio de la deuda.

\section{Flujo de caja financiero}

Debido a que el proyecto no incluye financiamiento no se ha procedido a la construcción respectiva. 


\section{CAPÍTULO X}

\section{EVALUACIÓN ECONÓMICO FINANCIERA}

\subsection{Evaluación financiera}

\subsubsection{La Tasa Interna de Retorno - TIR}

La tasa interna de retorno es la máxima tasa permitida para descontar los flujos de un proyecto. La Tasa Interna de Retorno máxima (TIR máxima), obliga a que el Valor Actual Neto (VAN) sea cero. De esta forma, la inversión inicial es igual a la sumatoria de los flujos del período 2 al periodo 5 que son descontados y actualizados al período cero.

La Tasa Interna de Retorno Económica (TIRE) se halla en base al Flujo de Caja Económico (FCE) y la Tasa Interna de Retorno Financiera (TIRF) se halla en base al flujo de caja financiero (FCF). El proyecto será considerado viable si la Tasa Interna de Retorno Económica (TIRE) es mayor al Costo Promedio Ponderado de Capital (CPPC) y la Tasa Interna de Retorno Financiera (TIRF) es mayor que el costo de oportunidad del inversionista (Ke).

Sin embargo, para el proyecto Animal Lovers, no se ha realizado financiamiento alguno, por este motivo, los flujos de la caja de tipo económico serán descontados con el costo de oportunidad del inversionista (Ke). El Flujo de Caja Económico (FCE) descontado a una Tasa Interna de Retorno Económica (TIR) de 46.2\% produce un Valor Actual Neto Económico VANE de cero. 
Tabla 145.- Tasa interna de retorno

\begin{tabular}{|c|c|c|c|c|c|c|c|c|c|c|}
\hline \multirow{3}{*}{$\frac{\text { RTHO DE CATA ECONOMTCO }}{4}$} & \multirow{2}{*}{\multicolumn{2}{|c|}{ Año $(0)$}} & \multirow{2}{*}{\multicolumn{2}{|c|}{2019}} & \multirow{2}{*}{\multicolumn{2}{|c|}{2020}} & & \multirow{2}{*}{\multicolumn{2}{|c|}{2022}} & \multirow[b]{2}{*}{2023} \\
\hline & & & & & & & & & & \\
\hline & $-\mathrm{S} /$ & 184,634 & S/ & 21,717 & $\mathrm{~S} /$ & 66,867 & S/ $\quad 145,663$ & S/ & 209,491 & S/ $\quad 307,804$ \\
\hline
\end{tabular}

\begin{tabular}{cc}
\hline TIR ECONOMICO & $K_{e}^{N}$ \\
\hline $46.2 \%$ & $22.6 \%$
\end{tabular}

Nota: Elaboración propia.

\subsubsection{El valor actual neto}

El Valor Actual Neto Económico (VANE) es el valor actual neto de los flujos de caja económicos generados por un proyecto.

Es recomendable invertir cuando el Valor Actual Neto (VAN) es positivo o mayor a cero. En otras palabras, es más conveniente cuando el Valor Actual Neto (VAN) es más elevado. El Valor Actual Neto Económico (VANE) se determina analizando el flujo de caja económico (FCE) por lo que se descuenta con el costo de oportunidad del inversionista (Ke). El Flujo de Caja Económico (FCE) descontado a un Ke de 22.6\% arroja un Valor Actual Neto Económico (VANE) de S/ 160,728.

Tabla 146.- Valor actual neto

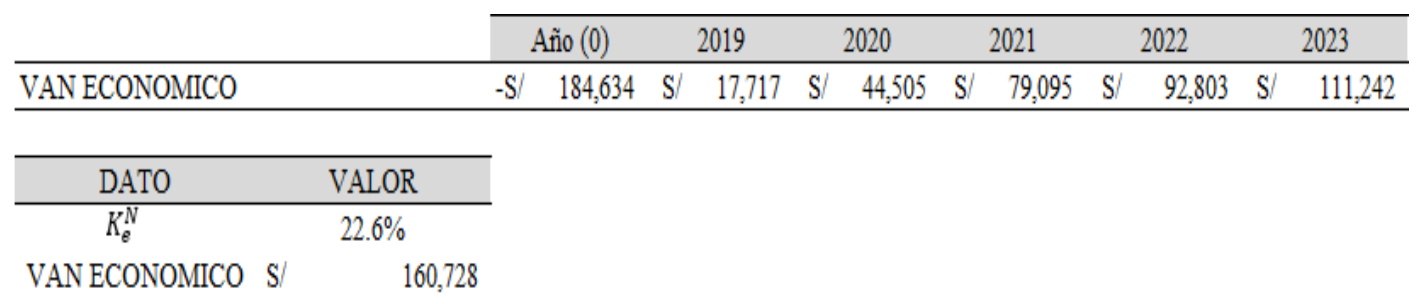

Nota: Elaboración propia

\subsubsection{ROE}

El retorno sobre el capital (ROE) mide la rentabilidad del aporte de los accionistas sobre las inversiones, para lo cual se presenta el resultado de los cinco (5) años proyectados. 


\section{Tabla 147.- ROE}

ROE

\begin{tabular}{rccccc}
\hline Resultado Base & Resultado Año 1 & Resultado Año 2 & Resultado Año 3 & Resultado Año 4 Resultado Año 5 \\
INEI 2018 & 2019 & 2020 & 2021 & 2022 & 2023 \\
\hline $28 \%$ & $0 \%$ & $13 \%$ & $23 \%$ & $26 \%$ & $23 \%$ \\
\hline
\end{tabular}

Nota: Elaboración propia

El primer año los inversionistas tienen un retorno negativo. A partir del segundo año, obtienen retornos de rentabilidad esperados.

Además, han sido considerados indicadores económicos registrados por el instituto de estadística e informática (INEI 2018). Como se puede apreciar una ratio de $28 \%$ corresponde a otras actividades manufactureras, teniendo el primer año un resultado por debajo del ratio base y para iniciar el segundo año, con un resultado por encima de dicho ratio base.

\subsubsection{RATIOS}

Los indicadores económicos contables y financieros ayudarán a comprender el comportamiento de los resultados en el proyecto durante los cinco años de operación, sin embargo, con un solo índice o ratio no se podrá evaluar el estado de la empresa u organización por lo cual se presentarán ratios organizados de evaluación que se clasifican en liquidez, gestión y rentabilidad.

\section{Liquidez}

Tabla 148.- Liquidez

\begin{tabular}{crrrrr}
\hline $\begin{array}{c}\text { Resultado Año 1 } \\
2019\end{array}$ & $\begin{array}{c}\text { Resultado Año 2 } \\
2020\end{array}$ & $\begin{array}{c}\text { Resultado Año 3 } \\
2021\end{array}$ & \multicolumn{2}{c}{ Resultado Año 4 Resultado Año 5 } \\
\hline & 2022 & 2023 \\
\hline 2.1 & 5.8 & 11.4 & 15.0 & 19.3 \\
\hline
\end{tabular}

Nota: Elaboración propia 
Para el primer año se logra afrontar las deudas corrientes con dinero en efectivo. En el segundo año se nivela y para los años posteriores se puede atender las deudas corrientes.

\section{GESTIÓN}

Tabla 149.- Rotación de inventario

\begin{tabular}{rrrrrr}
\hline $\begin{array}{c}\text { Resultado Año 1 } \\
2019\end{array}$ & Resultado Año 2 & Resultado Año 3 & \multicolumn{2}{c}{ Resultado Año 4 Resultado Año 5} \\
\hline 2020 & 2021 & 2022 & 2023 \\
\hline 8.1 & 8.4 & & 8.7 & 9.0 & 9.8 \\
\hline
\end{tabular}

Nota: Elaboración propia

Esta ratio identifica la frecuencia en que los inventarios salen a la venta, siendo 8 veces en promedio por año. No se debe perder de vista que los productos de Animal Lovers duran hasta dos meses congelado. Según el análisis realizado, la rotación supera las 6 unidades en promedio por año.

Tabla 150.- Inventario en días de venta

\begin{tabular}{ccccc}
\hline Resultado Año 1 & Resultado Año 2 & Resultado Año 3 & Resultado Año 4 Resultado Año 5 \\
2019 & 2020 & 2021 & 2022 & 2023 \\
\hline 45 & 44 & 42 & 40 & 37 \\
\hline
\end{tabular}

Nota: Elaboración propia

Ratio que identifica la frecuencia en que los inventarios salen a la venta calculado en días, siendo el promedio alrededor de 40 días.

\section{RENTABILIDAD}

Tabla 151.- Rentabilidad

\begin{tabular}{|c|c|c|c|c|}
\hline $\begin{array}{c}\text { Resultado Año } 1 \\
2019\end{array}$ & $\begin{array}{c}\text { Resultado Año } 2 \\
2020\end{array}$ & $\begin{array}{c}\text { Resultado Año } 3 \\
2021\end{array}$ & $\begin{array}{c}\text { Resultado Año } 4 \\
2022\end{array}$ & $\begin{array}{c}\text { Resultado Año } 5 \\
2023\end{array}$ \\
\hline $0 \%$ & $4 \%$ & $8 \%$ & $10 \%$ & $10 \%$ \\
\hline
\end{tabular}

Nota: Elaboración propia 
Ratio que mide la rentabilidad de las ventas frente a los costos de venta, cubriendo los gastos operativos del proyecto para la generación de utilidades. Por cada sol vendido se obtiene una utilidad neta del $10 \%$ el quinto año.

\subsection{Análisis del riesgo}

\subsubsection{Análisis del punto de equilibrio}

El punto de equilibrio determina el nivel de venta que permite igualar los ingresos con los costos (variables y fijos). En este nivel de ventas, no existe utilidad ni pérdida. El punto de equilibrio calculado establece la cantidad de productos que se deben vender para cubrir los costos fijos.

Tabla 152.- Análisis del punto de equilibrio

\begin{tabular}{|c|c|c|c|c|c|c|c|c|c|c|}
\hline \multirow[b]{2}{*}{ Costo fijo } & \multicolumn{2}{|c|}{$\begin{array}{c}\text { Resultado Año l } \\
2019\end{array}$} & \multicolumn{2}{|c|}{$\begin{array}{l}\text { Resultado Año } 2 \\
2020\end{array}$} & \multicolumn{2}{|c|}{$\begin{array}{l}\text { Resultado Año } 3 \\
2021\end{array}$} & \multicolumn{2}{|c|}{$\begin{array}{l}\text { Resultado Año } 4 \\
2022\end{array}$} & \multicolumn{2}{|c|}{$\begin{array}{c}\text { Resultado Año } 5 \\
2023\end{array}$} \\
\hline & S/ & 181,233 & \$ & 197,638 & \$/ & 214,417 & S/ & 232,096 & \$ & 258,672 \\
\hline Margen de contribución & \$/ & 4.87 & \$) & 5.62 & \$) & 6.19 & \$ & 6.68 & s/ & 7.01 \\
\hline Punto de equilibrio en unidades & & 37,236 & & 35,162 & & 34,667 & & 34,742 & & 36,921 \\
\hline Venta proyectada en unidades & & 44,887 & & 53,865 & & 63,560 & & 72,459 & & 80,429 \\
\hline
\end{tabular}

Nota: Elaboración propia.

\subsubsection{Análisis de sensibilidad}

Tomando en consideración los factores indicados, se establece una tabla que calcula: la Tasa Interna de Retorno Económico (TIRE) y el Valor Actual Neto Económico (VANE), bajo diversas combinaciones de variables. Se determinan como unidades vendidas para el año 2019 la cantidad de 44,887 unidades. Para los años posteriores del proyecto se han empleado crecimientos anuales que inician en $16 \%$. Ante estas variaciones la tasa interna de retorno crece $4 \%$ y el Valor Actual Neto (VAN) sufre también los cambios indicados. 
Tabla 153.- Análisis de sensibilidad

\begin{tabular}{|c|c|c|c|c|}
\hline $\begin{array}{l}\text { Unidades } \\
\text { Vendidas } \\
\text { (Año 1) }\end{array}$ & $\begin{array}{c}\text { Tasa de } \\
\text { Crecimiento } \\
\text { Anual } \\
\text { (año } 2 \text { al año 5) }\end{array}$ & $\mathrm{Ke}$ & $\begin{array}{c}\text { TIR } \\
\text { ECONÓMICO }\end{array}$ & $\begin{array}{c}\text { VAN } \\
\text { ECONÓMICO }\end{array}$ \\
\hline 45,000 & $16 \%$ & $22.6 \%$ & $47 \%$ & 169,000 \\
\hline 45,000 & $17 \%$ & $22.6 \%$ & $51 \%$ & 202,665 \\
\hline 45,000 & $18 \%$ & $22.6 \%$ & $55 \%$ & 236,214 \\
\hline 45,000 & $19 \%$ & $22.6 \%$ & $59 \%$ & 269,763 \\
\hline 45,000 & $20 \%$ & $22.6 \%$ & $63 \%$ & 303,313 \\
\hline 45,000 & $21 \%$ & $22.6 \%$ & $67 \%$ & 336,862 \\
\hline
\end{tabular}

Nota: Elaboración propia.

\subsubsection{Análisis de escenarios}

Tomando en consideración los factores indicados, se establece una tabla que calcula la Tasa Interna de Retorno Económica (TIRE) y el Valor Actual Neto Económico (VANE) bajo diversas combinaciones de variables.

En cada escenario, se aprecia una diferencia del $4 \%$ en la tasa interna de retorno (TIR), lo que arroja cambios considerables para el valor actual neto económico (VANE). 
Tabla 154.- Variaciones del VAN Económico, según el crecimiento porcentual anual en ventas, a lo largo de todo el proyecto.

$\begin{array}{cccccccc}\text { ESCENARIO } & \begin{array}{c}\text { UNIDADES } \\ \text { VENDIDAS } \\ \text { (año 1) }\end{array} & \begin{array}{c}\text { CRECIMIENTO } \\ \text { PORCENTUAL } \\ \text { ANUAL } \\ \text { (del año 2 al año } \\ 5 \text { ) }\end{array} & \begin{array}{c}\text { TIR } \\ \text { ECONOMICO }\end{array} & \text { Ke } & \begin{array}{c}\text { VAN } \\ \text { ECONOMICO }\end{array} & \begin{array}{c}\text { VANANCIERO } \\ \text { Moderado }\end{array} \\ & 45,000 & 16.0 \% & 47.0 \% & 22.6 \% & \mathrm{~S} / & 169,000 & 0 \\ & 45,000 & 17.0 \% & 51.0 \% & 22.6 \% & \mathrm{~S} / & 202,665 & 0 \\ & 45,000 & 18.0 \% & 55.0 \% & 22.6 \% & \mathrm{~S} / & 236,214 & 0 \\ & 45,000 & 19.0 \% & 59.0 \% & 22.6 \% & \mathrm{~S} / & 269,763 & 0 \\ \text { Optimista } & 45,000 & 20.0 \% & 63.0 \% & 22.6 \% & \mathrm{~S} / & 303,313 & 0 \\ & 45,000 & 21.0 \% & 67.0 \% & 22.6 \% & \mathrm{~S} / & 336,362 & 0\end{array}$

Nota: Elaboración propia. 


\section{CONCLUSIONES Y RECOMENDACIONES}

\section{CONCLUSIONES}

- $\quad$ El mercado objetivo identificado en los distritos de San Borja, Miraflores, San Isidro y Santiago de Surco, cuenta con una cantidad de hogares que alcanza: $1.78 ; 1.80 ; 1.83$ : 1.86 y 1.89 expresados en miles de hogares, para los cinco años del proyecto.

- Luego de realizar la investigación de mercado, correspondiente a la combinación preciovalor se determinó que el precio de entrada de Animal Lovers para sus productos, será de S/ 11.65 (pollo); S/ 13.81 (pescado); S/ 18.21 (carne), con la intención de ofrecer precios de entrada situados al inicio de la lista de productos de la competencia. Asimismo, el producto ha sido formulado atendiendo a las necesidades alimenticias de los canes, formulando un producto elaborado con insumos naturales, procesos no industrializados y ligeramente cocido, que lo definen como un producto superior con respecto a la competencia.

- El proyecto utiliza un área administrativa que representa el siguiente gasto en remuneraciones con respecto a las ventas anuales. Se obtuvo: $17 \% ; 14 \% ; 12 \% ; 10 \% \mathrm{y}$ 9\% (5 años del proyecto) con un gasto promedio anual del $12 \%$.

- El modelo de gestión en cuanto a niveles de decisión, operaciones y control, se basó en políticas que permitieron definir el nivel de ventas obtenido. Año 1: S/ 523,512; Año 2: S/ 659,625; Año 3: S/ 817,276; Año 4: S/ 978,279; Año 5: S/ 1,140,184. El crecimiento en ventas entre el primer y quinto año del proyecto es del doble aproximadamente. 
- Se cuenta con una capacidad instalada que soporta niveles de producción del orden de las 120 toneladas al año. Se proyecta vender para el año 1: 45 toneladas; año 2: 54 toneladas; Año 3: 64 toneladas; Año 4: 73 toneladas y año 5: 81 toneladas.

- La inversión del proyecto fue de S/ 184,634. Los indicadores obtenidos como fruto del proyecto son los siguientes: Ke; COK: 22.6\%; TIRE: 46.2\%; VANE: S/ 160,728. 


\section{RECOMENDACIONES}

- Realizar acciones de influencia en el mercado, para posicionar a Animal Lovers como un producto de calidad, incidiendo en que la competencia tiene productos de mayor duración, así como de mayor contenido químico, como preservantes en extremo que ocasionan una duración entre uno y dos años.

- Los municipios de todos los distritos de Lima deben preocuparse por controlar e identificar a la población canina para controlar un crecimiento poblacional canino ordenado y planificado.

- Se sugiere adoptar mascotas en vez de comprarlas. Y con mayor razón si son rescatadas.

- Impulsar la tenencia de pequeñas mascotas dado el espacio de uso reducido de los departamentos.

- Abordar el mercado desde la perspectiva de un producto de calidad acorde a las necesidades nutricionales de las mascotas y a las necesidades de los dueños de brindarles la seguridad de que su protección se traduce en calidad de vida. 


\section{REFERENCIAS}

América economía (2014, 30 de enero). Mercado de comida para mascotas en el Perú crecerá $25 \%$ durante este año. Recuperado de https://www.americaeconomia.com/negociosindustrias/mercado-de-comida-para-mascotas-en-el-peru-crecera-25-durante-este-ano

Arce, A. (07 de abril de 2017). Viviendas: conoce cómo viven los peruanos y los limeños. Elcomercio.pe. Recuperado de https:/elcomercio.pe/economia/viviendas-conoceviven-peruanos-limenos-422609

Asociación peruana de empresas de investigación de mercados (2018). Niveles socioeconómicos 2018. Lima: APEIM. Recuperado de http://www.apeim.com.pe/wpcontent/themes/apeim/docs/nse/APEIM-NSE-2018.pdf

Banco Central de Reserva del Perú (2018). Reporte de inflación: panorama actual y proyecciones macroeconómicas 2018 - 2020. Lima: BCRP. Recuperado de http://www.bcrp.gob.pe/docs/Publicaciones/Reporte-

Inflacion/2018/diciembre/reporte-de-inflacion-diciembre-2018-presentacion.pdf

Banco Central de Reserva del Perú (2018). Resumen informativo semanal ( $\mathrm{N}^{\circ}$ 12). Lima: BCRP. Recuperado de http://www.bcrp.gob.pe/docs/Publicaciones/NotaSemanal/2018/resumen-informativo-12-2018.pdf

Benassini, M. (2014). Introducción a la investigación de mercados: enfoque para América latina ( $3^{\mathrm{a}}$ ed.). México D.F.: Pearson Educación.

Bosarreyes, L. (2015) Matriz de propuesta de valor [Diapositiva]. Recuperado de https://es.slideshare.net/lervybosarreyes/matriz-de-propuesta-de-valor

Compañía peruana de estudios de mercados y opinión pública (2010). Market Report. (julio 2010). Lima: CPI. Recuperado de http://www.cpi.pe/images/upload/paginaweb/archivo/26/mr201007-01.pdf

Compañía peruana de estudios de mercados y opinión pública (2018). Market Report. Perú: Población $2018 \quad\left(\mathrm{~N}^{\circ} 5\right)$ Lima: CPI. Recuperado de http://www.cpi.pe/images/upload/paginaweb/archivo/26/mr_poblacional_peru_20180 5.pdf

Compañía peruana de estudios de mercados y opinión pública (2018). Market Report. Tenencia de mascotas en los hogares a nivel nacional ( $\left.{ }^{\circ} 8\right)$. Lima: CPI. Recuperado de https://www.cpi.pe/images/upload/paginaweb/archivo/26/mr_mascotas_201808.pdf

Diario Gestión (26 de noviembre de 2012). Más de 30 marcas compiten en alimento para mascotas. Gestion.pe. Recuperado de https://gestion.pe/impresa/30-marcascompiten-alimento-mascotas-25297 
Diario Gestión (23 de noviembre de 2016). Producción de alimentos para mascotas crecerá $12.3 \%$ este año. Gestion.pe. Recuperado de https://gestion.pe/economia/produccionalimentos-mascotas-crecera-12-3-ano-121501

Dispensador de comida y agua para perros. [Dispensadorde.net]. Recuperado de https://www.dispensadorde.net/comida-perros/

El Comercio (23 de mayo de 2018). Club WUF, la app que busca mejorar la vida de los perros sin hogar. Elcomercio.pe. Recuperado de https://elcomercio.pe/tecnologia/actualidad/club-wuf-app-busca-mejorar-vida-perroshogar-noticia-521910

Euromonitor (2018). Dog food in Peru. [Euromonitor.com]. Recuperado de https://www.euromonitor.com/dog-food-in-peru/report

Inga, C. (10 de abril de 2018). Pedigree apunta a liderar el mercado en el Perú. Día 1. Recuperado de https://elcomercio.pe/economia/dia-1/pedigree-apunta-liderarmercado-peru-noticia-510832

Instituto Nacional de estadística e informática (2017). Comportamiento de la economía peruana en el tercer trimestre de 2017 (Informe técnico $\mathrm{N}^{\circ} 4$ ). Lima: INEI. Recuperado de https://www.inei.gob.pe/media/MenuRecursivo/boletines/04-informe-tecnicon04_producto-bruto-interno-trimestral-2017iii.PDF

Instituto Nacional de estadística e informática (2018). Comportamiento de los indicadores de mercado laboral a nivel nacional (Informe técnico $\mathrm{N}^{\circ} 1$ ). Lima: INEI. Recuperado de https://www.inei.gob.pe/media/MenuRecursivo/boletines/01-informe-tecnicon01_empleo-nacional_oct-nov-dic2017.pdf

Instituto Nacional de estadística e informática (2018). Evolución de las exportaciones e importaciones (Informe técnico $\mathrm{N}^{\circ} 4$ ). Lima: INEI. Recuperado de https://www.inei.gob.pe/media/MenuRecursivo/boletines/04-informe-tecnicon04_exportaciones-e-importaciones-ene2018.pdf

Instituto Nacional de estadística e informática (2018). Variación de los indicadores de precios de la economía (Informe técnico $\mathrm{N}^{\circ} 4$ ). Lima: INEI. Recuperado de https://www.inei.gob.pe/media/MenuRecursivo/boletines/04-informe-tecnicon04_precios-mar2018_3.pdf

Ipet tracker. Localizador GPS para perros sin cuotas. [Ipet.es]. Recuperado de https://ipet.es/localizadores/ipet-tracker-localizador-gps.html

Kotler, P. y Armstrong, G. (2008). Principios de marketing (12 ${ }^{\mathrm{a}}$ ed.). Madrid: Pearson Educación.

Kotler, P. y Armstrong, G. (2012) Marketing (14ª ed.). México, D.F.: Pearson Educación

Kotler, P. y Keller, K. (2006) Dirección de marketing (12a ed.). México, D.F.: Pearson Educación 
Municipalidad de San Borja (2018). Plan estratégico de gobierno electrónico 2018 - 2020. Recuperado http://www.munisanborja.gob.pe/dmdocuments/PLAN_GOBIERNO_ELECTRONIC O_SAN_BORJA.pdf

Perú 21 (23 de septiembre de 2014). Tienda para mascotas, un negocio que te llevará 'de patitas' al éxito. Peru21.pe. Recuperado de https://peru21.pe/emprendimiento/tiendamascotas-negocio-llevara-patitas-exito-186876

Perú 21 (15 de febrero de 2017). Limeños engríen cada vez más a sus mascotas. Peru21.pe. Recuperado de https://peru21.pe/lima/limenos-engrien-vez-mascotas-encuesta-64135

Perú 21 (2 de agosto de 2017). ¿Cuánto invierte el peruano en el cuidado de su mascota? Peru21.pe. Recuperado de https://peru21.pe/vida/invierte-peruano-cuidado-mascota237945

Olivas, O. (2017, 04 de enero). Algunas tendencias en el mercado de mascotas en 2017. [merca20.com]. Recuperado de https://www.merca20.com/algunas-tendencias-enmercado-mascotas-2017/

Play Ground (2019). Recuperado de https://www.facebook.com/PlayGroundMag/?fref=ts

Publimetro (21 de julio de 2017). Día del perro: Conoce el primer programa de beneficios en Perú para tu mascota. Publimetro.pe. Recuperado de: https://publimetro.pe/actualidad/noticia-dia-perro-conoce-primer-programabeneficios-peru-tu-mascota-62710

¿Qué es el SEO y por qué es publicidad gratis? (2018, 21 de noviembre) [Emprendinauta.com]. Recuperado de https://www.emprendinauta.com/blog/que-es-el-seo-y-por-que-espublicidad-gratis/

¿Qué es wuf? [Wuf.pe]. Recuperado de http://www.wuf.pe/

Ripley se convirtió en la primera departamental "pet friendly" del Perú. [Peru-retail.com]. Recuperado de https://www.peru-retail.com/ripley-convirtio-primera-departamentalpet-friendly-peru/

Rosado, R. (11 de abril de 2013). Solo el 8\% de canes consume alimento balanceado en el país. Gestion.pe. Recuperado de https://gestion.pe/impresa/8-canes-consume-alimentobalanceado-pais-35821

Rotaeche, A. (2018, 02 de febrero). Accesorios modernos para mascotas que te sorprenderán. [Muymascotas.es]. Recuperado de https://www.muymascotas.es/accesorios/fotos/accesorios-modernos-para-mascotasque-te-sorprenderan/1

[San Borja] (2019). [Guía de calles]. Recuperado de http://planos.paginasamarillas.com.pe/guia-calles-san-borja.asp 
Sodimac implementa política "dog friendly" en cuatro de sus tiendas en Perú [Lucidez.pe]. Recuperado de http://lucidez.pe/negocios/sodimac-implementa-politica-dog-friendlyen-cuatro-de-sus-tiendas-en-peru/

¿Superior al pienso para perros y gatos? [Puromenu.es]. Recuperado de https://puromenu.es/pages/superior-al-pienso-para-perros-y-gatos-leer-para-creer

Superintendencia nacional de administración tributaria (2019, 19 de febrero). Iniciando mi negocio [Emprender.sunat.gob.pe]. Recuperado de http://emprender.sunat.gob.pe/quebeneficios-tengo

Tendencias 2018 en el segmento de mascotas: lo que el mercado debe saber $(2017,27$ de noviembre) [Petmi.com]. Recuperado de https://revistapetmi.com/tendencias-2018-enel-segmento-mascotas-lo-que-el-mercado-debe-saber/\#.XKZ0c5hKgdU

Urbania (2018). Departamentos en Lima. Reporte de mercado [Diapositiva]. Lima: Urbania. Recuperado de https://s3.amazonaws.com/wp.prod.urbania.pe/indicem2/wpcontent/uploads/2018/11/04163524/INDICE-M2-DEPARTAMENTOS-LIMA-201812.pdf

Yrigoyen, L. (18 de septiembre de 2014). De lobo a perro: Conoce su temperamento y evolución. El Comercio. Recuperado de https://elcomercio.pe/viu/actitud-viu/loboperro-conoce-temperamento-evolucion-364613 
ANEXOS 
ANEXO 1

\begin{tabular}{|c|c|c|c|c|}
\hline \multicolumn{5}{|c|}{$\begin{array}{l}\text { LIMA METROPOLITANA: } \\
\text { POBLACIÓN Y HOGARES SEGUN DISTRITOS } \\
2010 \\
\text { (En miles) }\end{array}$} \\
\hline No. & DISTRITO & POBLACION & $x$ & HOCARES \\
\hline 1 & SAN JUAN DE UARICANCHO & 9693 & 10.6 & 262.2 \\
\hline 2 & SAN UARTIN DE PCRRES & 6257 & 6.8 & $147 . \mathrm{B}$ \\
\hline 3 & COMAS & 5214 & 5.7 & 1270 \\
\hline 4 & RTE & 5164 & 5.6 & 156.4 \\
\hline 5 & VLLAE SALVDDOA & 4114 & 4.5 & 93.1 \\
\hline 6 & VLLA MAPIA OEL TRNNFO & 4567 & 4.5 & 1066 \\
\hline 7 & SAN JUWN OE VRAFLOFES & 3896 & 43 & 96.1 \\
\hline s & LOSOUNOS & 3434 & 3.7 & 101.0 \\
\hline 9 & LIWh - [Concede] & 3216 & 3.5 & 67.3 \\
\hline 10 & SANTHCO DE SUACO & 313 & 3.4 & 92.7 \\
\hline 11 & CHORRILOS & $310 \mathrm{~B}$ & 3.4 & B.S.S \\
\hline 12 & PUENTE PIEDRA & 2553 & 2.8 & Be.3 \\
\hline 13 & CAPNAMLLO & 2319 & 2.5 & 65.3 \\
\hline 14 & INDEPENDENCIA & 2222 & 2.4 & 629 \\
\hline 15 & LAVICTOFIA & 2064 & 2.3 & 53.9 \\
\hline 15 & SANTAANITA & 2013 & 22 & 57.1 \\
\hline 17 & ELACUSTINO & 1963 & 2. & 49.5 \\
\hline 18 & FIMAC & 1888 & 2.1 & 47.5 \\
\hline 10 & UURIGENCHO & to1 5 & 2.0 & 52.3 \\
\hline 20 & LAMOLINA & 1430 & 1.6 & 42.0 \\
\hline 21 & SAN MGUEL & 1389 & 1.5 & 40.3 \\
\hline 22 & SAN BORUA & 1130 & 1.2 & 33.7 \\
\hline 23 & SLRQUILLO & $\$ 64$ & $1: t$ & 29,6 \\
\hline 24 & MIRAFLOFES & 98 & 1.0 & 393 \\
\hline 25 & BRENA & 893 & 1.0 & 24.3 \\
\hline 28 & PUEELOLLRE & 802 & 0.9 & 22.9 \\
\hline 27 & JESUS MWRIA & 760 & 0.8 & 22.2 \\
\hline 28 & PNOWCAMAC & 739 & 0.3 & 25.7 \\
\hline 29 & LURIN & 685 & 0.7 & 20.9 \\
\hline 30 & SAN ISIDRO & 639 & 0.7 & 19.9 \\
\hline 31 & SAN LUIS & 603 & 0.7 & 18.4 \\
\hline 32 & UNCE & 599 & 0.7 & 18.1 \\
\hline 33 & MAGOALENA OEL MAR & $\$ 5.4$ & 0.6 & 16.5 \\
\hline 34 & CHECLACAYO & 463 & 0.5 & 11.3 \\
\hline 35 & ANCON & 37.4 & 0.4 & 11.5 \\
\hline 36 & BAPRANCO & 374 & 0.4 & 9.9 \\
\hline 37 & CIENEGULLA & 288 & 0.3 & 6.3 \\
\hline 38 & SANTA ROSA & 113 & 0.1 & 4.1 \\
\hline 39 & PUCUSAHA & 115 & 0.1 & 3.9 \\
\hline 40 & SAN BARTOLO & 7.1 & 0.1 & 2.1 \\
\hline 41 & PUNTAHEFMOSA & 69 & 0.1 & 2.9 \\
\hline 42 & PUNTANEGRA & 59 & 0.1 & 2.1 \\
\hline 43 & SANTA NARIA DEL. MAR & 02 & 0.0 & 0.1 \\
\hline \multicolumn{2}{|c|}{ SUB-TOTAL INA } & $8,221.6$ & 89.7 & $2,241.7$ \\
\hline 44 & CALlLO [Cexado] & 4458 & 4.9 & 114.3 \\
\hline 45 & VENTANLLA & 2583 & 3.3 & 95.5 \\
\hline 45 & GELANISTR & 810 & 0.9 & 20.1 \\
\hline $4 ?$ & LAPERLA & 664 & 0.7 & 17.4 \\
\hline 48 & CAFMEN DE LALECUA REYNOSO & 447 & 0.5 & 10.6 \\
\hline 42 & LAPUNTA & 47 & 0.1 & 13 \\
\hline \multicolumn{2}{|c|}{ SUB-TOTAL CALLAO } & 9413 & 10.3 & 253.7 \\
\hline \multicolumn{2}{|r|}{ TOTAL UNA NETROPOUTANA } & 9,1629 & 100.0 & $2,501.4$ \\
\hline
\end{tabular}

\begin{tabular}{|c|c|c|c|c|}
\hline \multicolumn{5}{|c|}{$\begin{array}{c}\text { Cuadro } \mathrm{N}^{\circ} 8 \\
\text { LIMA METROPOLITANA: } \\
\text { POBLACIÓN Y HOGARES SEGÚN DISTRITOS } \\
2011 \\
\text { (En miles) }\end{array}$} \\
\hline Wo. & DSTाR & POBLACION & 8 & HOGARES \\
\hline 1 & SWN JUNN DE WRENCHO & 2004.4 & ติ & 2493 \\
\hline 2 & SWN MRTN DEPORRES & 6453 & 70 & 1406 \\
\hline 3 & AE & 5860 & 60 & 145.7 \\
\hline 4 & coms & 5852 & 5s & 1212 \\
\hline 5 & MLAE. SNUVDOR & 4275 & 46 & 969 \\
\hline 6 & MLAMMRИ DE TRUNFO & $4 \% 9.1$ & 45 & 1003 \\
\hline 7 & SWN JUMN DE MRNRLORES & $3 \mathbf{a g}$ & 42 & sas \\
\hline a & Los cumos & 349.7 & $3 \mathbf{B}$ & 9as \\
\hline 9 & SWNTAGODESURCO & 3212 & 35 & 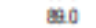 \\
\hline 10 & CHORALLS & 311 2 & 33 & 724 \\
\hline 11 & LM - (Coroado) & 2913 & 3.1 & at2 2 \\
\hline 12 & PUENTEPEORA & 2909 & 3.1 & a.2 2 \\
\hline 13 & сменайLO & 2496 & 27 & 21 \\
\hline 14 & INDEPENDENCA & 2833 & 23 & MS \\
\hline 15 & SNTTANTA & 2003 & 22 & 843 \\
\hline 16 & LURAGWCHO & 1965 & 2.1 & 300 \\
\hline 17 & E. MESSTNO & 103 & 20 & $\$ 2.6$ \\
\hline 18 & LAMCTORK & 132 & 20 & 30.2 \\
\hline 19 & RMUC & 1742 & 19 & 448 \\
\hline 20 & LAMOUNK & 139.1 & 16 & 4.7 \\
\hline 21 & SW MGUE & 1349 & 15 & 37.7 \\
\hline 22 & SWN BORJA & 1114 & 12 & 315 \\
\hline 23 & PACHACMUC & 937 & 10 & $2 \mathbf{x}_{0}$ \\
\hline 24 & SURCULLO & 926 & 10 & 쵸1 \\
\hline 25 & MRNLLRES & $\mathbf{3 5}$ & 0.9 & $\mathbf{z} 1$ \\
\hline 26 & BREM & $\mathbf{2} 6$ & 09 & 226 \\
\hline 27 & PUEALOLIGRE & $\pi 3$ & $0 \mathrm{a}$ & 214 \\
\hline $2 \mathrm{a}$ & LURN & 72.3 & Oa & 993 \\
\hline 29 & JESUSMMRA & $\mathrm{na}$ & os & 203 \\
\hline 30 & SWN ISIORO & 53 & 0.6 & 8.9 \\
\hline 31 & SANLUS & 873 & 06 & 96.8 \\
\hline 32 & MUGOLEN DE MR & 843 & 0.6 & 15.4 \\
\hline 33 & LNCE & 899 & 06 & 158 \\
\hline 34 & CHCANCAYO & 43.1 & 0.5 & 110 \\
\hline 35 & NNCON & 306 & 0.4 & 110 \\
\hline 36 & CENEGIUA & 35.5 & 0.4 & 7.9 \\
\hline 37 & BNRRWCO & 206 & 0.4 & 93 \\
\hline 3a & SWTAROSA & 144 & 02 & 41 \\
\hline 39 & PUCASWNA & is 5 & 0.1 & 3.7 \\
\hline 40 & PUNTA NEGPA & 66 & 0.1 & 20 \\
\hline 41 & SN BNRTOLO & 66 & 0.1 & 20 \\
\hline 42 & PUNTA IESAMCSA & 63 & 0.1 & 19 \\
\hline 43 & SWTAMRA DE. MR & 11 & 00 & a.3 \\
\hline & SUBTOTRL UMA & 3336.5 & 32.7 & 2118.7 \\
\hline 44 & CNШNO & $420 \mathrm{~B}$ & 45 & 969 \\
\hline 45 & VENTENLA & 3619 & 38 & 89.9 \\
\hline 46 & Be. LMVTA & 750 & Oa & a 1 \\
\hline 47 & LAPERLA & 615 & 03 & 14.4 \\
\hline 43 & CAEMEN DELALEGUAREYNOSO & 423 & OS & 114 \\
\hline 49 & LAPUNTA & 39 & 00 & 10 \\
\hline & SUBTOTRLCALLAO & 955.4 & 10.3 & 2247 \\
\hline & TOTAL UMA METROPOUTAMA & 92919 & 1000 & 23434 \\
\hline
\end{tabular}




\begin{tabular}{|c|c|c|c|c|}
\hline \multicolumn{5}{|c|}{$\begin{array}{l}\text { Lima metropolitana: población y hogares según distritos } \\
\qquad 2012 \text { (en miles) }\end{array}$} \\
\hline No. & DISTRITO & POBLACIÓN & \% & HOGARES \\
\hline 1 & SAN JUAN DE URIGANCHO & $1,005.9$ & 10.9 & 257.2 \\
\hline 2 & SAN MARTIH DEPOFRES & 659.6 & 7.0 & 1452 \\
\hline 3 & ATE & 573.9 & 61 & 1480 \\
\hline 4 & COMAS & 5178 & 5.5 & 125.4 \\
\hline 5 & ИLA EL SALYOOR & 4363 & 4.6 & 100.7 \\
\hline 6 & ИLA MAFIA DE TFIUUF 0 & 4264 & 4.5 & 1081 \\
\hline 7 & SAN JUAN DE MRAR_ORES & 323.5 & 4.2 & 97.1 \\
\hline 8 & LOS OLMOS & 355.1 & 38 & 96.6 \\
\hline$\theta$ & SANTLAGO DE SLRCO & 326.9 & 35 & 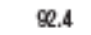 \\
\hline 10 & CHORPILUS & 314.8 & 33 & 80.8 \\
\hline 11 & PUENTE FIEDRA & 305.5 & 32 & 72.5 \\
\hline 12 & LMA & 2968 & 30 & 82.4 \\
\hline 13 & CARABAYL 0 & 268.0 & 28 & 65.4 \\
\hline 14 & INDEPEИDEИСA & 216.5 & 23 & 61.2 \\
\hline 15 & SANTAANITA & 213.5 & 23 & 56.1 \\
\hline 16 & LUFGAМСНО & 2012 & 21 & 51.4 \\
\hline 17 & EL AGUSTIND & 189.9 & 20 & 47.7 \\
\hline 18 & LA ИCTORIA & 182.5 & 1.9 & 50.9 \\
\hline 19 & FIMAC & 171.9 & 1.8 & 46.0 \\
\hline 20 & LA MOLIKA & 157.6 & 1.7 & 42.4 \\
\hline 21 & SWN MISLEL & $1 \% .1$ & 1.4 & 32.5 \\
\hline 22 & SAN BORIA & 111.5 & 1.2 & 32.1 \\
\hline 23 & PACHACAMAC & 102.7 & 1.1 & 25.7 \\
\hline 24 & SUROLLLO & 92.3 & 1.0 & 28.9 \\
\hline 25 & MIRAFLLFES & 844 & 0.9 & 25.1 \\
\hline 26 & ERERAA & 794 & 0.8 & 22.9 \\
\hline 27 & PLEEL 0 UERE & 77.0 & 0.8 & 21.8 \\
\hline 28 & LIFN & 76.9 & 0.8 & 188 \\
\hline 29 & JESUS MAFIA & 713 & 0.8 & 20.3 \\
\hline 30 & SAN LUIS & 574 & 0.6 & 17.3 \\
\hline 31 & SWN ISDPD & 56.5 & 0.6 & 17.1 \\
\hline 32 & MAGDALEHADELL MAR & 544 & 0.6 & 15.6 \\
\hline 3 & LNCE & 52.9 & 0.6 & 15.9 \\
\hline 34 & CHACLACAYO & 432 & 0.5 & 11.6 \\
\hline ж & ANDOH & 398 & 0.4 & 11.3 \\
\hline 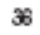 & AENEGULA & 38.3 & 0.4 & 81 \\
\hline 37 & BARRANCO & 320 & 0.3 & 96 \\
\hline 38 & SANTAROSA & 154 & 0.2 & 4.3 \\
\hline 39 & PUCUSANA & 144 & 0.2 & 3.8 \\
\hline 40 & SAN BARTOLO 0 & 7.0 & 0.1 & 2.1 \\
\hline 41 & PUNTAHERMOSA & 6.9 & 0.1 & 2.0 \\
\hline 42 & PUNTANEGRA & 6.9 & 0.1 & 2.0 \\
\hline 43 & SANTAMARIADEL MAR & 12 & 0.0 & 0.3 \\
\hline & SUB-TOTAL LIMA & $8,490.7$ & 287 & $2,124.7$ \\
\hline 44 & САШАО & 417.6 & 4.4 & 925 \\
\hline 45 & VENTANLLA & 370.5 & 39 & 283 \\
\hline 46 & EELLAMSTA & 74.3 & 0.8 & 186 \\
\hline 47 & LAPERLA & 60.9 & 0.6 & 14.7 \\
\hline 48 & CARMEN OELA LEFIARENDSO & 42.1 & 0.4 & 12.0 \\
\hline 49 & LAPUNTA & 38 & 00 & 1.1 \\
\hline
\end{tabular}

\begin{tabular}{|c|c|c|c|c|}
\hline \multicolumn{5}{|c|}{$\begin{array}{l}\text { LIMA ME TROPOLITARA: POEL LCION Y HDELRES SEGÚN DISTRITOS } \\
\qquad 2013 \text { (en miles) }\end{array}$} \\
\hline No. & DASTRTO & PoвLación & $\mathrm{s}$ & HOGARES \\
\hline 1 & SW JUN DE UFESENCHO & $1,047.7$ & 10.8 & 261.3 \\
\hline 2 & SWN WUATII DE POPFES & 673.1 & 6.9 & 148.6 \\
\hline 3 & ME & SB23 & 62 & 150.4 \\
\hline 4 & comus & 5204 & 5.4 & 129.7 \\
\hline 5 & VWAB SAVEDCR & 445.2 & 4.6 & 101.5 \\
\hline 6 & VLA MAPLA DE TFANF 0 & 433.9 & 4.5 & 108.3 \\
\hline 7 & SN JWWN DE MARZ_.FES & 397.1 & 4.1 & 100.5 \\
\hline 8 & Los anves & 300.5 & 3.8 & 100.3 \\
\hline 9 & SNTIUPO DE SUPOO & 3327 & 3.5 & 97.1 \\
\hline 10 & PLENIE PIECAA & 320.8 & 3.3 & 729 \\
\hline 11 & CHORAШOS & 318.5 & 3.3 & 83.3 \\
\hline 12 & UMa & 281.9 & 2.9 & 83.7 \\
\hline 13 & CARLEWULO & $2 \pi 9.0$ & 2.9 & 68.1 \\
\hline 14 & SANTAENTA & 218.5 & 2.3 & 58.7 \\
\hline 15 & IMDEРEСЕНСИ & 216.7 & 2.3 & 63.3 \\
\hline 16 & UFESWCHO & 207.1 & 22 & 529 \\
\hline 17 & EL_AENSTNO & 190.5 & 2.0 & 48.9 \\
\hline 18 & LАพстонА & 179.0 & 1.9 & 51.7 \\
\hline 19 & Piwec & 169.6 & 1.8 & 46.2 \\
\hline 20 & LA MOUNA & 1622 & 17 & 43.6 \\
\hline 21 & SN MEN⿴囗十 & 135.2 & 1.4 & $\$ 0.2$ \\
\hline 22 & SNEQRAM & 111.7 & 12 & 33.5 \\
\hline 20 & PеснасамМс & 111.0 & 12 & 28.1 \\
\hline 24 & supaumo & seo & 100 & 29.7 \\
\hline 25 & MRQFLCRES & 83.6 & 0.9 & 29.0 \\
\hline 28 & UFN & 79.6 & 0.8 & 204 \\
\hline $2 \pi$ & BABMA & 78.3 & 0.8 & 23.6 \\
\hline 28 & PLEBLD UEFE & 78.8 & 0.8 & 24.3 \\
\hline 29 & ESÚs WePiA & 71.4 & 07 & 20.9 \\
\hline 30 & SENLUS & 57.5 & 0.8 & 17.9 \\
\hline 31 & SANISCPO & 65.8 & 0.8 & 18.9 \\
\hline 32 & MUEDOLENA CE WUR & 54.5 & 0.8 & 16.8 \\
\hline 30 & UNCE & 521 & 0.5 & 16.7 \\
\hline 34 & CHACLACAONO & 43.3 & 0.5 & 121 \\
\hline 36 & CENEQUUA & 41.1 & 0.4 & 84 \\
\hline 36 & ancón & 41.0 & 0.4 & 11.4 \\
\hline 37 & BAFAnCO & 31.3 & 0.3 & 9.6 \\
\hline 38 & SNTA ROSA & 16.5 & 02 & 4.2 \\
\hline $3 \theta$ & PUCUESNA & 15.2 & 02 & 3.9 \\
\hline 40 & SN EARTCO & 7.2 & 0.1 & 21 \\
\hline 41 & PUNTA NEGPA & 7.2 & 0.1 & 20 \\
\hline 42 & PUNTA HEFMOSA & 7.2 & 0.1 & 21 \\
\hline 43 & SANTA MARLA OB MAR & 1.3 & 0.0 & 0.3 \\
\hline \multicolumn{2}{|c|}{ TOTLL PROMNCAA DE LIHA } & 8,617.6 & 898 & 2,2421 \\
\hline 44 & CAШAD & 414.3 & 4.3 & 101.1 \\
\hline 45 & VENTAMLA & 309.4 & 4.1 & 89.7 \\
\hline 46 & ERLAISTA & 73.5 & 0.8 & 18.2 \\
\hline 47 & LA FERLA & 60.2 & 0.8 & 14.9 \\
\hline 48 & CAAIEN WELALBEAA RENONSO & 41.8 & 0.4 & 126 \\
\hline 49 & LAPUNTA & 3.8 & 0.0 & 1.1 \\
\hline \multicolumn{2}{|c|}{ TOTA PROMNCAA DEL CALAO } & 9628 & 102 & 2386 \\
\hline \multicolumn{2}{|c|}{ TOTL LIHA ME TPOPOLITLHA } & 9,6003 & $100 \pi$ & $2 A 8007$ \\
\hline
\end{tabular}

EABOHACION: DENATLANENTO DE ESTROSTICA - C.M. 


\begin{tabular}{|c|c|c|c|c|}
\hline \multicolumn{5}{|c|}{$\begin{array}{l}\text { LMA METEOPOLITAMA POELACIOK Y HOGARES SECUOM DSTETOS } \\
\qquad 2014 \text { (en miles) }\end{array}$} \\
\hline No. & DSTRTO & POELACOCON & \% & HOGAIES \\
\hline 1 & SWN JUAN DE URESWCHO & $1,069.6$ & 10.9 & 205.1 \\
\hline 2 & SN WURTM DE PCFPES & 688.7 & 7.0 & 148.8 \\
\hline 3 & AE & 611.1 & 6.3 & 1526 \\
\hline 4 & comus & 5227 & 5.4 & 131.6 \\
\hline 5 & VWA E SAUVDCR & 454.1 & 47 & 103.0 \\
\hline 6 & VWA MМRA DE TFANF0 & 441.2 & 4.5 & 109.9 \\
\hline 7 & SWN JUWN DE MAQFLOFS & 400.6 & 4.1 & 1020 \\
\hline 8 & Los OUNos & 365.9 & 3.8 & 101.8 \\
\hline 9 & SNNTLAO DE SUROD & 338.5 & 3.5 & 98.6 \\
\hline 10 & PLENTE PIEXAA & 33.8 & 3.5 & 74.0 \\
\hline 11 & CHORA—OS & 3221 & за & 84.5 \\
\hline 12 & CARUBWUO & 290.3 & 3.0 & 69.2 \\
\hline 13 & UMA & 278.9 & 2.8 & 84.9 \\
\hline 14 & SANTA WNTA & 223.4 & 2.3 & 57.5 \\
\hline 15 & ІМОЕРЕСЕИСИ & 216.8 & 22 & 64.2 \\
\hline 16 & UFEЕNCHO & 213.0 & 22 & 53.6 \\
\hline 17 & EL AENSTND & 191.0 & 20 & 49.6 \\
\hline 18 & LA WCTORL & 175.4 & 1.8 & 524 \\
\hline 19 & AMEC & 167.3 & 17 & 48.9 \\
\hline 20 & LA MOUNA & 188.9 & 17 & 44.3 \\
\hline 21 & S*N MEㅔㅡ. & 135.4 & 1.4 & 40.8 \\
\hline 22 & 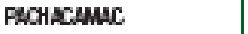 & 120.0 & 12 & 28.5 \\
\hline 23 & SWN BORA & 111.8 & 1.1 & 34.0 \\
\hline 24 & SURAMUO & 91.7 & 0.9 & 30.1 \\
\hline 25 & MAQFLCAES & 828 & 0.8 & 29.5 \\
\hline 26 & UFw & 823 & 0.8 & 20.7 \\
\hline 27 & BAEM & 77.1 & 0.8 & 24.0 \\
\hline 28 & PUEBLDUEFE & 76.4 & 0.8 & 24.6 \\
\hline 29 & ESUB WEFA & 71.5 & 07 & 21.2 \\
\hline 30 & SNLUS & 57.5 & 0.6 & 18.1 \\
\hline 31 & SNISDFD & 56.0 & 0.8 & 20.2 \\
\hline 32 & MESDMLANA DE WUR & 54.5 & 0.6 & 17.0 \\
\hline 30 & UNCE & 51.1 & 0.5 & 16.9 \\
\hline 34 & CENEGUUA & 4.0 & 0.5 & 8.5 \\
\hline 36 & CHAOLCAYO & 43.4 & 0.4 & 123 \\
\hline $\boldsymbol{3}$ & ANCON & $\$ 22$ & 0.4 & 11.5 \\
\hline 37 & BAFANCO & 30.7 & 0.3 & 9.8 \\
\hline 3 & SENTA ROSA & 17.6 & 02 & 4.2 \\
\hline $\boldsymbol{3}$ & PUCJesena & 16.1 & 02 & 4.0 \\
\hline 40 & PUNTA NEGAA & 7.6 & 0.1 & 21 \\
\hline 41 & SW BARTOLO & 7.5 & 0.1 & 21 \\
\hline 42 & PUNTA HEFMOSA & 7.4 & 0.1 & 21 \\
\hline 43 & SENTA MARA DE MAR & 1.4 & 0.0 & 0.3 \\
\hline \multicolumn{2}{|c|}{ TOTAL PAONMCA DE UMA } & $8,755.3$ & 89.8 & $2,275.0$ \\
\hline 44 & CAШAD & 410.6 & 42 & 1027 \\
\hline 45 & VЕМТАМА & 408.7 & 42 & 81.1 \\
\hline 46 & BELAISTA & 727 & 0.8 & 18.5 \\
\hline 47 & LAPERLA & 59.5 & 0.8 & 15.1 \\
\hline 48 & CAAIVN DE LALBGAA RENOSO | & 41.4 & 0.4 & 128 \\
\hline 49 & LAPUNTA & 3.5 & 0.0 & 1.1 \\
\hline \multicolumn{2}{|c|}{ TOTAL POOVKCLA DEL CALLAO } & 996.4 & 102 & 242.3 \\
\hline \multicolumn{2}{|c|}{ TOTAL UMA METROPOLITAKA } & $9,751.7$ & 1000 & $2,517.3$ \\
\hline
\end{tabular}

EABOHACION: DENTERAVENTO DE ESTAOISTCA - C.R.

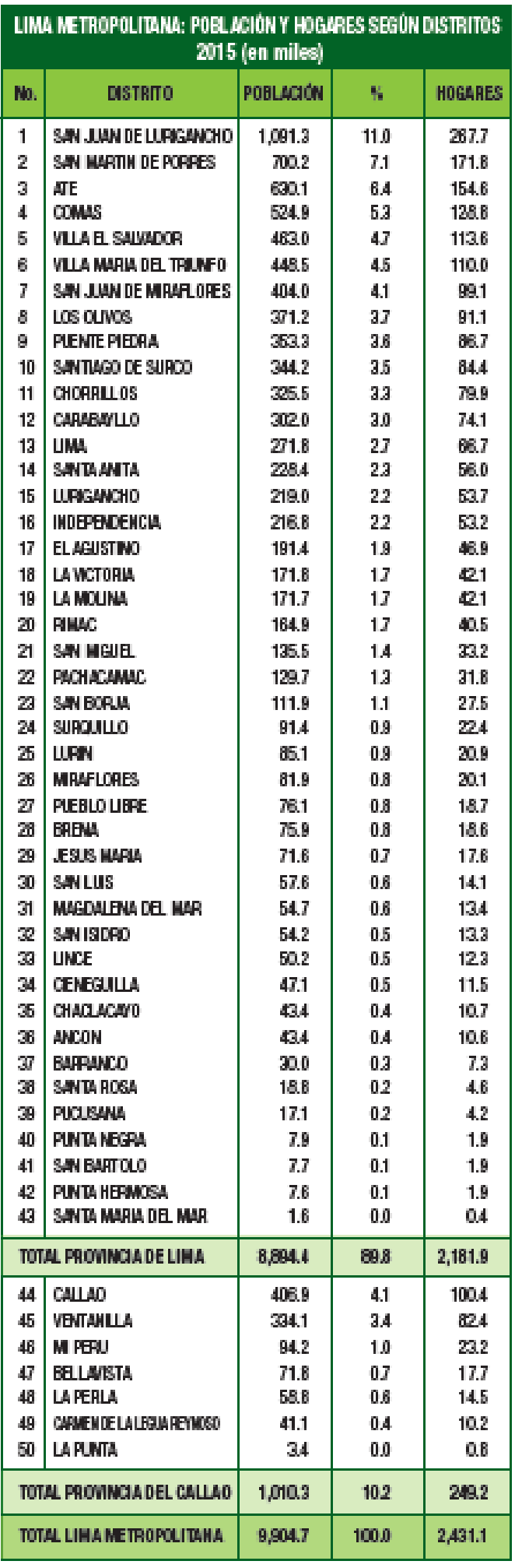

BABONACICN: DENUTANENTO DE ESTADISTCA - C.R. 


\begin{tabular}{|c|c|c|c|c|}
\hline \multicolumn{5}{|c|}{ 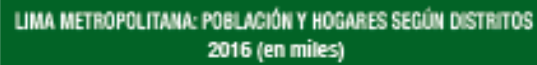 } \\
\hline ก.. & DSTRITO & POBLACín & $\%$ & HOGARES \\
\hline 1 & SAN JUN DE UFESANCHO & $1,105.8$ & 11.0 & $2 \pi 20$ \\
\hline 2 & SWN WURTNN DE POFFES & 711.3 & 7.1 & 1725 \\
\hline \multirow{2}{*}{$\begin{array}{l}3 \\
4\end{array}$} & ATE & 638.1 & 63 & 158.5 \\
\hline & comess & 5329 & 5.3 & 133.9 \\
\hline $\begin{array}{l}4 \\
5\end{array}$ & VLA日 SAUVEDCR & 469.2 & 47 & 114.1 \\
\hline 6 & VWA MQRИ DE TRINFO & 454.7 & 4.5 & 113.2 \\
\hline \multirow{2}{*}{$\begin{array}{l}7 \\
8\end{array}$} & SAN JUN DE MPQR OFES & 409.8 & 4.1 & 105.8 \\
\hline & Los aNves & 377.0 & 37 & 105.8 \\
\hline $\begin{array}{l}8 \\
9\end{array}$ & PIENIE PIETAA & 367.5 & 3.8 & 87.2 \\
\hline \multirow{2}{*}{10} & SANTLGO DE SUAOD & 361.2 & 3.5 & 105.9 \\
\hline & СНOARШ OS & 300.5 & 3.3 & 88.0 \\
\hline $\begin{array}{l}11 \\
12\end{array}$ & CARUEATLO & 305.9 & 3.0 & 74.2 \\
\hline $\begin{array}{l}12 \\
13\end{array}$ & uma & $2 \pi 8.9$ & 2.8 & 90.6 \\
\hline 14 & SENTA ANTA & 231.4 & 23 & 59.0 \\
\hline $\begin{array}{l}14 \\
15\end{array}$ & UFESWNCHO & 221.8 & 22 & 55.2 \\
\hline 16 & ІМОЕРЕСЕИСИ & 200.2 & 22 & 68.8 \\
\hline & EL LALSTIMO & 194.1 & 1.9 & 51.3 \\
\hline $\begin{array}{l}17 \\
18\end{array}$ & LA MOUNA & 175.1 & 17 & 47.2 \\
\hline $\begin{array}{l}18 \\
19\end{array}$ & LА истовнА & 174.7 & 17 & 55.5 \\
\hline 20 & Füc & 167.8 & 17 & 40.7 \\
\hline 21 & SNN M테는 & 138.3 & 1.4 & 4.0 \\
\hline 22 & Реснасемис & 131.2 & 13 & 320 \\
\hline 2 & SNNBOR.A & 114.4 & 1.1 & 37.0 \\
\hline 24 & Supaulo & 83.2 & 0.9 & 324 \\
\hline 25 & UFW & 88.2 & 0.8 & 21.2 \\
\hline 26 & MAOFLCAES & 84.0 & 0.8 & 33.0 \\
\hline $2 \pi$ & PLEBLOUERE & 77.8 & 0.8 & 27.1 \\
\hline 28 & EमENA & 774 & 0.8 & 25.9 \\
\hline 29 & ESUB WOFAA & 73.2 & 07 & 234 \\
\hline 30 & SWLLUS & 59.6 & 0.8 & 19.1 \\
\hline 31 & MLEDNAPNA CE WUR & 55.8 & 0.8 & 18.6 \\
\hline 32 & SNISCPD & 55.6 & 0.8 & 227 \\
\hline 30 & UNCE & 51.3 & 0.5 & 18.5 \\
\hline 34 & CENEEULA & 47.8 & 0.5 & 11.6 \\
\hline 36 & CHACLCANO & 4.2 & 0.4 & 13.0 \\
\hline 36 & ANCON & 43.9 & 0.4 & 11.9 \\
\hline 37 & BafPanco & 30.6 & 0.3 & 10.7 \\
\hline 30 & SWNTAPBSA & 19.0 & 02 & 4.6 \\
\hline $3 \theta$ & PUCUESNA & 17.3 & 02 & 4.2 \\
\hline 40 & PWNTANEGRA & 8.0 & 0.1 & 22 \\
\hline 41 & SN EARTOLO & 7.8 & 0.1 & 22 \\
\hline 42 & PUNTA|ERMOSA & 7.7 & 0.1 & 22 \\
\hline 43 & SNTA MUPA DE WUR & 1.6 & 0.0 & 0.4 \\
\hline & AL PBOVNCUA DE UNA & 9,00018 & 89.8 & $2,425.4$ \\
\hline 44 & CALAO & 428.6 & 4.3 & 108.1 \\
\hline 45 & VENTANUA & 368.0 & 3.8 & 90.9 \\
\hline 46 & EQLAMSTA & 78.0 & 0.8 & 21.4 \\
\hline 47 & LA FERLA & 64.1 & 0.8 & 16.6 \\
\hline 48 & M PEAN & 527 & 0.5 & 13.5 \\
\hline 49 & CAAVEN UE LALEGA RENOSO & 43.1 & 0.4 & 13.5 \\
\hline 50 & LAPUNTA & 3.9 & 0.0 & 1.3 \\
\hline & AL PBOVNCL DEL CALLO & $1,024.4$ & 102 & 265.3 \\
\hline & AL UMA METROPOLTAMA & $10,055.2$ & 1000 & $2,690.7$ \\
\hline
\end{tabular}

\begin{tabular}{|c|c|c|c|c|}
\hline \multicolumn{5}{|c|}{$\begin{array}{l}\text { LMA METHOPOUTANA: POBLACIONY Y HOGARES SEGLUN DISTRTTOS } 2 \\
\text { (En miles) }\end{array}$} \\
\hline No. & DISTRTO & POBLACION & 4 & HOGARES \\
\hline 1 & San Juan de Lurigancho & $1,121,3$ & 11.0 & 275.9 \\
\hline 2 & San Martin de Porres & 7223 & 7.1 & 175.2 \\
\hline 3 & Ave & 6469 & 6.3 & 158.6 \\
\hline 4 & Comas & 541.2 & 5.3 & 139.0 \\
\hline 5 & Vils E Salvedor & 475.5 & 4.7 & 115.7 \\
\hline 6 & Vila Mara del Triunfo & 461.2 & 4.5 & 114.8 \\
\hline 7 & San Juan de Mratiores & 4160 & 4.1 & 107.4 \\
\hline 8 & Los Olwos & 3828 & 3.7 & 107.4 \\
\hline 9 & Puente Pledra & 3621 & 3.5 & 8.3 \\
\hline 10 & Santego de Surco & 357.6 & 3.5 & 107.8 \\
\hline 11 & Chomilios & 335.8 & 3.3 & 89.4 \\
\hline 12 & Carabeylo & 3101 & 3.0 & 75.2 \\
\hline 13 & Lima & 2828 & 2.8 & 92.5 \\
\hline 14 & Santa Avita & 234.8 & 2.3 & 59.9 \\
\hline 15 & Lurigancho (Chosica) & 2249 & 2.2 & 56.0 \\
\hline 16 & Independencia & 223.6 & 2.2 & 67.8 \\
\hline 17 & 日 Agustino & 196.9 & 1.9 & 52.1 \\
\hline 18 & La Molina & 1782 & 1.7 & 48.0 \\
\hline 19 & La Victoria & 177.7 & 1.7 & 56.4 \\
\hline 20 & Fimac & 170.6 & 1.7 & 50.5 \\
\hline 21 & San Miguel & 1409 & 1.4 & 44.8 \\
\hline 2 & Pachacansc & 1328 & 1.3 & 324 \\
\hline 23 & $\operatorname{Sen} B$ Brja & 116.7 & 1.1 & 37.8 \\
\hline 24 & Surquilio & 949 & 0.9 & 330 \\
\hline z & Lurin & 87.4 & 0.9 & 21.5 \\
\hline 26 & Mratores & 85.8 & 0.8 & 33.7 \\
\hline 27 & Puebio Libre & 79.4 & 0.8 & 27.7 \\
\hline 28 & Brenta & 78.9 & 0.8 & 26.4 \\
\hline 2 & Jesús Maria & 74.7 & 0.7 & 23.9 \\
\hline 30 & Sen Luls & 59.6 & 0.6 & 19.5 \\
\hline 31 & Magdelena del Mr & 56.9 & 0.6 & 190 \\
\hline$x$ & Sen Isidro & 56.8 & 0.6 & 232 \\
\hline 3 & Linoe & 52.4 & 0.5 & 18.9 \\
\hline 34 & Clenegula & 48.4 & 0.5 & 11.8 \\
\hline x & Chaclscayo & 44.9 & 0.4 & 13.2 \\
\hline 36 & Anow & 44.6 & 0.4 & 120 \\
\hline 37 & Barranco & 31.2 & 0.3 & 10.9 \\
\hline 38 & Senta Rosa & 19.3 & 0.2 & 4.7 \\
\hline 3 & Pucusena & 17.5 & 0.2 & 4.3 \\
\hline 40 & Purta Negra & 8.1 & 0.1 & 22 \\
\hline 41 & Sen Bartolo & 7.9 & 0.1 & 22 \\
\hline & Purta Hermosa & 7.8 & 0.1 & 22 \\
\hline \multirow[t]{2}{*}{4} & Serta Marla del Mar & 1.6 & 0.0 & 0.4 \\
\hline & Total Prowndg Re Lima & 91706 & 89.8 & $2 \operatorname{sen} 6$ \\
\hline 4 & Callao & 433.0 & 4.3 & 109.7 \\
\hline 45 & Ventanilla & 360.0 & 3.6 & 920 \\
\hline 45 & Belavista & 79.4 & 0.8 & 21.8 \\
\hline 47 & La Perla & 65.2 & 0.6 & 17.0 \\
\hline 4 & Mi Peñ & 55.3 & 0.5 & 13.6 \\
\hline 4 & Camen de La Logu fieyroso & 43.7 & 0.4 & 13.7 \\
\hline 50 & La Punta & 4.1 & 0.0 & 1.3 \\
\hline \multicolumn{2}{|c|}{ Intal Prowinota del Callos } & 1.0387 & 102 & 269.1 \\
\hline \multicolumn{2}{|c|}{ Total Lma Matroxellitans } & 102003 & 1000 & $2 \pi 327$ \\
\hline
\end{tabular}

ELABCREACANe Departameto de Enaditica - CPI 


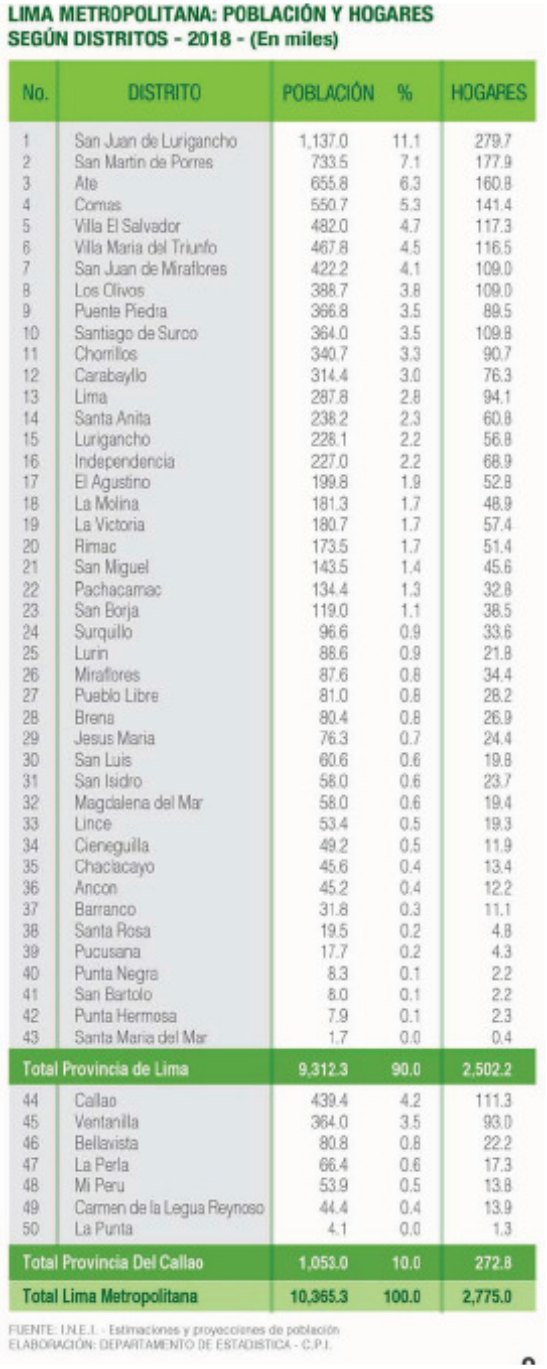


ANEXO 2

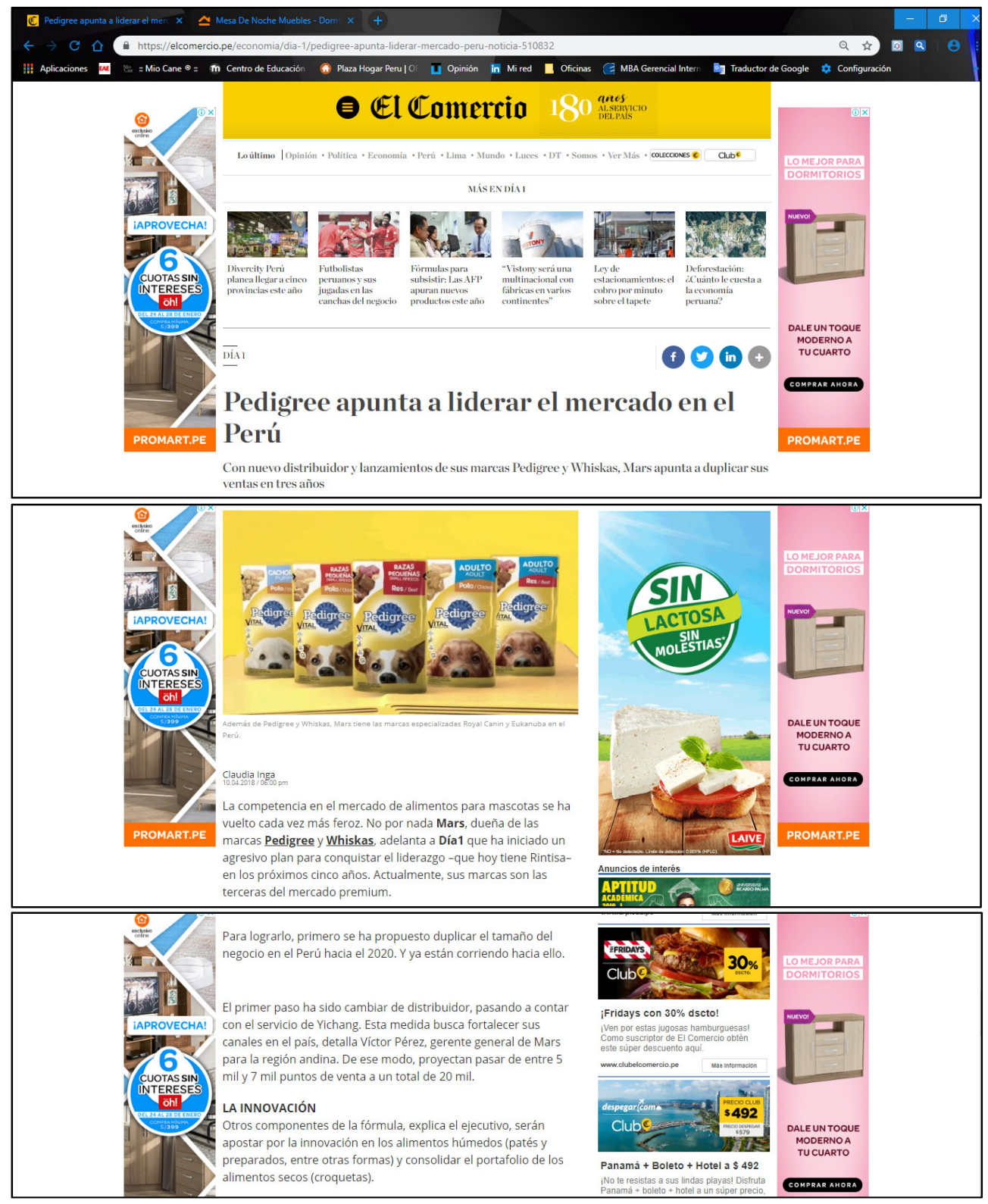



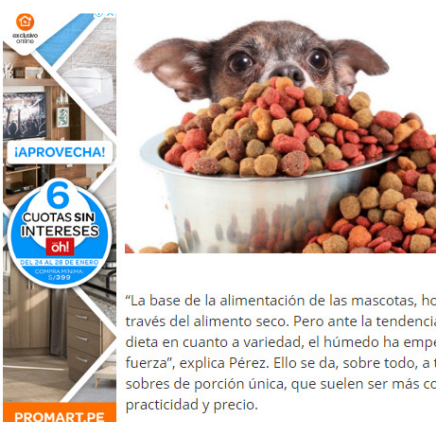

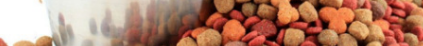

(a)

La base de la alimentación de las mascotas, hoy en dia, se da a
trimento seco. Pero ante la tendencia de 'humanizar'

dieta en cuanto a variedad, el húmedo ha empezado a ganar

sobres de porción única, que suelen ser más convenientes por

practicidad y precio.

En este segmento, Mars adelanta que lanzarán nuevas gamas de sabores y formatos. De acuerdo con Pérez, el alimento húmedo representa un $5 \%$ del consumo, por lo que hay un gran potencia de crecimiento a futuro. La especialización seguirá siendo la clave

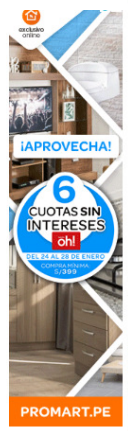
esta categoría.

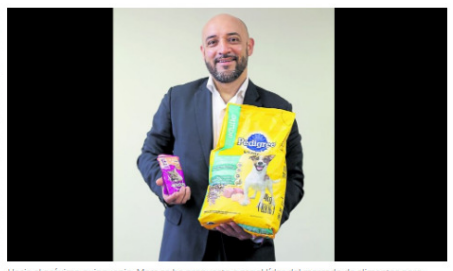

Para que este crecimiento 5 concrete, también es importante educación del cliente, sostiene el líder regional de Mars. Por ello, la compañia destinará entre el $10 \%$ y $12 \%$ de su inversión en el pais para ese fin, a través de publicidad, redes sociales y el reparto 政 el año pasado", precisa Pérez

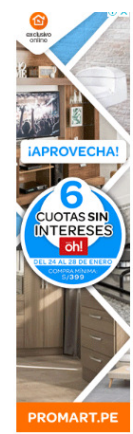

MERCADO Y COMPETENCIA

Pedigree $y$ Whiskas participan en el segmento premium, donde se

miden con las bien posicionadas marcas de Nestlé (Purina y

Proplan) y Rintisa (Ricocan). Mars, a la fecha, tiene a sus dos

Marcas estrella en el tercer lugar del mercado. Pedigree tiene el

$25 \%$ de la torta de alimento para perros y Whiskas, el 3296 en

Perez recuerda que hace 10 años, cuando Pedigree recién ingresó a mercado, apenas un $5 \%$ de la población le daba croquetas a sus da de comer alimento procesado a sus peludos compañeros.
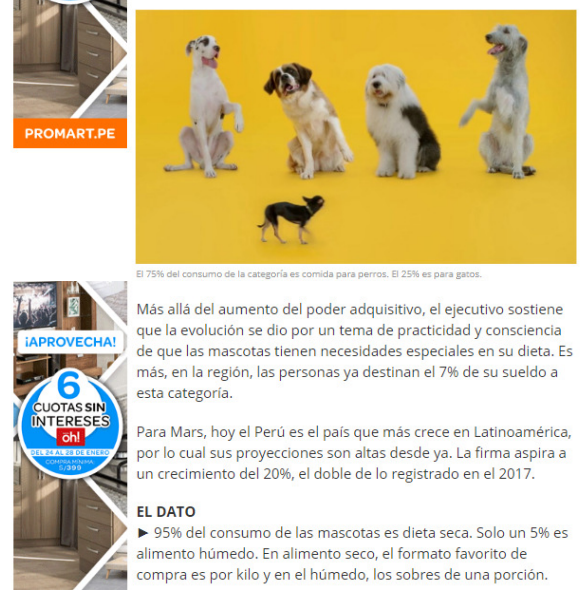

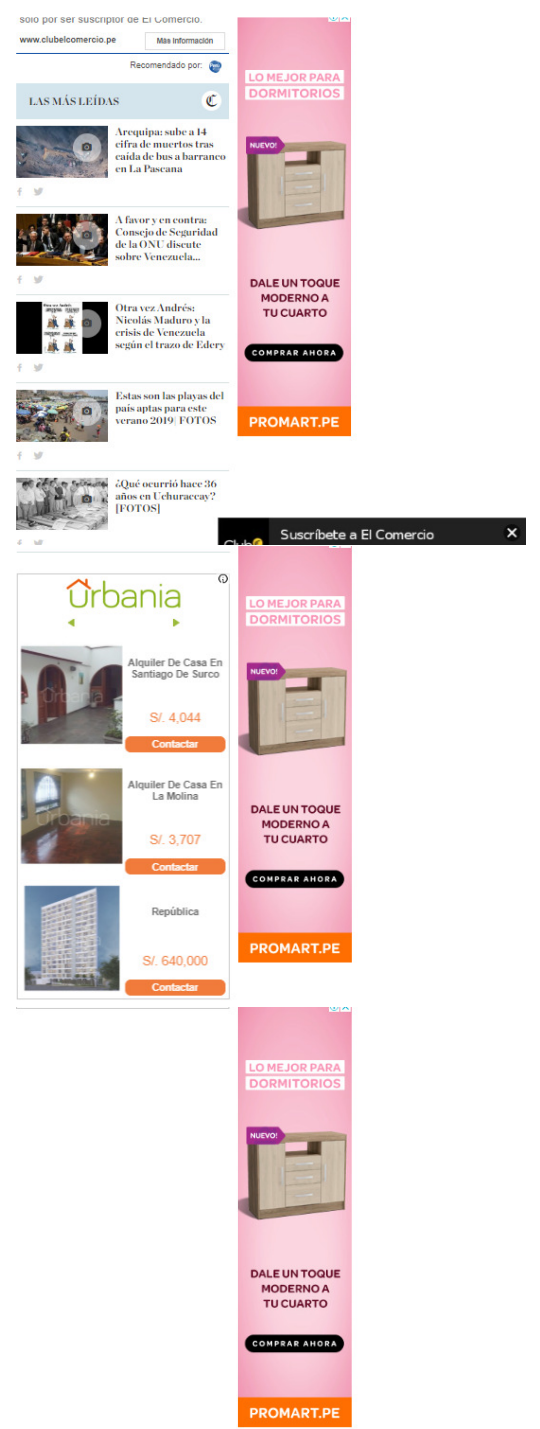

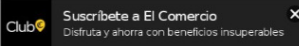

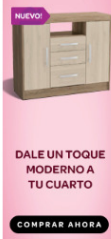


ANEXO 3

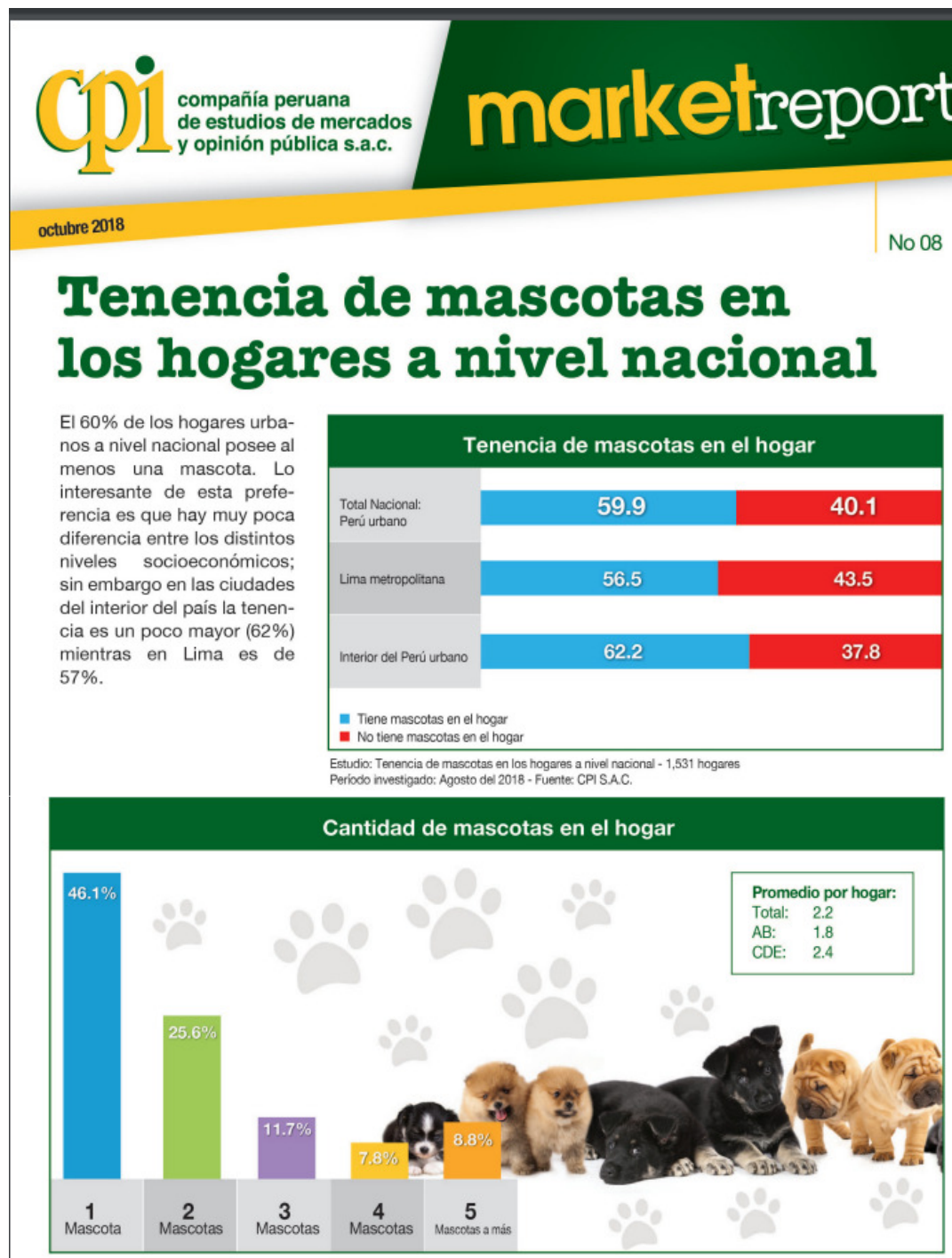

Estudio: Tenencia de mascotas en los hogares a nivel nacional - 1,531 hogares Periodo investigado: Agosto del 2018 - Fuente: CPI S.A.C.

Los perros y gatos son las mascotas preferidas en los hogares del Perú Urbano, con $79 \%$ y $42 \%$

en los estratos $\mathrm{DE}$, donde un $51 \%$ posee este tipo respectivam económicos $\mathrm{AB}$ el $87 \%$ tiene por lo menos un perro, $81 \%$ en el C y $74 \%$ en los estratos DE. En el caso de los gatos la mayor tenencia se concentra

de mascotas, $40 \%$ en el nivel C y un $24 \%$ en los estratos AB. Otros tipos de mascotas sólo alcanzan el $10 \%$ de los hogares, destacando los conejos con el $4 \%$.

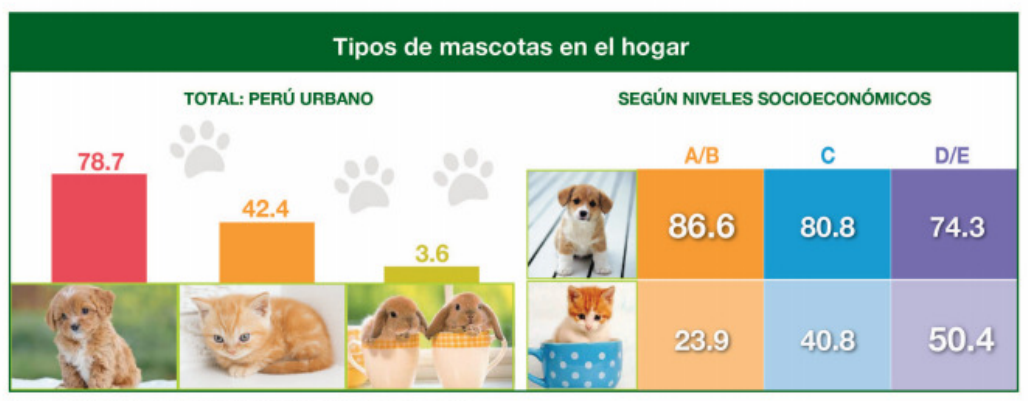

Estudio: Tenencia de mascotas en los hogares a nivel nacional - 1,531 hogares 


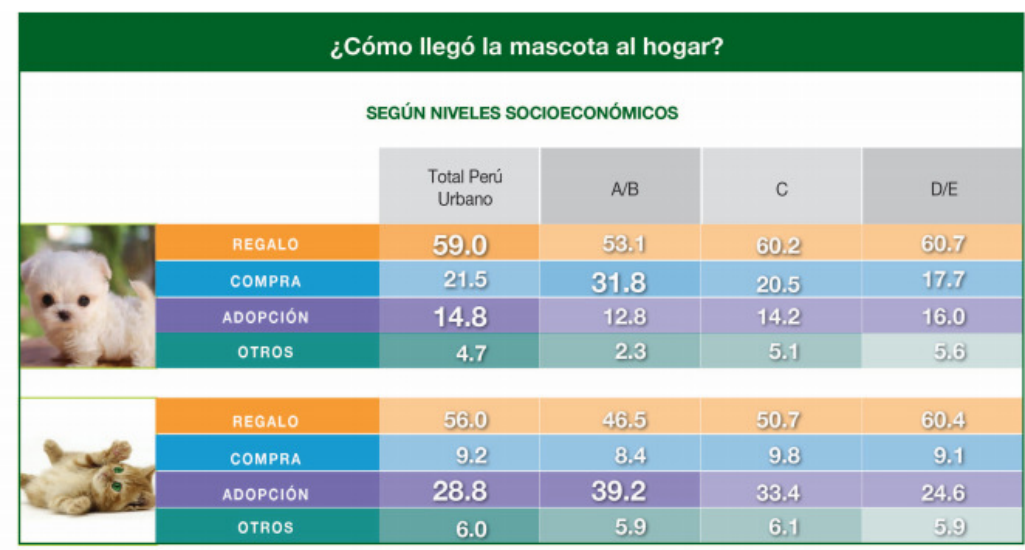

Estudio: Tenencia de mascotas en los hogares a nivel nacional - 1,531 hogares
Perído investigado: Agosto del 2018 - Fuente: CPI S.A.C.

Por lo general, un perro llega al hogar como un regalo, situación que se da mayoritariamente en todos los estratos socioeconómicos que tienen este tipo de mascotas.

La compra de perros alcanza el $22 \%$ y se da en mayor medida en los niveles $A B(32 \%)$. En el nivel $\mathrm{DE}$ sólo un $18 \%$ compra los perros que tienen. Cabe señalar que la adopción para este tipo de mascotas es de $15 \%$ de los hogares, siendo los hogares de nivel DE los que más optan por esta forma de adquisición.

En el caso específico de los gatos el 56\% de los hogares del Perú los reciben como regalo, especialmente en el nivel DE $(60 \%)$.

La compra de esta especie de mascotas sólo se da en el $9 \%$ de los hogares, casi por igual en los tres estratos considerados para el estudio. La adopción que es $29 \%$, es mayor en el estrato $A B(39 \%)$, quizás más sensibilizada por los anuncios en las redes sociales.

\begin{tabular}{|c|c|c|c|c|c|c|}
\hline \multicolumn{7}{|c|}{ Tipos de alimentos que consumen las mascotas } \\
\hline & & & & & & Total: $100 \%$ \\
\hline & $\begin{array}{c}\text { Total Perú } \\
\text { Urbano }\end{array}$ & $\begin{array}{c}\text { Lima } \\
\text { Metropolitana }\end{array}$ & $\begin{array}{l}\text { Interior } \\
\text { del Perú } \\
\text { Urbano }\end{array}$ & A/B & C & $\mathrm{D} / \mathrm{E}$ \\
\hline CASERA Y BALANCEADA & 46.3 & 53.9 & 41.7 & 46.1 & 56.1 & 39.9 \\
\hline SÓLO CASERA & 32.3 & 8.7 & 46.7 & 5.2 & 17.9 & 52.2 \\
\hline SOLLO BALANCEADA & 21.4 & 37.4 & 11.6 & 48.7 & 26.0 & 7.9 \\
\hline
\end{tabular}

Estudio: Tenencia de mascotas en los hogares a nivel nacional - 1,531 hogeres

En cuanto a la alimentación de las mascotas, en el $32 \%$ de los hogares sólo se les alimenta con comida casera; hábito más arraigado en los hogares del interior del país $(47 \%)$ y en los estratos DE $(52 \%)$. El 21\% alimentan a las mascotas sólo con comida balanceada, mucho más en los hogares de Lima Metropolitana y en los estratos AB (49\%). La alimentación sobre la base de productos balanceados en los estratos DE como promedio nacional es relativamente baja: Escasamente un $8 \%$ de hogares opta por este tipo de alimentos, por su elevado costo y por la poca costumbre que hay en los hogares en usar los productos balanceados.

En lo que respecta al cuidado en salud que se les brinda a perros, mascotas de mayor presencia en los hogares, un $76 \%$ de los dueños los llevan a sus controles o tratamiento veterinario por lo menos una vez al año como promedio nacional. Para el caso de Lima este porcentaje alcanza el $91 \%$, lo que evidencia que existe una buena atención médica para estas mascotas, a pesar de que hay un $25 \%$ que manifiesta nunca llevarlos al médico, especialmente en el interior del Perú Urbano (34\%).

Para el caso de los gatos un $41 \%$ de los propietarios a nivel nacional se preocupa por brindarles atención veterinaria una o más veces al año. Un porcentaje mayoritario del $59 \%$ menciona no darles atención médica.

El promedio de gasto veterinario mensual en soles es de 62 soles para perros y de 32 soles para el caso de los gatos. 


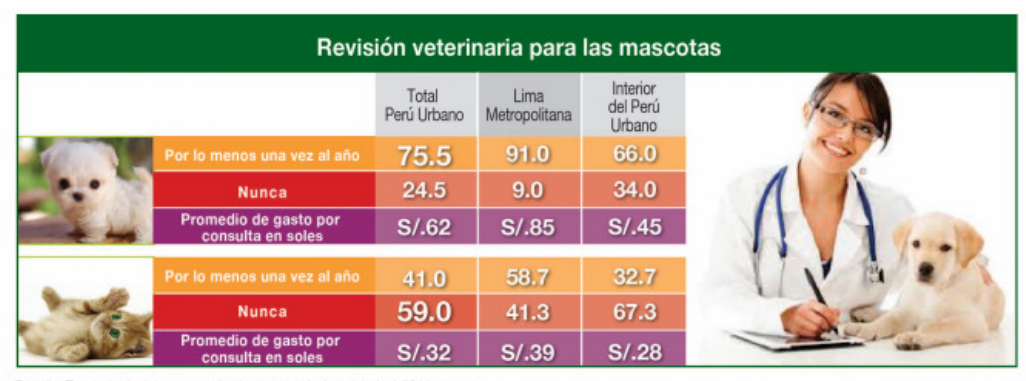

Estudio: Tenencia de mascotas en los hogares a nivel nacional - 1,531 hogares

Período investigado: Agosto del 2018 - Fuente: CPI S.A.C.

También podemos afirmar que es aceptable la dedicación de los dueños de perros por atender a sus mascotas preferidas en otro tipo de servicios que brindan las veterinarias o grooming, como por ejemplo el baño, corte de pelo y aseo en general. El $35 \%$ de los hogares que tienen perros utilizan estos

servicios por lo menos una vez al año, $9 \%$ en el caso de los gatos, la gran mayoría no gasta más de $\mathrm{S} / .50$ en el uso de estos servicios para ambos tipo de mascotas. Los hogares que en mayor porcentaje usan estos servicios se encuentran en Lima y en los NSE AB.

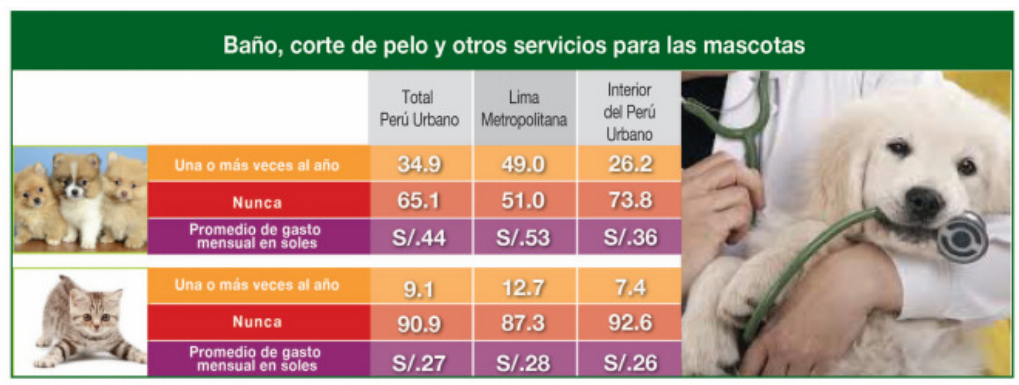

Estudio: Tenencia de mascons en los hogres a niver inacional - 1,531 hogares 
ANEXO 4

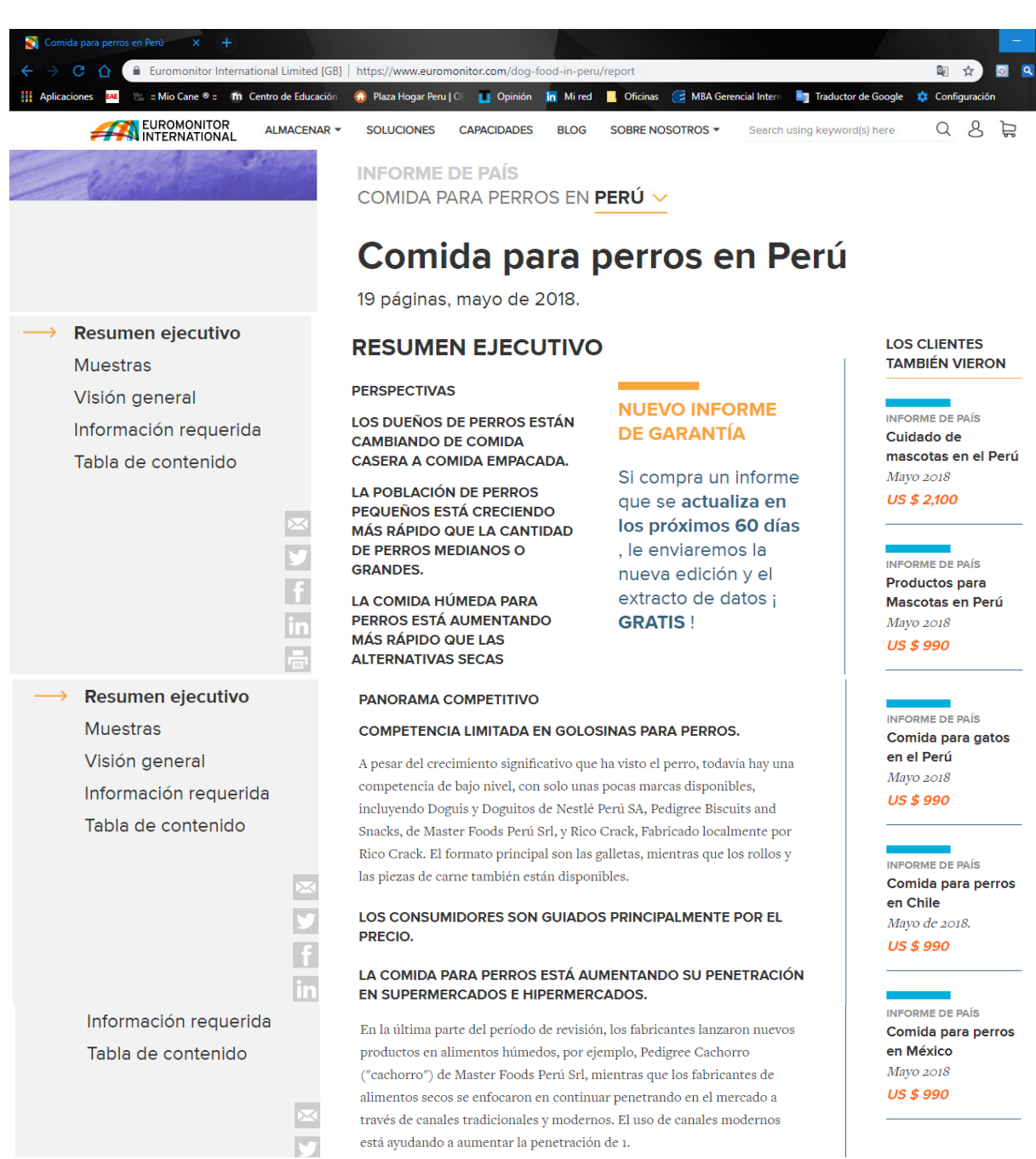


ANEXO 5

inicio > tendencias

\section{Mascotas: ¿Comida balanceada o comida fresca?}

La doctora Lindsey Bullen dice que aproximadamente el $20 \%$ de sus clientes dan a sus animales comida fresca. Ella les pregunta siempre qué les dan exactamente para asegurarse de que tienen todo lo necesario. Hay suplementos que pueden ayudar a compensar cualquier déficit en la dieta.

La doctora Lindsey Bullen dice que aproximadamente el $20 \%$ de sus clientes dan a sus animales comida fresca. Ella les pregunta siempre qué les dan exactamente para asegurarse de que tienen todo lo necesario. Hay suplementos que pueden ayudar a compensar cualquier déficit en la dieta.

in Compartir

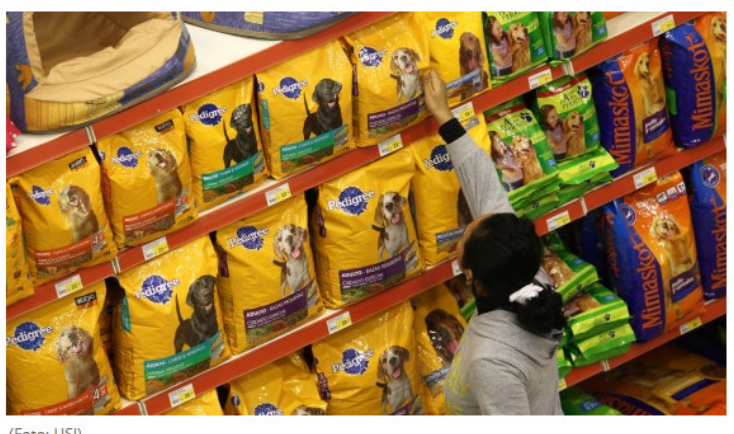

(Foto: USI)

AGENCIA AP / 06.04.2019-02:45 AM
G+ Compartir

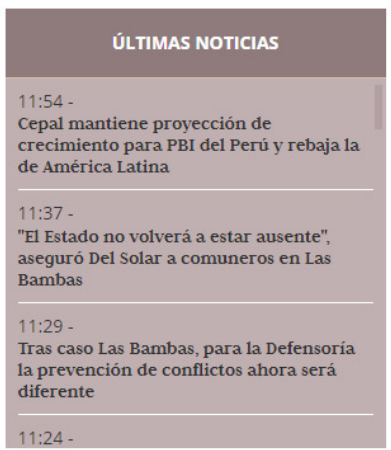

¿Comida balanceada para Blackie? La nueva onda es darle a las mascotas pollo trozado con camote (batata) y espinaca.

Los dueños de mascotas están dándoles a sus animales cada vez más comida fresca. Algunos ordenan porciones de carne y verduras o carne congelada online. Otros la compran en los supermercados.

Pronto Petco, una de las tiendas de animales más grandes de Estados Unidos , abrirá una cocina en su sede central de Nueva York en la que espera preparar casi mil kilos (2000 libras) de carne diarias.

Se dice que la comida fresca conserva los nutrientes mejor que la enlatada o la comida seca, reproduce las dietas ancestrales y mejora la salud de la mascota. 
"Así como la gente se muestra ahora escéptica de la comida procesada para los humanos, también se muestra crítica de la comida para animales", expresó Amy Zalneraitis, socia de We Feed Raw, un servicio del estado de Maine que ofrece planes alimenticios para mascotas a base de comida cruda.

"Nos preguntamos: ¿Cómo algo que dura un año puede ser mejor que la comida natural, fresca?".

Algunos veterinarios cuestionan esta moda. Dicen que hay empresas productoras de comida para animales que llevan décadas investigando el tema y que, por el contrario, no está claro hasta qué punto la comida fresca es buena para los animales.

"Hay que tomar en cuenta muchos nutrientes, de distintas clases", expresó la doctora Lindsey Bullen, del Hospital de Especialistas en Veterinaria de las Carolinas. "Si tienen demasiado o muy poco (de algún nutriente), o no tienen las proporciones indicadas, pueden causar problemas importantes a un animal, que el dueño tal vez no perciba por meses o años".

Bullen dice que aproximadamente el $20 \%$ de sus clientes dan a sus animales comida fresca. Ella les pregunta siempre qué les dan exactamente para asegurarse de que tienen todo lo necesario. Hay suplementos que pueden ayudar a compensar cualquier déficit en la dieta.

Deb Colgan tuvo sus dudas cuando vio que su marido le daba carne cruda a sus dos ovejeros alemanes hace siete años. Pero después de investigar los beneficios, empezó a comprar ella misma carne cruda con huesos. Asesorada por una veterinaria, agrega suplementos como vitamina $\mathrm{E}$, aceite de salmón, probióticos y un complejo vitamínico.

"Se los veía muy saludables y creemos que es por lo que comen", expresó Colgan, cuyos perros ya murieron. Pero tiene otros dos a los que les da la misma dieta. 
ANEXO 6

\section{O El Comercio 1800}

Lo último |Opinión • Política • Economía • Perú • Lima • Mundo • Luces • DT • Art Lima • Ver Más • Clube

SUSCRIBETE $\odot$

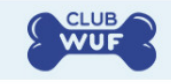

¡AFÍLIATE, AHORRA Y AYUDA!

MÁS EN MUNDO WUF

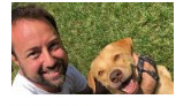

Perro que

aventaban de un

segundo piso hoy

vive tranquilo

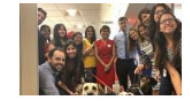

Perros de albergue

regaron amor en

oficina de

prestigiosa

consultora

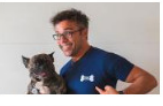

Renzo Schullerse une a WUF para apoyar a perros $\sin$ hogar

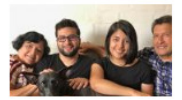

La pinta fue lo de menos cuando decidió adoptar Morita

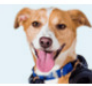

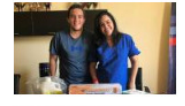
ayuda a perros don medicinas para

victimas de

MUNDOWUF

Comida casera para mascotas, más compleja de lo que parece

Experta en nutrición veterinaria recomienda seguir un plan nutricional diseñado por un profesional, si es que una alimentación natural para tus animales es lo que buscas

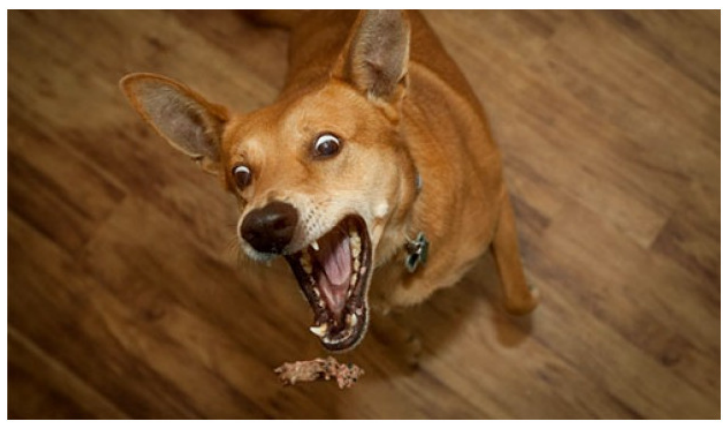

para siempre tener comida fresca lista para nuestras mascotas.

Andrea Carrión
$06.09 .2018 / 08: 41$ am

En los últimos años la comida sana, natural, orgánica, entre otros tipos de alimentación asociados con la salud de las personas, ha ido desplazando a la comida procesada, y en el terreno de las mascotas no ha habido excepciones.

La médica veterinaria Doris Reátegui, de la Clínica Veterinaria Prana, comenta que cada vez son más los clientes que buscan volver a la comida casera, ya sea porque sus mascotas están desarrollando síntomas que pueden tratarse con un cambio de dieta o, sencillamente, porque quieren alimentarlos con productos $100 \%$ frescos y naturales.

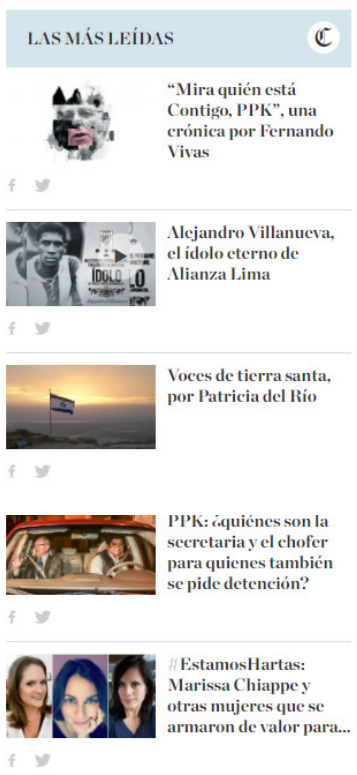


"La comida natural siempre será mejor, por más que te digan que el alimento balanceado que se vende en bolsas de manera comercial es completo. Aunque sea de excelente calidad, finalmente es procesado. Es como comprar un choclo fresco versus uno enlatado, al final del día la comida fresca es mejor. Sin embargo, darle alimento casero a tu mascota es más complejo de lo que parece", señala Reátegui.

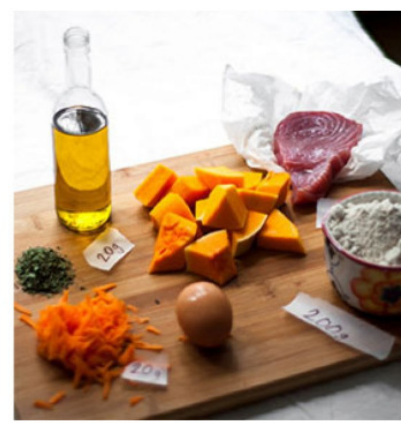

Cocina comida casera no solo consiste en saber elegir los mejores ingredientes, sino también aquellos que son buenos para tu mascota.

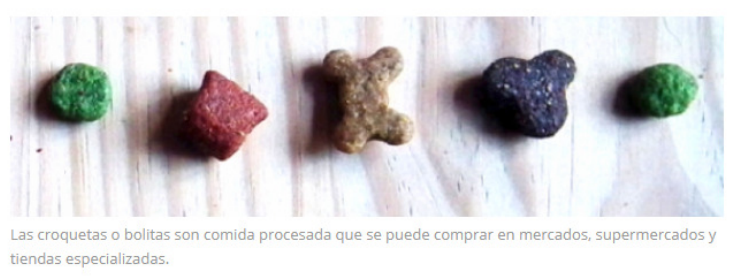

No solo hay que estar informado sobre las cantidades adecuadas para cada especie animal, también hay que tomar en cuenta factores como edad, estado físico, nivel de actividad, tipo de actividad, problemas de salud, alergias, entre otros.

Mucha gente le cocina a su perro, gato, etc. y no se da cuenta de que algo podría estar faltando, sobrando o causando alguna reacción alérgica.

"Por eso es que diseñamos recetas individuales, aunque también las hacemos para gente que tiene 3, 4 o más mascotas en casa. Y claro, siempre tomando en cuenta el presupuesto", agrega Reátegui. "Comida fresca siempre es mejor, pero siempre y cuando esté bien balanceada. Hay quienes sacan dietas de Internet y eso no siempre funciona".

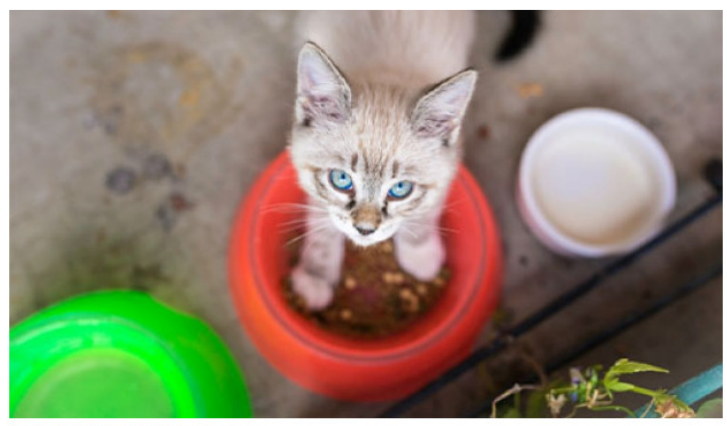

Cada animal es un mundo aparte. 


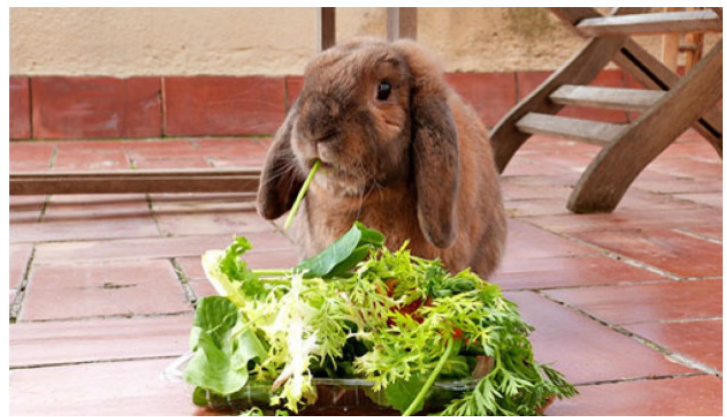

Hasta los conejos se pueden ver beneficiados con una dieta más natural, balanceada y sin preservantes.

En los últimos años ha crecido el nivel de consciencia respecto al cuidado de nuestras mascotas en el mundo, y el Perú poco a poco se va acoplando a esta tendencia. 


\section{ANEXO 7}

\section{ENTREVISTA A PROFUNDIDAD $\mathrm{N}^{\circ} 1$ FICHA TÉCNICA}

Objetivo:

Población:

Técnica:

Zona:

Muestra:

Trabajo de Campo:
Obtener información sobre las necesidades alimenticias de los canes para una debida nutrición y conservación de la salud.

Población general, veterinarios hombres y mujeres en pleno ejercicio profesional, que laboran en veterinarias dedicadas a brindar servicios de atención médica a mascotas caninas y que ostentan estudios y experiencia en el campo de la nutrición.

Entrevistas personales cara a cara, con aplicación de un cuestionario estructurado.

Surquillo.

Médico veterinario. Mayo de 2018.

\section{Profesión:}

Entrevistador:

\section{Médico Veterinario}

Luis Ibarra

\section{Colegiatura: CMVP}

A continuación, encontrará un conjunto de preguntas. Le agradeceremos responder de acuerdo con sus conocimientos y experiencia como médico veterinario especializado en nutrición canina.

\section{Cuestionario}

1. ¿Cuál es la función de un veterinario?

La función de un médico veterinario es la de prevenir, diagnosticar y tratar enfermedades y lesiones cuya causa puede ser diversa. Tanto de animales de compañía como de ganado.

2. ¿Cuál es la función de un médico veterinario nutricionista?

Se encarga de tratar las necesidades dietéticas de los animales, para una buena nutrición y al mismo tiempo prevenir enfermedades. El nutricionista es un especialista, pero existen otras especialidades como: dermatología, cirugía, oftalmología. Hay varias especialidades.

3. ¿Un médico veterinario puede trabajar con animales grandes y animales pequeños? 
Así es, aunque los veterinarios que trabajamos en la ciudad tratamos por lo general a animales de compañías como las mascotas.

4. ¿Qué factores son relevantes para una buena calidad de vida de la mascota?

La alimentación es uno de los factores más importantes si queremos brindarle calidad de vida a la mascota.

5. ¿Cuáles son las características de un buen alimento para mascotas?

Las características de un buen alimento radican en que la fórmula sea balanceada.

Una fórmula balanceada es aquellas que posee todos los elementos que la mascota necesita para una adecuada nutrición.

6. ¿Qué opinión le merece la comida casera?

La comida casera puede parecer buena, pero en verdad no lo es, por que al no elaborarse con una formula balanceada, puede ser que estemos alimentando al can con un exceso o deficiencia en alguno de sus componentes. Y esto se refleja en su salud.

7. ¿Qué opinión le merece la comida BARF?

El BARF es un alimento crudo triturado, diseñado desde la idea que un can es un lobo evolucionado y como tal se nutre de comida cruda. Esto no es totalmente cierto pues muchos canes no soportan el BARF como alimento, teniendo reacciones adversas en su salud. Además, el BARF al ser crudo posibilita la aparición de bacterias en el alimento. Se debe tener mucho cuidado.

8. ¿Qué opina de la comida seca?

La comida seca tiene una fórmula balanceada, pero así tenga insumos de primera, es un alimento procesado, preparado especialmente para que dure largo tiempo y además porque en mi experiencia profesional veo con frecuencia que se incrementa el número de personas que quieren regresar a la comida casera por las reacciones que tiene su can. 
9. ¿Hace un momento indicó que la comida casera no es buena tampoco?

La comida casera ni ninguna comida es buena si no tiene una fórmula balanceada. Si elaboramos una comida casera balanceada los resultados serán buenos.

10. Entonces ¿qué comida es mejor?

La comida natural siempre será mejor. Un alimento procesado al final del día no será mejor que un alimento natural.

11. ¿Qué cantidad en kilogramos debe comer una mascota al día?

Una mascota debe comer al día, de acuerdo con la cantidad de calorías que le proporciona la fórmula en la ración. Si un alimento tiene más peso que otro, no significa que tenga mayor calidad ni alimente más. El alimento adecuado es aquel que -independientemente del pesotenga la cantidad de calorías que el can requiere.

12. ¿Qué recomienda para la buena nutrición canina?

Una buena nutrición canina debe estar acompañada de una buena fórmula balanceada, alimentos no procesados, algo cocidos y en proporciones adecuadas para la edad, actividad, salud, entre otros.

13. ¿Es muy difícil el acceso a estos ingredientes para una comida de tipo natural?

Claro que no, hasta puede resultar más económica. Los ingredientes son los que conocemos y están disponibles en las carnes y verduras que conocemos. Claro está, además de unos suplementos que complementan el alimento para que no tenga deficiencias nutricionales.

14. ¿Una buena comida balanceada debe tener alguna forma en especial?

En verdad no, la forma es lo de menos. Lo importante es lo que contiene. Y lo que contiene debe ser balanceado y si es natural, mejor. 
15. ¿Las comidas deberían ser variadas?

Claro que sí. La mascota debe comer variado, por eso se pueden crear una gran variedad de fórmulas balanceadas, con pollo, con carne, con pescado, entre otras muchas proteínas.

16. ¿Qué debería hacerse para brindar un alimento natural, no procesado, que colabore con el poco tiempo que tienen las familias para cocinarle a su perro?

Lo que debería hacerse es tener una fórmula estándar (con variados insumos) y en base a ella generar un producto que pueda ser empacado y refrigerado para su venta. Para prepararlo bastará con sacarlo de la refrigeradora y ponerlo en baño maría para que esté listo.

17. ¿Entonces cuáles serían los pasos para la elaboración de este tipo de alimento?

Estos pasos se deben consultar con una personal especializado en industrias alimentarias. Desde mi rol profesional, la nutrición es mi especialidad, así como mi experiencia, pero la tecnología para preparar alimentos requiere la ayuda de otro profesional. Y ese profesional es de industrias alimentarias.

18. Para ir cerrando la entrevista ¿algo más que desee agregar sobre alimentación canina?

Solo hay que indicar que, para brindarles una buena calidad de vida a las mascotas, se les debe brindar comida balanceada elaborada con insumos naturales para evitar futuras enfermedades. Esa es una buena forma de cuidarlos, sobre todo si son considerados como uno más de la familia. 


\section{ANEXO 8 \\ ENTREVISTA A PROFUNDIDAD FICHA TÉCNICA}

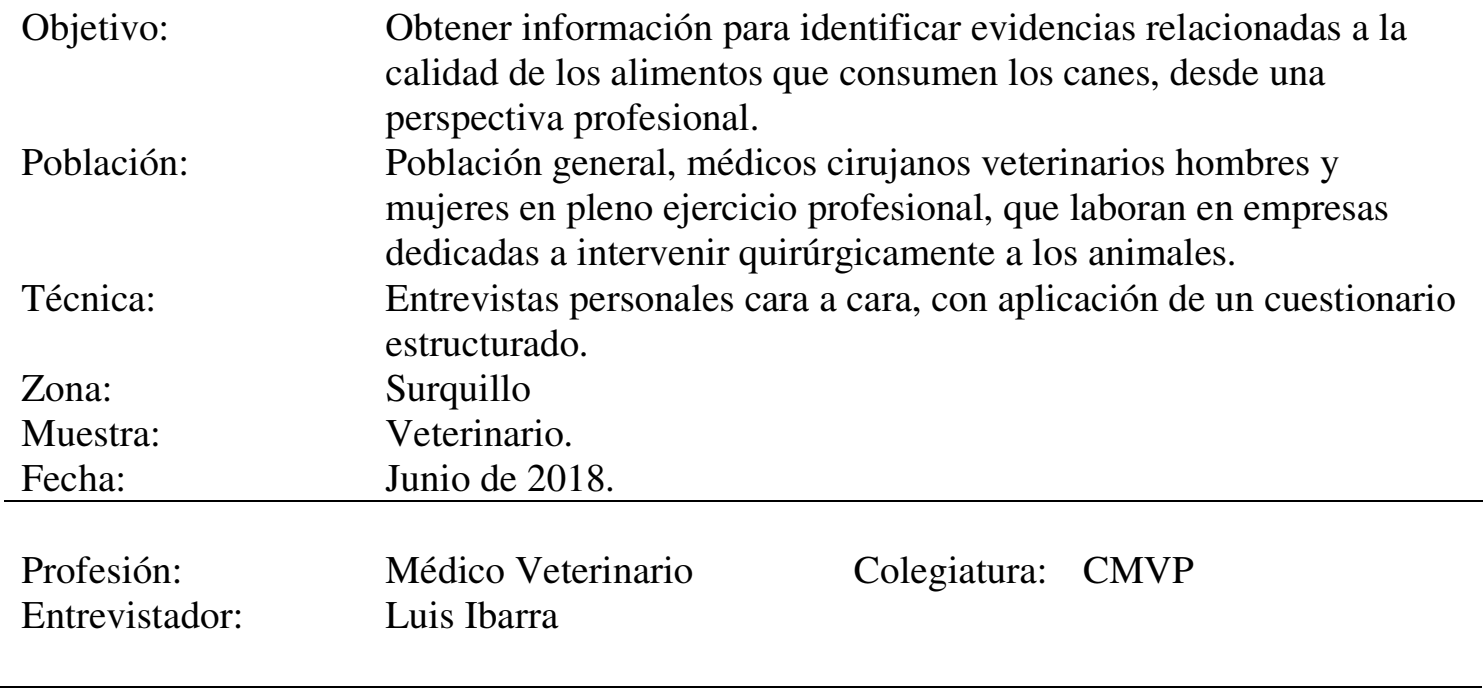

A continuación, encontrará un conjunto de preguntas. Le agradeceremos responderlas de acuerdo con sus conocimientos y experiencia como médico cirujano veterinario.

\section{Cuestionario}

A continuación, encontrará un conjunto de preguntas. Le agradeceremos responderlas de acuerdo con sus conocimientos y experiencia como médico cirujano veterinario.

1. ¿En su rol de médico cirujano veterinario, cual es la actividad que realiza frecuentemente?

La actividad que realizo frecuentemente es diagnosticar las enfermedades y/o lesiones que pueden presentar las mascotas.

2. Una vez identificada la enfermedad o dolencia ¿cuál es el siguiente paso?

El siguiente paso es tratarla a través de medicamentos. Aunque en ciertos casos es necesario una operación.

3. ¿En qué casos es conveniente optar por una operación?

En aquellos casos que presentan tumores o traumatismos, es decir, los golpes que son producto de un atropellamiento o lesión causada por un agente externo. 
4. ¿Al intervenir a una mascota mediante una operación, se tiene la oportunidad de apreciar información sobre el estado de la mascota, su alimentación, entre otros elementos visibles?

En verdad no mucho. Pero, cuando operas, uno se ve precisado a ver el organismo de la mascota.

5. ¿Observó algo que le llame la atención?

Si. En varios casos he observado una diferencia entre mascotas de casa alimentadas con comida balanceada y mascotas que vienen de la calle.

6. Pero se supone que cada operación tiene un costo. Entonces ¿cómo es posible que haya operado a un can de la calle?

Muy sencillo. En el caso de la mascota del hogar, lo pagan los dueños. En el caso de la mascota de la calle, lo asume la veterinaria. Esto se hace como un ejercicio de ayuda a tanto animalito que no tiene hogar. Los curamos, los alimentamos y luego lo damos en adopción.

7. Volviendo al punto inicial ¿qué diferencia ha observado en los canes de casa y los de la calle?

En los de la calle sus órganos no muestran nada anormal, pero en el caso de los canes de casa, sus órganos muestran formaciones atípicas y podría decir, que es un patrón que se cumple con cierta frecuencia, no en todos. Pero con cierta frecuencia.

8. ¿Con esta información se podría decir que la comida balanceada -comida seca- es mala para las mascotas?

No necesariamente. Recordemos que existen comidas muy baratas cuyos insumos son baratos y de baja calidad. En cambio, tenemos marcas que emplean insumos de primera y en este caso el precio es superior.

9. ¿Qué podríamos aconsejar a las familias que tienen canes? ¿Con qué podríamos alimentarlas?

Para dar una buena alimentación de los perros de casa, es necesario utilizar una fórmula balanceada y preocuparnos de que sea un producto de calidad. Les costará más, pero será un 
producto que nos brindará confianza. El producto puede ser comida seca o quizá comida casera balanceada, pero de la mano de un nutricionista, porque en el mercado no tenemos este tipo de comida. Algunas marcas se han especializado en alimentación y otras, en ayudar a que se curen de ciertas enfermedades. Por ejemplos Hill's tiene una gran cantidad de productos para enfermedades de tipo renal, artrosis, exceso de peso, entre otros factores. 


\section{ANEXO 9 \\ GRUPO DE ENFOQUE FICHA TÉCNICA}
Objetivo: Obtener información acerca del nivel de interés que tienen los dueños de un can. Como las ideas, gustos y preferencias con respecto a su alimentación, cuidado, así como la propuesta de valor de Animal Lovers.
Población: $\quad$ Miembros de hogares que residen en el distrito de San Borja y que tienen por lo menos un can como mascota canina, a la cual le brindan alimentación, bienestar y cuidados.
Técnica: $\quad$ Conversación en grupos cara a cara en un ambiente privado, con aplicación de una guía de indagación y pautas para la moderación de la conversación.
Zona: $\quad$ San Borja
Muestra: $\quad$ Se realizaron tres (3) reuniones compuestas en promedio por seis (6)
Fechas de Campo: $\quad$ Del 10 de junio al 30 de julio de 2018.

\section{INFORMACIÓN DEL GRUPO}

\begin{tabular}{llllll}
\hline Grupo: 1 & Sector 1-4 & Fecha 1: & 12 de junio & Hora 1: & \multirow{2}{*}{ 17:00 } \\
Grupo: 2 & Sector 2-6 & Fecha 2: & 20 de junio & Hora 2: & \\
Grupo: 3 & Sector $>7$ & Fecha 3: & 20 de julio & Hora 3: &
\end{tabular}

Participantes: Hombres y mujeres de 20 a 65 años

Características: Tenedores de canes que invierten en el cuidado de su mascota

$\begin{array}{llll}\text { Moderador: Luis Ibarra } \quad \text { Apoyo: } \quad \text { Miguel Serna Digitador: } & \text { Ronald } \\ \text { Martínez }\end{array}$

\section{GUIA DE INDAGACIÓN/PAUTAS FOCUS GROUP PARA MODERADORES}

\section{Calentamiento}

(10 minutos)

- Saludo

- Presentación del moderador

- Presentación del tema de la reunión

- Agradecimiento por la asistencia

- Tiempo proyectado para la duración de la reunión (máximo 2 horas)

- Invitación a la presentación de cada asistente

Identificación del estilo de vida de los hogares a los que pertenecen (10 minutos)

- ¿Cómo son en el trabajo o en su negocio? 
- ¿Qué les interesa?

- ¿Qué compran?

- ¿Qué expectativas tienen a mediano y largo plazo?

Recordación de la categoría (10 minutos)

- Tipos de alimento que conocen

- Las marcas de alimento que recuerdan

- Idea acerca de las marcas más prestigiosas

Relación familia - mascota (20 minutos)

- La forma en que la mascota llegó al hogar y que tiempo tienen con ella

- Los tipos de cuidado que le brindan a la mascota

- Factores que los motivan a prodigarle dichos cuidados

- Invitación a reflexionar, sobre cómo sería la vida sin su mascota

- Existe algún sentimiento hacia la mascota

- Consideración que le tienen a la mascota en la familia

Actitud, conducta y socialización entre personas que tienen una mascota canina (10 minutos)

- Actitud de la persona que tiene un can como mascota

- Conducta de la persona que tiene un can como mascota

- Perfil de socialización de la persona que tiene un can como mascota

- Perfil de una persona con una mascota canina

- Beneficios de tener una mascota canina en el hogar

Tipos de cuidado de la mascota (10 minutos)

- Cuidados que se le prodiga a la mascota

- Cuidados relacionados a la alimentación

- Cuidados relacionados a la salud

- Cuidados respecto a las dolencias más frecuentes

- Inversión en cuidados de la mascota 
Elección del tipo de alimento que le brindan a su mascota (10 minutos)

- Tipos de alimento que conocen (comida seca, húmeda, BARF, otros)

- Características de su mascota (raza, edad, peso, dolencias frecuentes) y su relación con el alimento

- Razones de elección de determinado tipo de alimento para su mascota

- Cantidad de alimento que consume una mascota según características propias

- Ventajas y desventajas para la mascota según el tipo de alimento (digestión, preservantes, otros)

- Ventajas y desventajas para el dueño del can (preparación, almacenamiento, mantenimiento, perecibilidad, entre otros)

- Inversión (según tipo de alimento y marca) al día, a la semana, al mes

Nivel de conocimiento acerca de la composición del producto y sus efectos en la salud (10 minutos)

- Grado de conocimiento acerca de los insumos que intervienen en el alimento

- Grado de conocimiento acerca de la producción del alimento elegido

- Grado de conocimiento acerca de la duración del alimento elegido

- Grado de conocimiento acerca de los efectos en el can por los preservantes el tipo de alimento 


\section{ANEXO 10 \\ TEST DE CONCEPTO DE PRODUCTO FICHA TÉCNICA}

Objetivo:

Población:

Técnica:

Zona:

Muestra:
Obtener información acerca del nivel de aceptación de las mascotas caninas con respecto a los productos Animal Lovers.

Miembros de hogares que residen en el distrito de San Borja y que tienen por lo menos un can como mascota canina, a la cual le brindan alimentación, bienestar y cuidados.

Conversación cara a cara en los parques frecuentados por los dueños de canes, con aplicación de una guía de pautas para la realización de la prueba.

San Borja

Se realizaron diez (20) test de concepto en cada uno de los parques visitados del distrito seleccionado, haciendo un total de visitas a 10 parques.

Fechas de Campo: Mes de agosto de 2018.

Pautas

1.- Visita al parque e identificación del can

2.- Saludo al dueño del can y pregunta sobre el nombre del can

3.- Levantamiento de información respecto al lugar de residencia, raza, alimento, dolencias y/o alergias del can

4.- Presentación del producto Animal Lovers

5.- Explicación de las bondades y calidad del producto

6.- Presentación de formatos (pollo, pescado y res)

7.- Instrucciones para su conservación

8.- Obsequio y entrega de la muestra

9.- Apunte de datos de la persona obsequiada

10.- Posterior comunicación para conocer sus opiniones después de la ingesta del producto de Animal Lovers

11.- Entrevista de cierre con opiniones relevantes

12.- Agradecimiento 


\section{ANEXO 11 \\ GESTIÓN DE PRUEBA DE CONCEPTO \\ Definir estrategias de y el costo de su implementación como ejercicio de marketing orientado al público objetivo. \\ Miembros de hogares que residen en el distrito de San Borja, con un estilo de vida sofisticado, que tienen por lo menos un can como mascota canina, a la cual le brindan alimentación, bienestar y cuidados.}

Objetivo:

Población:

Técnica:

Zona:

Muestra:

Trabajo de campo:
Conversación cara a cara en los parques frecuentados por los dueños de canes, con aplicación de una guía de pautas para la realización de la prueba.

San Borja

Se realizarán pruebas de concepto en cada uno de los parques visitados del distrito seleccionado, haciendo un total de visitas a 10 parques.

Se realizará en dos (2) momentos.

Momento 1.- Acciones a realizar relacionadas con:

- Presentación del producto

- Necesidad nutritiva del can

- Beneficios del producto

- Forma de conservación

- Ingesta

- Registro de datos del dueño de la mascota

- Entrega de obsequio (muestras de 200 gr.)

Momento 2.- Acciones a realizar relacionadas con:

- Coordinación con el dueño de la mascota

- Entrevista sobre la ingesta del producto

- Detalles relacionados a la palatabilidad del can

- Efectos del alimento en el can

- Registro de opinión 


\section{Distrito: San Borja}

Número de parques: 20 (lugares que concentran actividades de paseo de canes)

Días / horarios: Lunes a viernes de 17:00 a 19:00

Parques, visitas y horarios:

- Numero de parques $=20$

- Número de visitas por parque $=4$

- Número total de visitas $=160$ (2 visitas por can)

- Numero de parques visitados por día $=2$

- Horario de visita al parque: De lunes a viernes (17:00 a 19:00). Sábados y domingos $(11: 00$ a $16: 00)$

Costo de muestra y merchandising:

$\circ \quad$ Unidad de muestra $=$ S/ 2 (100 gr.)

- Cantidad de muestras por can $=\mathrm{S} / 10$ (5 muestras de 100 gr. cada una)

- Merchandising $=\mathrm{S} / 20$ por can

- Costo total $=\mathrm{S} / 2,400$

Costo operativos:

- Personal $=\mathrm{S} / 1,000$

○ Transporte $=\mathrm{S} / 800$

- Otros $=$ S/ 200

Costo de informes:

- Elaboración $=\mathrm{S} / 1,000$

- Físico $=\mathrm{S} / 1,000$

Costo total $=\mathrm{S} / 6,400$

Ubicación: perímetro del distrito de San Borja $\left(10 \mathrm{~km}^{2}\right)$

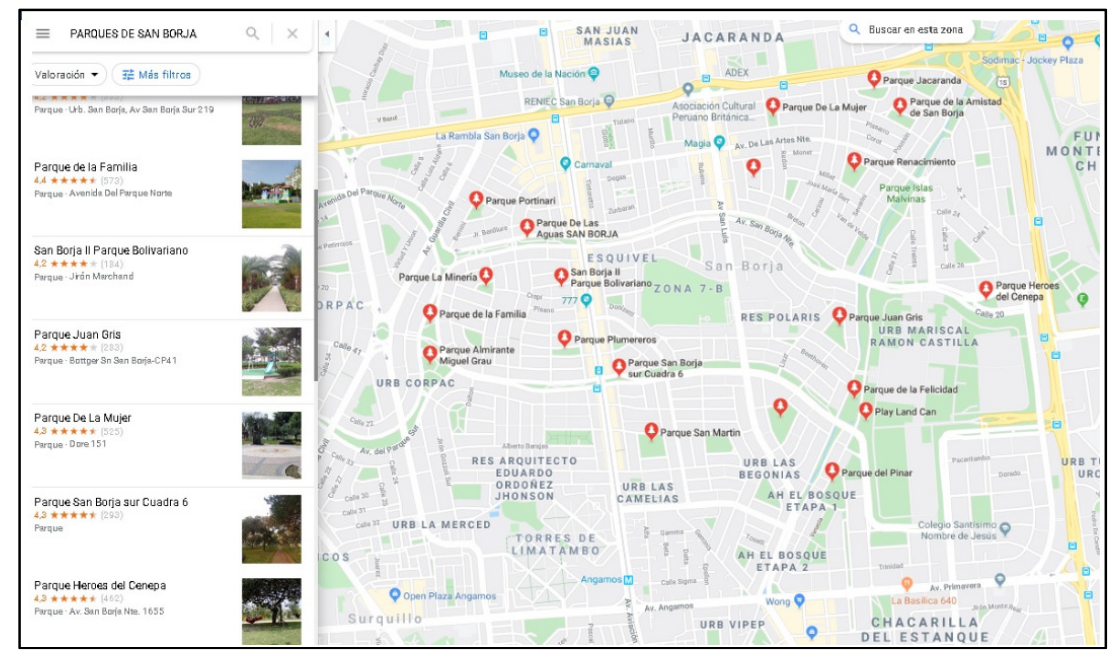


Parque de la Felicidad

- Calle San Borja Sur con del Bosque, Av. Blvd. de Surco

Parque de la Amistad de San Borja

- Gauguin

Parque Almirante Miguel Grau

- Urb. San Borja, Av. San Borja Sur 219

Parque República Popular China

- Jr. Romero Hidalgo

Parque de la Familia

- Avenida Del Parque Norte

Parque De La Mujer

- Dore 151

San Borja II Parque Bolivariano

- Jirón Marchand

Parque San Borja sur

- Avenida San Borja Sur cuadra 6

Parque Juan Gris

- Bottger Sn San Borja-CP41

Parque Heroes del Cenepa

- Av. San Borja Nte. 1655

Parque Jacaranda

- Calle Los Sauces

Parque Plumereros

Parque San Martin

Parque Renacimiento

- Cavallini

Parque 9 De Julio

- Calle Alonso del Arco

Parque De Las Aguas SAN BORJA

- Parque Av. San Borja Nte. 445 
Play Land Can

· Jirón Paseo del Bosque

Parque Portinari

- Calle Portinari

Parque del Pinar

Parque De La Juventud

- Rafael 281 